\title{
ANÁLISIS DE LA VARIABILIDAD EN LAS ESPECIES DEL SUBGÉNERO Eulycopersicon MÁS RELACIONADAS CON EL TOMATE CULTIVADO
}

José Pedro Domingos 


\section{UNIVERSIDAD POLITECNICA DE VALENCIA ESCUELA TÉCNICA SUPERIOR DE INGENIEROS AGRÓNOMOS DEPARTAMENTO DE BIOTECNOLOGÍA}
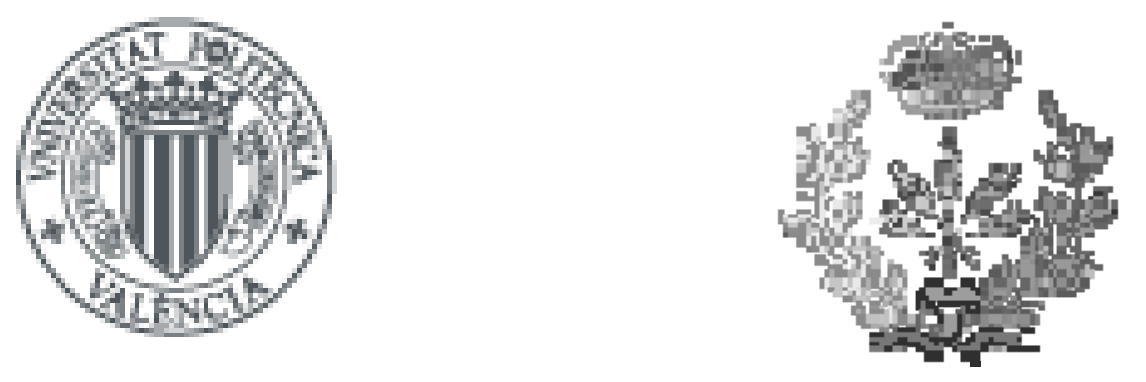

Análisis de la variabilidad en las especies del subgénero

Eulycopersicon más relacionadas con el tomate cultivado.

Directores: Dr. Fernando Nuez Viñals y Dra. Ma José Diez Niclós 
Esta editorial es miembro de la UNE, lo que garantiza la difusión y comercialización de sus publicaciones a nivel nacional e internacional.

(c) José Pedro Domingos, 2011

Primera edición, 2011

(C) de la presente edición:

Editorial Universitat Politècnica de València

www.editorial.upv.es

ISBN: 978-84-694-5598-2

Ref. editorial: 5498

Queda prohibida la reproducción, distribución, comercialización, transformación, y en general, cualquier otra forma de explotación, por cualquier procedimiento, de todo o parte de los contenidos de esta obra sin autorización expresa y por escrito de sus autores.

Impreso en España 


\section{RESUMEN}

El Centro de Conservación y Mejora de la Agrodiversidad (COMAV) de la Universidad Politécnica de Valencia alberga una de las colecciones más importantes de entradas del género Lycopersicon, incluyendo el tomate cultivado (Lycopersicon esculentum, $L$. esculentum var. cerasiforme) y sus especies silvestres relacionadas ( $L$. cheesmanii, L. pimpinellifolium, L. hirsutum, L. pennellii, L. chmilewskii, L. parviflorum L. peruvianum y L. chilense).

A pesar de ser el tomate una de las hortalizas de mayor importancia económica a nivel mundial, siguen existiendo ambigüedades en su taxonomía así como dudas sobre su domesticación. De hecho, se observan en muchas ocasiones formas intermedias entre el tomate cultivado y la variedad botánica cerasiforme, así como entre la forma cerasiforme y la especie L. pimpinellifolium. Igualmente se han detectado formas intermedias entre L. pimpinellifolium y la especie L. cheesmanii, endémica de las islas Galápagos. Estas especies constituyen el subgénero Eulycopersicon, interfértiles con el tomate cultivado. De ellas, la variedad botánica cerasifrome está considerada como el ancestro del tomate y se ha comprobado la existencia de fenómenos de introgresión entre L. pimpinellifolium y el tomate. Las teorías sobre la domesticación del tomate no son únicas, oponiéndose las teorías de Jenkins (1948) y Rick (1958) frente a las más recientes de Rick y Fobes (1975) y Rick y Holle (1990).

Para contribuir a la clarificación de estos aspectos, en la presente Tesis Doctoral se persiguen los siguientes objetivos:

1.- Estudio de la variabilidad morfológica y molecular de estas especies

2.- Esclarecimiento de las relaciones filogenéticos entre las especies del subgénero Eulycopersicon.

3.- Establecimiento de estrategias de conservación de estas especies y en especial de Lycopersicon pimpinellifolium, para la que se han descrito diferencias importantes en el grado de alogamia.

4.- Inicio de la formación de una colección nuclear en la colección de entradas de $L$. pimpinellifolium del COMAV.

Se han ensayado un total de 165 entradas del género Lycopersicon, perteneciendo 48 de ellas a Lycopersicon esculentun var. cerasiforme, 86 a L. pimpinellifolium y 31 a L. esculentum, en las campañas de otoño-invierno durante los años 2000-01 y 2001-02. Para la caracterización morfológica de las plantas se han seguido los descriptores de tomate publicados por el IPGRI. La caracterización molecular se realizó mediante marcadores AFLP. Los datos se han analizado mediante análisis multivariante, realizando Análisis de Componentes Principales y Análisis Cluster. En el análisis de datos cuantitativos se han calculado las distancias euclídeas y se ha empleado el método de agrupamiento UPGMA. La robustez y nivel de fiabilidad se ha medido mediante la técnica de remuestreo bootstrap. Se realizó un análisis de la Varianza (ANOVA) y posteriormente la prueba de comparación de medias de Newman-Keuls y un ANOVA factorial para determinar el efecto Entrada por Año. Se cálculo la similitud genética entre las diferentes entradas para cada combinación de cebadores, usando el coeficiente de Dice. Se estimó el nivel de polimorfismo y la diversidad genética según Nei (1973).

El análisis de componentes principales efectuado con el conjunto de las entradas estudiadas ha permitido la adscripción de gran parte de ellas a las especies de Lycopersicon esculentum, L. pimpinellifolium y L. esculentum var. cerasiforme. Sin embargo, la separación no fue completa, sino que se observó una gradación continua entre ellas, probablemente como consecuencia de un proceso de especiación simpátrica 
no finalizado en el momento actual. La no identificación de marcadores moleculares específicos de especie apoyan esta hipótesis. La existencia de cruzamientos interespecíficos contribuiría al mantenimiento de esta situación, constituyendo $L$. esculentum, L. esculentum var. cerasiforme y L. pimpinellifolium formas extremas de este continuo.

Se identificaron una serie de caracteres cualitativos propios de las formas más típicas de las especies en estudio. Así, el color antociánico del tallo, el tipo de hoja "pimpinellifolium", generalmente de menor tamaño, pinnada y con bordes enteros y el estilo muy proyectado fueron característicos de L. pimpinellifolium. L. esculentum se caracterizó fundamentalmente por caracteres relativos al fruto, como la variación en la forma y el color del fruto maduro y de la piel, formas irregulares de la sección transversal, de la cicatriz estilar y del ápice del fruto, todo ello asociado al proceso de domesticación sufrido por esta especie. La ausencia de los caracteres típicos de las dos especies descritas caracterizó a la var. cerasiforme. El número de flores por inflorescencia, el número de pétalos y la longitud, anchura y peso del fruto, no mostraron interacciones Entrada x Año. Estos caracteres, junto con los cualitativos comentados anteriormente, se consideran como los más discriminantes entre $L$. pimpinellifolium, L. esculentum var. cerasiforme y L. esculentum.

$\mathrm{El}$ análisis cluster efectuado con el conjunto de caracteres morfológicos agrupa a las entradas de L. pimpinellifolium con las de var. cerasiforme, mientras que el realizado con datos moleculares agrupa $L$. esculentum con var. cerasiforme, quedando $L$. pimpinellifolium separada de ambas. Esto apoya la hipótesis de que la var. cerasiforme es el ancestro a partir del cual se produjo la domesticación del tomate.

El conjunto de entradas estudiadas de $L$. pimpinellifolium ha presentado elevada variabilidad para características vegetativas, de flor y de fruto, contribuyendo a demostrar que L. pimpinellifolium, es una especie muy variable, en contra de lo establecido anteriormente. Otros estudios realizados con estas entradas han demostrado también su variabilidad para características de calidad y de resistencia a enfermedades, convirtiéndola en una colección sumamente útil para la mejora.

En las entradas estudiadas en este trabajo se observa una gradación en cuanto a la exerción estigmática, asociada a órganos florales de mayor tamaño y mayor grado de alogamia, encontrándose mayor frecuencia de estilo muy proyectado en los Departamentos más septentrionales de Piura y Lambayeque, mientras que en Cajamarca y La Libertad, abundan las entradas con estilos no proyectados o incluso insertos. Las poblaciones procedentes de Piura y Lambayeque tienen una diversidad genética total mayor, probablemente como consecuencia del mayor grado de alogamia. Este hecho tiene importantes implicaciones en las labores de muestreo y regeneración en los Bancos de Germoplasma.

El conjunto de entradas de L. esculentum var. cerasiforme caracterizadas han mostrado una elevada variabilidad para caracteres morfológicos, tanto vegetativos como de fruto. Esta variabilidad ha resultado estar asociada al origen, siendo mucho más uniformes y con características propias de cerasiforme las procedentes de México, mientras que las de Ecuador y otras procedencias son mucho más variables, no correspondiendo en ocasiones a la forma típica de esta variedad.

Las entradas de L. esculetum estudiadas se agrupan según su origen, México o España, tanto según sus características morfológicas como molecularmente. En el primer caso se debe probablemente a las diferentes presiones de selección ejercidas en ambos países. En el segundo sería consecuencia del distanciamiento geográfico de ambos grupos de entradas hace más de 500 años. Las entradas procedentes de México pertenecen a tipos criollos, muy apreciadas por sus características de calidad, resistencia 
al agrietado y capacidad para cuajar a bajas temperaturas. Estas entradas serán de gran utilidad para su empleo en programas de mejora. La mayor diversidad genética total encontrada para las entradas de México, apoyaría la existencia de un cuello de botella debido al limitado número de individuos transportados desde México a España, donde se inició la difusión por Europa.

Se han establecido tres grupos de entradas de L. pimpinellifolium, las procedentes de las Islas Galápagos, las colectadas en Cuzco y las del norte de Perú y Ecuador, con marcadas diferencias tanto morfológicas como moleculares. Todos ellos deberán estar representadas en la colección nuclear de esta especie del Banco de Germoplasma del COMAV.

Mediante la realización de análisis cluster se ha determinado la existencia de duplicados en la colección, mediante su agrupamiento en los árboles con valores de bootstrap muy elevados. Esta información permitirá la eliminación de tales entradas para la formación de la colección nuclear.

La mayor diversidad genética en las entradas procedentes de los Departamentos de Piura y Lambayeque frente a las de Cajamarca y La Libertad aconsejan una mayor representación de las primeras en la colección nuclear, a fin de asegurar que la mayor parte de esta diversidad genética quede recogida en la colección. 


\section{RESUM}

El Centre de Conservació i Millora de l'Agrodiversidad (COMAV) de la Universitat Politècnica de València recull una de les col-leccions més importants d'entrades del gènere Lycopersicon, incloent la tomaca cultivada (Lycopersicon esculentum, L. esculentum var. cerasiforme) i les seues espècies silvestres relacionades (L. cheesmanii, L. pimpinellifolium, L. hirsutum, L. pennellii, L. chmilewskii, L. parviflorum L. peruvianum i L. chilense).

Tot i tractar-se la tomaca d'una de les l'hortalisses de major importància econòmica a nivell mundial, segueixen existint ambigüitats en la seua taxonomia així com dubtes sobre la seua domesticació. De fet, en moltes ocasions s'observen formes intermèdies entre la tomaca cultivada i la varietat botànica cerasiforme, així com entre la forma cerasiforme i l'espècie $L$. pimpinellifolium. Igualment s'han detectat formes intermèdies entre L. pimpinellifolium i l'espècie L. cheesmanii, endèmica de les illes Galàpagos. Estes espècies constitueïxen el subgènere Eulycopersicon, interfértiles amb la tomaca cultivada. D'elles, la varietat botànica cerasifrome està considerada com l'ancestre de la tomaca i s'ha comprovat l'existència de fenòmens d'introgresió entre L. pimpinellifolium i la tomaca. Les teories sobre la domesticació de la tomaca no són úniques, oposant-se les teories de Jenkins (1948) i Rick (1958) enfront de les més recents de Rick i Fobes (1975) i Rick i Holle (1990).

Per a contribuir a l'aclariment d'aquests aspectes, en la present Tesi Doctoral es persegueixen els següents objectius:

1.- Estudi de la variabilitat morfològica i molecular d'aquests espècies

2.- Esclariment de les relacions filogenètiques entre les espècies del subgènere Eulycopersicon.

3.- Establiment d'estratègies de conservació d'aquestes espècies $i$ en especial de Lycopersicon pimpinellifolium, per a la qual s'han descrit diferències importants en el grau d'alogamia.

4.- Inici de la formació d'una col-lecció nuclear en la col·lecció d'entrades de $L$. pimpinellifolium del COMAV.

S'han assajat un total de 165 entrades del gènere Lycopersicon, pertanyent 48 d'elles a Lycopersicon esculentun var cerasiforme, 86 a L. pimpinellifolium i 31 a L. esculentum, en les campanyes de tardor-hivern durant els anys 2000-01 i 2001-02. Per a la caracterització morfològica de les plantes s'han seguit els descriptors de tomaca publicats per l'IPGRI. La caracterització molecular es va realitzar mitjançant marcadors AFLPs. Les dades s'han analitzat mitjançant un anàlisi multivariant, realitzant Anàlisi de Components Principals i Anàlisi Cluster. En l'anàlisi de dades quantitatives s'han calculat les distàncies euclídees i s'ha emprat el mètode d'agrupament UPGMA. La fortor i nivell de fiabilitat s'ha mesurat per mitjà de la tècnica de remostratge bootstrap. Es va realitzar una anàlisi de la Varianza (ANOVA) i posteriorment la prova de comparació de mitges de Newman-Keuls i un ANOVA factorial per a determinar la interacció Entrada per Any. S'ha calculat la similitut genètica entre les diferents entrades per a cada combinació de cebadors, usant el coeficient de Diu. Es va estimar el nivell de polimorfisme i la diversitat genètica segons Nei (1973).

L'anàlisi de components principals efectuat amb el conjunt de les entrades estudiades ha permés l'adscripció de gran part d'elles a les espècies de Lycopersicon esculentum, L. pimpinellifolium i L. esculentum var. cerasiforme. No obstant, la separació no va ser completa, sinó que es va observar una gradació contínua entre elles, probablement com a conseqüència d'un procés d'especiació simpàtrica no finalitzat en el moment actual. La no identificació de marcadors moleculars específics d'espècie recolzen aquesta hipòtesi. L'existència de creuaments interespecífics contribuiria al manteniment d'aquesta situació, constituint $L$. esculentum, $L$. esculentum var. cerasiforme i $L$. pimpinellifolium formes 
extremes aquest continu.

Es van identificar una sèrie de caràcters qualitatius propis de les formes més típiques de les espècies en estudi. Així, el color antocianic de la tija, el tipus de fulla "pimpinellifolium", generalment de menor tamany, pinnada i amb bords sencers i l'estil molt projectat van ser característics de L. pimpinellifolium. L. esculentum es va caracteritzar fonamentalment per caràcters relatius al fruit, com la variació en la forma i el color del fruit madur i de la pell, formes irregulars de la secció transversal, de la cicatriu estilar i de l'àpex del fruit, tot això associat al procés de domesticació sofrit per aquesta espècie. L'absència dels caràcters típics de les dues espècies descrites va caracteritzar a la var. cerasiforme. El nombre de flors per inflorescència, el nombre de pètals i la longitud, amplària $\mathrm{i}$ pes del fruit, no van mostrar interaccions Entrada $\mathrm{x}$ Any. Aquests caràcters, junt amb els qualitatius comentats anteriorment, es consideren com els més discriminants entre L. pimpinellifolium, $L$. esculentum var. cerasiforme i L. esculentum.

L'anàlisi cluster efectuat amb el conjunt de caràcters morfològics agrupa a les entrades de L. pimpinellifolium amb les de var. cerasiforme, mentre que el realitzat amb dades moleculars agrupa $L$. esculentum amb var. cerasiforme, quedant $L$. pimpinellifolium separada d'ambdues. Açò recolza la hipòtesi que la var. cerasiforme és l'ancestre a partir del qual es va produir la domesticació de la tomaca.

El conjunt d'entrades estudiades de L. pimpinellifolium ha presentat elevada variabilitat per a característiques vegetatives, de flor $\mathrm{i}$ de fruit, contribuint a demostrar que $L$. pimpinellifolium, és una espècie molt variable, en contra del que es pensava anteriorment. Altres estudis realitzats amb aquestes entrades han demostrat també la seua variabilitat per a característiques de qualitat $\mathrm{i}$ de resistència a malalties, convertint-la en una col·lecció summament útil per a la millora.

A les entrades estudiades en este treball s'observa una gradació quant a l'exerció estigmatica, associada a òrgans florals de major tamany i major grau d'alogamia, trobant-se major freqüència d'estil molt projectat en els Departaments més septentrionals de Piura i Lambayeque, mentre que en Cajamarca i La Libertad, abunden les entrades amb estils no projectats o inclús inserts. Les poblacions procedents de Piura i Lambayeque tenen una diversitat genètica total major, probablement com a conseqüència del major grau d'alogamia. Este fet té importants implicacions en les taques de mostratge i regeneració als Bancs de Germoplasma.

El conjunt d'entrades de L. esculentum var. cerasiforme caracteritzades han mostrat una elevada variabilitat per a caràcters morfològics, tant vegetatius com de fruit. Esta variabilitat ha resultat estar associada a l'orige, sent molt més uniformes i amb característiques pròpies de cerasiforme les procedents de Mèxic, mentre que les d'Equador i altres procedències són molt més variables, no corresponent en ocasions a la forma típica aquesta varietat.

Les entrades de L. esculetum estudiades s'agrupen segons el seu orige, Mèxic o Espanya, segons les seues característiques morfològiques i moleculars. En el primer cas es deu probablement a les diferents pressions de selecció exercides en aquests dos països. En el segon cas seria conseqüència del distanciament geogràfic aquests dos grups d'entrades fa més de 500 anys. Les entrades procedents de Mèxic pertanyen a tipus criolls, molt apreciat per les seues característiques de qualitat, resistència al clavillat i capacitat per a quallar a baixes temperatures. Estes entrades seran de gran utilitat per al a la seua utilització en programes de millora. La major diversitat genètica total trobada per a les entrades de Mèxic, recolzaria l'existència d'un coll de botella a causa del limitat nombre d'individus transportats des de Mèxic a Espanya, on es va iniciar la difusió per Europa.

S'han establit tres grups d'entrades de L. pimpinellifolium, les procedents de les Illes Galàpagos, les col-lectades a Cuzco i les del nord de Perú i Equador, amb marcades diferències tant morfològiques com moleculars. Totes elles hauran d'estar representades a la 
col-lecció nuclear d'esta espècie del Banc de Germoplasma del COMAV.

Mitjançant la realització d'un anàlisi cluster s'ha determinat l'existència de duplicats en la col-lecció, mitjançant el seu agrupament en els arbres amb valors de bootstrap molt elevats. Esta informació permetrà l'eliminació d'estes entrades per a la formació de la col·lecció nuclear.

La major diversitat genètica a les entrades procedents dels Departaments de Piura i Lambayeque front a les de Cajamarca i La Llibertat aconsellen una major representació de les primeres en la col-lecció nuclear, a fi d'assegurar que la major part d'aquesta diversitat genètica quede representada a la col·lecció. 


\section{SUMMARY}

The Center of Conservation and Improvement of Agrodiversity (COMAV) of the Polytechnical University of Valencia holds one of the most important collections of accessions of the genus Lycopersicon genus, including the cultivated tomato (Lycopersicon esculentum, L. esculentum var. cerasiforme) and its wild relatives ( $L$. cheesmanii, L. pimpinellifolium, L. hirsutum, L. pennellii, L. chmilewskii, $L$. parviflorum L. peruvianum and L. chilense).

In spite of tomato being one of the vegetables of greater economic importance at world-wide level, ambiguities in its taxonomy continue existing as well as doubts about its domesticación. In fact, intermediate forms are observed in many occasions between the cultivated tomato and the botanical variety cerasiforme, and between the cerasiforme form and $L$. pimpinellifolium. Also intermediate forms between $L$. pimpinellifolium and $L$. cheesmanii have been detected. These species constitute the Eulycopersicon subgenus, interfertile with the cultivated tomato. Of them, the botanical variety cerasifrome is considered as ancestry of the tomato and introgression phenomena between $L$. pimpinellifolium and the tomato have been reported. The theories regarding the domestication of the tomato are not unique, being the theories of Jenkins (1948) and Rick (1958) opposed to most recent ones of Rick and Fobes (1975) and Rick and Holle (1990).

In order to contribute to the clarification of these aspects, in the present Doctoral Thesis the following objectives are proposed:

1.- Study of the morphologic and molecular variability of these species

2.- Elucidation of the phylogenetic relations between the species of the Eulycopersicon subgenus.

3.- Establishment of strategies of conservation of these species and in special of Lycopersicon pimpinellifolium, for which important differences in the degree of alogamy have been described.

4.- Beginning of the establishment of a core collection in the collection of accessions of L. pimpinellifolium of the COMAV.

A total of 165 accessions of the Lycopersicon genus have been studied, belonging 48 of them to Lycopersicon esculentun var. cerasiforme, 86 to L. pimpinellifolium and 31 to L. esculentum. Experiments were carried out in 2000-01 and 2001-02 years during autumn-winter seasons. Morphological characterization was done following the tomato descriptors published by the IPGRI. AFLPs were used for molecular characterization. Data were analyzed by means of multivariant analysis, using Principal Components Analysis and Cluster Analysis. Euclidean distances were calculated for anlysis of quantitative data and the UPGMA clustering method was used. The robustness and level of reliability of clusters were fitted by bootstrap technique. ANOVA and NewmanKeuls test were performed. Genetic similarity between the different accessions were calculated. Polymorphism and the genetic diversity were calculated according to Nei (1973).

The analysis of main components carried out allowed the assignment of most part of the accessions studied to Lycopersicon esculentum, L. pimpinellifolium and $L$. esculentum var. cerasiforme species. Nevertheless, the separation was not complete, existing a continuous gradation among them, probably as a result of a not finalized simpatric speciation process. The lack of identification of specific molecular markers of species support this hypothesis. The existence of interspecific hybridization would 
contribute to the maintenance of this situation, constituting L. esculentum, L. esculentum var. cerasiforme and $L$. pimpinellifolium extreme forms of this continuous.

A series of specific qualitative characters of the most typical forms of the species in study was identified. Thus, the antocianic colour of the stem, the type of leaf "pimpinellifolium" (generally smaller, pinnate and with entire edges) and the style very projected were characteristic of $L$. pimpinellifolium. L. esculentum was characterized fundamentally by characters relative to the fruit, as the variation in the form and the color of the mature fruit, irregular forms of the cross-sectional section, the pistil scar and the apex of the fruit, all associated to the process of domesticación undergone by this species. var. cerasiforme was characterized by the absence of the typical characters of the two described species. The number of flowers per inflorescencia, the number and length of the petals and width and weight of the fruit, did not show interactions Accession $x$ Year. These characters, along with the qualitative ones previously cited, are considered like as discriminants between $L$. pimpinellifolium, L. esculentum var. cerasiforme and L. esculentum.

The cluster analysis carried out with morphological characters grouped $L$. pimpinellifolium accessions with those of var. cerasiforme, whereas the cluster made with molecular data grouped $L$. esculentum with var. cerasiforme, being $L$. pimpinellifolium separated of both. This supports the hypothesis that var. cerasiforme is the ancestry of the cultivated tomato.

Accessions of $L$. pimpinellifolium displayed a high variability for vegetative, of flower and fruit characteristics contributing to demonstrate that L. pimpinellifolium, is a very variable species, against the uniformity previously established. Other studies made with these accessions have also demonstrated their variability for characteristics of quality and resistance to diseases, making it an extremely useful collection for tomato breeding.

In the accesions studied in this work a gradation on the style exsertion is observed, associated to floral organs of greater size and greater degree of alogamy, being higher frequency of style very projected in the most northern Departments of Piura and Lambayeque, whereas in Cajamarca and La Libertad, abounds the entrances with styles nonprojected or even inserted. The populations from Piura and Lambayeque have a higher total genetic diversity, probably as a result of the higher degree of alogamia. This fact has important implications in the sampling and regeneration tasks in the Genebanks.

Accessions of characterized L. esculentum var. cerasiforme have shown a high variability for morphologic characters, both vegetative and fruit. This variability was associated to the origin, being much more uniform and having characteristics of cerasiforme coming from Mexico, whereas those of Ecuador and other origins were much more variable, not corresponding sometimes to the typical form of this variety.

Accessions of L. esculetum studied were grouped according to their origin, Mexico or Spain, regarding both for their morphologic and molecular characteristics. In the first case, it probably is due to the different exerted pressures of selection in both countries. In the second, it would be consequence of the geographic division of both groups for more than 500 years. Accessions from Mexico belong to "criollo" types, very appreciated by their characteristics of quality, resistance to cracking and the ability to fruits set at low temperatures. These accessions will be very useful for their use in breeding programs. The higher value of total genetic diversity for accession from Mexico, would support the existence of a bottle neck due to the limited number of 
individuals transported from Mexico to Spain, where the diffusion throughout Europe began.

Three groups of accessions of L. pimpinellifolium have been established. One of them from the Galápagos Islands, other collected in Cuzco and the other from the North of Peru and Ecuador, with great morphologic and molecular differences. All of them will have to be represented in the core collection of this species at the Genebank of the COMAV.

Cluster analisys allowed the identification of duplicated accessions in the collection. Duplicates appear grouped in the trees with considerably high bootstrap values. This information will allow the elimination of such duplicates for the formation of the core collection.

The higher genetic diversity of the accessions from Piura and Lambayeque Departments as opposed to those of Cajamarca and La Libertad advises a greater representation of the formers in the nuclear collection, in order to assure that most of this genetic diversity is represented in the core collection. 
AGRADECIMIENTOS 
Agradecer muy especialmente a mis directores D. Fernando Nuez y Dña. M ${ }^{a}$ José Diez Niclós, por su entrega, dedicación, enseñanzas y la amplia colaboración en la concepción y elaboración de este trabajo, al haber depositado en mí la confianza y los medios necesarios para su realización. Por su constante apoyo e interés por solucionar los diversos problemas que me fueron surgiendo a lo largo de este tiempo en el cual hemos compartido también muchos momentos felices. Que seguramente de no ser por ellos no vería cumplido este sueño.

A Laura y Gemma cuya inestimable cooperación, participación y esfuerzo han facilitado aun más si cabe la realización de este sueño.

A todo el personal del departamento de Biotecnología, particularmente los del área de Genética que me han acogido y ayudado en todo momento. Paco, Eva, Salva y Pascual en la ardua labor de la caracterización morfológica.

A todos los becarios y técnicos del laboratorio del COMAV. José Blanca por su siempre incondicional disponibilidad en la orientación del manejo de las técnicas de análisis molecular.

A la Universidad Politécnica de Valencia.

A la Agencia Española de Cooperación Internacional (AECI).

Al Ministerio de Agricultura e do Desenvolvimento Agrario (MINADER/Angola).

Al Instituto de Desenvolvimento Agrario (IDA/Angola).

Por último y no menos especial, agradecer a mi familia por comprender, acompañarme y animarme en todo momento.

A todos gracias. 
A la memoria de mi madre Antónia José Pedro.

A mi esposa Beatriz Gaspar da Silva Domingos.

\author{
A mis hijos: \\ Carlos Aldmar da Costa Domingos. \\ Emmanuel do Rosario da Silva Domingos. \\ Lidiany Darcília do Rosario da Silva Domingos
}


ÍNDICE 
1. INTRODUCCIÓN 1

1.1 Importancia económica del tomate. 2

1.2 El género Lycopersicon. 4

1.2.1 Clasificación taxonómica. $\quad 4$

1.2.2 El género Lycopersicon: distribución y relaciones filogenéticos. 4

1.3 Descripción de las especies del subgénero Eulycopersicon.

1.4 Origen, domesticación y difusión del tomate. 11

1.4.1 Origen y domesticación. 11

$\begin{array}{ll}\text { 1.4.2 Difusión del tomate. } & 14\end{array}$

1.5 Estudios de variabilidad realizados en el género Lycopersicon. 16

1.5.1 Estudios de variabilidad morfológica. $\quad 17$

1.5.2 Estudios isozímicos y alozímicos de la variabilidad. 18

1.5.3 Estudios realizados con marcadores de ADN. 18

$\begin{array}{lr}\text { 2. OBJETIVOS } & 21\end{array}$

3. MATERIALES Y MÉTODOS 23

$\begin{array}{ll}3.1 \text { Material vegetal. } & 24\end{array}$

3.2 Diseño experimental. 34

3.3 Caracterización morfológica. 35

3.3.1 Caracteres cuantitativos. 35

$\begin{array}{ll}\text { 3.3.2 Caracteres cualitativos. } & 37\end{array}$

3.4 Análisis de la variabilidad molecular mediante AFLP. 38

3.4.1 Material vegetal. 38

3.4.2 Toma de muestras. $\quad 38$

3.4.3 Extracción de ADN. 38

3.4.4 Cuantificación del ADN. 39

3.4.5 Análisis del polimorfismo en la Longitud de los Fragmentos Amplificados

$\begin{array}{ll}\text { (AFLP). } & 40\end{array}$

3.4.5.1 Fundamento. $\quad 40$

3.4.5.2 Protocolo. 41

3.4.6 Electroforesis en secuenciador automático. 43 
3.4.6.1 Funcionamiento del secuenciador. $\quad 43$

3.4.6.2 Análisis de datos moleculares. 44

3.5 Análisis estadístico $\quad 45$

3.5.1 Análisis de la varianza. $\quad 45$

3.5.2 Análisis multivariante: análisis cluster y análisis de componentes $\begin{array}{ll}\text { principales (ACP). } & 46\end{array}$

Análisis de componentes principales $\quad 47$

Análisis cluster $\quad 48$

Análisis de coordenadas principales $\quad 50$

3.5.3 Análisis de polimorfismo y diversidad genética. 50

4. RESULTADOS Y DISCUSIÓN 51

4.1 Análisis de la variabilidad morfológica 52

4.1.1 Análisis de la interacción Entrada x Año 52

4.1.2 Análisis de las entradas ensayadas en la campaña 2000-2001 53

4.1.2.1 Análisis de todas las entradas. 53

Agrupación de las entradas según ACP 53

Correlación entre caracteres. 57

Análisis cluster: Análisis Q. $\quad 62$

Variabilidad entre y dentro de especie. 66

Caracteres vegetativos. $\quad 66$

Caracteres de flor e inflorescencia. 67

Caracteres de fruto. $\quad 68$

Necesidad de revisión de los actuales descriptores de tomate. 71

Caracteres cualitativos diferenciales de especies. 71

$\begin{array}{ll}\text { Caracteres vegetativos. } & 71\end{array}$

Caracteres de flor e inflorescencia.

Caracteres de fruto. $\quad 72$

Estabilidad de los cuantitativos y elección de los caracteres diferenciales entre especies.

Análisis conjunto de los caracteres cuantitativos y cualitativos. $\quad 76$

Discusión de la caracterización morfológica del ensayo 2000-01. 78 
4.1.2.2 Lycopersicon esculentum var. cerasiforme 80

Agrupación de las entradas según ACP 80

Agrupación de las entradas según el análisis cluster: Análisis Q. 82

Discusión. $\quad 84$

4.1.2.3 Lycopersicon esculentum. $\quad 85$

Agrupación de las entradas según ACP. 85

Análisis conjunto con caracteres cuantitativos y cualitativos. $\quad 91$

Discusión. $\quad 92$

4.1.2.4 Lycopersicon pimpinellifolium. 93

Agrupación de las entradas según ACP. 93

Agrupación de las entradas según el Análisis cluster: Análisis Q. 98

Discusión. 99

4.1.3 Análisis de las entradas ensayadas en la campaña 2001-2002:

Lycopersicon pimpinellifolium. 101

Agrupación de las entradas según ACP. 101

Estudio de alogamia de las entradas según su procedencia. 106

Discusión 107

Entradas procedentes de las Islas Galápagos. 107

Estudio de alogamia de las entradas según su procedencia. $\quad 108$

4.2 Análisis de la variabilidad molecular mediante AFLP: estudio conjunto de las dos campañas.

4.2.1 Análisis de todas las entradas.

Agrupación de las entradas en función de la distancia genética. $\quad 110$

Análisis cluster. $\quad 110$

Análisis de coordenadas principales. 112

Discusión. 113

Polimorfismo y diversidad genética. $\quad 114$

Bandas específicas de especie. 118

Discusión. 119

4.2.2 Análisis de la variabilidad molecular por especie $\quad 120$

4.2.2.1 Lycopersicon esculentum var. cerasiforme. 120

Análisis cluster. $\quad 120$

Discusión 121

4.2.2.2 Lycopersicon esculentum. 122 
Análisis cluster. $\quad 122$

Discusión 123

4.2.2.3 Lycopersicon pimpinellifolium. 124

Análisis de las entradas ensayadas en las dos campañas $\quad 124$

Análisis de coordenadas principales y cluster. 124

$\begin{array}{ll}\text { Bandas específicas por origen. } & 127\end{array}$

Análisis de la variabilidad molecular de las poblaciones de Lycopersicon pimpinellifolium del norte del Perú. 128

Discusión 130

4.3 Comparación del análisis morfológico y molecular. 130

4. 4 Inicio de la formación nuclear de la colección de entradas de l. Pimpinellifolium del banco de germoplasma del COMAV.

5. CONCLUSIONES.

6. BIBLIOGRAFÍA.

7. ANEXOS.

Anexo 1. Niveles de los caracteres cualitativos determinados en la caracterización morfológica.

Anexo 2. Preparación de los diferentes reactivos usados en el análisis molecular 157 
ÍNDICE DE TABLAS 


\section{INTRODUCCIÓN}

Tabla 1.1. Producción y superficie de tomate por continentes en el año 2001 (Fuente: Anuario de Producción de la FAO, 2001).

Tabla 1.2. Taxonomía del género Lycopersicon (fuente: Cronquist 1981).

Tabla 1.3. Clasificación de las especies del género Lycopersicon (Basado en Muller, 1940; Palmer y Zamir, 1982; Taylor, 1986).

\section{OBJETIVOS}

\section{MATERIALES Y MÉTODOS}

Tabla 3.1. Entradas incluidas en el ensayo 2000-2001.

Tabla 3.2. Entradas incluidas en el ensayo 2001-2002.

Tabla 3.3. Entradas incluidas en ambos ensayos.

Tabla 3.4. Cebadores empleados en las amplificaciones selectivas de los AFLP.

\section{RESULTADOS Y DICUSIÓN}

Tabla 4.1. Efectos de Entrada por año e interacción entrada por año para cada carácter y especie, realizados con los caracteres cuantitativos de las entradas comunes a ambos ensayos, mediante un ANOVA factorial y modelo mixto.

Tabla 4.2 Procedencia de las formas intermedias entre las especies del subgénero Eulycopersicon.

Tabla 4.3. Correlaciones parciales entre caracteres cuantitativos evaluados en el ensayo 2000-01.

Tabla 4.4. Prueba de Newman-Keuls, para determinar los caracteres discriminantes exclusivos entre especies. Campaña 2000-01.

Tabla 4.5. Resultados de la caracterización molecular mediante marcadores AFLP, por especie.

Tabla 4.6. Análisis de la variabilidad genética, y diferenciación genética para las tres especies. 
Índice de Tablas

Tabla 4.7. Procedencia de las entradas de L. esculentun var. cerasiforme cultivadas en la campaña 2000-01.

4. CONCLUSIONES

5. BIBLIOGRAFIA

6. ANEXOS 


\section{ÍNDICE DE FIGURAS}




\section{INTRODUCCIÓN}

Figura 1.1. Distribución de las especies silvestres del género Lycopersicon (Basado en Cuartero et al., 1984; Taylor, 1986; Ayuso et al., 1987).

Figura 1.2. Frutos de L. esculentum.

Figura 1.3. Planta de L. esculentum var cerasiforme.

Figura 1.4. Frutos de L. pimpinellifolium.

Figura 1.5. Frutos de L. chemanii var minor.

Figura 1.6. Ilustración de la planta de tomate en el herbario de Konrad Gessener, realizada en 1553 .

Figura 1.7. Una de las primeras representaciones del tomate en los primeros herbarios europeos (Ilustración perteneciente a la obra Hortus Eystettensis (1613)).

Figura 1.8. Representación de la planta de tomate en "Icones Plantarum Medicinalium" (Joseph Jacobi Plenck, 1788).

Figura 1.9. Posibles rutas de propagación del tomate a partir del siglo XVI (Basado en Esquinas - Alcázar y Nuez. 1995).

\section{OBJETIVOS}

\section{MATERIALES Y MÉTODOS}

Figura 3.1. Localización geográfica de las entradas de Ecuador incluidas en los ensayos.

Figura 3.2. Localización geográfica de las entradas de Perú incluidas en los ensayos.

Figura 3.3. Localización geográfica de las entradas de Perú incluidas en los ensayos.

Figura.3.4. Longitud del pedicelo 1 y 2.

Figura 3.5. Cuantificación en gel de agarosa $0.8 \%$ con patrón de ADN de Arabidopsis thaliana.

Figura 3.6. Esquema de los AFLP utilizando los enzimas de restricción MseI y EcoRI y sus adaptadores (Fuente: Lin y Kuo, 1995).

Figura 3.7. Secuenciador automático ABI/PRISM 310 de PE Biosystems.

Figura 3.8. Fragmentos amplificados en forma de picos (imagen GeneScan). 
Figura 3.9. Fragmentos amplificados transformados en banda (Imagen Genographer).

\section{RESULTADOS Y DISCUSIÓN}

Figura 4.1. Representación de los coeficientes de los caracteres en los vectores propios que definen las dos primeras componentes principales. Ensayo 2000-01.

Figura 4.2. Representación de las entradas en función de las componentes principales 1 y 2, para el ensayo 2000-01.

Figura 4.3. Agrupación de los caracteres según el análisis cluster $\mathrm{R}$ efectuado con el conjunto de entradas del ensayo 2000-01, utilizando las distancias euclídeas y el método de agrupamiento UPGMA.

Figura 4.4. Grupos de caracteres establecidos según las correlaciones entre ellos.

Figura 4.5. Representación de las entradas frente a las componentes principales 1 y 2 en el análisis realizado con los caracteres seleccionados.

Figura 4.6. Representación de las entradas en el dendrograma realizado con todos los caracteres del ensayo 2000-01, utilizando las distancias euclídeas y el método de agrupamiento UPGMA.

Figura 4.7. Representación de las entradas del ensayo 2000-01. Dendrograma realizado con los caracteres seleccionados a partir de la Figura 4.4, utilizando distancias euclídeas y el método de agrupamiento UPGMA.

Figura 4.8. Histogramas de frecuencia de los caracteres cualitativos vegetativos para el ensayo 2000-01.

Figura 4.9. Histogramas de frecuencia de los caracteres cualitativos de flor e inflorescencia del ensayo 2000-01.

Figura 4.10. Histogramas de frecuencia de los caracteres cualitativos de fruto del ensayo 2000-01.

Figura 4.11. Ficha de algunos de los caracteres cuantitativos y cualitativos diferenciales entre especie.

Figura 4.12. Dendrograma para el conjunto de datos cuantitativos y cualitativos de la caracterización morfológica del ensayo 2000-01, utilizando distancias euclídeas y el método de análisis UPGMA.

Figura 4.13. Representación de los coeficientes de los caracteres en los vectores propios que definen las dos primeras componentes principales. Entradas de L. esculentum var. cerasiforme ensayo 2000-01. 
Figura 4.14. Representación de las entradas de L. esculentum var. cerasiforme, del ensayo 2000-01, respecto a las componentes principales 1 y 2 .

Figura 4.15. Frutos de L. esculentum var. cerasiforme.

Figura 4.16. Dendrograma de las entradas de var. cerasiforme obtenido a partir de los datos cuantitativos, utilizando las distancias euclídeas y el método de análisis UPGMA.

Figura 4.17. Representación de los coeficientes de los caracteres en los vectores propios que definen las dos primeras componentes principales Entradas de L. esculentum, ensayo 2000-01.

Figura 4.18. Representación de los coeficientes de los caracteres en los vectores propios que definen la primera y tercera componente principal. Entradas de L. esculentum, ensayo 2000-01.

Figura 4.19. Representación de las entradas de L. esculentum, del ensayo 2000-01, respecto a las componentes principales 1 y 2 .

Figura 4.20. Hojas de L. esculentum Campaña 2000-2001.

Figura 4.21.Frutos de L. esculentum de procedencia española. Campaña 2000-2001.

Figura 4.22. Frutos de L. esculentum de procedencia méxicana. MEX 14 es tipo "Tuchito", MEX 17R y MEX 21 de tipo "Zocato" y MEX 18 de tipo "Mazano". Campaña 2000-2001.

Figura 4.23. Representación de las entradas de L. esculentum, del ensayo 2000-01, respecto a las componentes principales 1 y 3 .

Figura 4.24. Representación de las entradas de L. esculentum frente a las componentes principales 1 y 2 , en el análisis de componentes principales realizado con todos los caracteres morfológicos (cuantitativos y cualitativos). Campaña 2000-2001.

Figura 4.25. Representación de los coeficientes de los caracteres en los vectores propios que definen las dos primeras componentes principales. Entradas de L. pimpinellifolium, para el ensayo 2000-01. 
Figura 4.26. Representación de los coeficientes de los caracteres en los vectores propios que definen la primera y tercera componentes principales. Análisis efectuado con las entradas de L. pimpinellifolium ensayadas en 200-01.

Figura 4.27. Representación de las entradas de L. pimpinellifolium, del ensayo 2000-01, respecto a las componentes principales 1 y 2 .

Figura 4.28. Frutos de L. pimpinellifolium.

Figura 4.29.A: Frutos y hoja de algunas entradas colectadas en Cuzco (Perú).

Figura 4.30. Dendrograma de las entradas de L. pimpinellifolium, del ensayo 2000-01, obtenido a partir de los datos cuantitativos, utilizando distancias euclídeas, con método de análisis UPGMA.

Figura 4.31. Localización geográfica de las entradas colectadas en el Valle de Urubamba, Departamento de Cuzco, incluidas en ensayo 2000-01 y las de L. esculentum var. cerasiforme del TGRC.

Figura 4.32. Representación de los coeficientes de los caracteres en los vectores propios que definen la primera y segunda componentes principales. Análisis efectuado con las entradas de L. pimpinellifolium ensayadas en 2001-02.

Figura 4.33. Representación de los coeficientes de los caracteres en los vectores propios que definen la primera y tercera componentes principales. Análisis efectuado con las entradas de L. pimpinellifolium ensayadas en 2001-02.

Figura 4.34. Representación de las entradas de L. pimpinellifolium del ensayo 2001-02 en el plano de las componentes principales 1 y 2 .

Figura 4.35. Frutos y hojas de diferentes entradas colectadas en las Islas Galápagos.

Figura 4.36. Histogramas realizados con los caracteres cualitativos de hoja y de flor de las entradas de L. pimpinellifolium procedentes de Perú y Galápagos del ensayo 200102 .

Figura 4.37. Histogramas de frecuencia de la exerción estigmática y tamaño de los órganos florales, de las entradas de L. pimpinellifolium del ensayo 2001-02, recolectadas en los Departamentos costeros más septentrionales de Perú: Piura, Lambayeque, Cajamarca y La Libertad. 
Figura 4.38. Representación del dendrograma realizado con datos moleculares obtenidos mediante AFLP, se indican en los nudos los valores de bootstrap superiores al $50 \%$ utilizando el coeficiente de similitud de Dice (1945) y aplicando el análisis UPGMA.

Figura 4.39. Representación de las entradas según el análisis de coordenadas principales realizado con datos obtenidos mediante AFLP.

Figura 4.40. Representación de las bandas obtenidas a partir de AFLPs, utilizando la combinación de cebadores EcoAGC/MseCAA.

Figura 4.41. Representación del dendrograma calculado con 37 entradas de $L$. esculentum var. cerasiforme cultivadas en la campaña 2000-01, se indican en los nudos los valores de bootstrap superiores al 50\% utilizando el coeficiente de similitud de Dice (1945) y aplicando el análisis UPGMA.

Figura 4.42. Representación del dendrograma calculado con 25 entradas de $L$. esculentum, utilizando el coeficiente de similitud de Dice (1945) y el método de análisis UPGMA.

Figura 4.43. Representación de las entradas de L. pimpinellifolium ensayadas en las dos campañas en función de la primera y segunda coordenadas principales.

Figura 4.44. Representación del dendrograma para el conjunto de entradas de $L$. pimpinellifolium ensayadas en las dos campañas. Análisis molecular con marcadores AFLP, utilizando el coeficiente de similitud de Dice (1945) y aplicando el análisis UPGMA.

Figura 4.45. Bandas obtenidas mediante el programa Genographer a partir de los fragmentos amplificados, utilizando las combinaciones de cebadores de la serie A (Tabla 3.4).

Figura 4.46. Localización de las entradas recolectadas en los Departamentos más septentrionales de Perú.

Figura 4.47. Dendrograma realizado con el conjunto de entradas del norte del Perú a partir de la matriz de datos moleculares, ensayo 2001-02 utilizando el coeficiente de similitud de Dice (1945) y aplicando el método de análisis UPGMA.

\section{CONCLUSIONES.}




\section{BIBLIOGRAFIA.}

\section{ANEXOS.}

Figura 7.1. Diferentes tipos de hojas.

Figura 7. 2 Diferentes formas del fruto. 
1. INTRODUCCIÓN 


\section{1. IMPORTANCIA ECONÓMICA DEL TOMATE}

\section{Situación a nivel mundial}

El tomate es la hortaliza más cultivada en numerosos países (Esquinas-Alcázar y Nuez, 1995). La producción mundial de tomates ha ido aumentado considerablemente en la última década, desde 74 millones de toneladas (media anual) en 1993 hasta $115,503,316$ de toneladas en 2001 (Tabla 1.1).

\begin{tabular}{|c|c|c|}
\hline CONTINENTES & PRODUCIÓN (t) & $\begin{array}{c}\text { SUPERFICIE } \\
\text { CULTIVADA(ha) }\end{array}$ \\
\hline AFRICA & $12,062,901$ & 616,244 \\
\hline $\begin{array}{c}\text { AMERICA DEL } \\
\text { NORTE Y } \\
\text { CENTRAL }\end{array}$ & $13,808,692$ & 296,414 \\
\hline $\begin{array}{c}\text { AMERICA DEL } \\
\text { SUR }\end{array}$ & $5,990,362$ & 152,813 \\
\hline ASIA & $47,289,707$ & $1,837,811$ \\
\hline EUROPA & $17,436,794$ & 407,020 \\
\hline UNION EUROPEA & $15,129,460$ & 254,489 \\
\hline ESPAÑA & $3,785,400$ & 63,000 \\
\hline $\begin{array}{c}\text { TOTAL } \\
\text { MUNDIAL }\end{array}$ & $\mathbf{1 1 5 , 5 0 3 , 3 1 6}$ & $\mathbf{3 , 6 2 7 , 7 9 1}$ \\
\hline
\end{tabular}

Tabla 1.1. Producción y superficie cultivada de tomate por continentes en el año 2001 (Fuente: Anuario de Producción de la FAO, 2001).

Su demanda aumenta continuamente y con ella, su cultivo, producción y comercio. El incremento anual de la producción, a nivel mundial, de los últimos años ha sido de aproximadamente un 3\%. Este incremento es debido, principalmente, al aumento del rendimiento proporcionado por el uso de variedades más productivas y por la mejora de las condiciones de cultivo.

Uno de los mayores atractivos de cualquier producto frente al consumidor es su diversidad. El tomate es una hortaliza que ha alcanzado una gran variedad de tipos. Hay variedades con distinto aspecto exterior (forma, tamaño, color) e interior (sabor, textura, dureza), variedades destinadas para consumo en fresco o procesado industrial y dentro de estos usos principales, muchas especializaciones del producto. Las preferencias por un tipo determinado son muy diversas y varían en función del país, tipo de población, uso al que se destina, etc. (Díez, 1995). En la actualidad se industrializa entre el 25 y $30 \%$ de la producción mundial, volumen que sitúa a este producto como la materia prima más importante de la industria de conservas hortícolas. 
El valor nutritivo del tomate no es muy elevado. No obstante, su popularidad, demostrada por el alto nivel de consumo, convierte a este cultivo en una de las principales fuentes de vitaminas y minerales en muchos países (Esquinas-Alcázar y Nuez, 1995).

\section{Situación en la Unión Europea y España.}

La producción de tomate en Europa en 2001 fue de 17,436,794 toneladas, con un rendimiento de 42,84 toneladas/hectárea. La productividad media en algunos países europeos, en particular en Holanda, Reino Unido, Bélgica, Dinamarca, etc., es más de diez veces superior a la media mundial. La importancia del tomate en el sector hortícola de estos países hace que sobre su cultivo incida en mayor medida la investigación y desarrollo de nuevas técnicas de cultivo y nuevas variedades.

La Unión Europea es autosuficiente y poco integrada en el mercado internacional, ya que sólo importa alrededor de un 5\% del tomate que consume en fresco y la mayor parte de la producción europea se destina al mercado interno.

En España, el tomate es un producto básico de la horticultura. Ocupa el $14 \%$ de la superficie de cultivo de hortícolas y aporta un 30,8 \% del valor de la producción de dicho sector (Anuario FAO, 2001). Es la hortaliza que abarca mayor superficie y producción. España produce actualmente 3,785,400 toneladas de tomate en 63,000 hectáreas, representando el 23,8\% de la producción de la Unión Europea y el 4\% de la producción mundial. El $70 \%$ se destina al consumo en fresco y el $30 \%$ restante a la industrialización.

Entre los países europeos, España es aquel en el que la producción de tomate abarca todo el abanico posible de actividades. Es tan importante la utilización del producto en fresco, como su carácter de materia prima industrial. Las regiones más productoras son el Sur-Este peninsular (Valencia, Alicante, Murcia y Almería), el Ebro (Navarra, Rioja y Zaragoza), Extremadura y Canarias. Las regiones del Ebro y Extremadura se especializan en la producción de tomate para la industria, en tanto que el resto de las regiones se enfocan hacia el mercado en fresco (Aldanondo, 1995).

España es el primer país exportador europeo. Las exportaciones de tomate han experimentado un aumento bastante acusado en los últimos años. En 1995 se exportaron 786,487 toneladas de tomate, mientras que en 1998, esta exportación fue de 910,873 toneladas. El 95\% de estas exportaciones fue destinado a países de la Unión Europea. 


\section{2. EL GÉNERO LYCOPERSICON}

\section{2. 1. Clasificación taxonómica.}

El tomate es una especie perteneciente a la familia de las solanáceas. Esta familia comprende unas 2300 especies agrupadas en 96 géneros, entre las cuales se incluyen algunas especies de gran importancia económica como la patata y la berenjena (D’Arcy, 1991).

Según Cronquist (1981), la clasificación taxonómica del tomate es la siguiente:

\begin{tabular}{|l|l|}
\hline CLASE & Magnoliopsida. \\
\hline ORDEN & Solanales. \\
\hline FAMILIA & Solanaceae. \\
\hline SUBFAMILIA & Solanoideae. \\
\hline TRIBU & Solaneae. \\
\hline GENERO & Lycopersicon. \\
\hline ESPECIE & Lycopersicon esculentum. \\
\hline
\end{tabular}

Tabla 1.2. Taxonomía del género Lycopersicon (fuente: Cronquist 1981).

\section{2. 2. El género Lycopersicon: distribución y relaciones filogenéticas.}

Actualmente, se incluyen en el género Lycopersicon ocho especies silvestres, además de la especie cultivada. El género presenta su hábitat natural en la zona situada en la costa occidental de Sudamérica, desde el sur de Ecuador hasta el norte de Chile, y en las Islas Galápagos. Esta franja se extiende entre el mar y la cordillera andina (Figura 1.1), presentando una gran diversidad de ambientes en los que se desarrollan estas especies silvestres, que suponen una fuente importante de variabilidad y reservorio de genes para características interesantes disponible para la mejora del tomate cultivado (Rick, 1979; Stevens y Rick, 1986; Daunay et al., 1991; Kalloo, 1991; Warnock, 1991). 


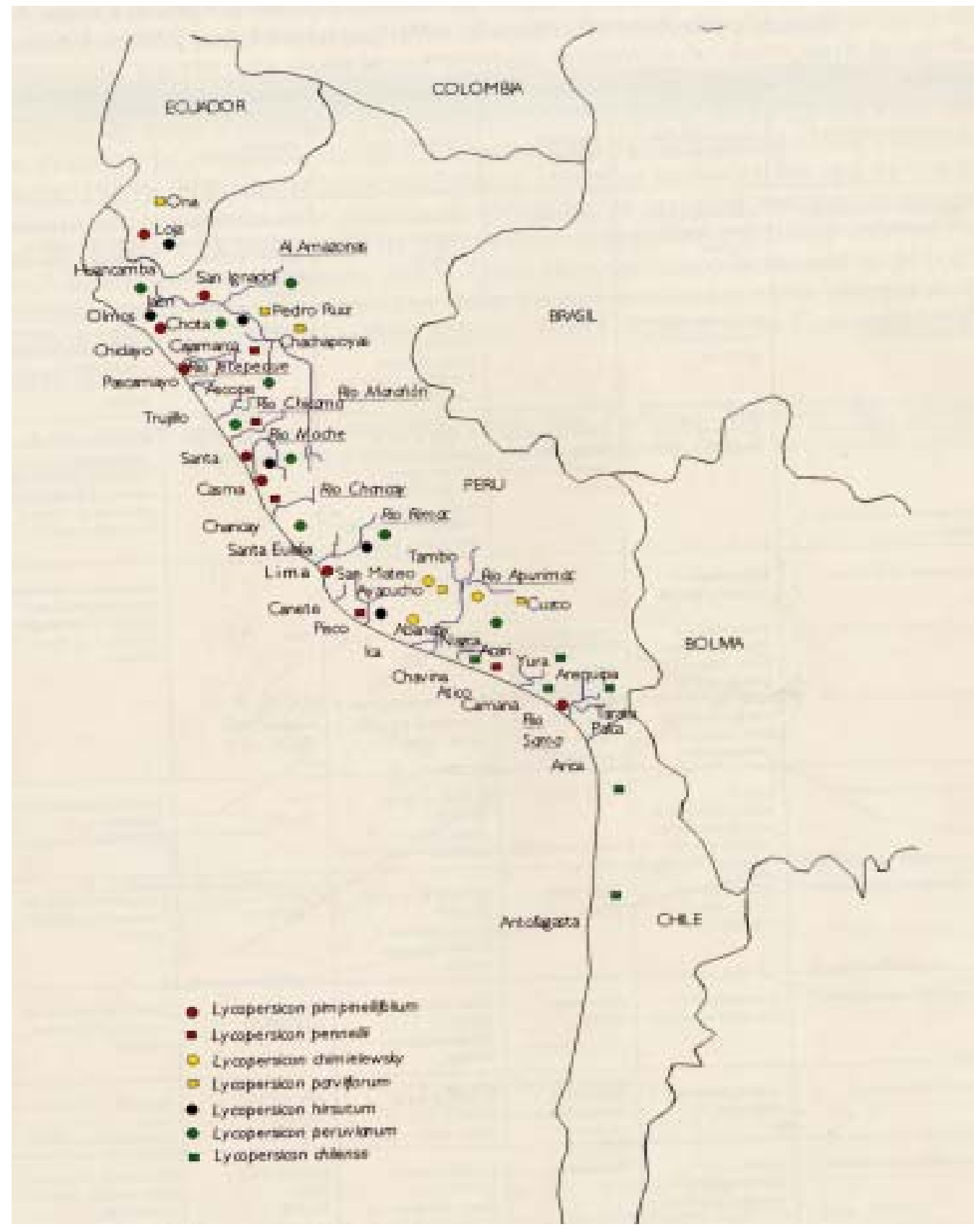

Figura 1.1. Distribución de las especies silvestres del género Lycopersicon (Basado en Cuartero et al., 1984; Taylor, 1986; Ayuso et al., 1987).

Una de las primeras clasificaciones intragenericas, basada en el color y la pubescencia del fruto, fue establecida por Muller (1940) que divide el género en dos subgéneros:

Eulycopersicon: especies con frutos rojos y glabros.

Eriopersicon: especies con frutos pubescentes, verdes, blancos o amarillentos.

Rick et al., (1976) incluyeron en el género dos nuevas especies; L. chmielewskii Rick, Kes, Fob. \& Holle y L. parviflorum Rick, Kes, Fob. \& Holle. Posteriormente, la 
especie Solanum pennelli, recogida en este género por la dehiscencia poral de sus anteras, fue incluida en el género Lycopersicon por D'Arcy (1979), en base a otras características morfológicas y moleculares. Por otra parte, Rick y Lamm (1955) concluyeron que la especie L. glandulosum Mull. no debería considerarse como tal, sino como una de las formas de la polimórfica especie L. peruvianum. De todos estos estudios resultaron las ocho especies silvestres relacionadas con L. esculentum Mill., consideradas en la actualidad (Tabla 1.3).

Posteriormente los estudios de cruzabilidad y citogenéticos han permitido la agrupación de las especies del género en complejos. El complejo peruvianum incluye dos especies silvestres que presentan dificultad de cruce con la especie cultivada, mientras que el complejo esculentum comprende las especies que cruzan con facilidad con el tomate. Dentro de este último se diferencia el complejo minutum que comprende las especies, L. parviflorum y L. chmielewskii, clasificadas en principio como una sola especie, L. minutum (Rick et al., 1976; Taylor, 1986). Estas especies se distribuyen a su vez en grupos filéticos establecidos en base a la comparación electroforética de ADN cloroplástico (Palmer y Zamir, 1982; Olmstead y Palmer, 1991) o mitocondrial (McClean y Hanson, 1986), o al empleo de marcadores moleculares, RFLP y RAPD (Miller y Tanskley, 1990; Williams y St.Clair, 1993). En la Tabla 1.3 se detallan las especies pertenecientes a cada grupo y sus relaciones filogenética.

\begin{tabular}{|c|c|c|}
\hline \multirow{4}{*}{$\begin{array}{l}\text { COMPLEJO } \\
\text { esculentum }\end{array}$} & EULYCOPERSICON & Grupo filético \\
\hline & $\begin{array}{c}\text { Lycopersicon esculentum } \\
\text { Lycopersicon esculentum var. cerasiforme } \\
\text { Lycopersicon pimpinellifolium } \\
\text { Lycopersicon cheesmanii }\end{array}$ & $\mathrm{I}$ \\
\hline & ERIOPERSICON & \\
\hline & $\begin{array}{l}\text { Lycopersicon hirsutum } \\
\text { Lycopersicon pennellii }\end{array}$ & II \\
\hline $\begin{array}{l}\text { COMPLEJO } \\
\text { minutum }\end{array}$ & $\begin{array}{l}\text { Lycopersicon parviflorum } \\
\text { Lycopersicon chmielewskii }\end{array}$ & \multirow{2}{*}{ III } \\
\hline $\begin{array}{l}\text { COMPLEJO } \\
\text { peruvianum }\end{array}$ & $\begin{array}{c}\text { Lycopersicon peruvianum } \\
\text { Lycopersicon chilense }\end{array}$ & \\
\hline
\end{tabular}

Tabla 1.3. Clasificación de las especies del género Lycopersicon (Basado en Muller, 1940; Palmer y Zamir, 1982; Taylor, 1986). 


\section{3. DESCRIPCIÓN DE LAS ESPECIES DEL SUBGÉNERO}

\section{EULYCOPERSICON}

Como ya se ha mencionado anteriormente las especies del subgénero Eulycopersicon se caracterizan por presentar frutos rojos y glabros. Dentro de este subgénero se incluyen:

\section{Lycopersicon esculentum.}

Es la especie tipo del género e incluye el tomate cultivado y la variedad cerasiforme, también denominada "tomate cereza" por el reducido tamaño del fruto, entre 1,5 y 2,5 $\mathrm{cm}$. Es una especie autógama, siendo las variedades cultivadas marcadamente homocigotas. Sin embargo, la situación en la región nativa, en el oeste de Sudamérica (Quito (Ecuador); Piura y Chepen (Perú); Arica (Chile)) es claramente diferente. Así, Rick (1950, 1958) dio evidencias de marcados niveles de polinización cruzada, variables de unas áreas a otras, facilitada por la variabilidad existente en caracteres florales como la exerción estigmática, valores de $(25,7 \%$ y $14,8 \%)$ de polinización cruzada ha sido obtenido por este autor en Calana y Tacna en la frontera con Chile. Este hecho ha contribuido no sólo a originar una importante variabilidad en los cultivares de L. esculetum propios de esta región, sino que ha posibilitado la existencia de cruzamientos naturales entre el tomate y otra especie compatible sexualmente, $L$. pimpinellifolium, habiéndose detectado fenómenos de introgresión en el tomate cultivado a partir de esta última especie (Rick y Fobes, 1975). A pesar de ello, los estudios enzimáticos llevados a cabo con esta especie demuestran la existencia de una escasa variabilidad frente a otras especies como L. pimpinelifolium (Rick y Fobes, 1975). 


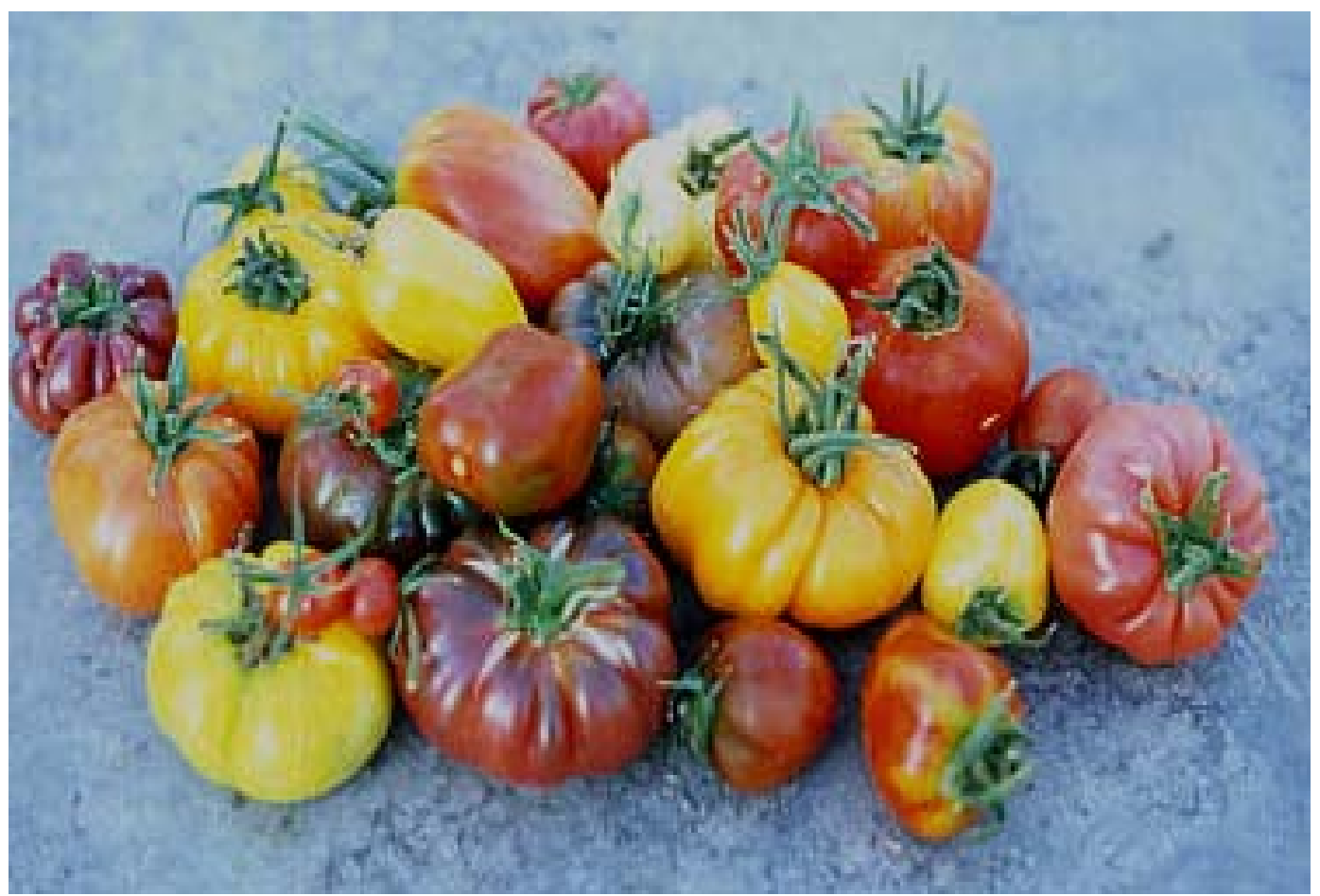

Figura 1.2. Frutos de L. esculentum.

\section{Lycopersicon esculentum var. cerasiforme.}

Rick et al. (1990) propusieron la misma especie para el tomate y cerasiforme, esta variedad botánica se considera el antepasado silvestre de las formas cultivadas. Se cultiva en ocasiones para consumo humano y puede encontrarse en forma adventicia en campos de cultivo de regadío o en zonas de elevada pluviometría. A pesar de que los límites para el tamaño del fruto se han establecido entre 1,5 y $3 \mathrm{~cm}$, algunas poblaciones son altamente polimórficas en cuanto a forma y tamaño del fruto y de la hoja, siendo en muchas ocasiones difícil de distinguir los límites entre esta forma silvestre del tomate y L. pimpinellifolium o el propio tomate cultivado (Rick, 1973; Rick y Holle, 1990). Ello es debido a la variación encontrada en los niveles de alogamia de distintas poblaciones. 
Algunos biotipos son extremadamente eficientes como malas hierbas, habiéndose extendido por toda América tropical, hasta el sur de Texas y Florida. A lo largo de este enorme rango de habitats se ha adaptado a una gran cantidad de condiciones ambientales, resistiendo desde la extrema sequedad de los desiertos del oeste de Perú, hasta las condiciones de elevada humedad de los bosques ecuatoriales. En estos ambientes húmedos se encuentran una elevada resistencia a hongos como Cladosporium.

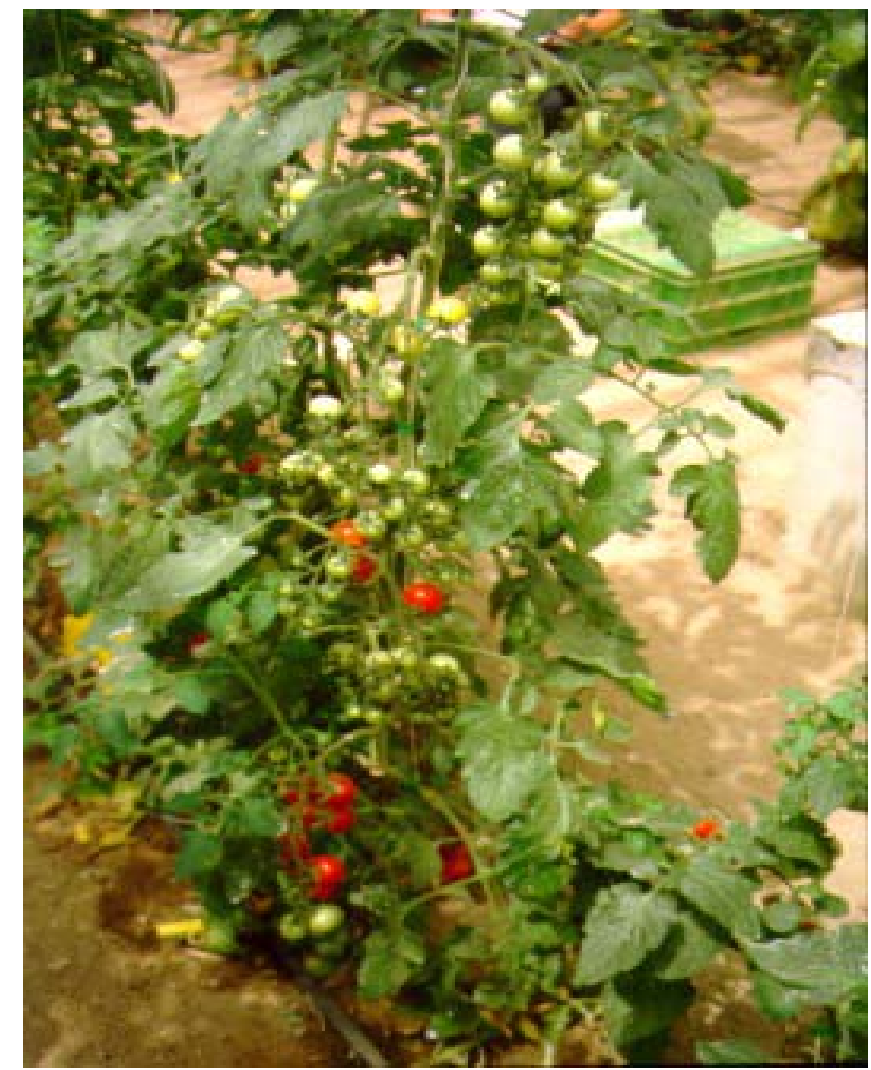

Figura 1.3. Planta de L. esculentum var. cerasiforme

\section{Lycopersicon pimpinellifolium.}

Se encuentra, en forma silvestre o adventicia, principalmente en las zonas bajas de los valles de los ríos, desde el sur de Ecuador, a lo largo de la costa peruana, llegando a la zona fronteriza con Chile. En sentido estricto se encuentra sólo en la costa de Perú, pero incluso en esta área restringida es altamente polimórfico y presenta fuertes diferenciaciones regionales. En la parte sur y central, las poblaciones son marcadamente constantes en los patrones alozímicos y en las características fenotípicas. En esta región, las flores y las inflorescencias son más pequeñas y la exerción estigmática es menor. En estas áreas incluso las poblaciones más polimórficas la heterocigosis es muy baja, generalmente menor del 1\%. A partir de la región del Río Pativilca hacia el norte, 
la proporción de heterocigosis va progresivamente en aumento. El tamaño de las estructuras florales y el grado de exerción del estigma aumenta, formándose una clina, hasta que se alcanza un máximo en los Departamentos de La Libertad y Lambayeque. Este cambio va unido a un incremento en la variación alozímica. Existe una elevada correlación entre la estructura floral, el grado de polinización cruzada y la variabilidad genética (Rick, 1976). La hipótesis propuesta respecto a su evolución es que las formas más uniformes y autógamas, se originaron a partir de las más variables, alógamas facultativas (Rick et al., 1976).

Morfológicamente es muy similar a la especie cultivada, presentando semillas de menor tamaño y frutos de diámetro no mayor de 1,5 cm. En general presentan hojas con márgenes poco aserrados e inflorescencias con un gran número de flores, lo que las distingue de la especie cultivada. Esta especie cruza en ambos sentidos con el tomate dando lugar a híbridos fértiles. Se trata de la única especie silvestre que ha introgresado genes, de forma natural, en la especie cultivada.

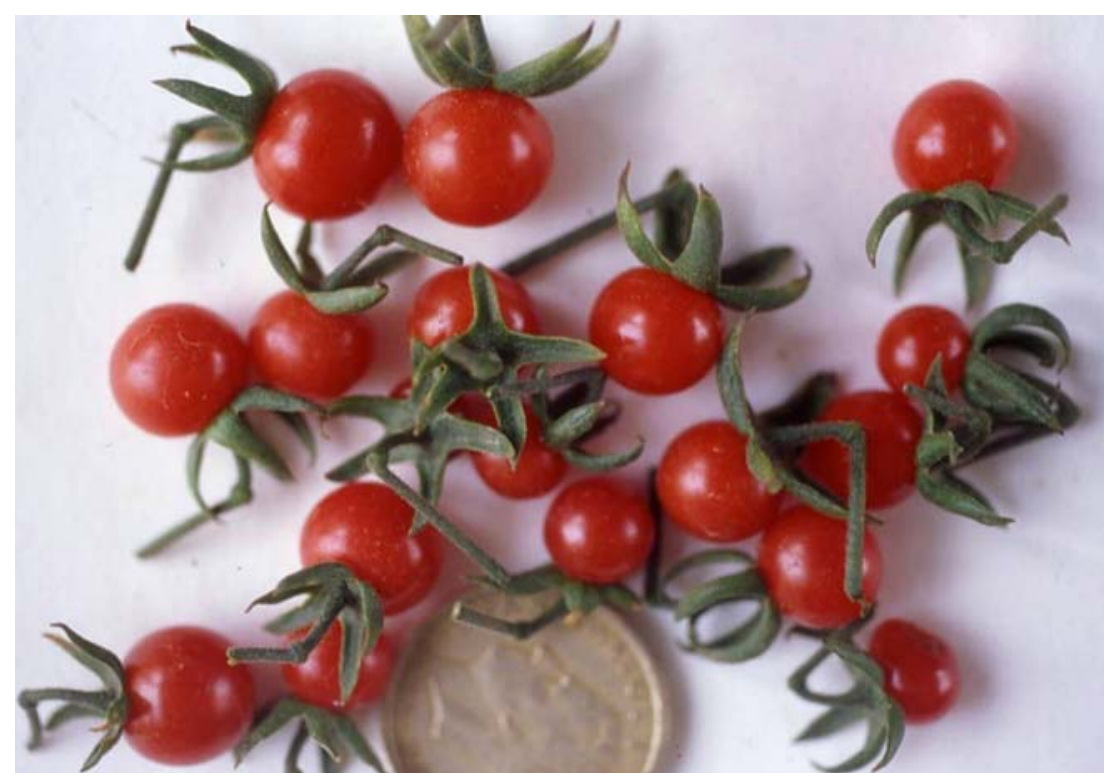

Figura 1.4. Frutos de Lycopersicon pimpinellifolium

\section{Lycopersicon cheesmannii.}

Es una especie endémica de las Islas Galápagos, donde ha evolucionado de forma independiente debido a su aislamiento geográfico. Pueden distinguirse algunas subespecies, en ocasiones en función de sus preferencias ecológicas. La subespecie minor es la más extendida por toda la isla, aunque prefiere bajas altitudes, con climas más secos y cálidos. Habita en suelos con una elevada salinidad, asociada a algunas 
especies halofitas. Ha sido probada su resistencia a la salinidad (Tal, 1971) y aprovechada en programas de mejora encaminados al desarrollo de cultivares mejorados respecto a este carácter.

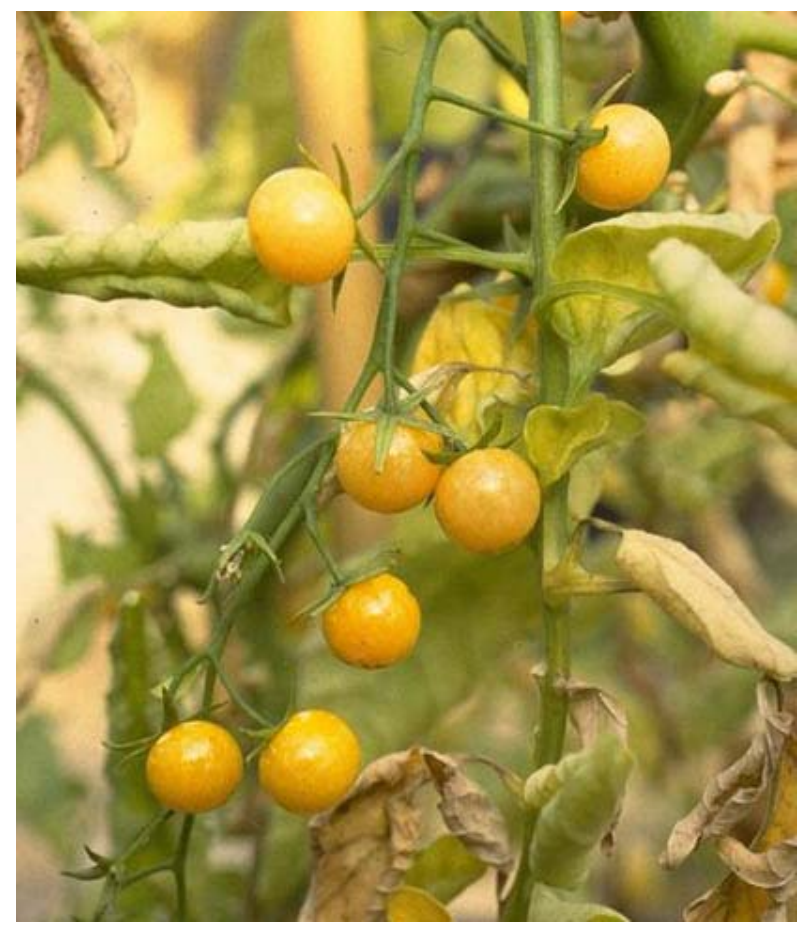

Figura 1.5. Frutos de L. chemanii var. minor.

\section{4. ORIGEN, DOMESTICACIÓN Y DIFUSIÓN DEL TOMATE}

\section{4. 1. Origen y domesticación}

El centro de origen del género Lycopersicon es la región andina que hoy comparten Colombia, Ecuador, Perú, Bolivia y Chile. En esta área crecen espontáneamente las diversas especies del género y también es donde L. esculentum presenta su mayor variación.

Aunque todavía son muchos los aspectos poco claros con respecto al origen, la mayoría de los estudios taxonómicos de Lycopersicon (Muller, 1940; Luckwill, 1943) acreditan a $L$. esculentum var. cerasiforme como el posible antecesor del tomate cultivado, L. esculentum. Su similitud morfológica, la concordancia de los patrones de alozimas entre ambas (Rick y Fobes, 1975; Rick y Holle, 1990) y su proximidad resultante en los dendrogramas de los estudios filogenéticos llevados a cabo con marcadores moleculares RFLPs y RAPDs (Miller y Tanksley, 1990; Williams y St. 
Clair, 1993; Villand, 1995), en los cuales, las entradas de L. esculentum y L. esculentum var. cerasiforme siempre aparecen entremezcladas, dan soporte a esta hipótesis.

El lugar donde se produjo la domesticación ha sido controvertido, sin embargo es comúnmente aceptada la hipótesis según la cual, L. esculentm var. cerasiforme, originaria de la región Andina, fue exportada a México como mala hierba, donde se domesticó y posteriormente se difundió hacia el Viejo Mundo (Jenkins, 1948; Rick, 1958). Hay evidencias históricas, arqueológicas y moleculares que apoyan esta hipótesis.

Sobre cómo se realizó la domesticación en México, existen hipótesis que sugieren que fue una domesticación tardía. En el sur de México el tomate se presenta como una mala hierba, siendo frecuente en los campos de maíz en barbecho y otros espacios modificados por el hombre. Es verosímil que esta mala hierba fuese la materia prima para la domesticación del tomate (Jenkins, 1948), posiblemente cuando ya otros cultivos como calabazas, chiles y maíz habían sido domesticados (Esquinas-Alcázar y Nuez, 1995).

Se mantiene además, que el tomate alcanzó un grado elevado de domesticación antes de su llegada a Europa. Esto se infiere de la gran diversidad de tipos, tamaños, formas y colores representados en los herbarios de la época. En ellos aparecen tanto tomates de fruto pequeño y liso de color amarillo o rojo, como tomates de tamaño grande, generalmente apostillados (Figuras 1.6, 1.7, 1.8). 


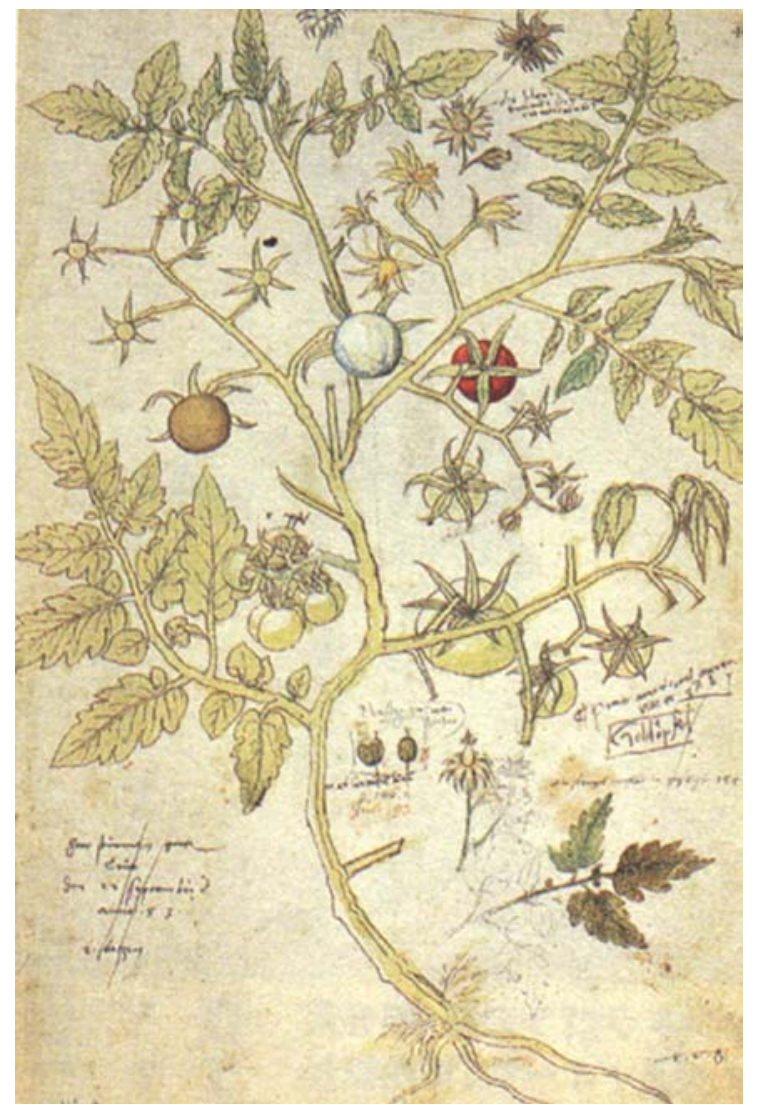

Figura 1.7. Ilustración de la planta de tomate en el herbario de Konrad Gessener, realizada en 1553 .

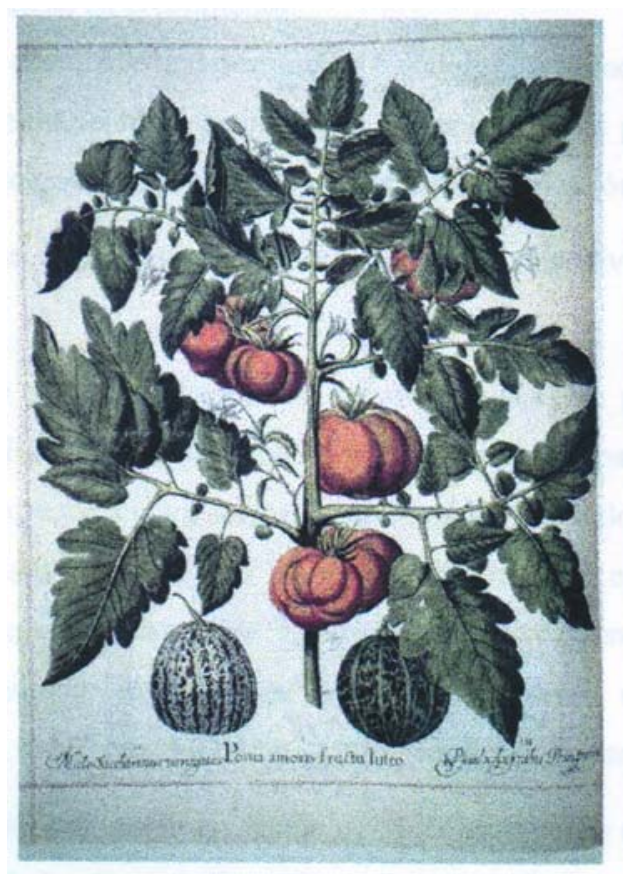

Figura 1.8. Una de las primeras representaciones del tomate en los primeros herbarios europeos (Ilustración perteneciente a la obra Hortus Eystettensis (1613)). 


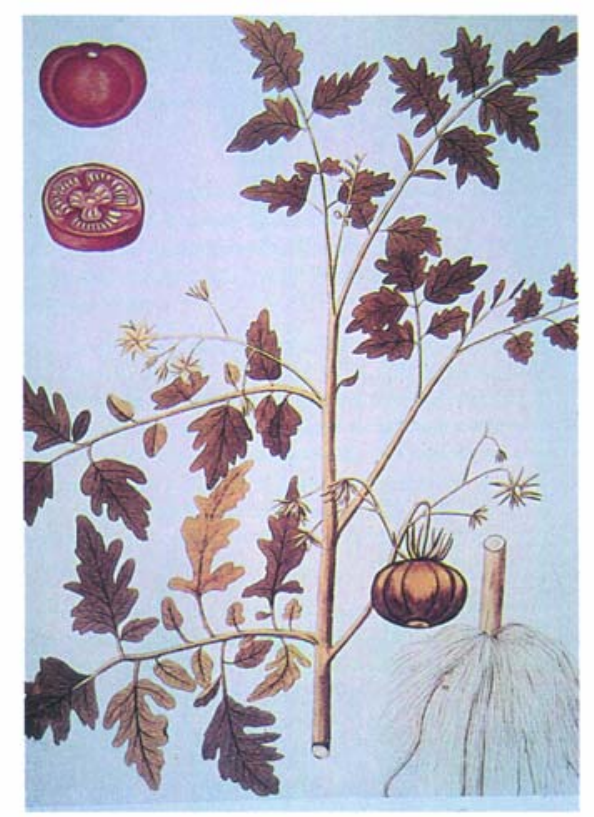

Figura 1.9. Representación de la planta de tomate en "Icones Plantarum Medicinalium" (Joseph Jacobi Plenck, 1788).

\section{4. 2. Difusión del tomate.}

Cuando el tomate ya había alcanzado un alto grado de domesticación en México (Rick, 1976, 1978), los colonos españoles lo transportaron a Europa, alrededor del año 1500. Este proceso de difusión sometió al tomate a una fuerte presión de selección, provocando el fenómeno genético conocido como "cuello de botella", que redujo extraordinariamente la variación genética de esta hortaliza (Rick, 1976; Rick y Yoder, 1978). Este hecho queda demostrado por la escasa presencia de polimorfismo en los cultivares europeos, respecto a los regionales de Sur América, Centro América y México (Miller y Tanksley, 1990; Williams y St. Clair, 1993; Smulders et al., 1997; Bredemeijer et al., 1998).

El tomate se extendió en Europa progresivamente, debido a lo vistoso del fruto y la existencia de formas de consumo independientes del chile (Montes y Aguirre, 1992).

La aceptación del tomate fue muy desigual. En España e Italia se utilizó en la alimentación humana prácticamente desde su introducción (Rick, 1978), en España se reporta por primera vez el consumo de esta hortaliza en 1608, al aparecer en la lista de compras del hospital de la sangre de Sevilla (Hamilton 1976). En la mayoría de los otros países fue utilizada sólo como planta ornamental debido a creencias infundadas sobre sus efectos, al relacionarla con otras solanáceas de reconocida toxicidad, ricas en 
alcaloides. Estas supersticiones perduraron en algunas zonas hasta el siglo XIX, de forma que en los países del centro y norte de Europa el cultivo del tomate no alcanzó importancia hasta principios del siglo XX.

En las primeras introducciones en África tuvieron un papel destacado los turcos y portugueses, además de los españoles. Los turcos controlaban una extensa red comercial y difundieron este cultivo desde el mar Mediterráneo hacia los Balcanes y Europa Oriental por un lado y hacia el golfo Pérsico por otro. Los comerciantes portugueses, con enclaves comerciales en Mozambique y Angola, llevaron el tomate al África tropical. Probablemente también tuvieron importancia los mercantes y colonos europeos posteriores (Tindall, 1977; Vilarreal, 1980).

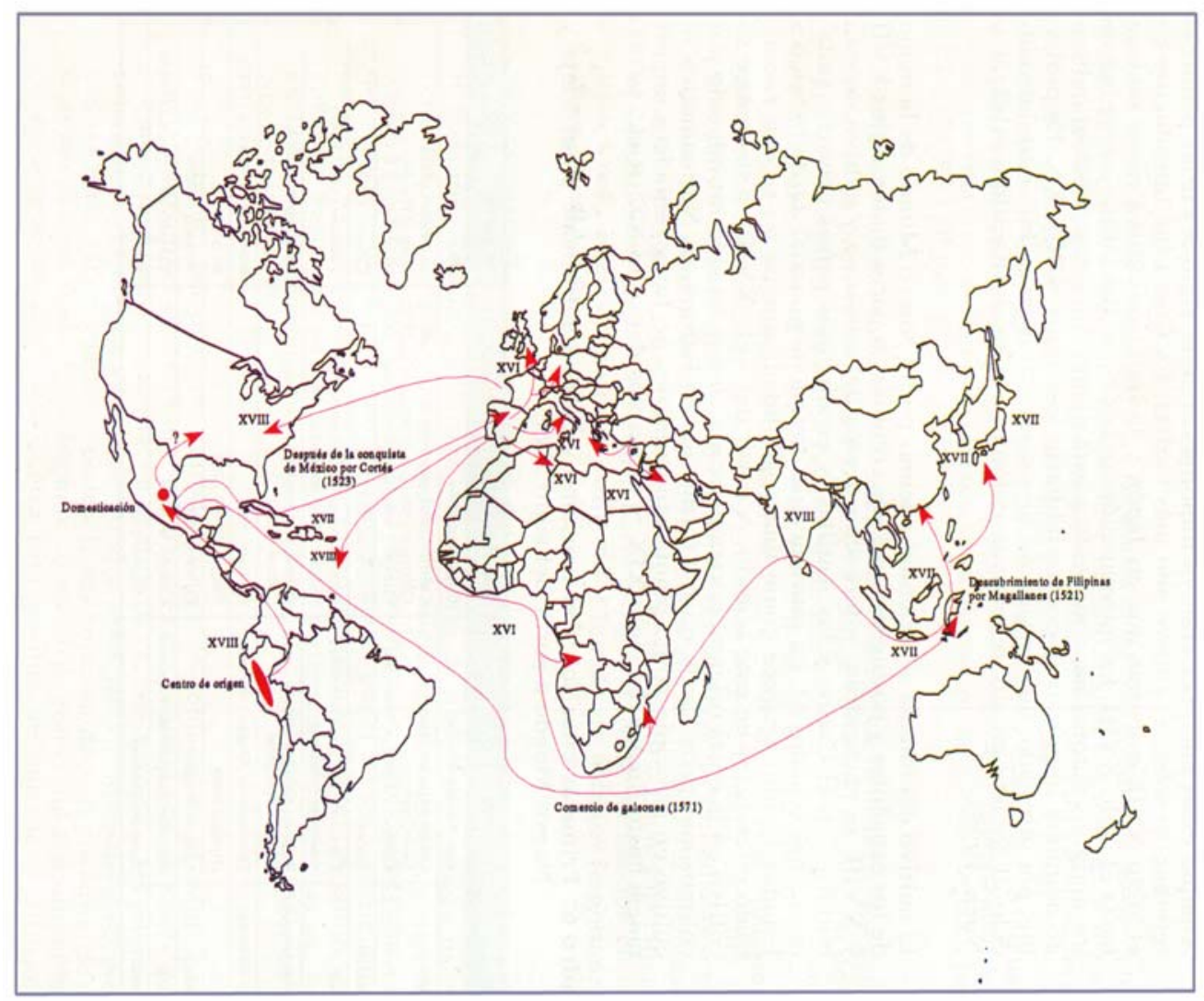

Figura 1.9. Posibles rutas de propagación del tomate a partir del siglo XVI (Basado en Esquinas - Alcázar y Nuez, 1995).

Posiblemente, las primeras introducciones de tomate en el continente asiático tuvieron lugar en Filipinas, a través del comercio de galeones que mantenía la ciudad de Manila con España y las colonias americanas, en el siglo XVI. El comercio marítimo entre estas islas y los países vecinos como China, Japón y la India podría haber contribuido a su posterior difusión por el continente. La existencia de enclaves 
comerciales portugueses en el sudeste asiático señala otra ruta posible de entrada y difusión. Aunque estos enclaves eran ya importantes en el siglo XVI, las primeras referencias sobre el cultivo son más tardías. En Corea fue introducido en el siglo XVII, mientras que en Japón y la India su cultivo no se conoce hasta el siglo XVIII. La introducción en la China fue tardía y ninguno de los antiguos autores hace mención a esta planta. En estas zonas el cultivo no adquiere importancia comercial hasta los siglos XIX y XX. Es probable por otro lado que británicos, alemanes y franceses, hubieran introducido el tomate en sus respectivas colonias asiáticas (Esquinas-Alcázar y Nuez, 1995).

El cultivo del tomate se extendió además por el Nuevo Mundo de la mano de los españoles y portugueses en sus colonias. A partir de los siglos XVII y XVIII se encuentran referencias acerca del cultivo y consumo de esta hortaliza en el Caribe y las Antillas y en distintos países centro y sudamericanos. La introducción directa de material desde México a Estados Unidos aparece como una posibilidad, aunque no se han encontrado referencias en este sentido. A partir del siglo XVIII ya se conoce su cultivo en la costa oriental norteamericana, donde ha sido introducido por colonos europeos. De la misma forma que en Europa, en Norteamérica se cultivó en principio como planta ornamental y no tuvo verdadera importancia hasta finales del siglo XIX y principios del siglo XX (Rick, 1978).

Una vez establecido en todo el mundo, y con el transcurso de los años, el tomate ha ido sometiéndose a múltiples programas de mejora, con la finalidad de introducir genes de interés como las resistencias procedentes de las especies silvestres relacionadas con el tomate. Esto explica que en algunos estudios con marcadores moleculares se haya apreciado una mayor variabilidad genética en los cultivares actuales de Europa y USA que en los antiguos cultivares europeos (Williams y St. Clair, 1993).

\section{5. ESTUDIOS DE VARIABILIDAD REALIZADOS EN EL GÉNERO LYCOPERSICON.}

En el género Lycopersicon se han realizados estudios de variabilidad genética empleando marcadores morfológicos, isozímicos y asociados al ADN. La finalidad de tales estudios ha sido muy diversa: 
1- Estudio de relación filogenéticos en la familia Solanaceae y entre las especies del género Lycopersicon.

2- Evaluación de la variabilidad intra y extraespecífica.

3- Estudios de diversidad genética entre distintos cultivares con el objeto de aprovechar potencialmente esta variabilidad en programas de mejora.

4- Identificación varietal entre distintas variedades de tomate cultivado.

Los marcadores de ADN han sido los más recientemente introducidos y han supuesto una importante fuente de posibilidades para el estudio de la variabilidad a todos los niveles.

\section{5. 1. Estudios de variabilidad morfólogica.}

La segregación de algunos caracteres cualitativos (frutos multiloculares, deformados y aplanados, gen $f$; ausencia de tricomas largos, gen $H$; piel del fruto incolora, gen $y$; hojas curvadas adaxialmente, gen $w t$ ) ha sido estudiada para evaluar la variación en el grado de alogamia en cultivares de L. esculentum en su lugar de origen.

Dieciocho de las 36 descendencias de frutos individuales mostraron segregación para estos caracteres, contrastando estos resultados fuertemente con la uniformidad de las descendencias de cultivares mejorados. La alogamia existente en el lugar de origen, y especialmente en Piura (Perú), contribuyó enormemente al aumento de la variabilidad de los tomates de esta zona (Rick, 1958, 1976).

Estos mismos estudios (Rick, 1976; Rick et al., 1977) han puesto de manifiesto la existencia de una gran variabilidad en el tamaño de las estructuras florales, exerción estigmática, pilosidad de la epidermis y pigmentación amarilla de la epidermis en $L$. pimpinellifolium, especie hasta entonces considerada como muy poco variable. Esta variabilidad está fuertemente asociada a su localización geográfica, pudiéndose encontrar gradualmente en clinas. La existencia de esta variabilidad en las estructuras florales tiene implicaciones en los procedimientos de muestreo así como en el mantenimiento de las colecciones, sirviendo ciertas metodologías para unas determinadas zonas, mientras que para otras no son validas (Widrlechener, 1987).

La especie L. esculentum var. cerasiforme, considerada como el ancestro del tomate, ha sido también objeto de estudios de variabilidad morfológica. Mientras que en unas áreas es marcadamente autogama, en otras, como Tarapoto (Bajo Mayo, Departamento de San Martín, Perú) exhibe una marcada variabilidad para caracteres de fruto (Rick y 
Holle, 1990). Este aumento de la variabilidad ha sido asociado a la existencia de cruzabilidad entre la var. cerasiforme y tomates introducidos en las mismas zonas. Ello ha contribuido a aumentar considerablemente la base genética de esta variedad y, consecuentemente sus posibilidades de uso en la mejora. En esta misma especie se han encontrado caracteres de elevado interés en zonas muy distantes a su lugar de origen como es la elevada capacidad para cuajar en condiciones de elevada temperatura en zonas de Filipinas (Schaible, 1962).

\section{5. 2. Estudios isozímicos y alozimicos de la variabiliad}

La variabilidad alozímica ha sido estudiada en tomate por Rick y Fobes (1975) y Rick y Holle (1990), principalmente en estudios sobre el grado de alogamia y las relaciones filogenéticas entre las especies del subgénero Eulycopersicon. Estos estudios han servido, entre otros aspectos, para afianzar la teoría de que L. esculentum var. cerasiforme es el ancestro a partir del cual se domesticó el tomate en México. Igualmente han puesto de manifiesto la existencia de lugares con variabilidad especialmente elevada como consecuencia de introgresión ocurrida en la var. cerasiforme a partir de tomates introducidos en las mismas zonas, y en L. esculentum a partir de L. pimpinellifolium. Los patrones enzimáticos de 11 isozimas fueron también empleados por Bretó et al., 1993 para estudiar las relaciones filogenéticas entre las distintas especies del género Lycopersicon, así como para estudiar su diversidad genética. Encontraron una elevada correlación entre el sistema reproductivo y la diversidad genética (mayor diversidad genética en las especies alogamas más estrictas) y agruparon a esculentum con la var. cerasiforme y éstas muy cercanas a $L$. pimpinellifolium y L. chesmannii.

Los estudios realizados por Henn et al., (1992) empleando un conjunto de 6 isozimas, pusieron de manifiesto la imposibilidad de identificación de cultivares de tomate emparentados, usando este tipo de marcadores.

\section{5. 3. Estudios realizados con marcadores de ADN}

Los RFLP han sido empleados principalmente para abordar estudios filogenéticos en el género Lycopersicon y también para estudios de variabilidad.

Miller y Tanksley (1990) llevaron a cabo estudios filogenéticos para aclarar las discrepancias encontradas entre las agrupaciones realizados con ADN de orgánulos por Palmer y Zamir (1982) y McClean y Hensen (1986) y las establecidas por Rick (1979), 
basándose en relaciones de cruzabilidad. Encontraron una fuerte asociación entre las especies de fruto rojo L. esculentum y L. pimpinellifolium y entre estas y L. chesmannii, más en concordancia con las agrupaciones efectuadas por Rick (1979).

Estudios realizados por Williams y St. Clair (1993) con un conjunto de $L$. esculentum y L. esculentum var. cerasiforme, pusieron de manifiesto los diferentes niveles de variabilidad encontrados en distintos grupos de cultivares en función de su lugar de origen (mayor variabilidad entre los cultivares procedentes de Sudamérica frente a cultivares antiguos y otros mejorados). Encontraron niveles similares de polimorfismo detectado por los RFLP y RAPD, resaltando la validez del empleo de los RAPD para distinguir entre distintos genotipos de L. esculentum y para estudios de diversidad genética. Estos mismos autores y Villand et al (1998) estudiaron las relaciones filogenéticos entre L. esculentum y la variedad cerasiforme, encontrando una distribución mezclada en los árboles filogenéticos. Confirmaron, de esta forma, la hipótesis de que L. esculentum var. cerasiforme es el ancestro de L. esculentum, aunque la existencia de entradas de cerasiforme que permanecen alejadas de L. esculentum indicando que la domesticación del tomate se produjo a partir de un "reducido" de germoplasma de L. esculentum var. cerasiforme contribuyendo este hecho a la marcada uniformidad genética en el tomate cultivado.

Los primeros estudios con microsatélites en tomate se hicieron para comprobar su capacidad en la identificación de cultivares de tomate (Vosman et al., 1992; Smulders et al., 1997), consiguiendo diferenciar 15 cultivares antiguos. Se comprobó además la segregación mendeliana del locus (GATA) 4 . Resultados similares obtuvo RusKortekaas et al. (1993), comprobando además la mayor capacidad para detectar polimorfismos de los microsatélites frente a los RAPD. Kaemmer et al (1995) pusieron de manifiesto la distinta capacidad de generar polimorfismo de distintos loci microsatélites, destacando (GATA $)_{4}$ por su elevada capacidad de detectar polimorfismos. Recientemente, se ha establecido una base de datos de microsatélites, conteniendo más de 500 variedades de tomate, que posibilita y facilita la identificación varietal con este tipo de marcadores (Bredemeijer et al., 2002).

Los microsatélites han sido empleados también para estimar la distribución de la diversidad en el género Lycopersicon y evaluar la eficiencia de los microsatélites en el establecimiento de las relaciones entre especies en comparación con otras construcciones filogenéticos establecidas con anterioridad (Alvarez et al., 2001). En general los árboles obtenidos a partir de este tipo de marcadores fueron consistentes con los 
previamente publicados basados en RFLP y las clasificaciones basadas en caracteres morfológicos y sistema reproductivo (Rick, 1979).

La aptitud de los marcadores AFLP para estudios biosistemáticos, ha sido demostrada en el trabajo realizado por Kardolus et al., (1998), incluyendo las secciones Petota y Lycopersicum de Solanum. Los resultados separaron perfectamente las dos secciones, así como los diversos taxas de cada sección incluidas en este estudio, coincidiendo de forma general la clasificación encontrada basada en marcadores moleculares AFLP con las opiniones actuales sobre la taxonomía de Solanum.

Los AFLP no se han empleado hasta el momento para el estudio de las relaciones filogenéticos entre distintas especies de Lycopersicon. El uso de estos marcadores para este objetivo tiene interés debido a que recientemente se ha descubierto que ciertas regiones genómicas escapan a la detención de los marcadores RFLP (Bonnema et al., 2002). Estos autores, estudiando mediante AFLP un conjunto de 3 líneas de introgresión que contenían en conjunto el cromosoma 7 de L. pennellii (Eshed y Zamir, 1995) descubrieron otra introgresión del cromosoma 10 de L. pennellii no detectada con anterioridad usando RFLP. Igualmente la distribución de las regiones de ADN altamente polimórficas conteniendo las repeticiones GATA y GACA, no se distribuyen aleatoriamente por el genoma, sino que se encuentran en las mismas regiones cromosómicas (Arens et al., 1995), preferentemente centroméricas (Grandillo y Tanksley, 1996; Areshchenkova y Ganal, 1999). El estudio mediante AFLP de las relaciones filogenéticos entre las distintas especies del género Lycopersicon podría contribuir a descubrir aspectos no contemplados en los análisis realizados con los marcadores anteriormente comentados. 
2. OBJETIVOS 
El Centro de Conservación y Mejora de la Agrodiversidad (COMAV) de la Universidad Politécnica de Valencia alberga una de las colecciones más importantes de entradas del género Lycopersicon, incluyendo el tomate cultivado (Lycopersicon esculentum, Lycopersicon esculentum variedad cerasiforme) y sus especies silvestres relacionadas (L. cheesmanii, L. pimpinellifolium, L. hirsutum, L. pennellii, L. chmilewskii, L. parviflorum, L. peruvianum y L. chilense). En total suponen 2045 entradas. Las especies silvestres del género Lycopersicon, suponen una fuente inagotable de genes de interés para la mejora del tomate, habiendo sido introducidos gran número de ellos en los cultivares comerciales actuales.

Sin embargo, a pesar del enorme interés y valor económico que esta hortaliza tiene en la actualidad, siguen existiendo ambigüedades en su taxonomía así como dudas sobre su domesticación.

Teniendo en cuenta estas ambigüedades se formulan los siguientes objetivos para el presente trabajo:

1.- Estudio de la variabilidad morfológica y molecular de estas especies, lo que permitirá un uso más preciso como fuentes de genes de interés

2.- Esclarecer las relaciones filogenéticos entre las especies del subgénero Eulycopersicon, determinando los fenómenos de introgresión existentes entre ellas. Elección de caracteres discriminantes entre especies.

3.- Establecer estrategias de conservación de estas especies y en especial de Lycopersicon pimpinellifolium, para la que se han descrito diferencias importantes en el grado de alogamia en función de su origen geográfico.

4.- Inicio de la formación de una colección nuclear en la colección de entradas de $L$. pimpinellifolium del COMAV. 
3. MATERIALES Y MÉTODOS 


\section{1. MATERIAL VEGETAL.}

Se han ensayado un total de 165 entradas del género Lycopersicon, subgénero Eulycopersicon, perteneciendo 48 de ellas a Lycopersicon esculentum var. cerasiforme, 86 a Lycopersicon pimpinellifolium y 31 a Lycopersicon esculentum (Tablas 3.1, 3.2, y 3.3). La mayoría de ellas proceden de colectas realizadas en Ecuador y Perú por el equipo del Centro de Conservación y Mejora de la Agrodiversidad (COMAV) de la UPV, en colaboración con la Universidad de la Loja (Ecuador) y de Piura (Perú). Otras han sido solicitadas al Tomato Genetic Resources Center (Univ. de Davis, California, USA) y al EMBRAPA (Brasil).En total cubren una amplia área geográfica, incluyendo países que se encuentran en el Centro primario de diversidad (Ecuador y Perú), regiones contiguas al Centro primario (México) y países pertenecientes al Centro secundario de diversidad (España).

Se realizaron dos ensayos en las campañas 2000-01 y 2001-02 (ver diseño experimental en el apartado siguiente). En las Tablas 3.1, 3.2 y 3.3 y las Figuras 3.1, 3.2, y 3.3, se relacionan el material incluido en cada ensayo.

\begin{tabular}{|c|c|c|c|c|c|c|}
\hline \multirow{2}{*}{ Entrada } & \multicolumn{3}{|c|}{ Procedencia } & \multirow{2}{*}{ Latitud } & \multirow{2}{*}{ Longitud } & \multirow{2}{*}{ Altitud(m) } \\
\hline & Ubicación & Provincia & País & & & \\
\hline \multicolumn{7}{|c|}{ ENSAYO 2000-01 } \\
\hline \multicolumn{7}{|c|}{ Lycopersicon esculentum var. cerasiforme } \\
\hline CNPH81 & - & - & Brasil & - & - & - \\
\hline CNPH82 & - & - & Brasil & - & - & - \\
\hline CNPH83 & - & - & Brasil & - & - & - \\
\hline ECU-0457 & Namirez & $\begin{array}{l}\text { Zamora- } \\
\text { Chinchipe }\end{array}$ & Ecuador & 0404--S & 07857--W & - \\
\hline ECU-0459 & Indanza & $\begin{array}{l}\text { Morona- } \\
\text { Santiago }\end{array}$ & Ecuador & 0304--S & 07829--W & - \\
\hline ECU-0460 & Indanza & $\begin{array}{l}\text { Morona- } \\
\text { Santiago }\end{array}$ & Ecuador & 0304--S & 07829--W & - \\
\hline ECU-0461 & Indanza & $\begin{array}{l}\text { Morona- } \\
\text { Santiago }\end{array}$ & Ecuador & 0304--S & 07829--W & - \\
\hline ECU-0462 & Indanza & $\begin{array}{l}\text { Morona- } \\
\text { Santiago }\end{array}$ & Ecuador & 0304--S & 07829--W & - \\
\hline ECU-0463 & Indanza & $\begin{array}{l}\text { Morona- } \\
\text { Santiago }\end{array}$ & Ecuador & 0304--S & 07829--W & - \\
\hline ECU-0465 & Logroño & $\begin{array}{l}\text { Morona- } \\
\text { Santiago }\end{array}$ & Ecuador & 0236--S & 07811--W & - \\
\hline
\end{tabular}

Tabla 3.1. Entradas incluidas en el ensayo 2000-2001. Las coordenadas geográficas fueron determinadas por un sistema global de posicionamiento basado en la posición relativa con respeto a un sistema artificial satélite (GPS, Magullan XL, San Dimas, California). Los valores que aparecen en las columnas de Latitud y Longitud* son: los dos primeros los Grados, los dos siguientes los minutos y los dos últimos los segundos.

* Los grados son los tres primeros números. 


\begin{tabular}{|c|c|c|c|c|c|c|}
\hline \multirow{2}{*}{ Entrada } & \multicolumn{3}{|c|}{ Procedencia } & \multirow{2}{*}{ Latitud } & \multirow{2}{*}{ Longitud } & \multirow{2}{*}{ Altitud(m) } \\
\hline & Ubicación & Provincia & País & & & \\
\hline ECU-0466 & Logroño & $\begin{array}{l}\text { Morona- } \\
\text { Santiago }\end{array}$ & Ecuador & 0236--S & 07811--W & - \\
\hline ECU-0467 & Timbara & $\begin{array}{c}\text { Zamora- } \\
\text { Chinchipe } \\
\end{array}$ & Ecuador & 0402--S & 07853--W & - \\
\hline ECU-0468 & Indanza & $\begin{array}{l}\text { Morona- } \\
\text { Santiago }\end{array}$ & Ecuador & 0304--S & 07829--W & - \\
\hline ECU-81 & Timbara & $\begin{array}{l}\text { Zamora- } \\
\text { Chinchipe }\end{array}$ & Ecuador & 0401--S & 07833--W & 975 \\
\hline ECU-96 & Yantzara & Loja & Ecuador & - & - & - \\
\hline GLP-0022 & $\begin{array}{c}\text { Ctra. Bellavista- } \\
\text { Cascajo.Santa Cruz }\end{array}$ & Galápagos & Ecuador & 004006S & 0901618W & 400 \\
\hline GLP-0026 & $\begin{array}{c}\text { Ctra. Bellavista- } \\
\text { Cascajo.Santa Cruz }\end{array}$ & Galápagos & Ecuador & $003140 \mathrm{~S}$ & 0901921W & 360 \\
\hline GLP-0073 & Puerto Ayora.Santa Cruz & Galápagos & Ecuador & 0045--S & 09010--W & - \\
\hline MEX-0072 & Huenchinango & Puebla & México & $20----\mathrm{N}$ & 098----W & 1600 \\
\hline MEX-0084 & $\begin{array}{c}\text { Apachitempa (Platón } \\
\text { Sánchez) }\end{array}$ & Veracruz & México & $2115--\mathrm{N}$ & 09823--W & 150 \\
\hline MEX-0085 & Huejufla & Hidalgo & México & 21----N & 09830--W & 180 \\
\hline MEX-0086 & Tehuetlan & Hidalgo & México & 21----N & 09830--W & $100-200$ \\
\hline MEX-0088 & Huejufla & Hidalgo & México & 21----N & 09830--W & 180 \\
\hline MEX-0089 & $\begin{array}{c}\text { Ciudad Vallés(Palo } \\
\text { arco) }\end{array}$ & $\begin{array}{l}\text { S. Luis de } \\
\text { Potosí }\end{array}$ & México & 22----N & 099----W & 100 \\
\hline MEX-0090 & Tamazunchale & $\begin{array}{l}\text { S. Luis de } \\
\text { Potosí }\end{array}$ & México & $2130--\mathrm{N}$ & 099----W & 200 \\
\hline MEX-0091 & Chapulhuacan Grande & Hidalgo & México & 2109--N & 09853--W & 600 \\
\hline MEX-0092 & Chapulhuacan Grande & Hidalgo & México & 2109--N & 09853--W & 600 \\
\hline MEX-0101 & Río verdito & Querétaro & México & $2130--\mathrm{N}$ & 099----W & 1000 \\
\hline MEX-0103 & Xilitla(El Balcón) & San Luís & México & 2130--N & 099----W & 800 \\
\hline MEX-0104 & Auatcatlan & Querétaro & México & 2113--N & 09932--W & 1100 \\
\hline MEX-0110 & Culiacan.(El Vergel) & Sinaloa & México & $25----\mathrm{N}$ & 10730--W & $<100$ \\
\hline MEX-0111 & $\begin{array}{c}\text { Guasavé(Ejido Juan José } \\
\text { Ríos) }\end{array}$ & Sinaloa & México & $2530--\mathrm{N}$ & 10830--W & $<100$ \\
\hline MEX-0113 & $\begin{array}{c}\text { Ahomé (aeropuerto viejo } \\
\text { de los Mochis) }\end{array}$ & Sinaloa & México & 2530--N & 10830--W & $<100$ \\
\hline MEX-0115 & $\begin{array}{c}\text { Ahomé (higuera de } \\
\text { Zaragoza) }\end{array}$ & Sinaloa & México & 2530--N & 10830--W & $<100$ \\
\hline MEX-0116 & Ahomé (La Biznaga) & Sinaloa & México & $2530--\mathrm{N}$ & 10830--W & $<100$ \\
\hline PE-0063 & Molinopata(Pachachaca) & Apurimac & Perú & 1556--S & 07137--W & 2400 \\
\hline PE-0064 & Bellavista(Pachachaca) & Apurimac & Perú & 1556--S & 07137--W & 2300 \\
\hline \multicolumn{7}{|c|}{ Lycopersicon esculentum } \\
\hline MEX-0008 & $\begin{array}{l}\text { Xcanatán (cerca de } \\
\text { Mérida) }\end{array}$ & Yucatán & México & 21----N & 08930--W & $<100$ \\
\hline
\end{tabular}

Tabla 3.1. Entradas incluidas en el ensayo 2000-2001. Las coordenadas geográficas fueron determinadas por un sistema global de posicionamiento basado en la posición relativa con respeto a un sistema artificial satélite (GPS, Magullan XL, San Dimas, California). Los valores que aparecen en las columnas de Latitud y Longitud* son: los dos primeros los Grados, los dos siguientes los minutos y los dos últimos los segundos.(continuación). * Los grados son los tres primeros números. 


\begin{tabular}{|c|c|c|c|c|c|c|}
\hline \multirow{2}{*}{ Entrada } & \multicolumn{3}{|c|}{ Procedencia } & \multirow{2}{*}{ Latitud } & \multirow{2}{*}{ Longitud } & \multirow{2}{*}{ Altitud(m) } \\
\hline & Ubicación & Provincia & País & & & \\
\hline MEX-0013 & $\begin{array}{c}\text { Dzidzautum Hacienda } \\
\text { Tthoilen } \\
\end{array}$ & Yucatán & México & 21----N & 089----W & $<100$ \\
\hline MEX-0014 & $\begin{array}{c}\text { San Román de Dzitam } \\
\text { González }\end{array}$ & Yucatán & México & 2130--N & 089----W & $<100$ \\
\hline MEX-0015 & $\begin{array}{c}\text { San Eduardo (entre } \\
\text { Dzidzautum y Dzitam) }\end{array}$ & Yucatán & México & 2130--N & 089----W & $<100$ \\
\hline MEX-0016 & $\begin{array}{c}\text { San Eduardo (entre } \\
\text { Dzidzautum y Dzitam) }\end{array}$ & Yucatán & México & 2130--N & 089----W & $<100$ \\
\hline MEX-0017 & $\begin{array}{c}\text { San Eduardo (entre } \\
\text { Dzidzautum y Dzitam) }\end{array}$ & Yucatán & México & 2130--N & 089----W & $<100$ \\
\hline MEX-0018 & $\begin{array}{c}\text { San Eduardo (entre } \\
\text { Dzidzautum y Dzitam) }\end{array}$ & Yucatán & México & 2130--N & 089----W & $<100$ \\
\hline MEX-0019 & Uman & Yucatán & México & $21----\mathrm{N}$ & 090----W & $<100$ \\
\hline MEX-0021 & Uman & Yucatán & México & $21----\mathrm{N}$ & 090----W & $<100$ \\
\hline MEX-0022 & Uman & Yucatán & México & $21----N$ & 090----W & $<100$ \\
\hline MEX-0023 & Muna & Yucatán & México & 2030--N & 08930--W & $<100$ \\
\hline MEX-0024 & Muna & Yucatán & México & $2030--\mathrm{N}$ & 08930--W & $<100$ \\
\hline \multicolumn{7}{|c|}{ Lycopersicon pimpinellifolium } \\
\hline ECU-0376 & $\begin{array}{c}\text { ciudadd + proxParroquia } \\
\text { eEl Rosario } \\
\end{array}$ & Loja & Ecuador & 034749S & 0793679W & 850 \\
\hline GLP-0005 & $\begin{array}{c}\text { Puerto Ayora. A } 2 \mathrm{~km} \\
\text { dirección Baltra.Santa } \\
\text { Cruz } \\
\end{array}$ & Galápagos & Ecuador & 004318S & 0901935W & 100 \\
\hline GLP-0006 & $\begin{array}{c}\text { Puerto Ayora. A 2,2 km } \\
\text { dirección Baltra.Santa } \\
\text { Cruz } \\
\end{array}$ & Galápagos & Ecuador & 004315S & $0901937 \mathrm{~W}$ & 100 \\
\hline GLP-0007 & $\begin{array}{c}\text { Puerto Ayora. A } 5 \mathrm{~km} \\
\text { dirección Baltra.Santa } \\
\text { Cruz } \\
\end{array}$ & Galápagos & Ecuador & 004141S & 0901926W & 200 \\
\hline GLP-0008 & $\begin{array}{c}\text { Bellavista. A } 3 \mathrm{~km} \\
\text { dirección Camote.Santa } \\
\text { Cruz } \\
\end{array}$ & Galápagos & Ecuador & 004044S & $0901841 \mathrm{~W}$ & 300 \\
\hline GLP-0009 & $\begin{array}{c}\text { A } 2 \mathrm{~km} \text { cruce Pto. } \\
\text { Ayora-Baltra.Santa Cruz }\end{array}$ & Galápagos & Ecuador & 004131S & $0902024 \mathrm{~W}$ & 200 \\
\hline ECU-0516 & carretera Olmos-Jaen & Lambayeque & Perú & $055942 \mathrm{~S}$ & 0794303W & 230 \\
\hline PE-0065 & $\begin{array}{c}\text { Umashbamba, } \\
\text { Urubamba }\end{array}$ & Cuzco & Perú & 1304--S & 07227--W & 1700 \\
\hline PE-0066 & Chilca Ccasa & Cuzco & Perú & 1336--S & 07219--W & 1900 \\
\hline PE-0067 & $\begin{array}{c}\text { Pacchac- } \\
\text { chico(Urumbaca) }\end{array}$ & Cuzco & Perú & 1318--S & 07207--W & 1000 \\
\hline PE-0068 & $\begin{array}{c}\text { Pacchac- } \\
\text { chico(Urumbaca) }\end{array}$ & Cuzco & Perú & 1318--S & 07207--W & 1000 \\
\hline PE-0069 & $\begin{array}{c}\text { Tornillochayoc(Urubam } \\
\text { ba) }\end{array}$ & Cuzco & Perú & 1318--S & 07207--W & 1000 \\
\hline
\end{tabular}

Tabla 3.1. Entradas incluidas en el ensayo 2000-2001. Las coordenadas geográficas fueron determinadas por un sistema global de posicionamiento basado en la posición relativa con respeto a un sistema artificial satélite (GPS, Magullan XL, San Dimas, California). Los valores que aparecen en las columnas de Latitud y Longitud* son: los dos primeros los Grados, los dos siguientes los minutos y los dos últimos los segundos.(continuación). * Los grados son los tres primeros números. 


\begin{tabular}{|c|c|c|c|c|c|c|}
\hline \multirow{2}{*}{ Entrada } & \multicolumn{3}{|c|}{ Procedencia } & \multirow{2}{*}{ Latitud } & \multirow{2}{*}{ Longitud } & \multirow{2}{*}{ Altitud(m) } \\
\cline { 2 - 4 } & Ubicación & Provincia & País & & & \\
\hline PE-0070 & $\begin{array}{c}\text { Tornillochayoc(Urubam } \\
\text { ba) }\end{array}$ & Cuzco & Perú & $1318--S$ & $07207--W$ & 1000 \\
\hline PE-0071 & Calzada(Urubamba) & Cuzco & Perú & $1318--S$ & $07207--W$ & 900 \\
\hline PE-0072 & $\begin{array}{c}\text { Chontachayoc(Urubamb } \\
\text { a) }\end{array}$ & Cuzco & Perú & $1318--S$ & $07207--W$ & 950 \\
\hline PE-0075 & Huayopata(Urubamba) & Cuzco & Perú & $1318--S$ & $07207--W$ & 1400 \\
\hline PE-0077 & Sicre(Urubamba) & Cuzco & Perú & $1318--S$ & $07207--W$ & 1650 \\
\hline PE-0078 & Huayopata(Urubamba) & Cuzco & Perú & $1318--S$ & $07207--W$ & 1650 \\
\hline
\end{tabular}

Tabla 3.1. Entradas incluidas en el ensayo 2000-2001. Las coordenadas geográficas fueron determinadas por un sistema global de posicionamiento basado en la posición relativa con respeto a un sistema artificial satélite (GPS, Magullan XL, San Dimas, California). Los valores que aparecen en las columnas de Latitud y Longitud* son: los dos primeros los Grados, los dos siguientes los minutos y los dos últimos los segundos.(continuación). * Los grados son los tres primeros números.

\begin{tabular}{|c|c|c|c|c|c|c|}
\hline \multirow{2}{*}{ Entrada } & \multicolumn{3}{|c|}{ Procedencia } & \multirow{2}{*}{ Latitud } & \multirow{2}{*}{ Longitud } & \multirow{2}{*}{ Altitud(m) } \\
\hline & Ubicación & Provincia & País & & & \\
\hline \multicolumn{7}{|c|}{ ENSAYO 2001-02 } \\
\hline \multicolumn{7}{|c|}{ Lycopersicon pimpinellifolium } \\
\hline ECU-0412 & $\begin{array}{l}\text { media montaña.ciudad }+ \\
\text { prox Parroquia río negro }\end{array}$ & El Oro & Ecuador & 031904S & 0794820W & 50 \\
\hline ECU-0421 & $\begin{array}{c}\text { Cooperativa } 26 \text { de } \\
\text { Marzo. Cantón-Milagro }\end{array}$ & Azuay & Ecuador & 033580S & 0792844W & 200 \\
\hline ECU-0424 & Cochancas & Cañar & Ecuador & $022810 \mathrm{~S}$ & $0792716 \mathrm{~W}$ & 250 \\
\hline GLP-0001 & Santa Rosa. Santa Cruz & Galápagos & Ecuador & $004103 \mathrm{~S}$ & $0902205 \mathrm{~W}$ & - \\
\hline GLP-0011 & $\begin{array}{l}\text { Santa Rosa.A } 18 \mathrm{~km} \text { de } \\
\text { Pto. Ayora dirección } \\
\text { Baltra.Santa cruz } \\
\end{array}$ & Galápagos & Ecuador & 004103S & 0902205W & 420 \\
\hline GLP-0013 & $\begin{array}{c}\text { Puerto Ayora. A 20,5 } \\
\text { km dirección } \\
\text { Baltra.Santa Cruz }\end{array}$ & Galápagos & Ecuador & $003725 \mathrm{~S}$ & 0902255W & 600 \\
\hline GLP-0015 & $\begin{array}{c}\text { El Cascajo. Ctra. Pto. } \\
\text { Ayora-Garrapatero.Santa } \\
\text { Cruz }\end{array}$ & Galápagos & Ecuador & 004010S & 0901555W & 300 \\
\hline GLP-0016 & $\begin{array}{c}\text { El Cascajo. Ctra. Pto. } \\
\text { Ayora-Garrapatero.Santa } \\
\text { Cruz }\end{array}$ & Galápagos & Ecuador & 004010S & 0901555W & 300 \\
\hline GLP-0017 & $\begin{array}{l}\text { El Barranco. Puerto } \\
\text { Ayora. Santa Cruz }\end{array}$ & Galápagos & Ecuador & 004449S & 0901910W & 10 \\
\hline GLP-0018 & Puero Ayora.Santa Cruz & Galápagos & Ecuador & 004449S & $0901853 \mathrm{~W}$ & - \\
\hline GLP-0020 & $\begin{array}{c}\text { Camote. A } 1 \mathrm{Km} \\
\text { dirección Cascajo. Santa } \\
\text { Cruz }\end{array}$ & Galápagos & Ecuador & 003932S & 0901648W & 450 \\
\hline GLP-0021 & $\begin{array}{c}\text { Ctra. Bellavista- } \\
\text { Cascajo.Santa Cruz }\end{array}$ & Galápagos & Ecuador & 004006S & 0901618W & 400 \\
\hline
\end{tabular}

Tabla 3.2. Entradas incluidas en el ensayo 2001-2002. Las coordenadas geográficas fueron determinadas por un sistema global de posicionamiento basado en la posición relativa con respeto a un sistema artificial satélite (GPS, Magullan XL, San Dimas, California). Los valores que aparecen en las columnas de Latitud y Longitud* son: los dos primeros los Grados, los dos siguientes los minutos y los dos últimos los segundos.(continuación). * Los grados son los tres primeros números. 


\begin{tabular}{|c|c|c|c|c|c|c|}
\hline \multirow{2}{*}{ Entrada } & \multicolumn{3}{|c|}{ Procedencia } & \multirow{2}{*}{ Latitud } & \multirow{2}{*}{ Longitud } & \multirow{2}{*}{ Altitud(m) } \\
\hline & Ubicación & Provincia & País & & & \\
\hline GLP-0023 & $\begin{array}{c}\text { Ctra. Bellavista- } \\
\text { Cascajo.Santa Cruz }\end{array}$ & Galápagos & Ecuador & 003140S & 0901921W & 380 \\
\hline GLP-0024 & $\begin{array}{c}\text { Ctra. Bellavista- } \\
\text { Cascajo.Santa Cruz }\end{array}$ & Galápagos & Ecuador & 003140S & $0901921 \mathrm{~W}$ & 360 \\
\hline GLP-0027 & $\begin{array}{l}\text { A } 17 \mathrm{Km} \text { del Canal de } \\
\text { Santa Cruz de Baltra. }\end{array}$ & Galápagos & Ecuador & $003337 \mathrm{~S}$ & 0901958W & 330 \\
\hline GLP-0028 & $\begin{array}{c}\text { A } 17 \text { km del Canal de } \\
\text { Santa Cruz de } \\
\text { Baltra.Ctra. Canal-Santa } \\
\text { Rosa.Santa Cruz }\end{array}$ & Galápagos & Ecuador & $003338 \mathrm{~S}$ & $0901957 \mathrm{~W}$ & 340 \\
\hline GLP-0029 & $\begin{array}{c}\text { A } 17 \text { km del Canal de } \\
\text { Santa Cruz de } \\
\text { Baltra.Ctra. Canal-Santa } \\
\text { Rosa.Santa Cruz }\end{array}$ & Galápagos & Ecuador & 003338S & 0901957W & 340 \\
\hline GLP-0030 & $\begin{array}{c}\text { A } 17 \text { km del Canal de } \\
\text { Santa Cruz de } \\
\text { Baltra.Ctra. Canal-Santa } \\
\text { Rosa.Santa Cruz }\end{array}$ & Galápagos & Ecuador & $003341 \mathrm{~S}$ & $0902001 \mathrm{~W}$ & 360 \\
\hline ECU-0440 & Chaguarpamba & Loja & Ecuador & 0035--S & 07939--W & 1453 \\
\hline ECU-0580 & Salida de Sechura & Piura & Perú & 0533--S & 08049--W & 30 \\
\hline ECU-0581 & Carretera Olmos & Piura & Perú & 0516--S & 08006--W & 200 \\
\hline ECU-0582 & Ctra. Olmos km 78 & Piura & Perú & 0526--S & 08006--W & 190 \\
\hline ECU-0583 & Carretera Olmos km 83 & Piura & Perú & 0526--S & 08001--W & 150 \\
\hline ECU-0640 & Ctra. Olmos km 101 & Piura & Perú & 0526--S & 08006--W & 325 \\
\hline ECU-0648 & Dos Pueblos & Piura & Perú & 0527--S & 08046--W & 25 \\
\hline ECU-0658 & Ctra. Olmos km 91 & Piura & Perú & 0526--S & 08006--W & 160 \\
\hline ECU-0692 & $\begin{array}{l}\text { Vicus. A } 58 \mathrm{~km} \text { de Piura } \\
\text { y a } 203 \text { de Lambayeque }\end{array}$ & Piura & Perú & 0510--S & 08008--W & - \\
\hline ECU-0693 & $\begin{array}{l}\text { A } 70 \mathrm{~km} \text { de Piura y a } \\
189 \text { de Lambayeque }\end{array}$ & Piura & Perú & $051602 \mathrm{~S}$ & 0800612W & 140 \\
\hline ECU-0694 & $\begin{array}{c}\text { A } 82 \mathrm{~km} \text { de Piura y a178 } \\
\text { de Lambayeque }\end{array}$ & Lambayeque & Perú & 0522--S & 08003--W & 160 \\
\hline ECU-0695 & $\begin{array}{c}\text { A } 82 \mathrm{~km} \text { de Piura y a178 } \\
\text { de Lambayeque }\end{array}$ & Lambayeque & Perú & 0522--S & 08003--W & 160 \\
\hline ECU-0687 & $\begin{array}{c}\text { Carretera Piura-Chiluca. } \\
\text { A } 42 \mathrm{~km} \text { de Piura }\end{array}$ & Piura & Perú & 050839S & 08016--W & 130 \\
\hline ECU-0689 & $\begin{array}{l}\text { Carretera Piura-Chiluca. } \\
\text { A } 42.3 \mathrm{~km} \text { de Piura }\end{array}$ & Piura & Perú & $050851 \mathrm{~S}$ & 08016--W & 130 \\
\hline ECU-0700 & A $110 \mathrm{~km}$ de Piura & Lambayeque & Perú & 053459S & 07957--W & 260 \\
\hline ECU-0701 & A $161 \mathrm{~km}$ de Piura & Lambayeque & Perú & $0535--\mathrm{S}$ & 07957--W & 300 \\
\hline ECU-0702 & A $111 \mathrm{~km}$ de Piura & Lambayeque & Perú & $055522 \mathrm{~S}$ & 07945--W & - \\
\hline ECU-0711 & $\begin{array}{l}\text { Olmos. A } 177 \mathrm{~km} \mathrm{de} \\
\text { Piura }\end{array}$ & Lambayeque & Perú & $060050 \mathrm{~S}$ & 07940--W & - \\
\hline
\end{tabular}

Tabla 3.2. Entradas incluidas en el ensayo 2001-2002. Las coordenadas geográficas fueron determinadas por un sistema global de posicionamiento basado en la posición relativa con respeto a un sistema artificial satélite (GPS, Magullan XL, San Dimas, California). Los valores que aparecen en las columnas de Latitud y Longitud* son: los dos primeros los Grados, los dos siguientes los minutos y los dos últimos los segundos.(continuación). * Los grados son los tres primeros números. 


\begin{tabular}{|c|c|c|c|c|c|c|}
\hline \multirow{2}{*}{ Entrada } & \multicolumn{3}{|c|}{ Procedencia } & \multirow{2}{*}{ Latitud } & \multirow{2}{*}{ Longitud } & \multirow{2}{*}{ Altitud(m) } \\
\hline & Ubicación & Provincia & País & & & \\
\hline ECU-0712 & $\begin{array}{l}\text { Olmos. A } 178 \mathrm{~km} \mathrm{de} \\
\text { Piura }\end{array}$ & Lambayeque & Perú & 0600--S & 07940--W & - \\
\hline ECU-0713 & $\begin{array}{l}\text { Olmos. A } 181 \mathrm{~km} \mathrm{de} \\
\text { Piura }\end{array}$ & Lambayeque & Perú & $060205 \mathrm{~S}$ & 07940--W & 250 \\
\hline ECU-0732 & $\begin{array}{c}\text { A } 3 \mathrm{~km} \text { del cruce } \\
\text { Cajamarca-Trujillo. } \\
\text { Dirección Cajamarca. }\end{array}$ & La Libertad & Perú & $071825 \mathrm{~S}$ & $0792645 \mathrm{~W}$ & 200 \\
\hline ECU-0733 & $\begin{array}{c}\text { A } 3 \mathrm{~km} \text { del cruce } \\
\text { Cajamarca-Trujillo. } \\
\text { Dirección Cajamarca. }\end{array}$ & La Libertad & Perú & $071825 \mathrm{~S}$ & $0792645 \mathrm{~W}$ & 150 \\
\hline ECU-0736 & $\begin{array}{c}\text { A } 3 \text { km del cruce } \\
\text { Cajamarca-Trujillo. } \\
\text { Dirección Cajamarca. }\end{array}$ & La Libertad & Perú & $071825 \mathrm{~S}$ & $0792645 \mathrm{~W}$ & 200 \\
\hline ECU-0737 & $\begin{array}{l}\text { A } 3.8 \mathrm{~km} \text { del cruce } \\
\text { Cajamarca-Trujillo. } \\
\text { Dirección Cajamarca. }\end{array}$ & La Libertad & Perú & $071825 \mathrm{~S}$ & 0792645W & 200 \\
\hline ECU-0738 & $\begin{array}{l}\text { A } 3.8 \mathrm{~km} \text { del cruce } \\
\text { Cajamarca-Trujillo. } \\
\text { Dirección Cajamarca. }\end{array}$ & La Libertad & Perú & $071825 \mathrm{~S}$ & $0792645 \mathrm{~W}$ & 250 \\
\hline ECU-0739 & $\begin{array}{l}\text { A } 12 \mathrm{~km} \text { del cruce } \\
\text { Cajamarca-Trujillo. } \\
\text { Dirección Cajamarca. }\end{array}$ & La Libertad & Perú & 071911S & $0792213 \mathrm{~W}$ & 250 \\
\hline ECU-0740 & $\begin{array}{l}\text { A } 12 \mathrm{~km} \text { del cruce } \\
\text { Cajamarca-Trujillo. } \\
\text { Dirección Cajamarca. }\end{array}$ & La Libertad & Perú & 071911S & 0792213W & 250 \\
\hline ECU-0742 & $\begin{array}{c}\text { A } 31 \mathrm{~km} \text { del cruce } \\
\text { Cajamarca-Trujillo. } \\
\text { Dirección Cajamarca. }\end{array}$ & Cajamarca & Perú & 0714--S & 07914--W & 250 \\
\hline ECU-0744 & $\begin{array}{c}\text { A } 35 \mathrm{~km} \text { del cruce } \\
\text { Cajamarca-Trujillo. } \\
\text { Dirección Cajamarca. }\end{array}$ & Cajamarca & Perú & 071320S & $0791251 \mathrm{~W}$ & 360 \\
\hline ECU-0746 & $\begin{array}{c}\text { A } 36 \text { km del cruce } \\
\text { Cajamarca-Trujillo. } \\
\text { Dirección Cajamarca. }\end{array}$ & Cajamarca & Perú & 0714--S & 07911--W & 500 \\
\hline ECU-0748 & $\begin{array}{c}\text { A } 39 \mathrm{~km} \text { del cruce } \\
\text { Cajamarca-Trujillo. } \\
\text { Dirección Cajamarca. }\end{array}$ & Cajamarca & Perú & 071244S & $0791131 \mathrm{~W}$ & 500 \\
\hline ECU-0749 & $\begin{array}{c}\text { Pampa Larga. A } 54 \mathrm{~km} \\
\text { del cruce Cajamarca- } \\
\text { Trujillo. Dirección } \\
\text { Cajamarca. }\end{array}$ & Cajamarca & Perú & 0713--S & 07858--W & 500 \\
\hline ECU-0750 & $\begin{array}{c}\text { Pampa Larga. A } 54 \mathrm{~km} \\
\text { del cruce Cajamarca- } \\
\text { Trujillo. Dirección } \\
\text { Cajamarca. } \\
\end{array}$ & Cajamarca & Perú & 0713--S & 07858--W & 500 \\
\hline ECU-0752 & $\begin{array}{c}\text { A } 92 \mathrm{~km} \text { del cruce } \\
\text { Cajamarca-Trujillo. } \\
\text { Dirección Cajamarca. }\end{array}$ & Cajamarca & Perú & 071343S & 0784958W & 850 \\
\hline
\end{tabular}

Tabla 3.2. Entradas incluidas en el ensayo 2001-2002. Las coordenadas geográficas fueron determinadas por un sistema global de posicionamiento basado en la posición relativa con respeto a un sistema artificial satélite (GPS, Magullan XL, San Dimas, California). Los valores que aparecen en las columnas de Latitud y Longitud* son: los dos primeros los Grados, los dos siguientes los minutos y los dos últimos los segundos.(continuación). * Los grados son los tres primeros números. 


\begin{tabular}{|c|c|c|c|c|c|c|}
\hline \multirow{2}{*}{ Entrada } & \multicolumn{3}{|c|}{ Procedencia } & \multirow{2}{*}{ Latitud } & \multirow{2}{*}{ Longitud } & \multirow{2}{*}{ Altitud(m) } \\
\hline & Ubicación & Provincia & País & & & \\
\hline ECU-0843 & A $100 \mathrm{~m}$ de Paltachaco & Piura & Perú & 0506--S & 07953--W & 140 \\
\hline ECU-0844 & Chililique & Frías & Perú & $0425--\mathrm{S}$ & 08018--W & 270 \\
\hline ECU-0866 & - & - & - & - & - & - \\
\hline ECU-0867 & Yapatera & Piura & Perú & 0452--S & 07957--W & 160 \\
\hline ECU-0873 & $\begin{array}{c}\text { A } 39 \mathrm{~km} \text { de Piura } \\
\text { dirección Chulucanas }\end{array}$ & Piura & Perú & 0508--S & 08026--W & $0-30$ \\
\hline ECU-0951 & $\begin{array}{l}\text { A } 78 \text { Km de Cuenca. } \\
\text { Dirección Machala }\end{array}$ & Azuay & Ecuador & 0310--S & 07937--W & 1580 \\
\hline ECU-0966 & $\begin{array}{c}\text { Valle del Río Santa km } \\
58.7 \\
\end{array}$ & Ancash & Perú & 0840--S & 07818--W & 560 \\
\hline PE-0010 & $\begin{array}{c}\text { Tembladera } \\
\text { (Jequetepeque) }\end{array}$ & Cajamarca & Perú & 0715--S & 07909--W & 380 \\
\hline PE11 & Yonan.Jequetepeque & La Libertad & Perú & 0720--S & 07934--W & 390 \\
\hline PE12 & Yatahual.Jequetepeque & La Libertad & Perú & 0720--S & 07934--W & 550 \\
\hline PE13 & La Moyuna.Magdalena & La Libertad & Perú & 0715--S & 07840--W & 870 \\
\hline PE15 & Túturo.Casma & Ancash & Perú & 0926--S & 07840--W & 980 \\
\hline PER-602 & $\begin{array}{l}\text { Chosica. Salida de } \\
\text { Chosica por la Ctra. } \\
\text { Central de Perú }\end{array}$ & Lima & Perú & $115458 \mathrm{~S}$ & 0763747W & 1070 \\
\hline
\end{tabular}

Tabla 3.2. Entradas incluidas en el ensayo 2001-2002. Las coordenadas geográficas fueron determinadas por un sistema global de posicionamiento basado en la posición relativa con respeto a un sistema artificial satélite (GPS, Magullan XL, San Dimas, California). Los valores que aparecen en las columnas de Latitud y Longitud* son: los dos primeros los Grados, los dos siguientes los minutos y los dos últimos los segundos.(continuación). * Los grados son los tres primeros números.

\begin{tabular}{|c|c|c|c|c|c|c|}
\hline \multirow{2}{*}{ Entrada } & \multicolumn{3}{|c|}{ Procedencia } & \multirow{2}{*}{ Latitud } & \multirow{2}{*}{ Longitud } & \multirow{2}{*}{$\begin{array}{c}\text { Altitud } \\
\text { (m) }\end{array}$} \\
\hline & Ubicación & Provincia & País & & & \\
\hline \multicolumn{7}{|c|}{ ENSAYOS 2000-01/2001-02 } \\
\hline \multicolumn{7}{|c|}{ Lycopersicon esculentum var. cerasiforme } \\
\hline CNPH80 & - & - & Brasil & - & - & - \\
\hline ECU-401 & Pueblo de Lourdes & Loja & Ecuador & $034293 \mathrm{~S}$ & $0793479 \mathrm{~W}$ & 1000 \\
\hline ECU-78 & Timbara & $\begin{array}{l}\text { Zamora- } \\
\text { Chinchipe }\end{array}$ & Ecuador & 0401--S & 07833--W & 975 \\
\hline MEX-0012 & $\begin{array}{c}\text { Entre Cansahcab y } \\
\text { Dizdzautum }\end{array}$ & Yucatán & México & 21----N & 089----W & $<100$ \\
\hline MEX-0070 & Huenchinango & Puebla & México & 20----N & 098----W & 1500 \\
\hline MEX-0120 & Santispac & Nayarif & México & 22----N & $105----W$ & $<100$ \\
\hline LA1329 & Yaca (Yacahuailla) & Apurimac & Perú & $1417--S$ & 07212--W & 2100 \\
\hline LA-1312 & Paisanato & Cuzco & Perú & - & - & 600 \\
\hline LA1286 & San Martín de Pangoa & Junín & Perú & - & - & 800 \\
\hline LA1388 & San Ramón & Junín & Perú & $1107--\mathrm{N}$ & 07519--W & 700 \\
\hline LA1307 & $\begin{array}{c}\text { Hotel Oasis, San } \\
\text { Francisco } \\
\end{array}$ & Ayacucho & Perú & $1235--\mathrm{S}$ & 07349--W & 600 \\
\hline
\end{tabular}

Tabla 3.3. Entradas incluidas en ambos ensayos. Las coordenadas geográficas fueron determinadas por un sistema global de posicionamiento basado en la posición relativa con respeto a un sistema artificial satélite (GPS, Magullan XL, San Dimas, California). Los valores que aparecen en las columnas de Latitud y Longitud* son: los dos primeros los Grados, los dos siguientes los minutos y los dos últimos los segundos. * Los grados son los tres primeros números. 


\begin{tabular}{|c|c|c|c|c|c|c|}
\hline \multirow{2}{*}{ Entrada } & \multicolumn{3}{|c|}{ Procedencia } & \multirow{2}{*}{ Latitud } & \multirow{2}{*}{ Longitud } & \multirow{2}{*}{$\begin{array}{c}\text { Altitud } \\
(\mathrm{m})\end{array}$} \\
\hline & Ubicación & Provincia & País & & & \\
\hline \multicolumn{7}{|c|}{ Lycopersicon esculentum } \\
\hline A $-L-12$ & Fraga & Huesca & España & 0413--N & 00025--W & 118 \\
\hline AN-L - 74 & Santa Fe & Granada & España & 0371--N & 00342--W & 580 \\
\hline AN-L -133 & Laujar de Andarax & Almería & España & $0595--\mathrm{N}$ & 00254--W & 950 \\
\hline AN-L -178 & Graena & Granada & España & $0180--\mathrm{N}$ & $03125--W$ & 1006 \\
\hline B -L - 6 & Menorca & Baleares & España & - & - & - \\
\hline B -L - 7 & Menorca & Baleares & España & - & - & - \\
\hline C-L-3 & Amposta & Tarragona & España & $4040--\mathrm{N}$ & $00035--\mathrm{E}$ & 10 \\
\hline C -L - 52 & San Martín de Santa Pau & Girona & España & $0421--\mathrm{N}$ & 00232--E & 496 \\
\hline C-L-251 & La Bauma.Castellbell i el Vilar & Barcelona & España & $4138--\mathrm{N}$ & 00151--E & - \\
\hline C -L - 221 & El Vendrell & Tarragona & España & - & - & - \\
\hline $\mathrm{E}-\mathrm{L}-11$ & Pinofranqueado & Cáceres & España & $0400--\mathrm{N}$ & 00604--W & 450 \\
\hline MU-L-2 & Campo Cartagena & Murcia & España & $3730--\mathrm{N}$ & $00100--W$ & 20 \\
\hline $\mathrm{S}-\mathrm{L}-4$ & Torrebuega & Santander & España & $0432--\mathrm{N}$ & 00404--W & 23 \\
\hline V-L-11 & Venta del Moro & Valencia & España & $3928--\mathrm{N}$ & 00120--W & 730 \\
\hline $\mathrm{V}-\mathrm{L}-61$ & Ademuz & Valencia & España & $0400--\mathrm{N}$ & 00116--W & 670 \\
\hline V -L - 77 & La Foya & Castellón & España & $0400--\mathrm{N}$ & 00014--W & 140 \\
\hline $\mathrm{V}-\mathrm{L}-85$ & Villahermosa del Río & Castellón & España & $0401--\mathrm{N}$ & $00027--W$ & 731 \\
\hline PE-0061 & Naranjillo(Huallaga) & Huanuco & Perú & 0913--S & 07559--W & 630 \\
\hline PE-0062 & $\begin{array}{c}\text { Santa Lucía } \\
\text { Tulumaio(Huallaga) } \\
\end{array}$ & Huanuco & Perú & 0913--S & 07559--W & 630 \\
\hline \multicolumn{7}{|c|}{ Lycopersicon pimpinellifolium } \\
\hline ECU-0415 & $\begin{array}{c}\text { Quebradada de Santo } \\
\text { Tomás.carretera Pasaje-Cuenca }\end{array}$ & El Oro & Ecuador & 032009S & 0794182W & 150 \\
\hline ECU-0417 & Sarayunga & El Oro & Ecuador & 031908S & $0793528 \mathrm{~W}$ & 575 \\
\hline ECU-0443 & Cantón Sta Isabel & Azuay & Ecuador & 031894S & $0792124 \mathrm{~W}$ & 1345 \\
\hline ECU-0927 & A $155,7 \mathrm{~km}$ de Loja & Loja & Ecuador & $040837 \mathrm{~S}$ & $0795050 \mathrm{~W}$ & 800 \\
\hline LA1236 & Tinelandia, Santo Domingo & Pichincha & Ecuador & 0007--N & 07848--W & 900 \\
\hline LA1245 & $2 \mathrm{~km}$ oeste de Santa Rosa & El Oro & Ecuador & 0327--S & 07957--W & 100 \\
\hline LA1261 & Babahoyo & Los Ríos & Ecuador & $0147--\mathrm{S}$ & 07931--W & 10 \\
\hline ECU-0604 & Carretera Piura-Talara & Piura & Perú & $0451--\mathrm{S}$ & $08050--W$ & 25 \\
\hline ECU-0655 & carretera Olmos-Jaen & $\begin{array}{l}\text { Lambayeq } \\
\text { ue }\end{array}$ & Perú & 0559--S & 07943--W & 230 \\
\hline ECU-0660 & San Isidro I & Piura & Perú & $044837 \mathrm{~S}$ & 0801746W & 200 \\
\hline PE14 & Casma Valley & Ancash & Perú & 0926--S & $07840--\mathrm{W}$ & 1450 \\
\hline LA1607 & $\begin{array}{c}\text { Canete-La Victoria, a } 3 \mathrm{~km} \text { de } \\
\text { Panamericana en la parte sur } \\
\text { del valle de Cañete }\end{array}$ & Lima & Perú & $130524 \mathrm{~S}$ & $0762324 \mathrm{~W}$ & - \\
\hline ECU-0425 & $\begin{array}{l}\text { Cochancai.carretera Troncal- } \\
\text { Cañar } \\
\end{array}$ & Cañar & Ecuador & 022810S & 0792716W & 250 \\
\hline ECU-0354 & $\begin{array}{c}\text { A } 50 \mathrm{Km} . \text { de Unucapa.San } \\
\text { Pedro de la Bendita }\end{array}$ & Loja & Ecuador & $035711 \mathrm{~S}$ & 0792613W & 1850 \\
\hline ECU-0597 & carretera Olmos-Jaen & $\begin{array}{c}\text { Lambayeq } \\
\text { ue }\end{array}$ & Perú & $055942 \mathrm{~S}$ & 0794303W & 230 \\
\hline
\end{tabular}

Tabla 3.3. Entradas incluidas en ambos ensayos. Las coordenadas geográficas fueron determinadas por un sistema global de posicionamiento basado en la posición relativa con respeto a un sistema artificial satélite (GPS, Magullan XL, San Dimas, California). Los valores que aparecen en las columnas de Latitud y Longitud* son: los dos primeros los Grados, los dos siguientes los minutos y los dos últimos los segundos (continuación). * Los grados son los tres primeros números. 


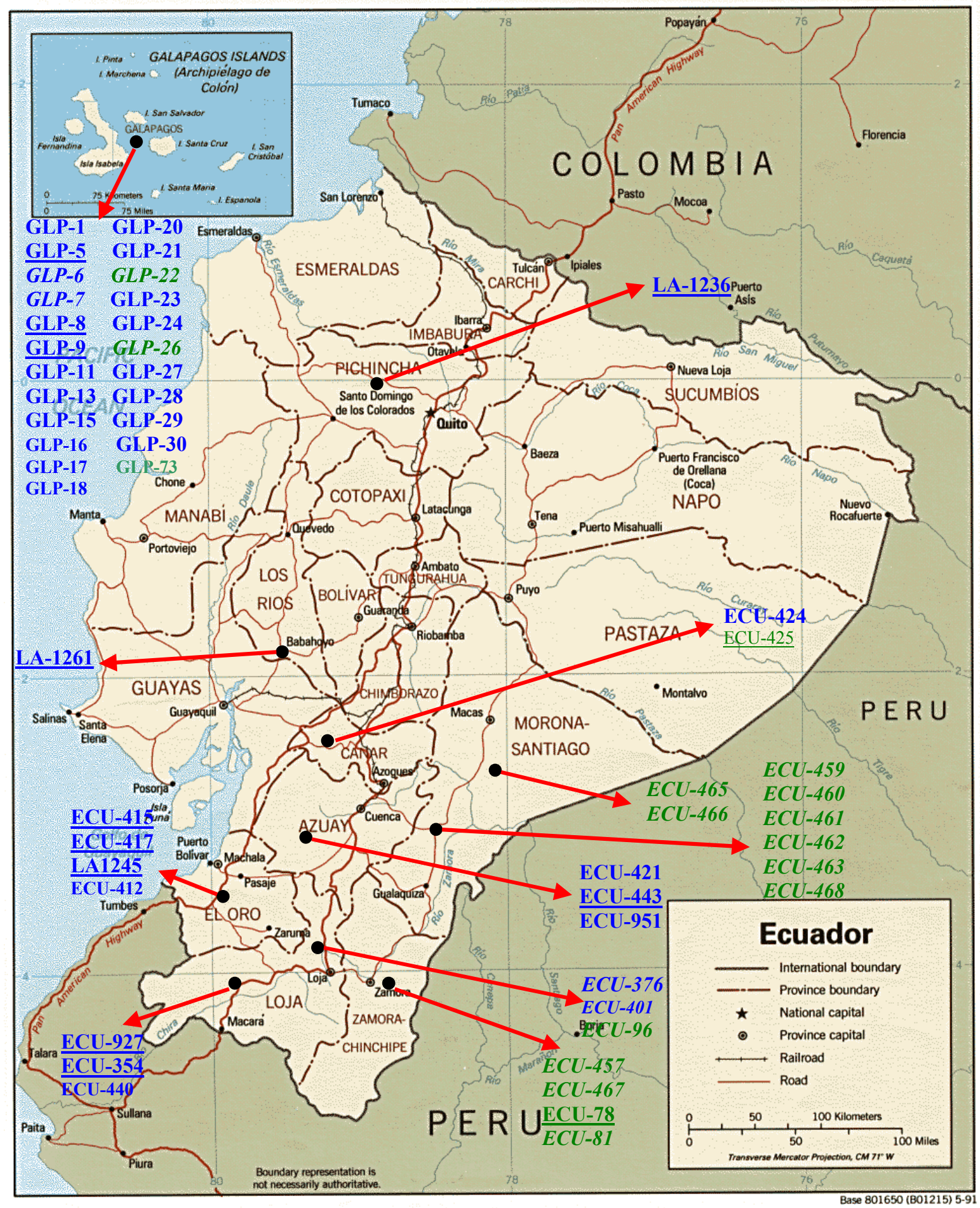

Figura 3.1. Localización geográfica de las entradas de Ecuador incluidas en los ensayos. En azul L. pimpinellifolium, en verde L. esculentum var. cerasiforme. En cursiva están las entradas del ensayo 2000-01, en negrita las del 2001-02 y subrayadas las incluidas en los dos ensayos. 


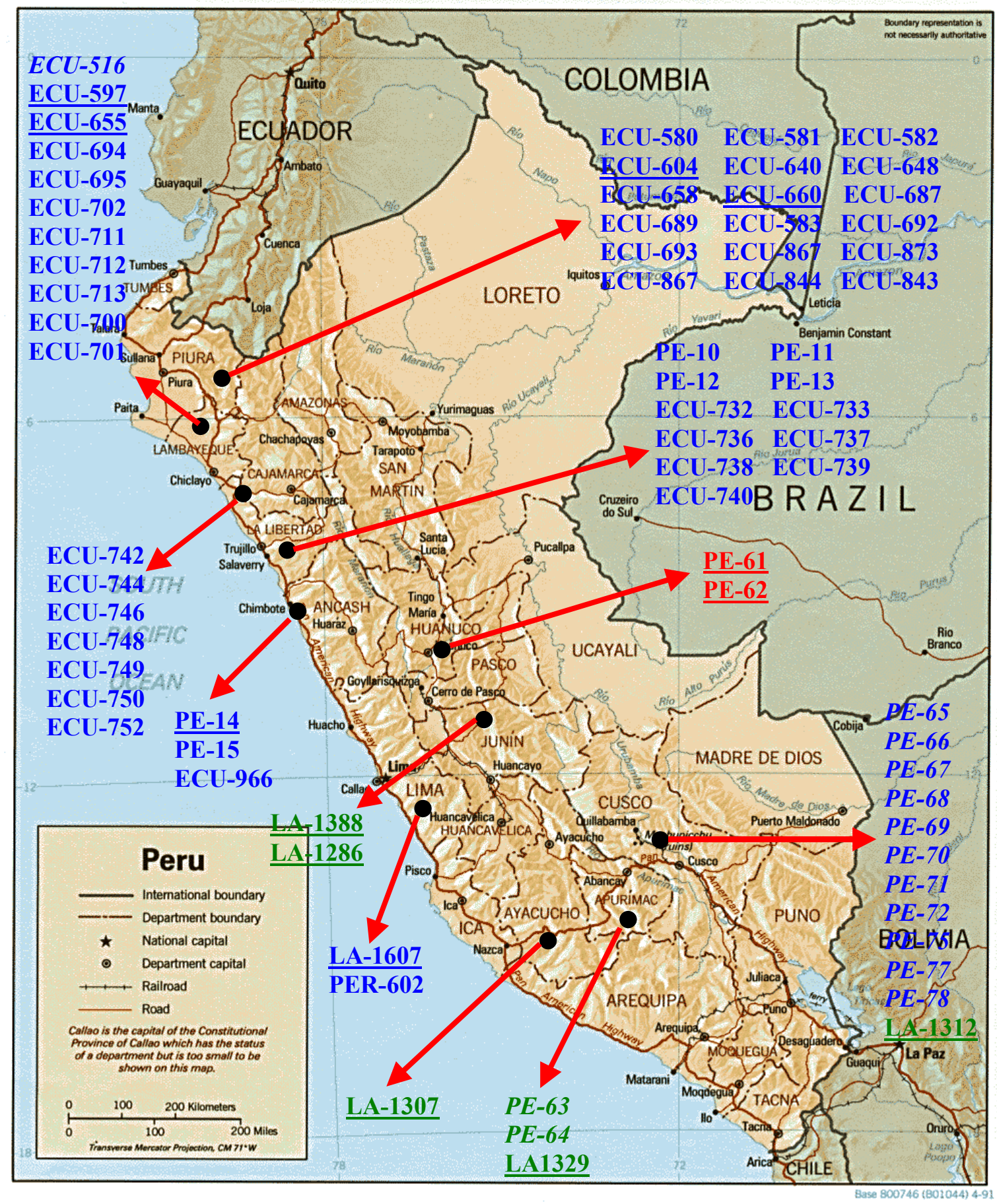

Figura 3.2. Localización geográfica de las entradas de Perú incluidas en los ensayos. En azul L. pimpinellifolium, en verde $L$. esculentum var. cerasiforme y en rojo $L$. esculentum. En cursiva están las entradas del ensayo 2000-01, en negrita las del 200102 y subrayadas las incluidas en los dos ensayos. 


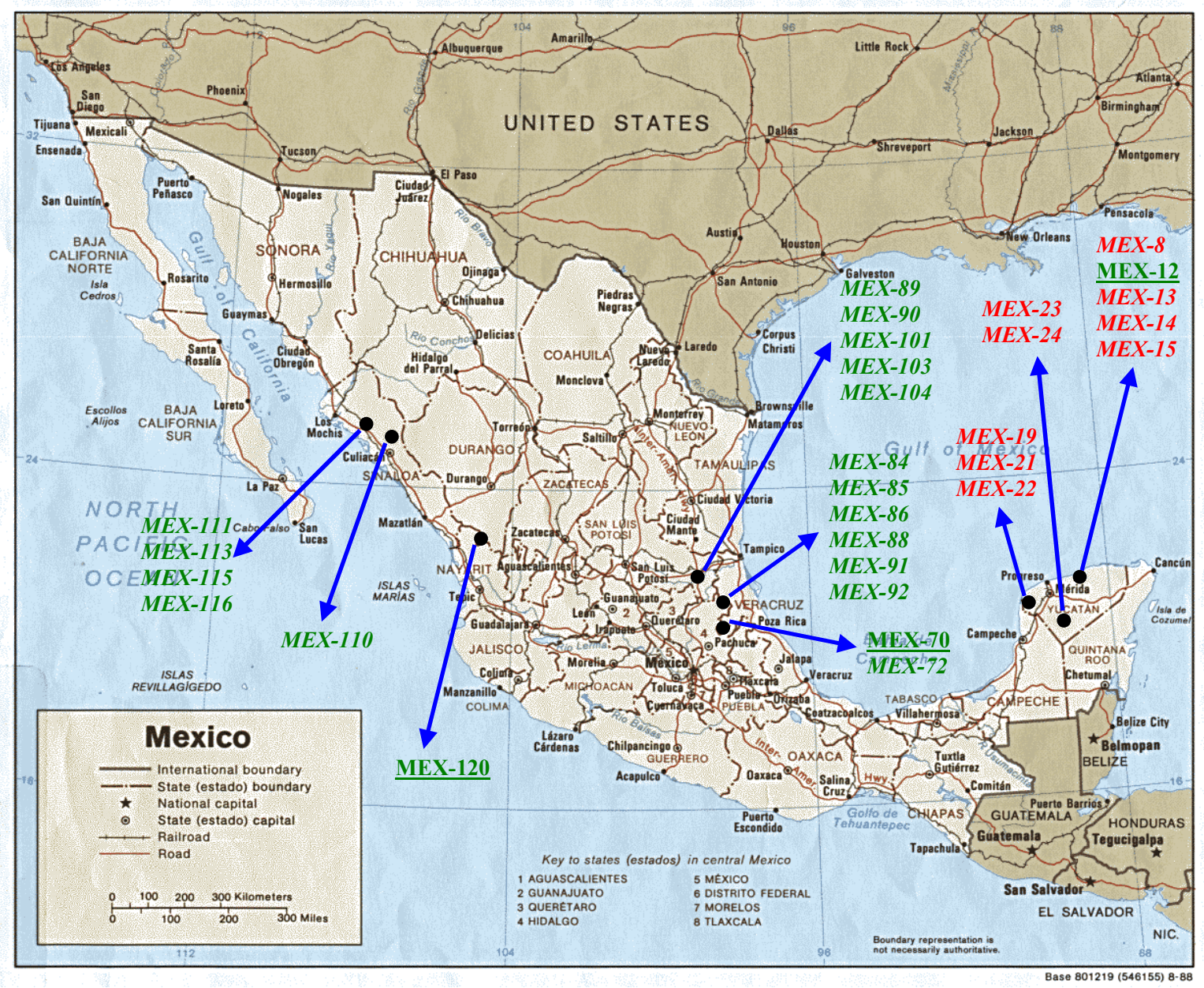

Figura 3.3. Localización geográfica de las entradas de Perú incluidas en los ensayos. En azul L. pimpinellifolium, en verde $L$. esculentum var. cerasiforme y en rojo $L$. esculentum. En cursiva están las entradas del ensayo 2000-01, en negrita las del 200102 y subrayadas las incluidas en los dos ensayos.

\section{2. DISEÑO EXPERIMENTAL}

Se realizaron dos ensayos, uno en 2000-01 y el otro en el año 2001-02. Ambos se llevaron a cabo en la campaña otoño-invierno, en la Universidad Politécnica de Valencia, en un invernadero provisto de control de temperatura mediante calefacción y apertura de los cenitales regulable. Las entradas estudiadas en cada ensayo se indican en la Tabla 3.1, 3.2 y 3.3. En el primero se incluyeron un total de 94 entradas de las cuales 48 de L. esculentum var. cerasiforme, 15 de L. pimpinellifolium y 34 de L. esculentum y en el segundo todas las entradas comunes (Tabla 3.3) y 71 entradas de L. pimpinellifollium. En ambos casos las semillas se pregerminaron en placas Petri, depositandolas sobre un algodón empapado en agua recubierto por un papel de filtro. 
Tras la emergencia de los cotiledones se sembraron en una bandeja de semilleros, donde permanecieron hasta el momento del transplante a terreno definitivo.

Se transplantaron 6 plantas de cada entrada, agrupadas en dos parcelas elementales de tres plantas cada una. Estas parcelas elementales se distribuyeron aleatoriamente por todo el invernadero. Se escogió un conjunto de 15 entradas de L. pimpinellifolium, 10 de L. esculentum var. cerasiforme y 20 de L. esculentum (Tabla 3.3), que se pusieron en los dos ensayos (años 2000-01 y 2001-02) para que sirvieran de comparación. De estas entradas se plantaron 12 plantas de cada una, dispuestas al azar en todo el invernadero en 4 parcelas elementales de 3 plantas.

\section{3. CARACTERIZACION MORFOLÓGICA}

Para la caracterización morfológica de las plantas se consideraron los descriptores publicados por el IPGRI (IPGRI, 1996), tomando un total de 24 caracteres vegetativos, 19 relativos al fruto y 21 de inflorescencia y flor.

\section{3. 1. Caracteres cuantitativos}

\section{* Caracteres de planta}

Estos caracteres se midieron en cada una de las plantas.

- Altura hasta la $3^{\mathrm{a}}$ inflorescencia (cm).

- Número de hojas bajo la primera inflorescencia.

- Número de foliolos por hoja.

- Número de hojas entre racimos.

- Número de racimos de la guía principal.

- Número de días transcurridos desde el transplante hasta la apertura de la primera flor.

- Longitud de la hoja $(\mathrm{cm})$.

- Anchura de la hoja (cm).

- Longitud del foliolo (cm).

- Anchura del foliolo $(\mathrm{cm})$.

- Grosor del tallo (cm).

\section{Caracteres de flor e inflorescencia}

Se midieron en cada una de las plantas los siguientes caracteres: 
- Número de flores de la $2^{\mathrm{a}}$ inflorescencia.

- Días desde el trasplante hasta la primera flor.

- Longitud de la inflorescencia (cm).

Se midieron en tres flores de cada entrada los siguientes:

- Longitud de los pétalos (mm).

- Anchura de los pétalos ( $\mathrm{mm})$.

- Longitud de los sépalos (mm).

- Anchura de los sépalos (mm).

- Longitud del estambre ( $\mathrm{mm})$.

- Anchura del cono estaminal (mm).

- Número de pétalos.

- Número de sépalos.

- Número de estambres.

\section{Caracteres de fruto}

Los caracteres de fruto se determinaron en el tercer fruto de la segunda inflorescencia de cada planta o en su defecto el más próximo:

- Peso del fruto $(\mathrm{g})$.

- Longitud del fruto ( $\mathrm{mm})$.

- Anchura del fruto (mm).

- Longitud del pedicelo $1(\mathrm{~mm})$ : desde el ráquiz hasta la capa de abscisión (Figura $3.4)$.

- Longitud del pedicelo 2 (mm): desde la capa de abscisión al cáliz (Figura 3.4).

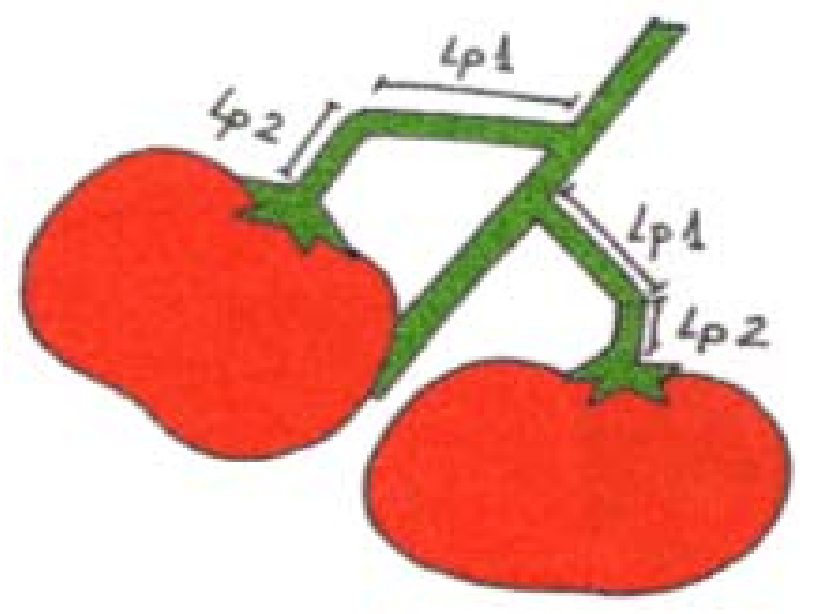

Figura.3.4. Longitud del pedicelo 1 y 2. 


\section{3. 2. Caracteres cualitativos:}

Los niveles de cada carácter se especifican en el Anexo 1.

\section{* Caracteres de planta}

Estos caracteres se determinaron en cada una de las plantas:

- Tipo de crecimiento.

- Densidad de la pubescencia del tallo.

- Longitud de la pubescencia del tallo.

- Densidad del follaje.

- Posición de la hoja.

- Coloración antociánica del tallo.

- Tipo de hoja.

- Pubescencia de los foliolos.

- Color de los foliolos.

- Vigor de la planta.

- Borde de los foliolos.

- Presencia de estípulas en la inserción de las hojas.

- Coloración antociánica de las venas.

\section{* Caracteres de flor e inflorescencia}

- Posición del estilo.

- Brácteas en la inserción de la inflorescencia con el tallo.

- Tipo de inflorescencia.

- Inflorescencia terminada en hoja.

\section{Caracteres de fruto}

Los caracteres del fruto se determinaron en el tercer fruto de la segunda inflorescencia de cada planta o en su defecto en el más próximo:

- Color del fruto no maduro.

- Forma del hombro del fruto.

- Forma del fruto.

- Color del fruto maduro. 
- Anchura de la cicatriz peduncular.

- Color de la carne del pericarpio.

- Forma del corte transversal del fruto.

- Capa de abscisión.

- Forma del terminal de la floración del fruto.

- Número de lóculos.

- Color de la piel.

- Acostillado.

- Intensidad de los hombros.

- Frutos biloculares.

\section{4. ANÁLISIS DE LA VARIABILIDAD MOLECULAR MEDIANTE AFLP.}

\section{4. 1. Material vegetal}

El material vegetal estuvo constituido por todas las plantas de los ensayos 2000-01 y 2001-02 (Tablas 3.1, 3.2 y 3.3).

\section{4. 2. Toma de muestras.}

Se pesaron $50 \mathrm{mg}$ de tejido de cada planta, 6 para las entradas de cada uno de los ensayos y 12 para las comunes a ambos ensayos. Las muestras se conservaron en congelador de $-80^{\circ} \mathrm{C}$ hasta que se realizó la extracción de ADN.

\section{4. 3. Extracción del ADN}

Se siguió el protocolo de Bernatzky y Tanksley (1986), con algunas modificaciones del método CTAB (Vosman et al., 1992).

1- Triturar el contenido del tubo eppendorf, con un homogeneizador.

2- Añadir $700 \mu 1$ de tampón de extracción (Anejos 2) y $40 \mu 1$ del antioxidante ditriotheitol $1 \mathrm{M}$ (DTT).

3- Añadir $100 \mu 1$ de cloroformo/alcohol isoamílico (24/1).

4- Agitar.

5- Incubar durante 30 minutos a $65^{\circ} \mathrm{C}$.

6- Añadir cloroformo/isoamílico (24/1) hasta llenar el tubo.

7- Agitar.

8- Centrifugar a $11.000 \mathrm{rpm}$ durante 5 minutos. 
9- Recuperar la fase acuosa.

10- Añadir etanol absoluto a cada tubo hasta llenarlo.

11- Mantener 10 minutos a $-20^{\circ} \mathrm{C}$.

12- Centrifugar a $13.000 \mathrm{rpm}$ durante 10 minutos.

13- Eliminar el sobrenadante.

14- Lavar el ADN con $500 \mu 1$ de etanol al 70\%.

15- Centrifugar a $13.000 \mathrm{rpm}$ durante 5 minutos.

16- Eliminar el sobrenadante.

17- Secar el pellet.

18- Resuspender en $100 \mu 1$ de tampón TE (Anexo 2).

\section{4. 4. Cuantificación del ADN}

La cuantificación del ADN extraído a partir de cada muestra se realizó mediante electroforesis en un gel de agarosa al 0,8\% teñido con bromuro de etidio (Anexo 2).

La intensidad de las bandas obtenida indica la cantidad de ADN que presenta cada muestra, comparada con el patrón de bandas del marcador utilizado para la cuantificación, que fue el ADN de Arabidopsis thaliana (Invitrogen)(Figura 3.5). Se usó el programa informático 1D Manager (versión 2.0 de T.D.I). Una vez realizada la cuantificación se tomó la misma cantidad de ADN de cada planta, hasta obtener una cantidad final de $125 \mathrm{ng}$ en un volumen de 7,2 $\mu 1$ de solución por genotipo.

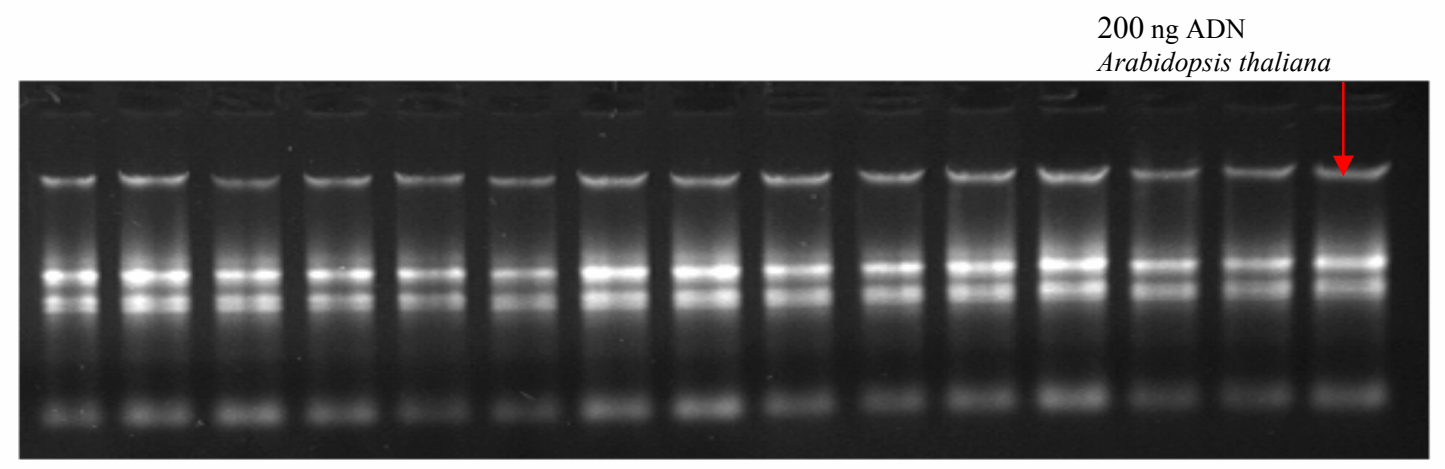

Figura 3.5. Cuantificación en gel de agarosa $0.8 \%$ con patrón de ADN de Arabidopsis thaliana. 


\section{4. 5. Análisis del Polimorfismo en la Longitud de los Fragmentos Amplificados (AFLP)}

\section{4. 5. 1. Fundamento}

Los AFLP se basan en la combinación de dos técnicas usadas para la generación de marcadores moleculares (Vos et al.; 1995): la digestión con enzimas de restricción, propias de los RFLP y la amplificación por PCR (Figura 3.6).

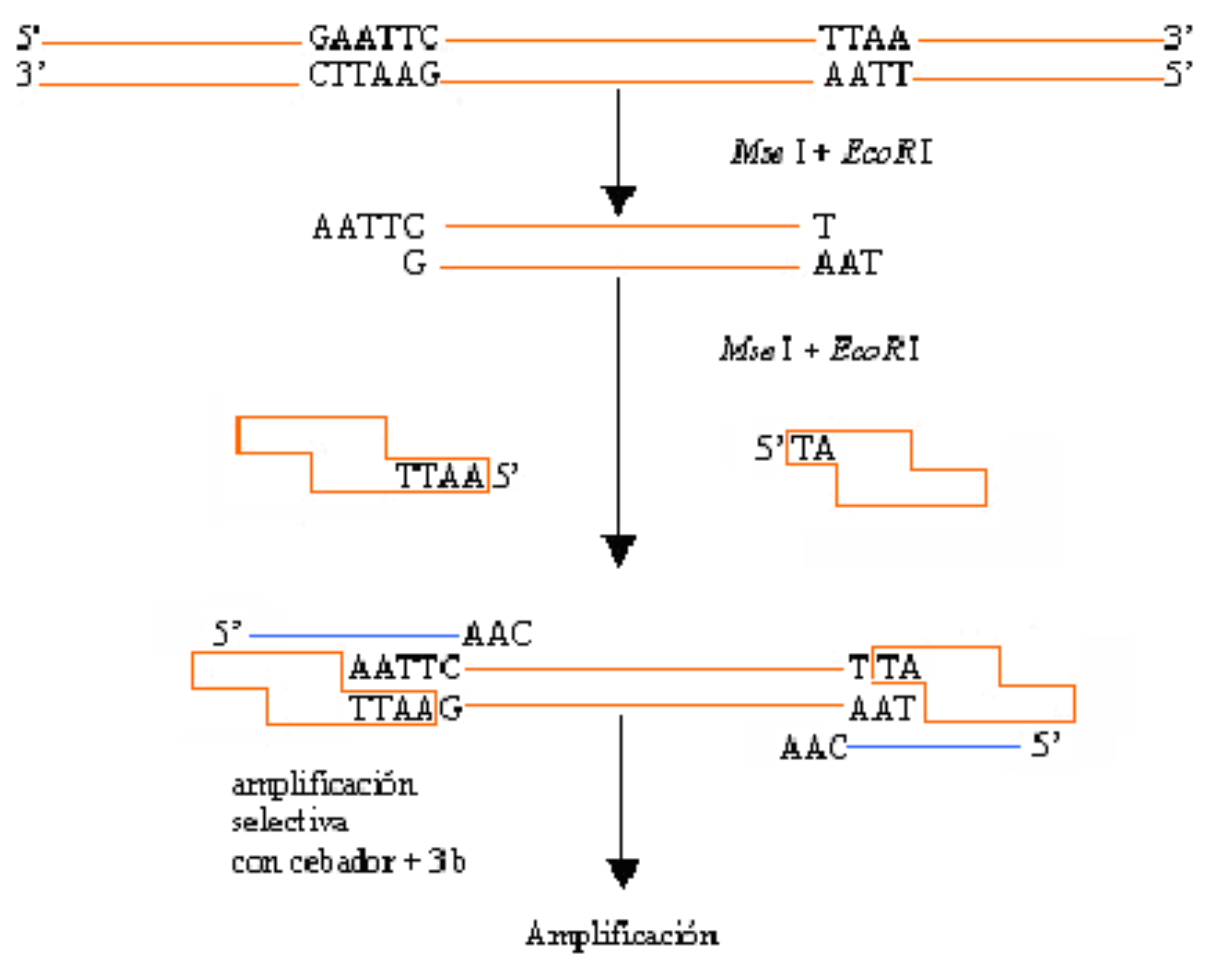

Figura 3.6. Esquema de los AFLP utilizando los enzimas de restricción MseI y EcoRI y sus adaptadores (Fuente: Lin y Kuo, 1995). (En este esquema se ha obviado la fase de amplificación preselectiva.).

Los fragmentos de restricción son generados mediante el empleo de las enzimas de restricción (EcoRI y Msel). Mediante una reacción de ligación se unen unos adaptadores de doble cadena a los extremos de los fragmentos generados para que sirvan de molde en la amplificación por PCR. A continuación se realiza una amplificación preselectiva de los fragmentos de restricción, en la que los cebadores utilizados poseen una secuencia complementaria a la del adaptador más un nucleótido adicional en el extremo 3' para reducir el exceso número de fragmentos a amplificar. Por último se realiza la amplificación selectiva, en la que los cebadores contienen la secuencia complementaria a la del adaptador más tres nucleótidos adicionales, lo que provocará que únicamente los 
fragmentos digeridos que contengan la secuencia complementaria a la de los cebadores se amplifique de forma exponencial durante la PCR.

\section{4. 5. 2. Protocolo}

Se siguió el protocolo descrito por Vos et al.; 1995.

\section{Digestión:}

A una cantidad de $125 \mathrm{ng}$ de $\mathrm{ADN}$ se añadieron $2 \mu \mathrm{l}$ de tampón de reacción y $0,8 \mu 1$ de mezcla de enzimas EcoRI/MseI. Se ajustó a un volumen final de $10 \mu \mathrm{l}$ con agua destilada estéril. Posteriormente se incubó durante 2 horas 30 minutos a $37^{\circ} \mathrm{C}$ y 15 minutos a $70^{\circ} \mathrm{C}$.

\section{Ligación:}

La secuencia de los cebadores utilizados fue la siguiente:

Adaptador EcoRI: 5'- CTCGTAGACTGCGTACC

CATCTGACGCATGGTTAA-5,

Adaptador MseI: 5' - GACGATGAGTCCTGAG

\section{TACTCAGGACTCAT-5,}

Se añadió al volumen digerido 9,6 $\mu 1$ de solución de ligación (mezcla de adaptadores y tampón de reacción) y $0,4 \mu 1$ de T4 ADN ligasa. Se incubó durante 3 horas a $20^{\circ} \mathrm{C}$.

\section{Amplificación preselectiva:}

La secuencia de los cebadores utilizados fue la siguiente:

Cebador EcoRI+1(o E+1): 5'- GACTGCGTACCAATTCA

Cebador MseI+1 (o M+1): 5'- GATGAGTCCTGAGTAA $\underline{\mathbf{C}}$

Siendo $\underline{\mathbf{A}}$ y $\underline{\mathbf{C}}$, los nucleótidos selectivos.

Se preparó una dilución 1/10 del ADN digerido/ligado. Por cada reacción se añadió $0,16 \mu 1$ de Taq polimerasa, $5 \mu 1$ de la dilución de $\mathrm{ADN}, 2,5 \mu 1$ de tampón de reacción con $\mathrm{Mg}^{+}, 0,5 \mu \mathrm{l}$ de cada uno de los cebadores a una concentración de $10 \mathrm{pmol} / \mu \mathrm{l}, 1 \mu \mathrm{l}$ de dNTPs a una concentración de $10 \mathrm{mM}$ y $1 \mu \mathrm{lde} \mathrm{Mg}^{+}$, se ajustó el volumen final a $25 \mu 1$ con agua milliQ. El programa de amplificación preselectiva constó de los siguientes ciclos:

- $\quad$ Un ciclo de desnaturalización a $94^{\circ} \mathrm{C}$ durante 2 minutos;

- $\quad 20$ ciclos:

- 20 segundos de desnaturalización a $94^{\circ} \mathrm{C}$.

- $\quad 30$ segundos de unión de cebadores a $56^{\circ} \mathrm{C}$.

- 25 segundos de extensión a $72^{\circ} \mathrm{C}$. 
- Un ciclo de 30 minutos a $60^{\circ} \mathrm{C}$.

El producto de amplificación se conservó a $-20^{\circ} \mathrm{C}$.

\section{Amplificación selectiva:}

Se preparó una dilución 1/10 a partir de la PCR preselectiva. Para cada reacción de PCR se añadió $0,16 \mu 1$ de Taq polimerasa, $5 \mu 1$ de la dilución de ADN, 2,5 $\mu 1$ de tampón de reacción con $\mathrm{Mg}^{+}, 0,5 \mu \mathrm{l}$ de cada uno de los cebadores, $1 \mu \mathrm{l}$ de dNTPs a una concentración de $10 \mathrm{mM}$ y $1 \mu \mathrm{lde} \mathrm{Mg}^{+}$, se ajustó el volumen final a $25 \mu \mathrm{l}$ con agua milliQ. El programa de amplificación constó de:

- Un ciclo de desnaturalización a $94^{\circ} \mathrm{C}$ durante 2 minutos

- 10 ciclos:

- 20 segundos de desnaturalización a $94^{\circ} \mathrm{C}$.

- 30 segundos de unión de cebadores a $66^{\circ} \mathrm{C}$.

- 25 segundos de extensión a $72^{\circ} \mathrm{C}$.

- 10 ciclos:

- 20 segundos de desnaturalización a $94^{\circ} \mathrm{C}$.

- 30 segundos de unión de cebadores desde $66^{\circ} \mathrm{C}$ hasta $56^{\circ} \mathrm{C}$ diminuyendo $1{ }^{\circ} \mathrm{C}$ cada ciclo.

- $\quad 25$ segundos de extensión a $72^{\circ} \mathrm{C}$.

- 10 ciclos:

- 20 segundos de desnaturalización a $94^{\circ} \mathrm{C}$.

- 30 segundos de unión de cebadores a $56^{\circ} \mathrm{C}$.

- 25 segundos de extensión a $72^{\circ} \mathrm{C}$.

El producto de amplificación se conservó a $-20^{\circ} \mathrm{C}$.

Los cebadores utilizados para la amplificación selectiva fueron idénticos a los de la preamplificación, pero con tres nucleótidos selectivos adicionales (Tabla 3.4). 


\begin{tabular}{|c|c|c|c|}
\hline \multicolumn{2}{|c|}{ CEBADORES } & FLUOROCROMO & SECUENCIA ( $\left.5^{\prime}-3^{\prime}\right)$ \\
\hline \multirow{3}{*}{$\begin{array}{c}\text { GRUPO } \\
\text { A }\end{array}$} & $\begin{array}{l}\text { EcoRI } \mathrm{ACA}^{*} \\
\text { MseI } \mathrm{CAC}\end{array}$ & FAM & $\begin{array}{l}\text { GAC TGC GTA CCA ATT CAC A } \\
\text { GAT GAG TCC TGA GTA ACA C }\end{array}$ \\
\hline & $\begin{array}{l}\text { EcoRI } \mathrm{AGC}^{*} \\
\text { MseI } \mathrm{CAA}\end{array}$ & HEX & $\begin{array}{l}\text { GAC TGC GTA CCA ATT AGC C } \\
\text { GAT GAG TCC TGA GTA ACA C }\end{array}$ \\
\hline & $\begin{array}{l}\text { EcoRI } \mathrm{AAC}^{*} \\
\text { MseI CAC }\end{array}$ & NED & $\begin{array}{l}\text { GAC TGC GTA CCA ATT CAA C } \\
\text { GAT GAG TCC TGA GTA ACA C }\end{array}$ \\
\hline \multirow{3}{*}{$\begin{array}{c}\text { GRUPO } \\
\text { B }\end{array}$} & $\begin{array}{l}\text { EcoRI } \mathrm{ACT}^{*} \\
\text { MseI } \\
\text { CAA }\end{array}$ & FAM & $\begin{array}{l}\text { GAC TGC GTA CCA ATT ACT T } \\
\text { GAT GAG TCC TGA GTA ACA A }\end{array}$ \\
\hline & $\begin{array}{l}\text { EcoRI } \mathrm{AGG}^{*} \\
\text { MseI CAC }\end{array}$ & JOE & $\begin{array}{l}\text { GAC TGC GTA CCA ATT CAG G } \\
\text { GAT GAG TCC TGA GTA ACA C }\end{array}$ \\
\hline & $\begin{array}{l}\text { EcoRI } \mathrm{ACG}^{*} \\
\text { MseI CTA }\end{array}$ & NED & $\begin{array}{l}\text { GAC TGC GTA CCA ATT ACG G } \\
\text { GAT GAG TCC TGA GTA ACT A }\end{array}$ \\
\hline
\end{tabular}

* Marcados con fluorocromos.

Tabla 3.4. Cebadores empleados en las amplificaciones selectivas de los AFLP.

\section{4. 6. Electroforesis en secuenciador automático.}

\section{4. 6. 1. Funcionamiento del secuenciador.}

La base del funcionamiento del secuenciador ABI/Prism 310 Genetic Analyzer consiste en la electroforesis de las muestras a través de un capilar, que a su vez contiene un polímero, circulan los fragmentos de ADN amplificados y marcados con fluorocromos que un láser va detectando a medida que pasan por un detector. Uno de los cebadores utilizados en la amplificación selectiva, en este caso la EcoRI, está marcado con un flourocromo. Los fluorocromos utilizados son: FAM (lee en longitudes de onda del azul), NED (amarillo), JOE (verde) y ROX (rojo). El GeneScan-500 (ROX) se ha utilizado como marcador de peso molecular, el láser del secuenciador, lee simultáneamente los cuatro marcajes, así en una sola inyección del capilar puede leerse el producto amplificado con tres cebadores diferentes (multiplexing). 


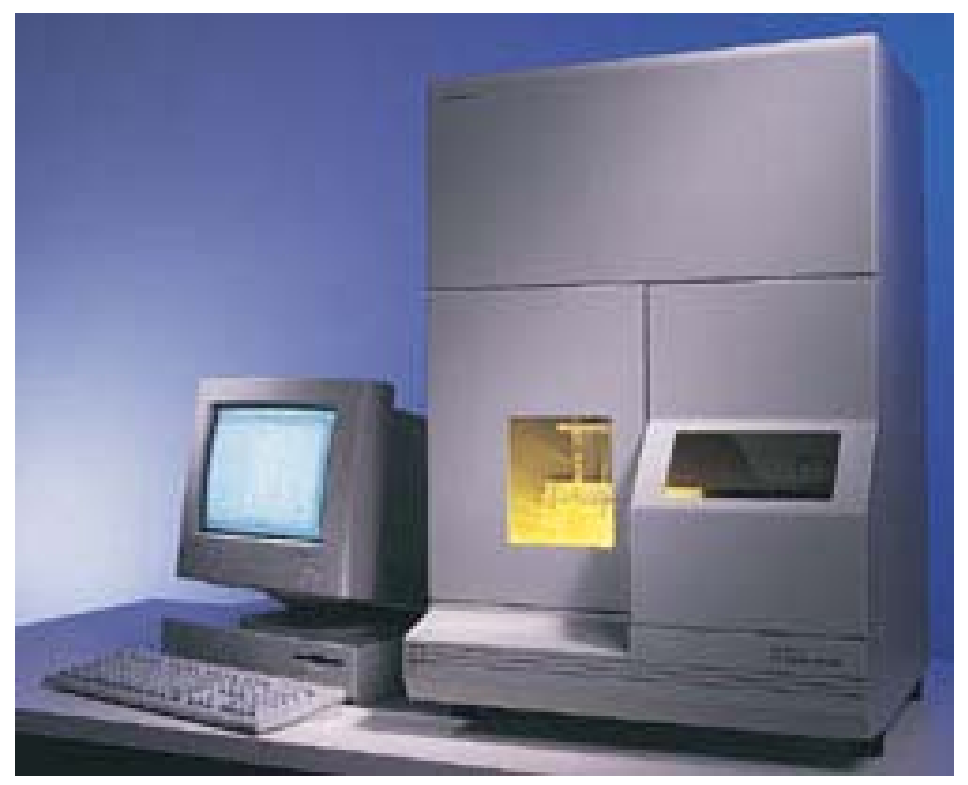

Figura 3.7. Secuenciador automático ABI/PRISM 310 de PE Biosystems.

\section{Preparación de las muestras:}

De los productos de la PCR selectiva se tomó $1 \mu 1$ de cada una de las combinaciones de cebadores, se añadió $12 \mu \mathrm{l}$ de formamida desionizada y 0,35 $\mu 1$ del marcador de pesos moleculares (400-HD Rox). Se desnaturalizó el producto de la PCR durante aproximadamente 5 minutos a $95^{\circ} \mathrm{C}$. Antes de terminar el programa se pusieron las muestras en hielo, para evitar la renaturalización.

\section{4. 6. 2. Análisis de datos moleculares.}

Los resultados obtenidos de los fragmentos amplificados se visualizan en forma de un gráfico de picos, en el que cada pico corresponde a un fragmento de ADN amplificado (Figuras 3.8 y 3.9 ). 


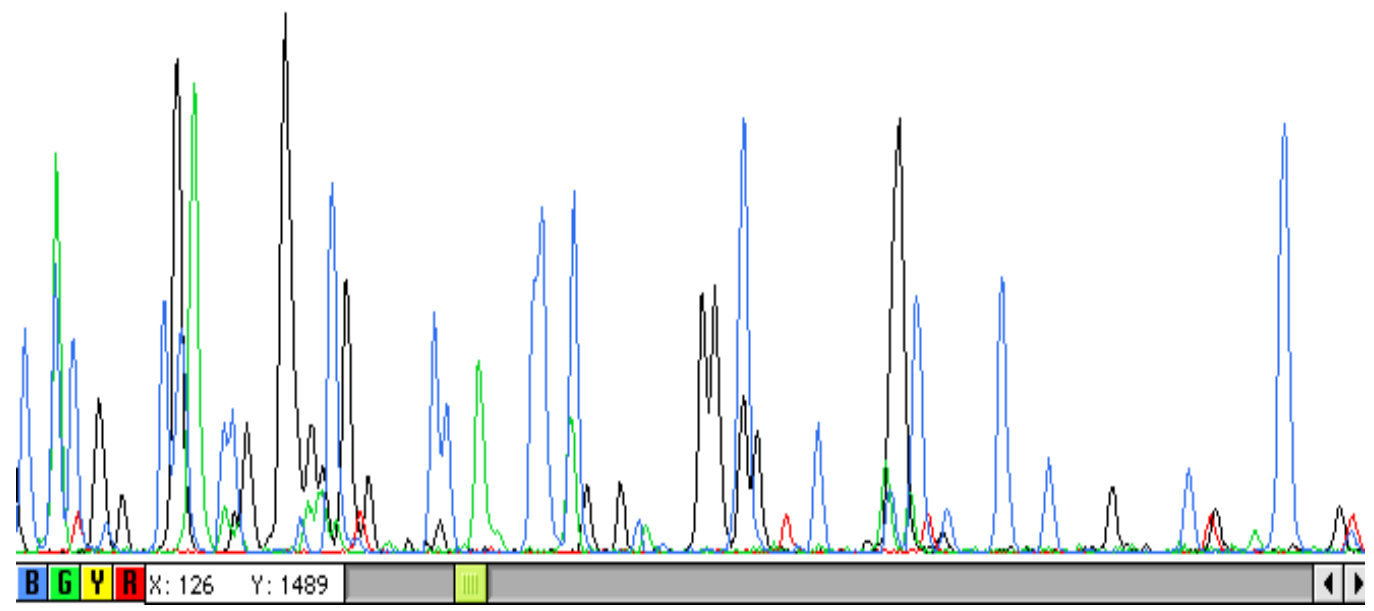

Figura 3.8. Fragmentos amplificados en forma de picos (imagen GeneScan).

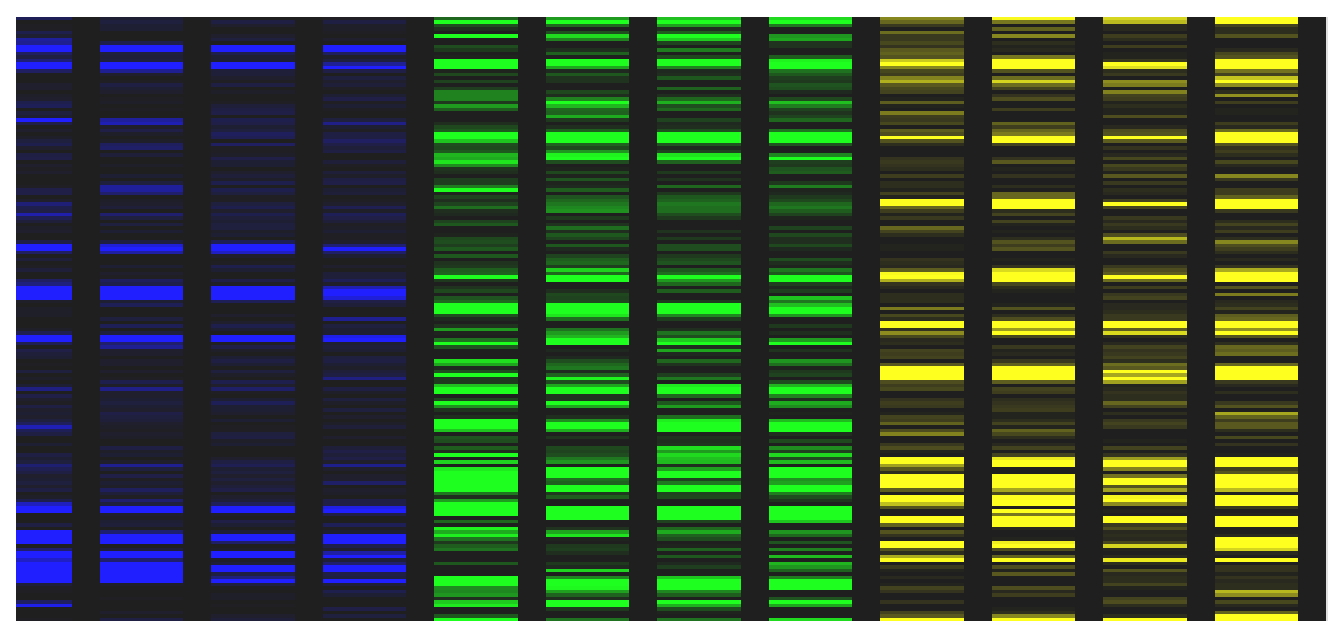

Figura 3.9. Fragmentos amplificados transformados en banda (Imagen Genographer).

\section{5. ANÁLISIS ESTADÍSTICO}

\subsubsection{Análisis de la varianza}

- Con las entradas cultivadas en las dos campañas se realizó un ANOVA factorial para determinar las posibles interacciones Entrada x Año. El modelo utilizado fue el siguiente:

$$
\mathbf{Y}_{\mathrm{ijk}}=\mu+\mathbf{E}_{\mathbf{i}}+\mathbf{A}_{\mathbf{j}}+(\mathbf{E x A})_{\mathrm{ij}}+\varepsilon_{\mathrm{ijk}}
$$


donde:

$\mathbf{Y}_{\mathbf{i}, \mathbf{j k}}$ : valor fenotípico de la entrada i-ésima en el j-ésimo ambiente.

$\mu$ : media total de las observaciones.

$\mathbf{E}_{\mathbf{i}}$ : efecto aditivo de la entrada i-ésima.

$\mathbf{A}_{\mathbf{j}}$ : efecto aditivo del ambiente j-ésimo.

$(\operatorname{ExA})_{\mathrm{ij}}$ : interacción ExA de la entrada i-ésima y del ambiente j-ésimo.

$\varepsilon_{\mathbf{i}, \mathbf{j k}}$ : variación residual de la observación k-ésima de la entrada i-ésima y del ambiente j-ésimo.

- Los caracteres discriminantes entre especies se establecieron mediante la realización de un ANOVA y posteriormente la prueba de comparación de medias de Newman-Keuls. La estructura de la variación para los caracteres estudiados en cada especie se calculó a partir de las componentes de la varianza entre entradas y dentro de entradas.

El modelo utilizado fue:

$$
\mathbf{x}_{\mathbf{i}, \mathbf{j}}=\mu+\mathbf{E}_{\mathbf{i}}+\mathbf{P j}+\varepsilon_{\mathbf{k}(\mathbf{i}, \mathbf{j})}
$$

Donde:

$\mathbf{x}_{\mathbf{i}, \mathbf{j}}$ : variable respuesta.

$\mu$ : media total de las observaciones.

$\mathbf{E}_{\mathbf{i}}$ : efecto entrada i-ésima.

$\mathbf{P}_{\mathbf{j}}$ : efecto planta j-ésima.

$\varepsilon_{\mathbf{k}(\mathbf{i}, \mathbf{j}):}$ variación residual de la observación k-ésima de la entrada i-ésima y de la planta j-ésima.

Para estos análisis se utilizaron los programas NTSYSpc 2.0 y S-PLUS 6.1 professional (Fraley y Raftery, 2002).

\subsubsection{Análisis multivariante: análisis cluster $y$ análisis de componentes} principales (ACP)

Los métodos matemáticos de análisis cluster permiten una agrupación de los objetos en función de su similitud, ya sea morfológica o molecular. Por convención en la literatura del análisis multivariante, cuando se aplican estas técnicas para el estudio de 
las asociaciones entre indivíduos se les llama Análisis Q, mientras que cuando se aplican al estudio de los caracteres o atributos se les denomina Análisis R. Tanto en la explicación de los análisis efectuados, como en la de los resultados nos ajustaremos a esta terminología.

El análisis multivariante se empleó para el estudio de los caracteres cuantitativos y cualitativos determinados en la caracterización morfológica y para los datos moleculares obtenidos mediante AFLP.

\section{Análisis de componentes principales: $A C P$}

El ACP se realizó a partir de las correlaciones totales entre los caracteres cuantitativos transformados de la siguiente forma:

$$
X_{i j e}=\frac{X_{i j}-\min _{j}}{\left(\max _{j}-\min _{j}\right)}
$$

Donde: $\quad \mathbf{X}_{\mathrm{ije}}$ es el valor medio estandarizado del carácter j para la entrada ${ }_{\mathrm{i}}$. $\mathbf{X}_{\mathbf{i j}}$ es el valor medio del carácter ${ }_{j}$ para la entrada ${ }_{\mathrm{i}}$. $\mathbf{m i n}_{\mathbf{j}}$ es el valor mínimo de las medias de todas las entradas para el carácter ${ }_{\mathrm{j}}$. $\mathbf{m a x}_{\mathbf{j}}$ es el valor máximo de las medias de todas las entradas para el carácter ${ }_{\mathbf{j}}$.

Se calcularon también las correlaciones parciales. El coeficiente de correlación parcial mide la relación existente entre dos caracteres diminuyendo el efecto que sobre ellos pueden tener otros caracteres correlacionados. Ello nos permitió seleccionar los caracteres no correlacionados con los que se realizó un nuevo ACP.

Para el cálculo del ACP se empleó el programa NTSYSpc 2.0 y para el cálculo de las correlaciones parciales el STATGRAPHICS Plus 5.1.

Se realizó un ACP Q para determinar qué caracteres explican la mayor parte de la variación. Así mismo, permitió conocer la agrupación de las entradas según su similitud. Las entradas se proyectaron en los planos definidos por las 2 ó 3 primeras componentes. Ello permitió visualizar las agrupaciones entre las mismas. 
El análisis se realizó con el conjunto de todas las entradas de este estudio y también para las entradas de cada especie por separado, L. esculentum, L. esculentum var. cerasiforme y L. pimpinellifolium.

El programa estadístico utilizado fue el NTSYSpc 2.0.

\section{$\underline{\text { Análisis cluster }}$}

El análisis cluster se efectuó con los caracteres cuantitativos y conjuntamente con los caracteres cuantitativos y cualitativos. En el caso de los cuantitativos se realizó un análisis Q (agrupación de las entradas) y un análisis R (agrupación de los caracteres).

- Para el análisis de los caracteres cuantitativos se realizó la transformación descrita anteriormente. Posteriormente se calcularon las distancias euclídeas mediante la siguiente fórmula:

$$
\mathbf{E}_{\mathrm{ij}}=\sqrt{\sum_{\mathrm{K}}\left(\mathrm{X}_{\mathrm{ki}}-\mathrm{X}_{\mathrm{kj}}\right)^{2}}
$$

Donde: $\mathbf{E}_{\mathbf{i j}}$ es la distancia euclídea entre la entrada i y la entrada $\mathbf{j}$

$\mathbf{X}_{\mathbf{k i}}$ es el valor medio transformado de la entrada i para el carácter k.

$\mathbf{X}_{\mathbf{k j}}$ es el valor medio de la entrada j para el carácter k.

El cluster se realizó empleando el método UPGMA (Unweighted Pair-Group Method Arithmetic Average) (Sneath y Sokal, 1973) utilizando el programa NTSYSpc 2.0 .

- Para obtener un dendrograma utilizando toda la información de la caracterización morfológica (caracteres cuantitativos y cualitativos), se siguió el siguiente método:

En el caso de los caracteres cualitativos, cada uno de ellos se escindió en tantos como opciones presentaba (Romersburg, 1984), estando formada la matriz de datos cualitativos por 1 y 0 dependiendo de la presencia o ausencia de un determinado nivel del carácter en la entrada correspondiente.

Como para algún carácter cualitativo se encontró variación dentro de entrada cada número 1 de la matriz de datos cualitativos se dividió por la raíz cuadrada del número de niveles de carácter presentes en una misma entrada, más uno (Cole-Rodgers et al 
1997). De esta forma, al calcular la distancia euclídea, ésta será 0 en el caso de dos entradas totalmente iguales y 1 para entradas totalmente distintas.

Con los caracteres cuantitativos se realizó la transformación descrita anteriormente.

Posteriormente, se unieron ambas matrices y a partir de la resultante se calculó la matriz de disimilitudes, utilizando las distancias euclídeas, con el programa NTSYSpc 2.0. A partir de la matriz de distancias se obtuvo el dendrograma, utilizando el método de agrupamiento UPGMA.

\section{- Datos de la caracterización molecular}

Se analizó el electroferograma de AFLP en el intervalo de 50-400pb usando los programas GeneScan y Genographer (v.1.6.0). Cada fragmento amplificado fue tratado como un carácter unitario para el análisis y convertido a la clave binaria, presencia o ausencia (1-0), a partir de las cuales se obtuvieron las matrices binarias para cada uno de los genotipos y combinaciones de cebadores por separado.

Para el análisis de la variabilidad molecular se procedió de la forma siguiente:

1. A partir de la matriz de 1 y 0 obtenida, se cálculo la similitud genética entre las diferentes entradas para cada combinación de cebadores, usando el coeficiente de Dice (1945).

$$
S_{i j}=\frac{2 a}{(2 a+b+c)}
$$

Donde: $\quad$ a: es el número de bandas compartidas entre las entradas ${ }_{\mathbf{i}} \mathrm{y}_{\mathbf{j}}$.

b: es el número de bandas presentes sólo en la entrada $\mathbf{i}$

c: es el número de bandas presentes sólo en la entrada $\mathbf{j}$.

2. Obtención de la matriz de distancia $\left(1-\mathrm{S}_{\mathrm{ij}}\right)$ y cálculo a partir de ella de:

- Construcción de un dendrograma a partir de las matrices de distancias genéticas usando el método UPGMA (Unweighted Pair-Group Method Arithmetic Average) (Snaeth y Sokal, 1973), para observar la agrupación de las diferentes entradas.

- Análisis mediante la técnica de remuestreo bootstrap (con 1000 réplicas) (Felsenstein, 1985), para determinar la fiabilidad y robustez del dendrograma, empleando el limite de confianza del análisis bootstrap sobre el 50\%, para 
considerar un agrupamiento estadísticamente significativo para la topología de un nodo (Highton, 1993).

Para este análisis se utilizaron los programas NTSYSpc 2.0 y PHYLIP.3.57c.

\section{Análisis de coordenadas principales}

A partir de la matriz de distancia $\left(1-S_{\mathrm{ij}}\right)$ obtenida se realizó un análisis de coordenadas principales para el conjunto de los datos moleculares, con el objeto de visualizar la dispersión de los individuos en relación con los factores principales responsables de la variación. Para ello se empleó el programa NTSYSpc 2.0.

\section{5. 3. Análisis de polimorfismo y de la diversidad genética.}

La variación genética se estimó como la proporción de fragmentos polimórficos $(P)$ y la diversidad genética total en todas las poblaciones $\left(H_{T}\right)$ (Nei, 1973).

La $H_{T}$ se estimó a partir del índice $H e$ (diversidad genética media):

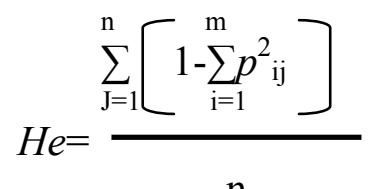

Donde:

$p_{\mathrm{ij}}$ : frecuencia del alelo i del locus $\mathrm{j}$

$\mathrm{m}$ : número de alelos en el locus $\mathrm{j}$

n: número de loci considerados

La diversidad total fue particionada en diversidad genética media entre $D_{S T}$ $\left(D_{S T}=H_{T}-H S\right)$ y dentro de poblaciones $\left(H_{S}\right)$. La magnitud relativa de la diferenciación genética entre poblaciones $\left(G_{S T}\right)$ se calculó mediante la relación $D_{S T} / H_{T}$. Para estos análisis se utilizó el programa PopGene32. 
4. RESULTADOS Y DISCUSIÓN 


\section{1. ANÁLISIS DE LA VARIABILIDAD MORFOLOGICA}

\section{1. 1. Análisis de la interacción Entrada por Año.}

Se calcularon las interacciones Entrada x Año con el conjunto de entradas ensayadas en ambas campañas, con el objeto de determinar si era posible realizar un análisis conjunto de ambas campañas (Tabla 4.1).

Las interacciones Entrada x Año fueron significativas para la mayoría de los caracteres en L. pimpinellifolium, a excepción de los relativos al fruto: longitud, anchura y peso del fruto y longitud del pedicelo 1. El número de flores de la segunda inflorescencia y el número de estambres no presentaron tampoco interacción. En el caso de L. esculentum var. cerasiforme la longitud del fruto y el peso del fruto tampoco mostraron interacción, al igual que el número de flores de la segunda inflorescencia. $L$. esculentum fue la especie más estable, no existiendo interacciones Entrada x Año para gran parte de los caracteres controlados.

Dado que la mayor parte de entradas del segundo año correspondían a $L$. pimpinellifollium, fue imposible analizar de forma conjunta todas las entradas, siendo necesaria su separación según la campaña.

Por otro lado, la existencia de diferencias altamente significativas entre entradas para la mayoría de caracteres estudiados, pone de manifiesto la importancia de la variabilidad existente en esta colección. Muchos de estos caracteres podrían tener un interés directo en mejora. Parte de las entradas estudiadas en este trabajo han sido caracterizadas para caracteres de calidad y resistencia a enfermedades (Picó et al., 2000; Sánchez et al., 2000) habiendo encontrado algunas de ellas de interés para su uso en mejora. Diferentes programas de mejora con este objetivo están actualmente en progreso. 


\begin{tabular}{|c|c|c|c|c|c|c|c|c|c|}
\hline \multirow{2}{*}{ Caracteres } & \multicolumn{3}{|c|}{ L. pimpinellifolium } & \multicolumn{3}{|c|}{ L. esculentum var. cerasiforme } & \multicolumn{3}{|c|}{ L. esculentum } \\
\hline & Entrada & Año & Interacción & Entrada & Año & Interacción & Entrada & Año & Interacción \\
\hline$A$ & $2332,2^{\star \star}$ & $8613^{* *}$ & $362^{* *}$ & $1837^{\star *}$ & $2822^{* *}$ & 203,6 & 3023 & 8310 & 501,2 \\
\hline $\mathrm{NH}$ & $15,04^{* *}$ & $103,8^{* *}$ & $11,8^{* *}$ & $32,82^{\star *}$ & $19,82^{*}$ & 3,47 & $10,16^{\star *}$ & $43,63^{* *}$ & $8,1^{* *}$ \\
\hline $\mathrm{LH}$ & $225,27^{\star \star}$ & $551,1^{* *}$ & $105^{\star *}$ & $316,1^{* *}$ & $391,6^{\star *}$ & $191,7^{*}$ & $351,9^{* *}$ & 12,25 & $105,4^{*}$ \\
\hline $\mathrm{AH}$ & $226,49^{* *}$ & $671,1^{* *}$ & $196^{\star *}$ & $220,3^{* *}$ & $1284^{\star *}$ & $205,3^{*}$ & $322,2^{\star \star}$ & 41,27 & $2,36^{*}$ \\
\hline LF & $53,63^{* *}$ & 1,19 & $59,5^{\star *}$ & $114,7^{\star *}$ & $172,2^{\star \star}$ & $64,81^{*}$ & $84,14^{\star *}$ & $171,5^{\text {** }}$ & $38,81^{*}$ \\
\hline AF & $11,48^{\star *}$ & 0,97 & $8,58^{\star *}$ & $25,76^{\star *}$ & $97,86^{\star *}$ & $31,87^{*}$ & 11,47 & $66,24^{* *}$ & 7,97 \\
\hline GT & $0,56^{\star *}$ & 0,22 & $0,15^{\star *}$ & $0,32^{* *}$ & 0,05 & 0,06 & $0,22^{*}$ & $1,19^{* *}$ & 0,09 \\
\hline NR & $20,28^{\star *}$ & $11,67^{*}$ & $7,27^{\star *}$ & $14,06^{* *}$ & $27,42^{\star *}$ & $8,39^{*}$ & $36,89^{*}$ & 0,06 & $2,45^{\star}$ \\
\hline DT1F & $641,87^{*}$ & $7173^{* *}$ & $362^{*}$ & $1201^{* *}$ & $2772^{* *}$ & 431,7 & $651,1^{*}$ & $526,5^{\star *}$ & $717,6^{*}$ \\
\hline NF & $1645,7^{*}$ & $1166^{* *}$ & 109 & $27,29^{*}$ & $83,71^{* *}$ & 9,95 & $132,1^{*}$ & 0,22 & 27 \\
\hline NS & $0,09^{*}$ & $0,09^{*}$ & $0,09^{*}$ & 0,04 & $0,11^{*}$ & 0,04 & $4,11^{*}$ & 0,79 & 0,71 \\
\hline NP & $0,1^{*}$ & $0,17^{*}$ & $0,1^{*}$ & 0,27 & 1 & 0,27 & $4,87^{*}$ & 0,48 & 0,56 \\
\hline LP & $48,62^{*}$ & $65,1^{*}$ & $9,21^{*}$ & $13,35^{*}$ & 5,95 & $6,91^{*}$ & $24,5^{*}$ & - & - \\
\hline AP & $10,28^{*}$ & $10,94^{*}$ & $4,06^{*}$ & $2,14^{*}$ & 0,14 & $3,72^{*}$ & $2,35^{*}$ & 0,72 & 1,3 \\
\hline LS & $18,71^{*}$ & 0,01 & $5,24^{*}$ & $53,52^{*}$ & $39,31^{*}$ & $7,51^{*}$ & $53,33^{*}$ & $415,2^{*}$ & $19,23^{*}$ \\
\hline AS & $0,91^{*}$ & $0,67^{*}$ & $0,33^{*}$ & 10,5 & $0,09^{*}$ & $0,69^{*}$ & 0,64 & 0,06 & 0,72 \\
\hline LE & $5,9^{*}$ & 0,71 & $1,59^{*}$ & $9,89^{*}$ & $4,3^{*}$ & $1,15^{*}$ & $3,88^{*}$ & 1,87 & 1,17 \\
\hline ACE & $0,31^{*}$ & 0,05 & $0,5^{*}$ & $0,17^{*}$ & $0,16^{*}$ & $0,45^{*}$ & $1,17^{*}$ & 0,14 & 0,49 \\
\hline NE & $0,05^{*}$ & 0,01 & 0,05 & $0,11^{*}$ & 0,11 & $0,11^{*}$ & $4,87^{*}$ & 0,35 & 0,52 \\
\hline LF & $597,83^{\star \star}$ & $158,4^{* *}$ & 19,4 & $1842^{\star \star}$ & 27,75 & 28,53 & - & - & - \\
\hline AF & $817,95^{\star *}$ & 106,9 & 57,1 & $252,2^{* *}$ & 43,15 & $66,97^{*}$ & - & - & - \\
\hline $\mathrm{PF}$ & $703,01^{* *}$ & 62,22 & 11,3 & $253,6^{* *}$ & 35,78 & 17,78 & - & - & - \\
\hline LP 1 & $107,57^{* *}$ & 9,9 & 14,3 & $101,6^{* *}$ & $50,99^{*}$ & $37,78^{*}$ & $79,16^{\star *}$ & $210^{*}$ & $34,22^{*}$ \\
\hline LP 2 & $17,49^{* *}$ & 0,43 & $2,24^{*}$ & $55,04^{* *}$ & 5,01 & $4,05^{*}$ & $63,12^{* *}$ & $87,37^{* *}$ & $8,64^{* *}$ \\
\hline
\end{tabular}

Tabla 4.1. Efectos de Entrada, año e interacción entrada por año para cada carácter y especie, realizados con los caracteres cuantitativos de las entradas comunes a ambos ensayos, mediante un ANOVA factorial y modelo mixto. Las medias seguidas con un asterisco $(*)$ presentan una signíficación al $95 \%$ y las que tienen dos $(* *)$ una significación al 99\%.

A) Altura hasta el tercer racimo, NH) Número de hojas bajo la primera inflorescencia, LH) Longitud de la hoja, LH) Longitud de la hoja, AH) Anchura de la hoja, LF) Longitud del foliolo, AF) Anchura del foliolo, GT) Grosor del tallo, NR) Número de racimo en la guía principal, DT1F) Número de días transcurridos hasta la primera flor, NF) Número de flores en la segunda inflorescencia, NS) Número de sépalos, NP) Número de pétalos, LP Longitud del pétalo, AP) Anchura del pétalo, LS)Longitud del sépalo, AS) Anchura del sépalo, LE) Longitud de los estambres, ACE) Anchura del cono estaminal, NE) Número estambre, LF) Longitud del fruto, AF) Anchura del fruto, PF) Peso del fruto, LP1) Longitud del pedicelo, LP2) Longitud del pedicelo 2.

\section{1. 2. Análisis de las entradas ensayadas en la campaña 2000-2001.}

\section{1. 2. Análisis de todas las entradas.}

\section{Agrupación de las entradas según $A C P$.}

Empleando los caracteres cuantitativos se realizó un análisis de componentes principales para determinar cuáles de ellos explicaban la mayor parte de la variación observada.

Las tres primeras componentes principales explicaron un $40 \%$, un $9,6 \%$ y un $8,1 \%$ de la varianza, respectivamente, totalizando un 57,7\% de la variación observada. 


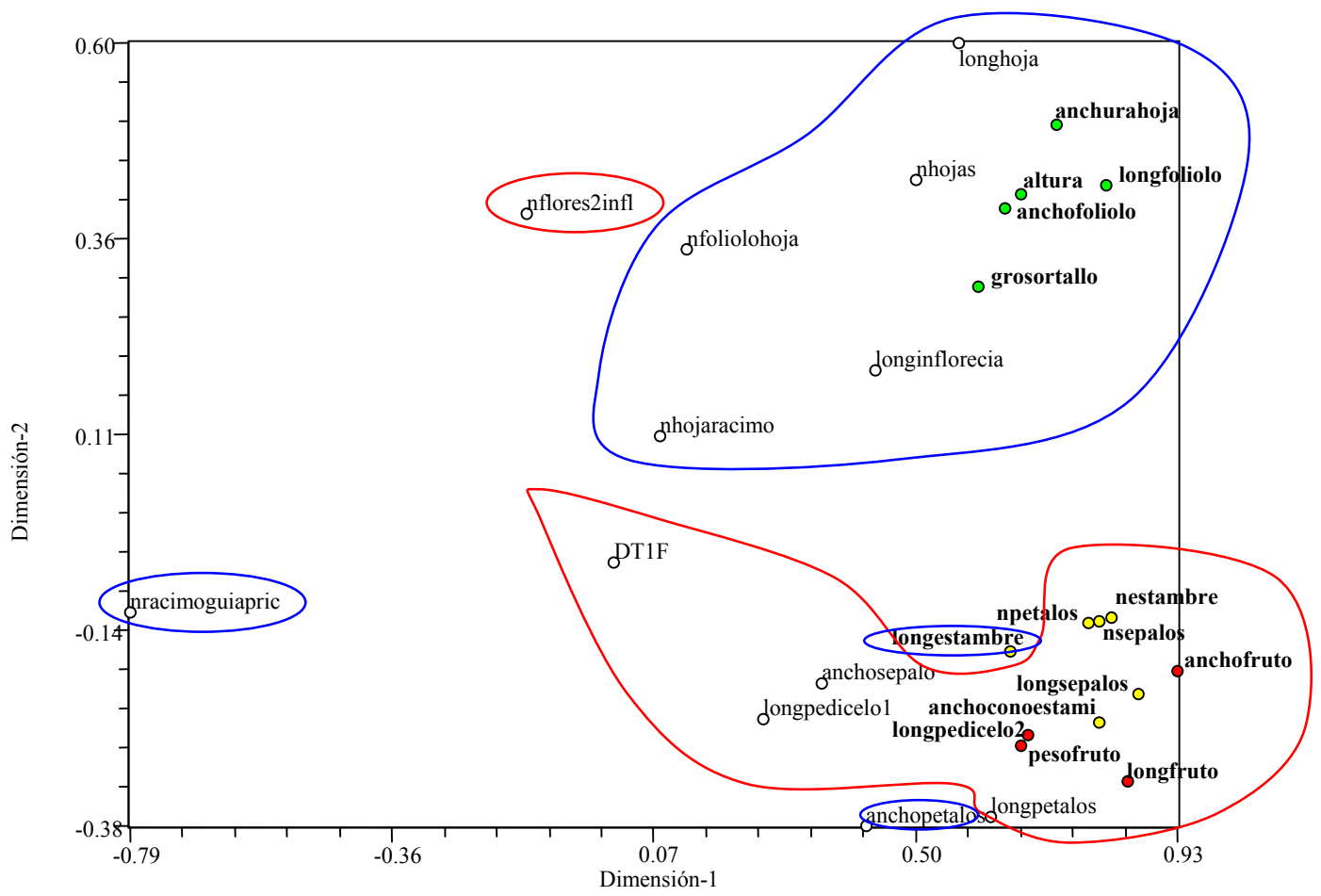

Figura 4.1. Representación de los coeficientes de los caracteres en los vectores propios que definen las dos primeras componentes principales. Ensayo 2000-01. En verde se representan los caracteres vegetativos, en amarillo los de flor e inflorescencia y en rojo los de fruto. Los caracteres rodeados del mismo color se corresponden con los de la Figura 4.3 (ver apartado Correlaciones entre caracteres).

Varios de los caracteres estudiados presentaron elevadas correlaciones con la primera componente principal (Figura 4.1). Entre ellos los hay de flor y de fruto. El grupo de caracteres de flor está formado por el número de sépalos, número de pétalos, longitud de los sépalos, ancho del cono estaminal y número de estambres y el de fruto lo constituyen la anchura del fruto, longitud del fruto, peso del fruto y longitud del pedicelo 2 .

Correlacionados positivamente con la segunda componente principal aparecen los siguientes caracteres vegetativos: anchura de la hoja, longitud y anchura del foliolo, altura de la planta hasta el tercer racimo y el grosor del tallo.

Las diferencias morfológicas entre las entradas estudiadas, pertenecientes a distintas especies, podrían explicar la diversidad de caracteres vegetativos, de flor y de fruto responsables de la variación observada.

La primera componente, separa las entradas según una gradación continua, donde las de L. esculentum (de frutos más grandes y flores de hasta 6 pétalos y sépalos) se encuentran situadas a la derecha, las de L. pimpinellifolium (de fruto más pequeño) a la izquierda y las de L. esculentum var. cerasiforme en una posición intermedia (Figura 
4.2). El hecho de que no se encuentre una separación clara entre especies apoya la existencia de formas intermedias tanto entre $L$. esculentum var. cerasiforme y $L$. esculentum (Rick y Holle, 1990), como entre L. pimpinellifolium y L. esculentum (Rick, 1958).

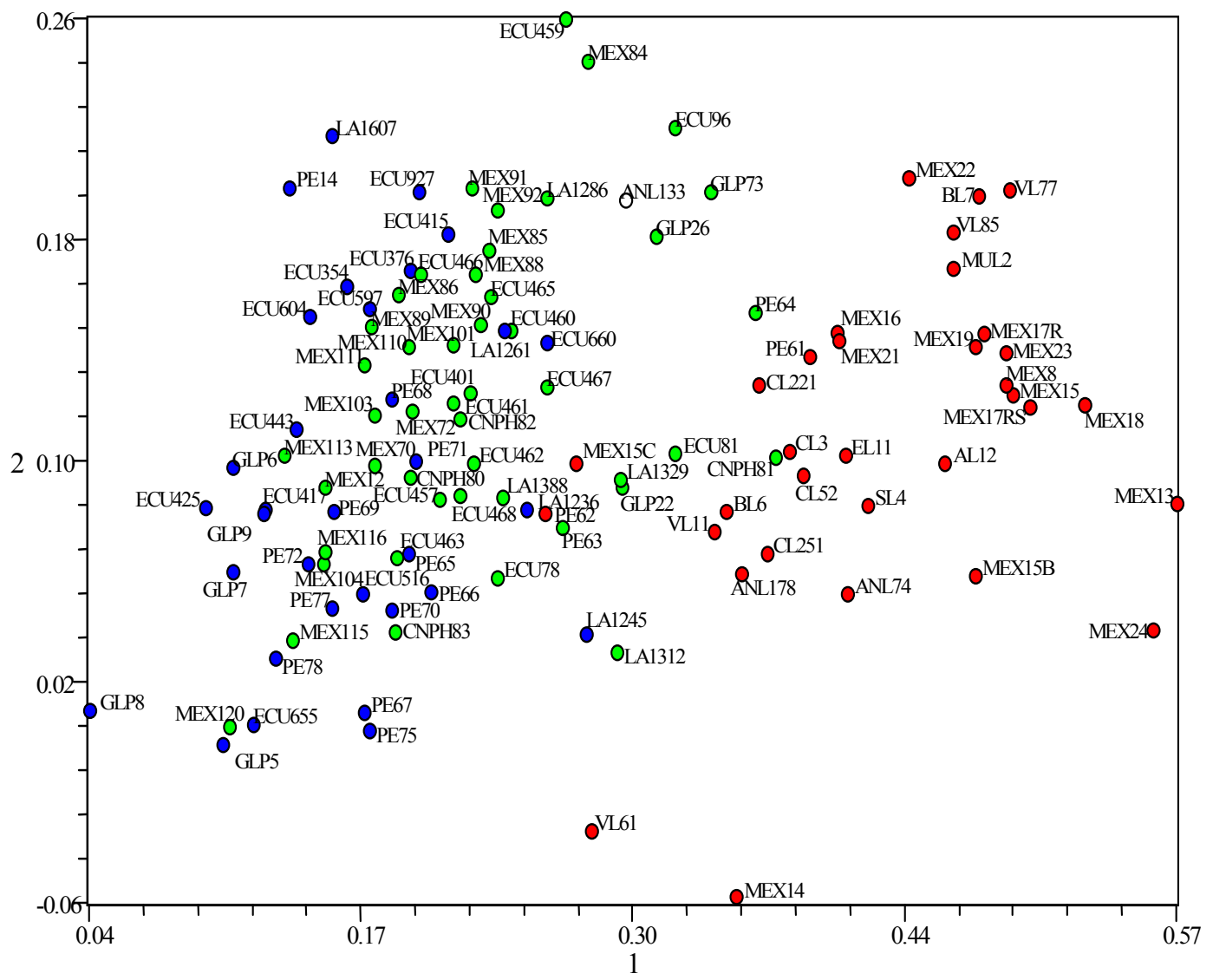

Figura 4.2. Representación de las entradas en función de las componentes principales 1 y 2, para el ensayo 2000-01. En azul se representan las entradas de L. pimpinellifolium, en verde las de L. esculentum var. cerasiforme y en rojo las de L. esculentum. 


\begin{tabular}{|c|c|c|c|c|c|c|}
\hline \multirow{2}{*}{ Entrada } & \multicolumn{3}{|c|}{ Procedencia } & \multirow{2}{*}{ Latitud } & \multirow{2}{*}{ Longitud } & \multirow{2}{*}{$\begin{array}{l}\text { Altitud } \\
\text { (m) }\end{array}$} \\
\hline & Ubicación & Provincia & País & & & \\
\hline \multicolumn{7}{|c|}{ L. pimpinellifolium / L. esculentum var cerasiforme } \\
\hline ECU376 & Parroquia El Rosario & Loja & Ecuador & $034749 \mathrm{~S}$ & 0793679W & 850 \\
\hline ECU415 & Quebradada Sto Tomás. & El Oro & Ecuador & 032009S & $0794182 \mathrm{~W}$ & 150 \\
\hline ECU516 & carretera Olmos-Jaen & Lambayeque & Perú & $055942 \mathrm{~S}$ & 0794303W & 230 \\
\hline GLP5 & Puerto Ayora. & Galápagos & Ecuador & $004318 \mathrm{~S}$ & $0901935 \mathrm{~W}$ & 100 \\
\hline GLP6 & Puerto Ayora. & Galápagos & Ecuador & $004315 \mathrm{~S}$ & $0901937 \mathrm{~W}$ & 100 \\
\hline GLP7 & Puerto Ayora. & Galápagos & Ecuador & $004141 \mathrm{~S}$ & 0901926W & 200 \\
\hline GLP9 & Puerto Ayora. & Galápagos & Ecuador & $004131 \mathrm{~S}$ & $0902024 \mathrm{~W}$ & 200 \\
\hline LA1236 & Tinelandia, Sto Domingo & Pichincha & Ecuador & $0007--\mathrm{N}$ & $07848--W$ & 900 \\
\hline LA1245 & $2 \mathrm{~km}$ oeste de Santa Rosa & El Oro & Ecuador & 0327--S & 07957--W & 100 \\
\hline LA1261 & Babahoyo & Los Ríos & Ecuador & 0147--S & 07931--W & 10 \\
\hline PE65 & Umashbamba, Urubamba & Cuzco & Perú & $1304--\mathrm{S}$ & $07227--W$ & 1700 \\
\hline PE66 & Chilca Ccasa & Cuzco & Perú & $1336--\mathrm{S}$ & 07219--W & 1900 \\
\hline PE67 & Pacchac-chico(Urumbaca) & Cuzco & Perú & $1318--S$ & 07207--W & 1000 \\
\hline PE68 & Pacchac-chico(Urumbaca) & Cuzco & Perú & $1318--S$ & 07207--W & 1000 \\
\hline PE69 & Tornillochayoc(Urubamba) & Cuzco & Perú & $1318--S$ & 07207--W & 1000 \\
\hline PE70 & Tornillochayoc(Urubamba) & Cuzco & Perú & $1318--\mathrm{S}$ & 07207--W & 1000 \\
\hline PE71 & Calzada(Urubamba) & Cuzco & Perú & $1318--S$ & $07207--W$ & 900 \\
\hline PE72 & Chontachayoc(Urubamba) & Cuzco & Perú & $1318--S$ & 07207--W & 950 \\
\hline PE75 & Huayopata(Urubamba) & Cuzco & Perú & $1318--S$ & 07207--W & 1400 \\
\hline PE77 & Sicre(Urubamba) & Cuzco & Perú & $1318--S$ & $07207--W$ & 1650 \\
\hline PE78 & Huayopata(Urubamba) & Cuzco & Perú & $1318--\mathrm{S}$ & 07207--W & 1650 \\
\hline \multicolumn{7}{|c|}{ L. esculentum /L. esculentum var cerasiforme } \\
\hline CNPH80 & - & - & Brasil & - & - & - \\
\hline CNPH81 & - & - & Brasil & - & - & - \\
\hline ECU81 & Timbara & Zamora & Ecuador & $0401--\mathrm{S}$ & $07833--W$ & 975 \\
\hline ECU96 & Yantzara & Loja & Ecuador & - & - & - \\
\hline ECU457 & Namirez & Zamora & Ecuador & 0404--S & 07857--W & - \\
\hline GLP22 & Santa Cruz & Galápagos & Ecuador & $004006 \mathrm{~S}$ & $0901618 \mathrm{~W}$ & 400 \\
\hline GLP26 & Santa Cruz & Galápagos & Ecuador & $003140 \mathrm{~S}$ & $0901921 \mathrm{~W}$ & 360 \\
\hline GLP73 & Puerto Ayora.Santa Cruz & Galápagos & Ecuador & $0045--\mathrm{S}$ & 09010--W & - \\
\hline LA1329 & Yaca (Yacahuailla) & Apurimac & Perú & $1417--S$ & $07212--W$ & 2100 \\
\hline LA1388 & San Ramón & Junín & Perú & $1107--\mathrm{N}$ & 07519--W & 700 \\
\hline LA1312 & Paisanato & Cuzco & Perú & - & - & 600 \\
\hline MEX-8 & Xcanatán & Yucatán & México & $21----N$ & 08930--W & $<100$ \\
\hline PE61 & Naranjillo(Huallaga) & Huanuco & Perú & 0913--S & 07559--W & 630 \\
\hline PE62 & $\begin{array}{c}\text { Santa Lucía } \\
\text { Tulumaio(Huallaga) } \\
\end{array}$ & Huanuco & Perú & 0913--S & 07559--W & 630 \\
\hline PE63 & Molinopata(Pachachaca) & Apurimac & Perú & $1556--\mathrm{S}$ & 07137--W & 2400 \\
\hline PE64 & Bellavista(Pachachaca) & Apurimac & Perú & $1556--S$ & 07137--W & 2300 \\
\hline
\end{tabular}

Tabla 4.2 Procedencia de las formas intermedias entre las especies del subgénero Eulycopersicon.

Ejemplos de lo anteriormente comentado son las entradas de la Tabla 4.2. En ambos casos, el tamaño de los frutos y ciertos caracteres vegetativos son los que causan esta desviación. Estudiaremos este hecho con detalle cuando consideremos los análisis para cada una de las especies. 
Respecto a la segunda componente se observa una gran dispersión de las entradas de L. pimpinellifolium. Eso es debido a la gran variación existente en el número de flores por inflorescencia, carácter correlacionado con la segunda componente principal.

Observando la representación de las entradas en el análisis de componentes principales, se aprecia el desplazamiento de las entradas VL61 y MEX14 hacia la parte inferior, muy separada del resto de las entradas de L. esculentum. Estas entradas son de crecimiento determinado y semideterminado respectivamente, lo que lleva asociado una menor altura de la planta hasta la tercera inflorescencia, menor número de hojas bajo la primera inflorescencia y menor tamaño de las hojas. Estos caracteres están altamente correlacionados con la segunda componente principal lo que provocaría el desplazamiento anteriormente comentado (Figura 4.2).

La existencia de un continuo en el conjunto de entradas estudiadas podría explicarse asumiendo que el proceso completo de especiación simpátrica a partir de un ancestro común no habría finalizado en el momento actual, existiendo formas extremas que han sido consideradas especies distintas (L. pimpinellifolium y L. esculentum). Además, la conservación de estas formas intermedias se vería favorecida por la existencia de cruzabilidad entre todas las especies incluidas en el subgénero Eulycopersicon (Stevens y Rick, 1986), así como por la coexistencia en los mismos hábitats y la evidencia de ciertos porcentajes de alogamia en el tomate en su zona de origen (Rick, 1958). Todo ello habría posibilitado la existencia de cruzamientos entre ellas, favoreciendo la permanencia de formas que no se adaptan estrictamente a los caracteres definidos para cada especie.

\section{Correlaciones entre caracteres.}

La caracterización morfológica se realizó determinando una gran cantidad de caracteres cuantitativos y cualitativos, desconociendo las posibles correlaciones entre los cuantitativos. La existencia de tales correlaciones podría originar grupos de caracteres altamente correlacionados, los cuales a su vez podrían influir sobre las correlaciones entre caracteres incluidos en estos grupos y otros independientes. Una forma de determinar las relaciones entre los caracteres evaluados es la realización de un análisis cluster $\mathrm{R}$ que permita visualizar las agrupaciones entre ellos. El dendrograma efectuado con la totalidad de los caracteres evaluados ha permitido establecer dos grupos, uno de ellos formado por los caracteres vegetativos y el otro por los caracteres 
de flor y fruto (Figura 4.3). Estas agrupaciones se corresponden con las establecidas en la Figura 4.1.

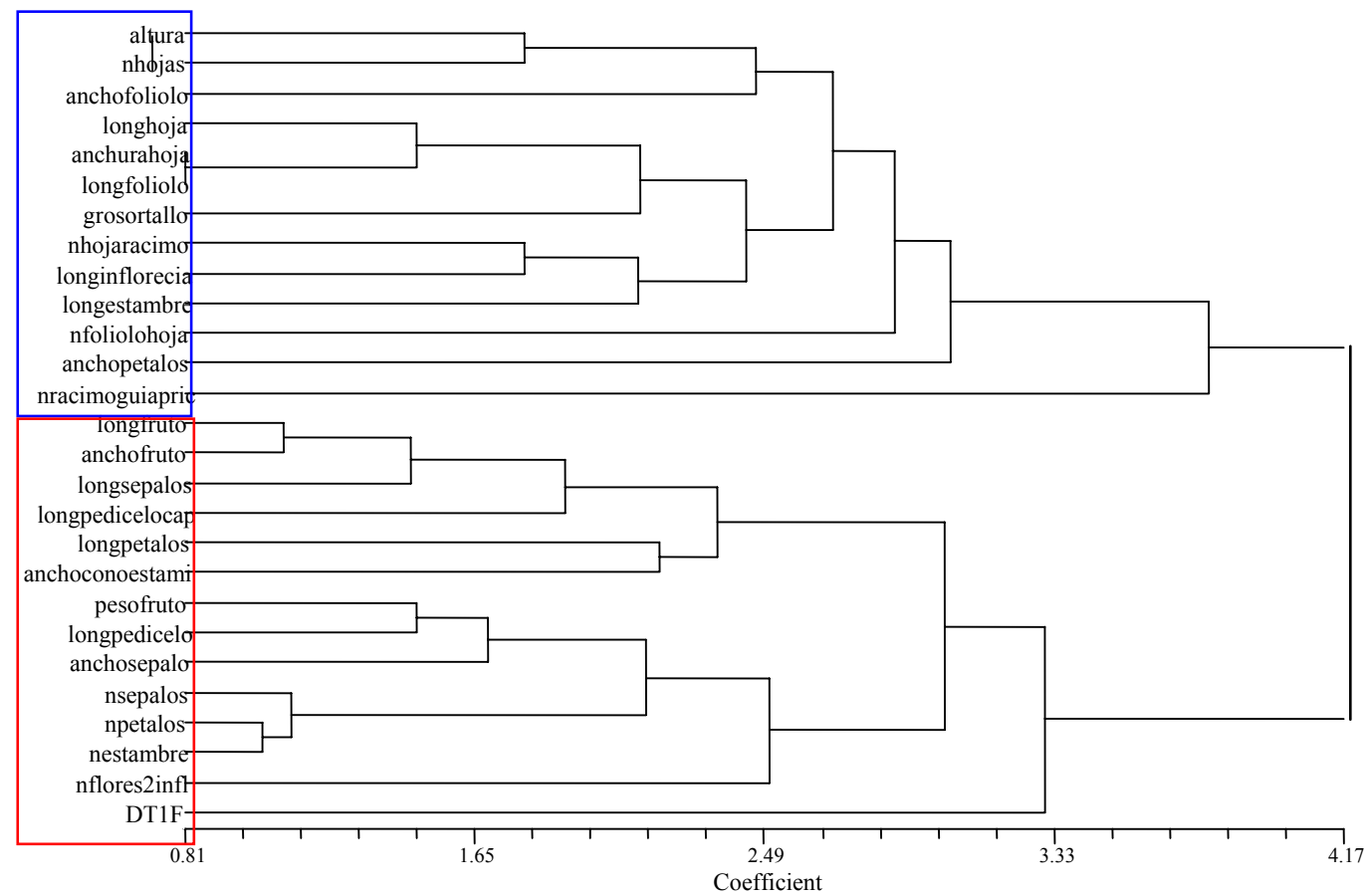

Figura 4.3. Agrupación de los caracteres según el análisis cluster $\mathrm{R}$ efectuado con el conjunto de entradas del ensayo 2000-01, utilizando las distancias euclídeas y el método de agrupamiento UPGMA.

Alternativamente pueden establecerse grupos de caracteres altamente correlacionados a partir de la matriz de correlaciones del análisis ACP. De esta forma, se ha realizado el grafico de la (Figura 4.4), en el que los dos grandes grupos del cluster se han subdivididos en otros de caracteres más estrechamente correlacionados. Así, destacan dos grupos formados por caracteres florales (grupos I y II), otro que incluye los caracteres relativos al fruto (grupo III) y otros dos relacionados con caracteres vegetativos (grupos IV y V), mientras que los otros siete caracteres aparecen incorrelacionados entre sí. El valor de las correlaciones parciales obtenidas entre los caracteres estudiados corroboró la existencia de la elevada asociación entre los caracteres incluidos en cada grupo (Tabla 4.3). 


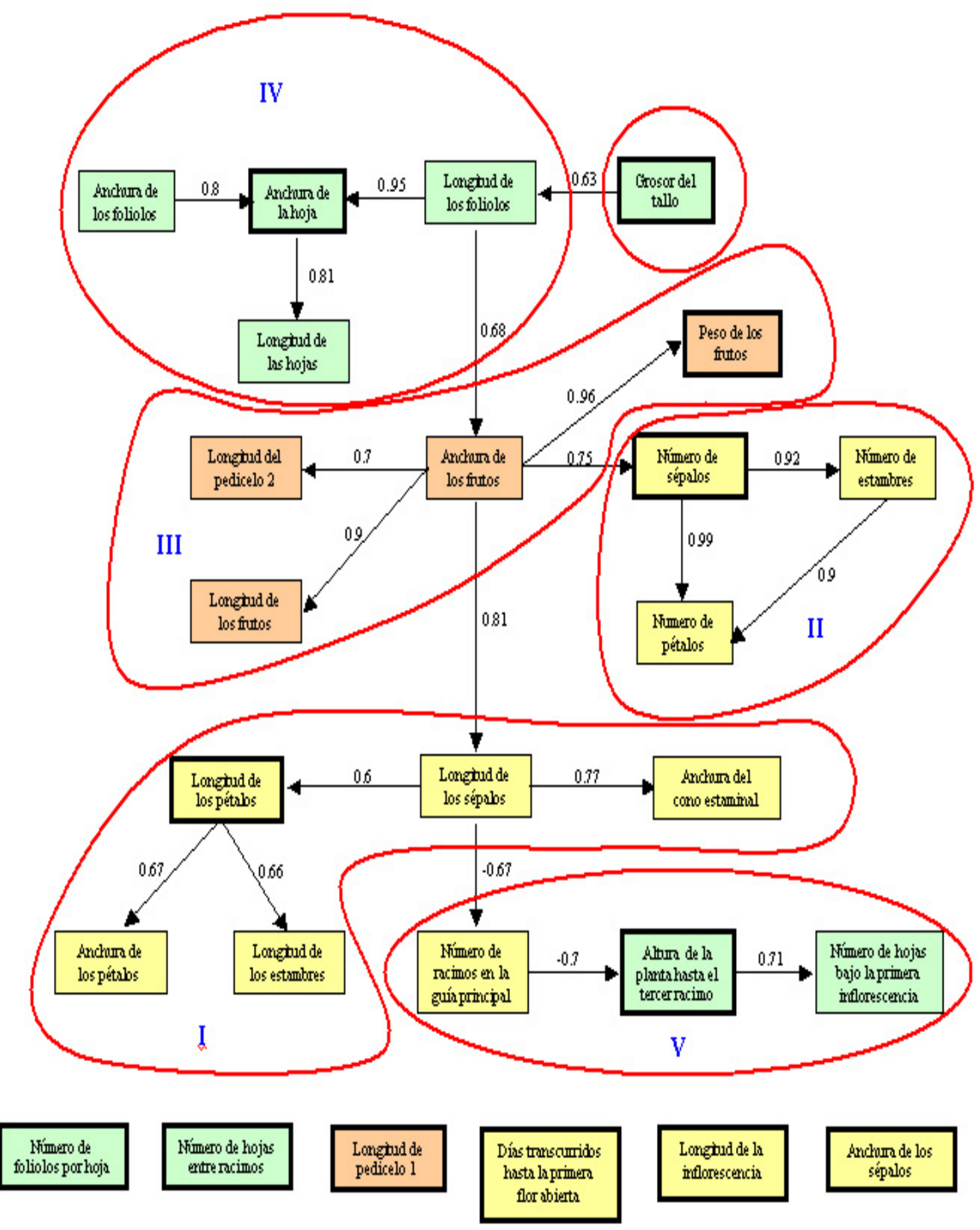

Figura 4.4. Grupos de caracteres establecidos según las correlaciones entre ellos. Los caracteres seleccionados aparecen enmarcados en negrita. Los números situados junto a cada flecha indican los valores de las correlaciones. 


\begin{tabular}{|c|c|c|c|c|c|c|}
\hline Caracteres & 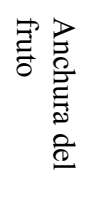 & 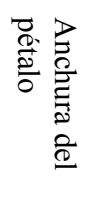 & 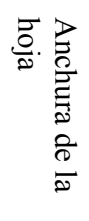 & 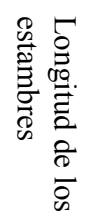 & 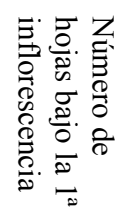 & 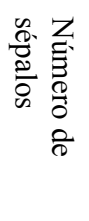 \\
\hline $\begin{array}{l}\text { Longitud del } \\
\text { fruto }\end{array}$ & 0.6 & & & & & \\
\hline Peso del fruto & 0.77 & & & & & \\
\hline $\begin{array}{c}\text { Longitud del } \\
\text { pétalo }\end{array}$ & & 0.67 & & 0.55 & & \\
\hline $\begin{array}{l}\text { Longitud del } \\
\text { foliolo }\end{array}$ & & & 0.73 & & & \\
\hline $\begin{array}{l}\text { Altura de la } \\
\text { planta hasta el } \\
\text { tercer racimo }\end{array}$ & & & & & 0.45 & \\
\hline $\begin{array}{l}\text { Número de } \\
\text { pétalos }\end{array}$ & & & & & & 0.42 \\
\hline
\end{tabular}

Tabla 4.3. Correlaciones parciales entre caracteres cuantitativos evaluados en el ensayo 2000-01.

El hecho de hacer intervenir todos los caracteres en los análisis anteriores podría estar dando mayor peso a los grupos de caracteres estrechamente correlacionados que hemos identificado, repercutiendo sobre las agrupaciones finales de las entradas estudiadas.

Para contrastar esta hipótesis se realizó un nuevo análisis tomando los 7 caracteres no correlacionados y un solo representante de cada uno de los grupos establecidos (enmarcados en negrita en la Figura 4.4).

En este análisis la primera componente principal explicó un 53\% de la variación, un $13 \%$ la segunda y un $10 \%$ la tercera, acumulando entre las tres un $77 \%$ del total. 


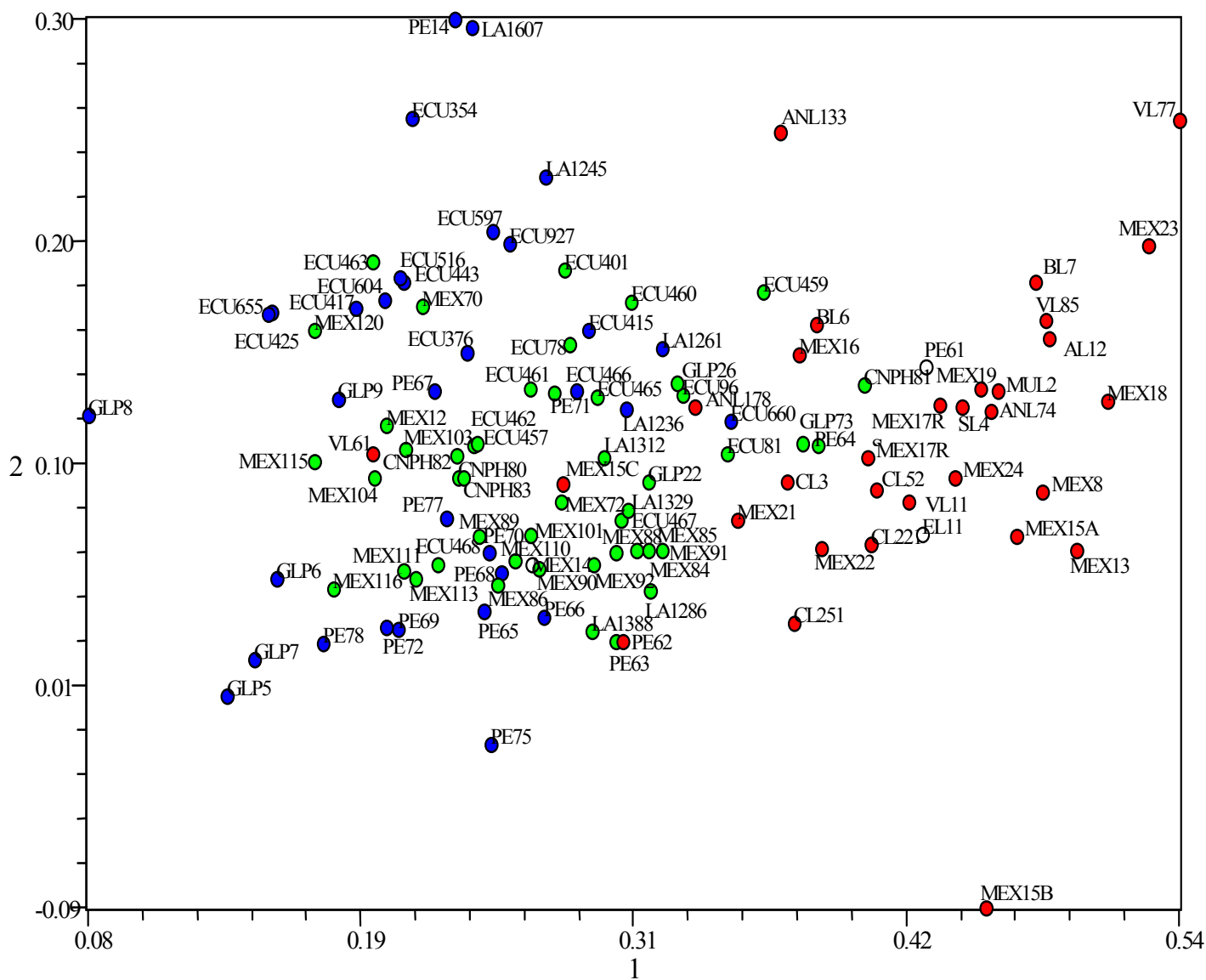

Figura 4.5. Representación de las entradas frente a las componentes principales 1 y 2 en el análisis realizado con los caracteres seleccionados. Las entradas de color rojo son las que pertenecen a la especie Lycopersicon esculentum, las verdes a Lycopersicon esculentum var. cerasiforme y las azules a Lycopersicon pimpinellifolium.

En la representación según la primera y segunda componentes se observa que el conjunto de entradas se sitúan más cercanas al centro del gráfico, lo que estaría sugiriendo una mayor similitud entre todas ellas. Esto sería consecuencia de dar menor peso en el análisis a caracteres altamente discriminantes entre especies, como los relacionados con el peso y tamaño del fruto, estructuras florales o ciertos caracteres vegetativos. La distribución relativa de las entradas permanece, sin embargo, bastante constante. Así, las entradas MEX 13 y MEX 18 ocupan posiciones extremas en ambas representaciones. Es de destacar, sin embargo, el caso de las entradas MEX 14 y VL61, que en la representación sobre las dos primeras componentes principales en el análisis efectuado con todas las entradas, se situaban en el borde inferior de la figura. Como se comentó anteriormente estas entradas son de crecimiento determinado y semideterminado respectivamente, provocando una menor altura de la planta hasta el tercer racimo, número de hojas bajo la primera inflorescencia y otros caracteres vegetativos de las hojas. Precisamente entre estos caracteres se han detectado elevadas 
correlaciones (grupos IV y V, Figura 4.4). Al disminuir el peso de estos caracteres en el análisis efectuado, eligiendo solo un representante de cada grupo, la localización de las entradas se corrige, agrupándose mucho más cercanas a las de su especie (Figura 4.4). En casos como éstos, el hecho de eliminar caracteres altamente correlacionados tendría una repercusión clara en las conclusiones obtenidas.

En términos generales, las escasas variaciones obtenidas en la representación de las entradas con ambos análisis, tiene una consecuencia práctica de interés: para realizar un análisis filogenético en un conjunto de entradas de las especies incluidas en este trabajo, no es necesario realizar una caracterización tan exhaustiva como la que se ha llevado a cabo, sino que bastaría con tomar los caracteres seleccionados, evitando la determinación de otros altamente correlacionados que aportan escasa información complementaria.

\section{Análisis Cluster: Análisis Q}

El análisis cluster efectuado (Figura 4.6) separa dos grupos muy diferenciados, uno compuesto por las entradas de L. esculentum y el otro por las de L. esculentum var. cerasiforme y L. pimpinellifolium a unas distancias de 1,43 y 1,46 respectivamente. En este último grupo las entradas de L. esculentum var. cerasiforme se sitúan más cercanas de las de L. esculentum, mientras que las de L. pimpinellifolium quedan más alejadas. Sin embargo esta separación no es total, quedando la mayor parte de entradas de cerasiforme procedentes de Ecuador mezcladas con las de L. pimpinellifolium. 


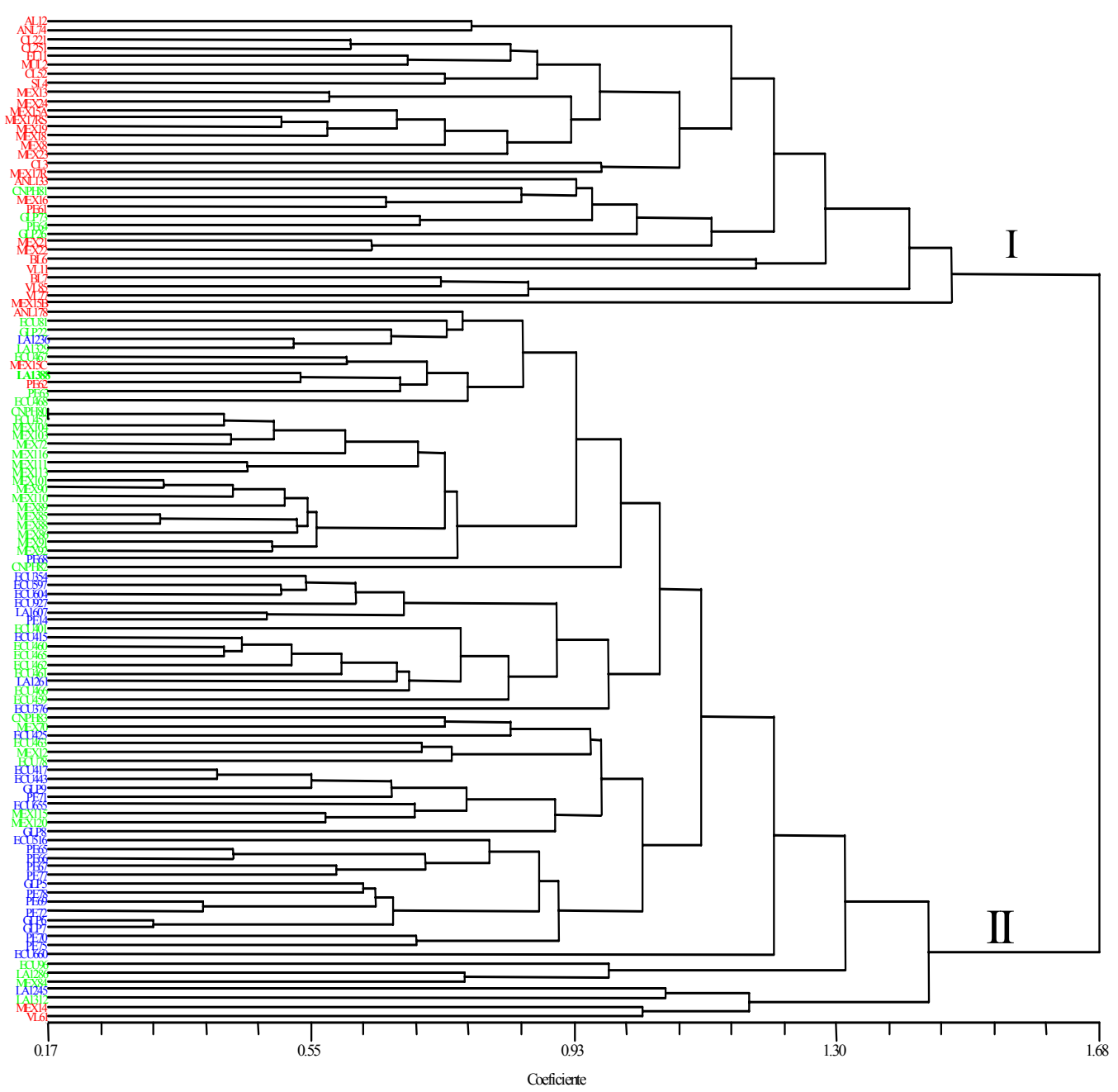

Figura 4.6. Representación de las entradas en el dendrograma realizado con todos los caracteres del ensayo 2000-01, utilizando las distancias euclídeas y el método de agrupamiento UPGMA. Las entradas de color rojo pertenecen a la especie Lycopersicon esculentum, las verdes a Lycopersicon esculentum var. cerasiforme y las azules a Lycopersicon pimpinellifolium. 
En esta representación, se aprecia que las entradas VL61 y MEX14, se separan del resto de las entradas pertenecientes a la especie L. esculentum, como ya habíamos observado en la representación de la componentes principales (Figura 4.1).

En el dendrograma de la Figura 4.7, se observa la representación de las entradas con los caracteres seleccionados. Comparando las Figuras 4.6 y 4.7, se observa que en esta última se pueden establecer un mayor número de grupos, muchos de ellos formados por una o muy pocas entradas y siempre de L. esculentum. Precisamente, esta especie es la que presenta mayor variabilidad, tanto para caracteres vegetativos (Figura 4.20, Apartado 4.1.2.3) como de flor y fruto. Así, dos entradas pueden ser similares para un carácter, por ejemplo longitud de la hoja mientras que pueden no serlo para otros altamente correlacionados. Concluimos que, en estos casos, es corriente considerar un mayor número de caracteres para su caracterización, mientras que en el caso de otras especies con menor variabilidad, un menor número de caracteres sería suficiente para tener una buena caracterización de las mismas. 


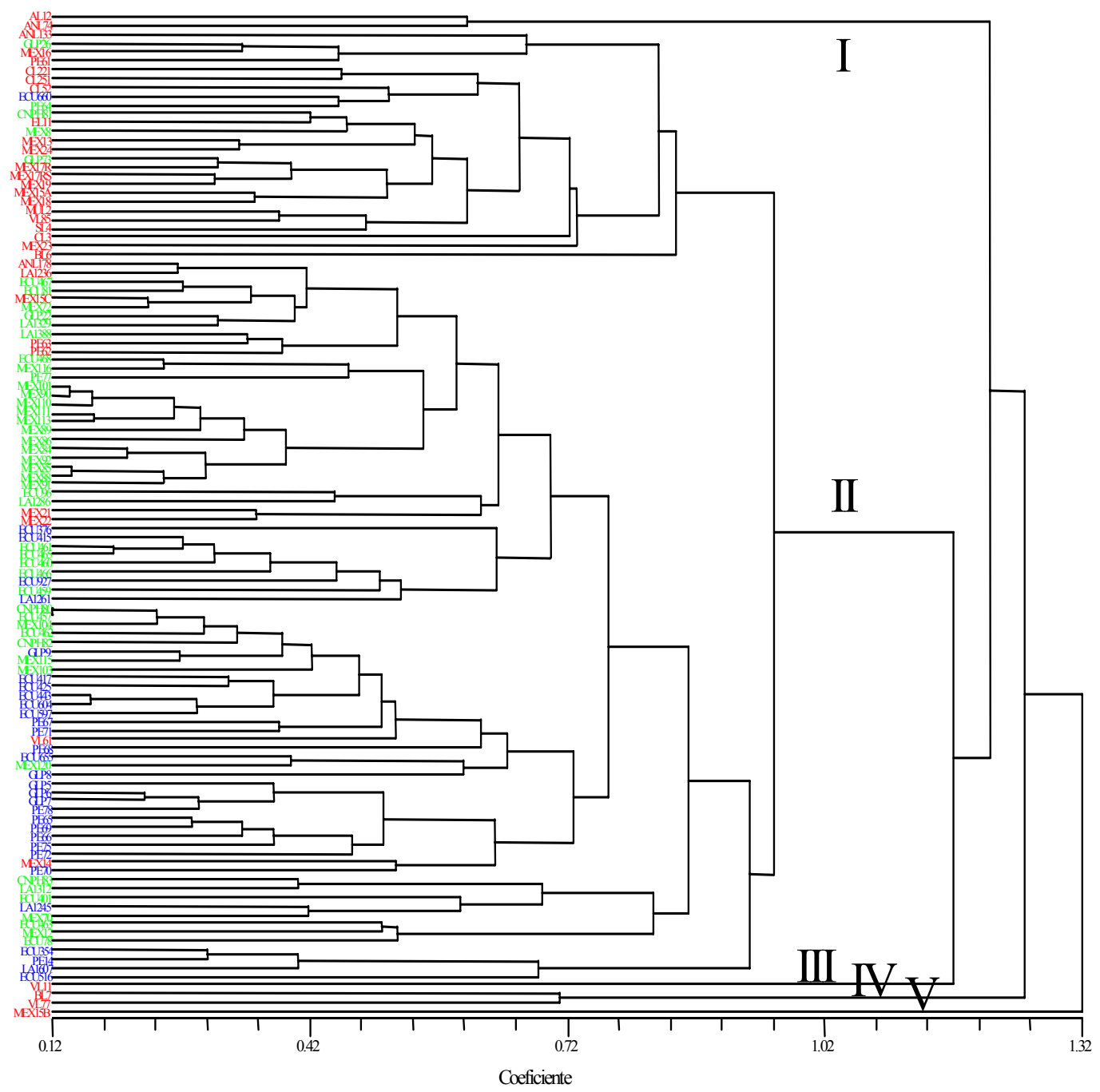

Figura 4.7. Representación de las entradas del ensayo 2000-01. Dendrograma realizado con los caracteres seleccionados a partir de la Figura 4.4, utilizando distancias euclídeas y el método de agrupamiento UPGMA. Las entradas de color rojo pertenecen a la especie Lycopersicon esculentum, las verdes a Lycopersicon esculentum var. cerasiforme y las azules a Lycopersicon pimpinellifolium. 


\section{Variabilidad entre y dentro de especie}

\section{Caracteres vegetativos}

En general los caracteres cualitativos estudiados presentaron una elevada variabilidad entre las entradas en cada una de las especies estudiadas. Es el caso de la densidad del follaje, la posición de la hoja, la presencia de estípulas y el color antociánico de las nerviaduras. Las distintas opciones para cada carácter estuvieron presentes en las tres especies. Para otros caracteres, determinadas opciones aparecieron sólo en una especie, siendo éstos de utilidad para diferenciarlas.

Los caracteres que se comentan a continuación fueron mucho más frecuentes en alguna de las especies, pero aparecieron también en algunas entradas de las otras estudiadas. Así la densidad y longitud de la pubescencia del tallo fue escasa y corta el $L$. pimpinellifolium, presentando unas características intermedias en L. esculentum y $L$. esculentum var. cerasiforme. Ello es debido a la presencia del gen $H$, propio de $L$. pimpinellifolium, que determina la ausencia de tricomas largos (Rick y Butler, 1956). También el color verde claro de los foliolos fue mucho más frecuente en esta especie.

Las características exclusivas de una especie fueron las siguientes: color antociánico del tallo, tipo de hoja "pimpinellifolium" y borde entero de los foliolos, presentes sólo en L. pimpinellifolium, pero no en todas las entradas. De hecho, algunas de ellas presentaron hojas tipo estándar con bordes algo aserrados u ondulados. Estas entradas fueron aquellas catalogadas como intermedias (Tabla 4.2) y han sido ya comentadas en el análisis conjunto de todas las entradas.

Por último una característica que sólo estuvo presente en L. esculentum fue el tipo de crecimiento determinado. 

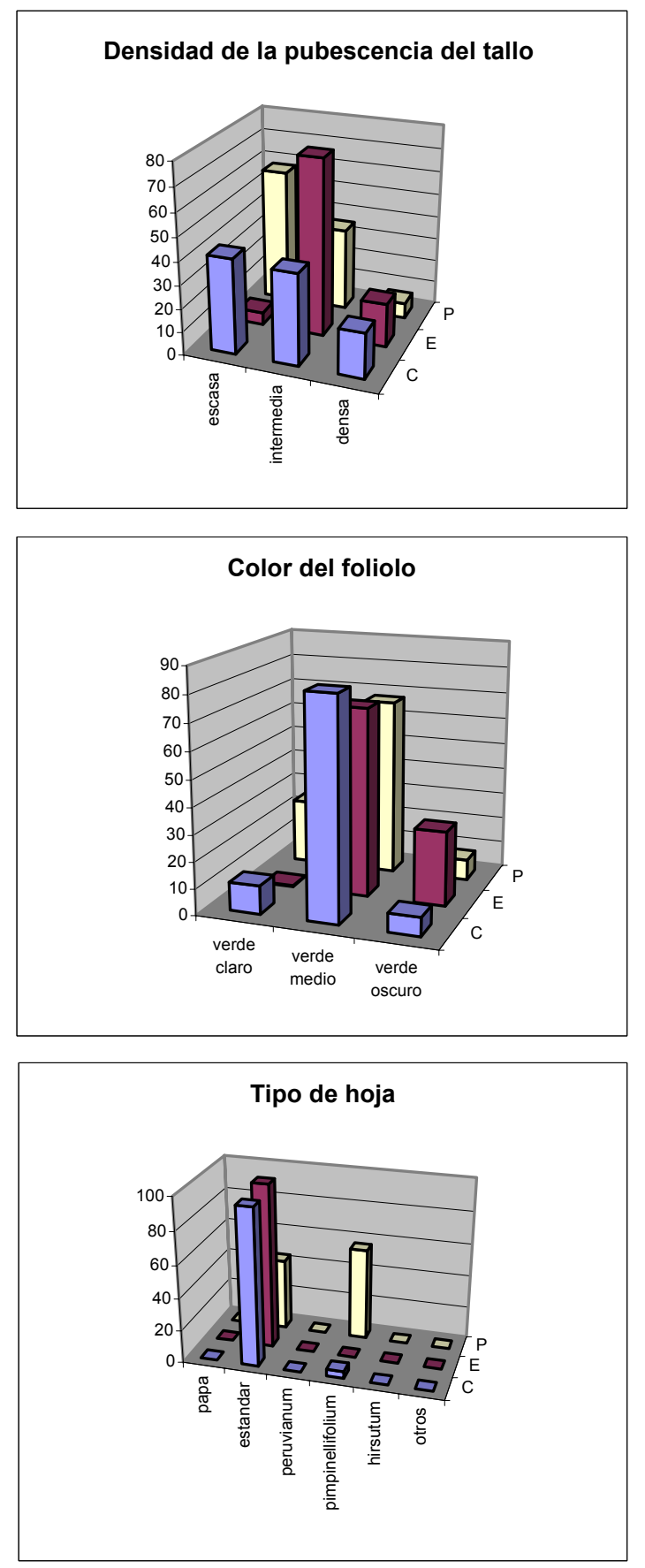
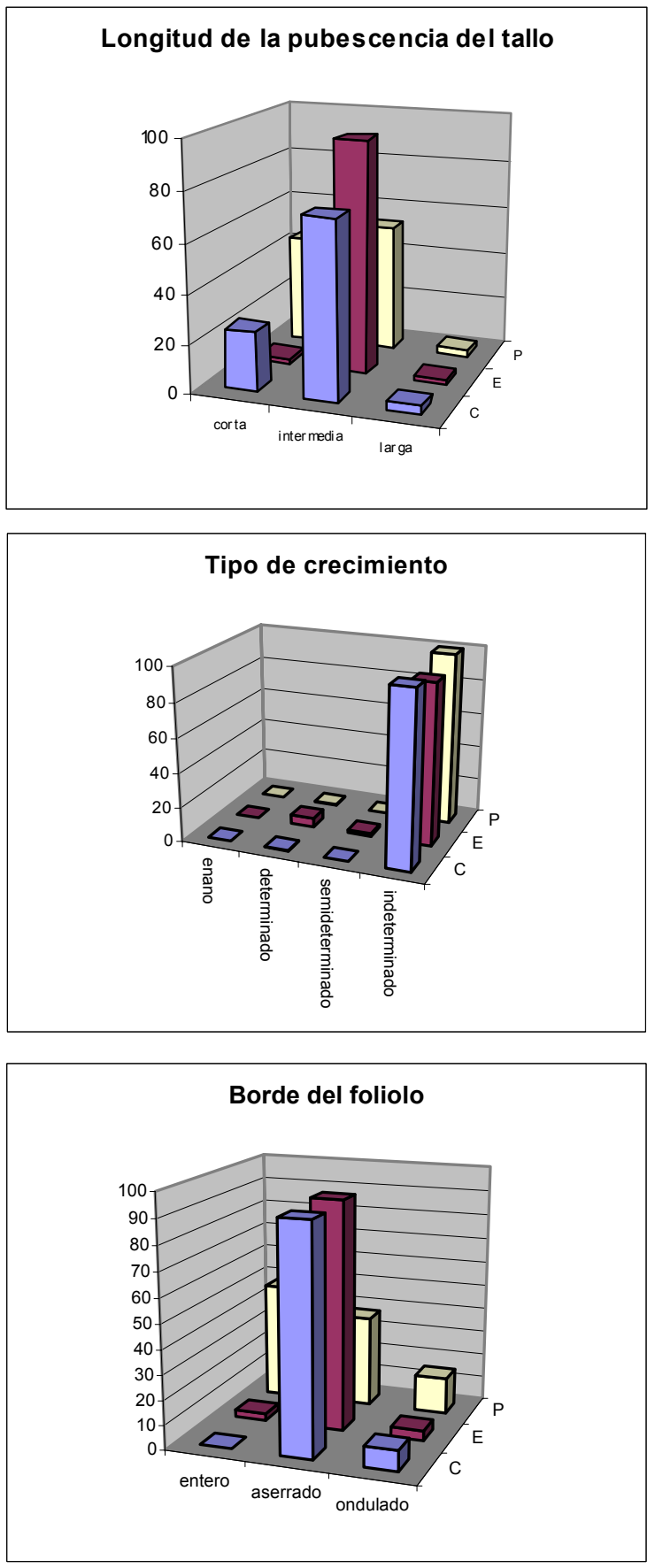

Figura 4.8. Histogramas de frecuencia de los caracteres cualitativos vegetativos para el ensayo 2000-01. C: L. esculentum var. cerasiforme, E: L. esculentum y P: $L$. pimpinellifolium.

\section{Caracteres de flor e inflorescencia}

No se encontraron diferencias para la presencia de brácteas y pétalos soldados entre las especies consideradas. Sin embargo, la posición del estilo si que permitió distinguir a la especie L. pimpinellifolium de las demás. Las entradas de L. pimpinellifolium generalmente presentaron estilo ligeramente proyectado o muy proyectado, dada la 
alogamia de esta especie. La mayor parte de las entradas de L. esculentum tuvieron el estilo inserto (especie típicamente autógama), mientras que L. esculentum var. cerasiforme presentó entradas con diferencias notables en la proyección del estilo, como corresponde a la existencia de poblaciones citadas en las que el porcentaje de polinización cruzada o autogamia es muy diferente.

La presencia de inflorescencias multíparas y sépalos soldados fueron características de L. esculentum, apareciendo en muy pocas entradas de L. pimpinellifolium o de la var. cerasiforme.

El carácter inflorescencia acabada en hoja, aunque se observó en las tres especies, fue más abundante en L. pimpinellifolium.
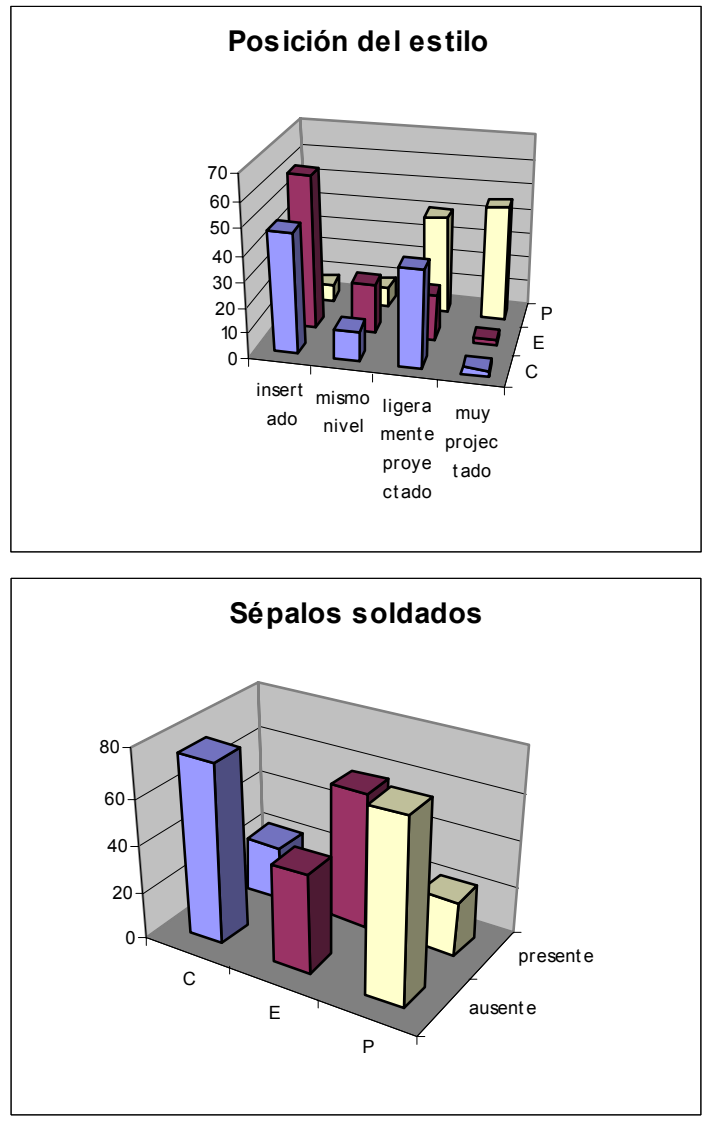
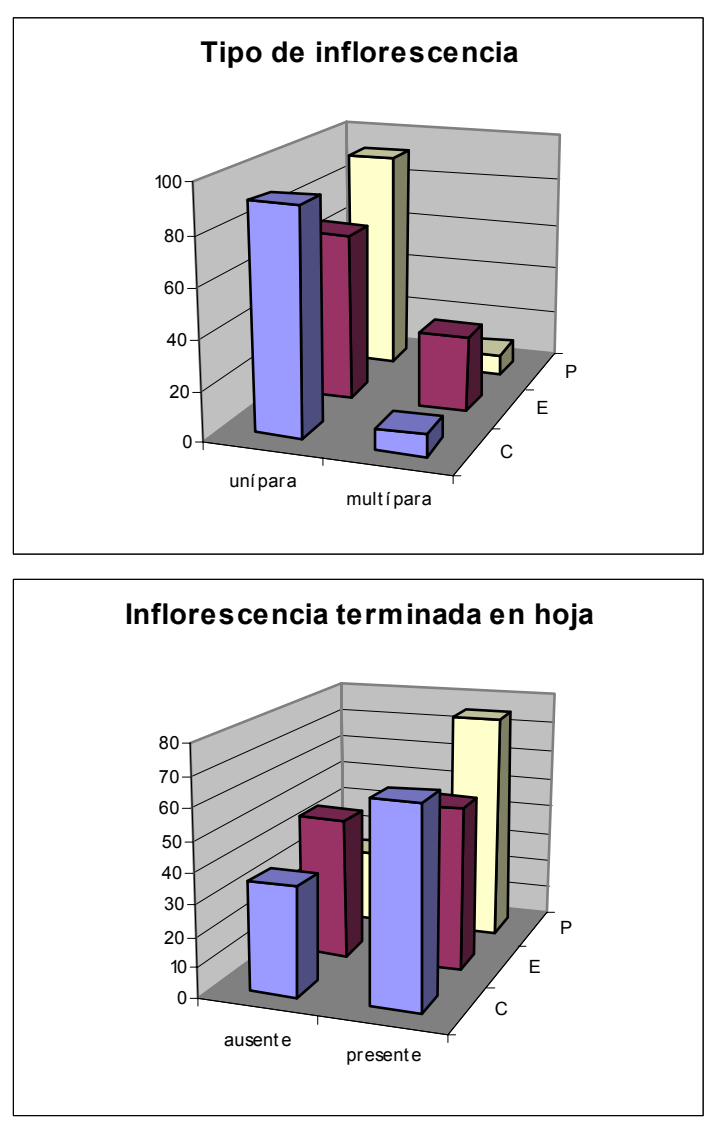

Figura 4.9. Histogramas de frecuencia de los caracteres cualitativos de flor e inflorescencia del ensayo 2000-01. C: L. esculentum var. cerasiforme, E: L. esculentum y $\mathrm{P}:$ L. pimpinellifolium.

\section{Caracteres de fruto}

La forma del fruto, siempre redondeada y muy uniforme, permitió diferenciar a $L$. pimpinellifolium del resto de las especies. En la homogeneidad de la forma se refleja la 
condición silvestre de esta especie, en la que la característica asociada a la domesticación, como la elevada variabilidad para formas del fruto, no es evidente.

El resto de los caracteres, por el contrario, separó claramente a L. esculentum, siendo similares en L. pimpinellifolium y en la var. cerasiforme. L. esculetum presentó mayor variación tanto en el color del fruto maduro como en el de la carne del pericarpio (frutos rosados o anaranjados en algunas entradas). También se encontraron entradas con la piel del fruto maduro incolora (en los frutos rosados).

La forma del corte transversal del fruto, de la cicatriz del pistilo y del terminal de la floración son muy variables en la especie cultivada, como corresponde a la diversidad de formas existente. El acostillado del fruto, que debería estar ausente en los frutos de $L$. pimpinellifolium y en la var. cerasiforme, aparecen, sin embargo, en algunas entradas, aquellas que fueron consideradas como formas intermedias entre distintas especies, detectadas ya en los análisis de datos cuantitativos (Figura 4.10).
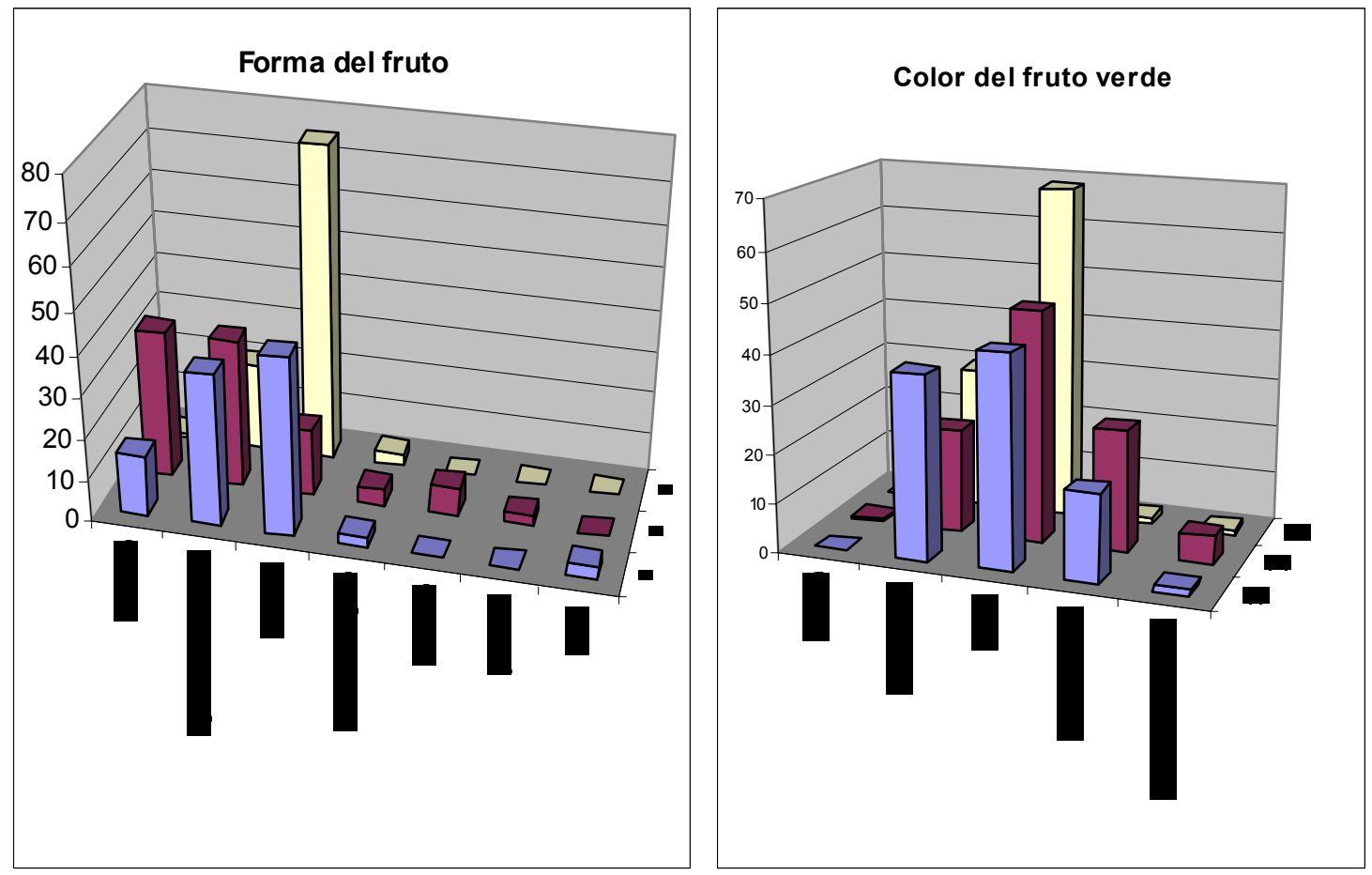

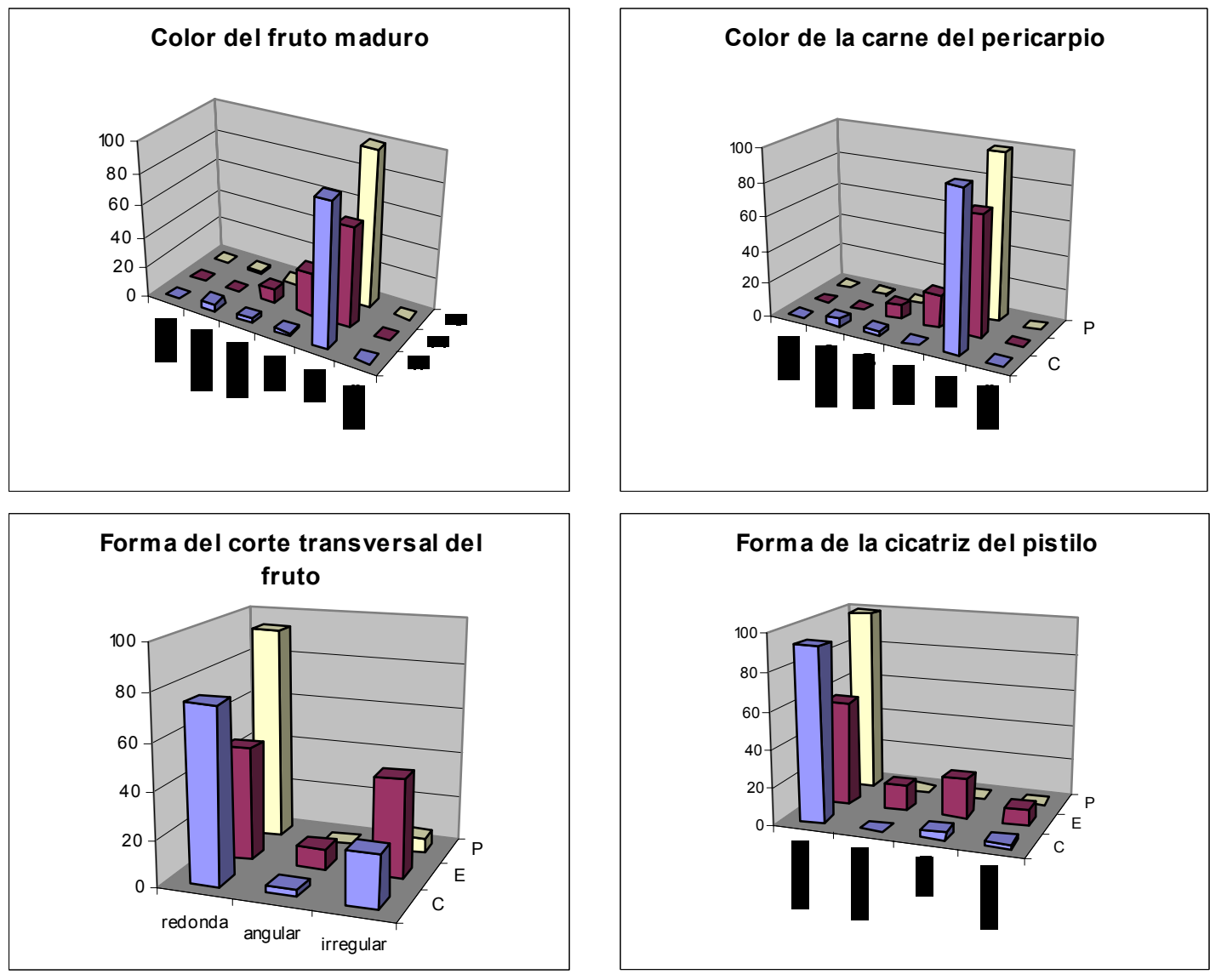

Forma del terminal de la floración del fruto
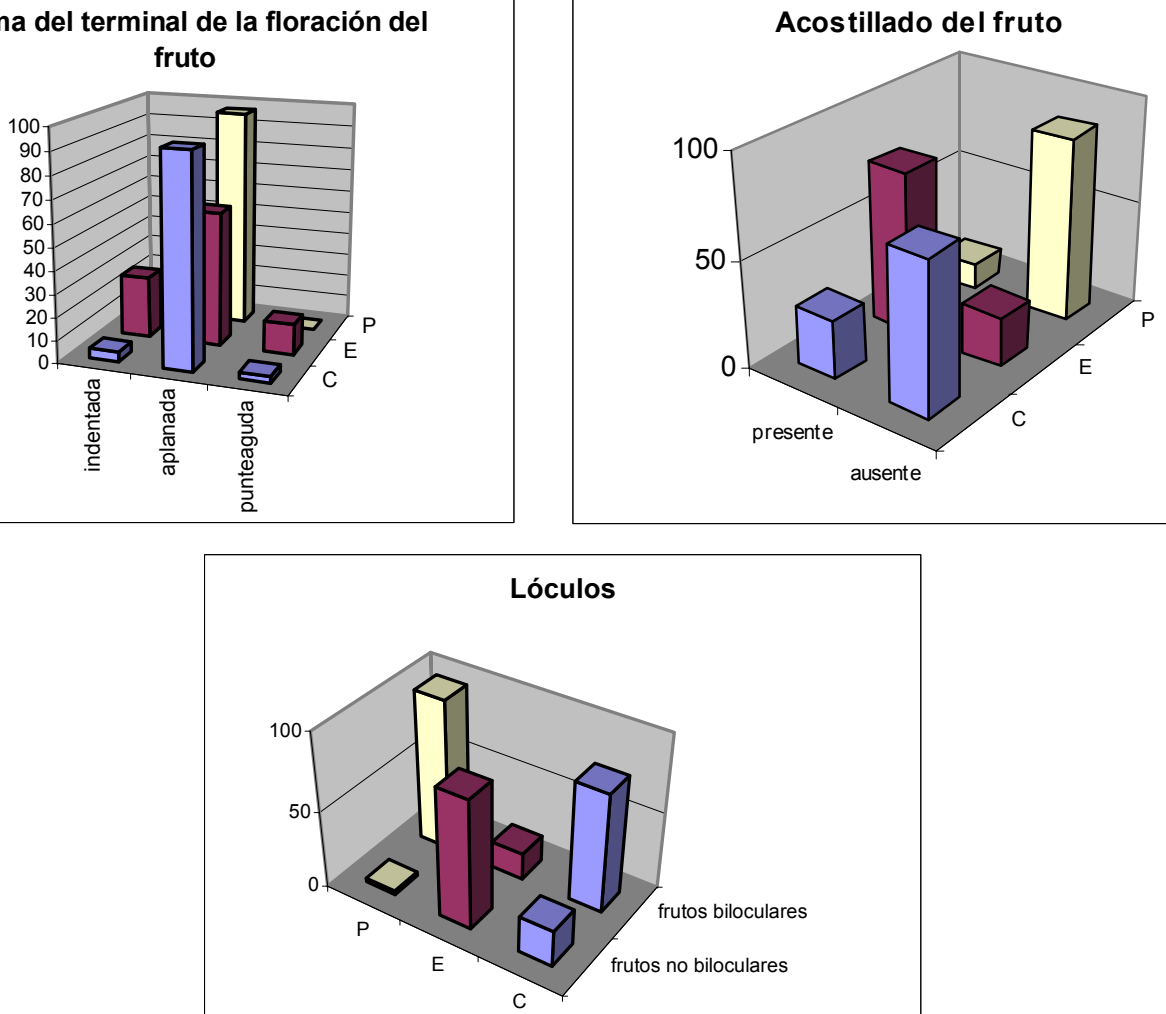

Figura 4.10. Histogramas de frecuencia de los caracteres cualitativos de fruto del ensayo 2000-01. C: L. esculentum var. cerasiforme, E: L. esculentum y P: L. pimpinellifolium. 


\section{Necesidad de revisión de los actuales descriptores de tomate.}

Según los resultados expuestos, hemos podido comprobar que no todos los caracteres propios de una especie determinada están incluidos en el actual descriptor para el tomate publicado por el IPGRI. Así, la presencia de antocianina en el tallo se considera sólo en estado de plántula, mientras que no aparece en la planta adulta. Lo mismo ocurre con la longitud de la pubescencia del tallo. En este caso sólo la densidad de la pubescencia aparece como un carácter a determinar. Sin embrago, la presencia de antocianina en el tallo es propia de L. pimpinellifolium y no aparecen en la otra especie incluida en nuestro ensayo. Esto mismo podría hacerse extensivo a las otras especies incluidas en el género Lycopersicon. De hecho, la ausencia de tricomas largos se da en otras especies como L. cheesmannii o L. chilense. El número de flores por inflorescencia, mucho mayor en L. pimpinellifolium, es otro ejemplo de esta situación. Lo mismo podría ocurrir con caracteres específicos de otras especies no incluidas en este trabajo. Sería pues necesario, a pesar de la reciente revisión realizada en los descriptores para tomate, plantear la inclusión de más caracteres capaces de distinguir entre las nueve especies incluidas en el género o realizar un nuevo descriptor específico para especies silvestres del género Lycopersicon.

El estudio realizado permite además determinar los caracteres más importantes e incorrelacionados entre si, para ser considerados en futuras caracterizaciones de entradas pertenecientes a estas especies, eliminando caracteres correlacionados que no aportan nueva información.

\section{Caracteres cuantitativos diferenciales entre especies.}

Con los caracteres cuantitativos medidos se efectuaron análisis de la varianza y posteriormente la prueba de Newman-Keuls para determinar cuáles de ellos diferían significativamente entre las especies estudiadas, siendo por tanto de valor taxonómico.

\section{Caracteres vegetativos.}

Gran parte de los caracteres vegetativos medidos permitieron diferenciar las tres especies entre si. Es el caso de las longitudes y anchuras de las hojas y foliolos y también del grosor del tallo. En todos los casos, los valores más bajos correspondieron a L. pimpinelifollium y los mayores a L. esculentum, ocupando la var. cerasiforme posiciones intermedias (Tabla 4.4). La altura de la planta hasta la tercera inflorescencia y el número de racimos de la guía principal, sólo diferenciaron a L. esculetum de las demás, mientras que el número de hojas entre racimos y la precocidad, medida como el 
número de días entre el transplante y la apertura de la primera flor, fueron constantes en las tres especies.

\section{Caracteres de flor e inflorescencia}

El número de flores de la segunda inflorescencia presentó diferencias entre la especie $L$. pimpinellifolium y $L$. esculentum, ya que una característica típica de $L$. pimpinellifolium es precisamente el poseer unas inflorescencias muy largas.

De los caracteres de flor, sólo la longitud de los sépalos y la anchura del cono estaminal separaron con claridad las tres especies, presentando L. pimpinellifolium siempre los valores más bajos. Sin embargo, para el resto de caracteres, la var. cerasiforme resultó más similar a L. pimpinellifolium, siendo característico únicamente del tomate cultivado la existencia de flores con más de cinco pétalos, sépalos y estambres, así como unos órganos florales de mayor tamaño.

\section{Caracteres de fruto}

Todos los caracteres de fruto medidos (longitud y anchura del fruto, longitud del pedicelo 1 y 2) permitieron diferenciar las tres especies a excepción del peso del fruto, que sólo fue significativamente diferente en L. esculentum. Este resultado es lógico, ya que precisamente el tamaño del fruto es una de las claves utilizadas para la clasificación de estas especies. Sin embargo, el hecho de que el peso del fruto no presente diferencias significativas entre L. pimpinellifolium y la variedad cerasiforme, cuestiona la validez de estos caracteres como discriminantes exclusivos entre especies siendo necesario establecer la clasificación sobre la observación conjunta de varios caracteres. 


\begin{tabular}{|c|c|c|c|c|c|c|}
\hline \multirow[t]{2}{*}{ Caracteres } & \multicolumn{2}{|c|}{ L. pimpinellifolium } & \multicolumn{2}{|c|}{$\begin{array}{l}\text { L. esculentum var. } \\
\text { cerasiforme }\end{array}$} & \multicolumn{2}{|c|}{ L.esculentum } \\
\hline & media & desviación & media & desviación & media & desviación \\
\hline Altura hasta el tercer racimo & $78,91 \mathrm{a}$ & 18 & $79,25 \mathrm{a}$ & 20,7 & $97,83 \mathrm{~b}$ & 20.8 \\
\hline $\begin{array}{l}\text { Numero de hojas bajo la primera } \\
\text { inflorescencia }\end{array}$ & $9,8 \mathrm{a}$ & 2,57 & $10,13 \mathrm{a}$ & 2,82 & $11,38 \mathrm{~b}$ & 2,27 \\
\hline Longitud de la hoja & $36,6 \mathrm{a}$ & 7,34 & $41,66 \mathrm{~b}$ & 9,08 & $44,88 \mathrm{c}$ & 9,83 \\
\hline Anchura de la hoja & $30,94 a$ & 7,47 & $35 \mathrm{~b}$ & 8,89 & $40,32 \mathrm{c}$ & 9 \\
\hline Longitud del foliolo & $15,94 a$ & 4,07 & $18,09 \mathrm{~b}$ & 4,64 & $21,55 \mathrm{c}$ & 5,21 \\
\hline Anchura del foliolo & $7,27 \mathrm{a}$ & 1,12 & $7,79 \mathrm{~b}$ & 2,14 & $9,09 \mathrm{c}$ & 2,66 \\
\hline Grosor del tallo & $1,01 \mathrm{a}$ & 0,31 & $1,2 \mathrm{~b}$ & 0,27 & $1,33 \mathrm{c}$ & 0,29 \\
\hline $\begin{array}{l}\text { Número de días transcurridos hasta la } \\
\text { primera flor abierta. }\end{array}$ & $39,68 \mathrm{a}$ & 11,64 & $37,8 \mathrm{a}$ & 17,22 & $36,97 \mathrm{a}$ & 10,37 \\
\hline Número de racimos en la guía principal & $8,87 \mathrm{a}$ & 2,17 & $8,54 \mathrm{a}$ & 1,97 & $6,2 \mathrm{~b}$ & 1,91 \\
\hline Número de hojas entre racimos & $3 a$ & 0 & $2,98 \mathrm{a}$ & 0,15 & $3 a$ & 0 \\
\hline Número de flores segunda inflorescencia. & $12,25 \mathrm{a}$ & 8,01 & $7,5 \mathrm{~b}$ & 3,32 & $8,16 \mathrm{~b}$ & 5,62 \\
\hline Número de pétalos & $5,02 \mathrm{a}$ & 0,21 & $5,17 \mathrm{a}$ & 0,4 & $6,22 \mathrm{~b}$ & 1,1 \\
\hline Longitud de pétalos & $5,02 \mathrm{a}$ & 0,15 & $5,12 \mathrm{a}$ & 0,35 & $6,13 \mathrm{~b}$ & 1,05 \\
\hline Anchura de pétalos & $12,2 \mathrm{a}$ & 2,24 & $11,64 \mathrm{a}$ & 8,22 & $14,53 \mathrm{~b}$ & 2,62 \\
\hline Número de sépalos & $5,52 \mathrm{a}$ & 1,4 & $5,25 \mathrm{a}$ & 1,2 & $6,29 \mathrm{~b}$ & 1,09 \\
\hline Longitud de sépalos & 5,96 a & 1,74 & $8,65 \mathrm{~b}$ & 2,57 & $15,66 \mathrm{c}$ & 3,85 \\
\hline Anchura de sépalos & $1,57 \mathrm{a}$ & 0,69 & $1,88 \mathrm{a}$ & 0,42 & $2,29 \mathrm{~b}$ & 2,13 \\
\hline Longitud estambre & $7,22 \mathrm{a}$ & 1,44 & $7,11 \mathrm{a}$ & 1,16 & $8,83 \mathrm{~b}$ & 1,13 \\
\hline Anchura cono estaminal & $1,91 \mathrm{a}$ & 0,41 & $2,28 \mathrm{~b}$ & 0,36 & $2,99 \mathrm{c}$ & 0,59 \\
\hline Número de estambres & $5,02 \mathrm{a}$ & 0,14 & $5,19 \mathrm{a}$ & 0,49 & $6,33 \mathrm{~b}$ & 1,14 \\
\hline Longitud fruto & $12,22 \mathrm{a}$ & 4,87 & $16,53 \mathrm{~b}$ & 6,27 & $32,49 \mathrm{c}$ & 7,05 \\
\hline Peso fruto & $2,85 \mathrm{a}$ & 5,46 & $6,01 \mathrm{a}$ & 3,49 & $50,15 \mathrm{~b}$ & 5,8 \\
\hline Anchura fruto & $13,72 \mathrm{a}$ & 8,88 & $18,8 \mathrm{~b}$ & 7,38 & $43 \mathrm{c}$ & 12,54 \\
\hline Longitud del pedicelo 1 & $6,39 \mathrm{a}$ & 1,53 & $6,94 \mathrm{~b}$ & 3,37 & $10,51 \mathrm{c}$ & 5,22 \\
\hline Longitud del pedicelo 2 & $11,41 \mathrm{a}$ & 4,17 & $10,52 \mathrm{~b}$ & 3,36 & $12,6 \mathrm{c}$ & 3,73 \\
\hline
\end{tabular}

Tabla 4.4. Prueba de Newman-Keuls, para determinar los caracteres discriminantes exclusivos entre especies. Campaña 2000-01. Las medias seguidas de letras distintas difieren significativamente.

$\underline{\text { Estabilidad de los caracteres cuantitativos y elección de los caracteres diferenciales }}$ entre especies.

La validez de los caracteres identificados como discriminantes entre especies se comprobó mediante la realización de un ANOVA para determinar las interacciones Entrada x Año (Apartado 4.1.1, Tabla 4.1). 
Los caracteres vegetativos, varios de los cuales resultaban útiles en la diferenciación entre especies (longitudes y anchuras de las hojas y foliolos y grosor del tallo), presentaron en las dos especies estudiadas interacciones Entrada x Año altamente significativas, cuestionando su validez como caracteres específicos de una especie, ya que para una misma entrada se obtienen valores diferentes según el año. Lo mismo ocurre con la mayoría de caracteres relacionados con el tamaño (anchura y longitud) de los órganos florales.

Los caracteres que se mostraron más consistentes, no existiendo diferencias significativas entre años para las diferentes entradas estudiadas fueron los relativos al fruto (longitud, anchura y peso del fruto), el número de flores de la segunda inflorescencia y el número de pétalos.

Estos resultados tiene claras implicaciones para las labores de caracterización y evaluación de las entradas mantenidas en los Bancos de Germoplasma, en el sentido de que los datos de una única caracterización tiene sólo una validez parcial, no repetible en muchos casos en otras condiciones de cultivo y deben siempre ir acompañados de los máximos datos posibles relativos a las condiciones en las que se realizó el ensayo: localidad, época de cultivo, prácticas culturales, datos climatológicos, incidencia de estreses bióticos o abióticos, tipo de suelo, abonado, etc.

Por otro lado, los caracteres que muestran una consistencia mayor en los dos años, no detectándose interacciones Entrada x Año son los más apropiados para su uso como discriminantes entre especies: longitud, anchura y peso del fruto, número de flores de la segunda inflorescencia y número de pétalos. 


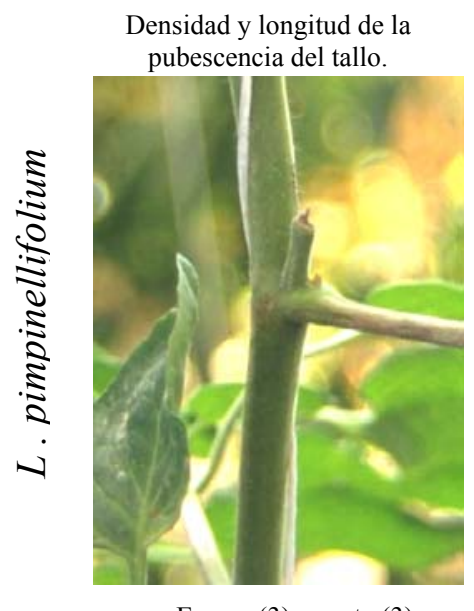

Escasa (3) y corta (3)

ई

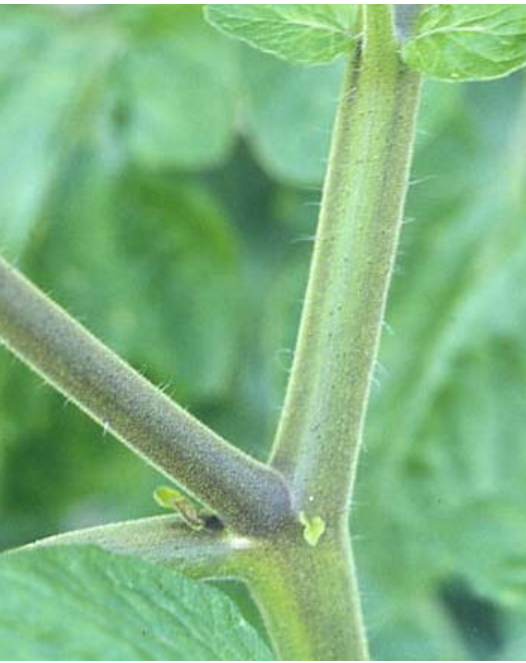

Intermedia y variable

Figura 4.11
Tipo de hoja y borde de los foliolos

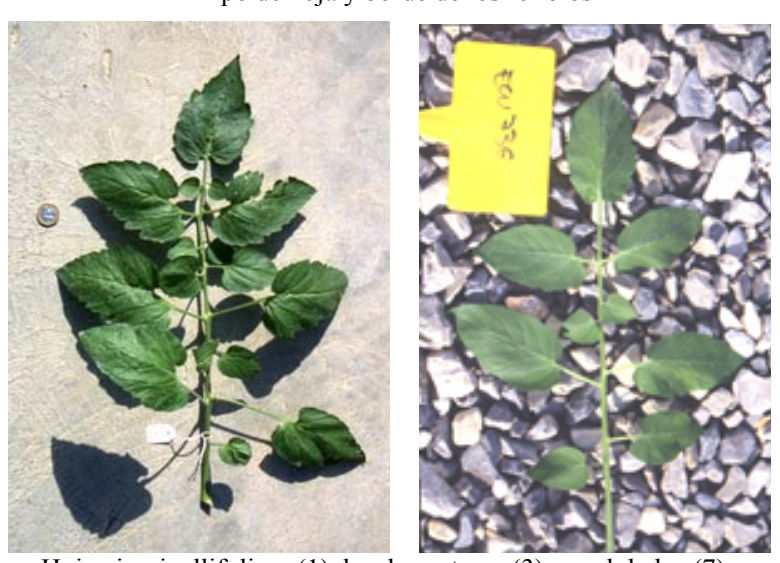

Hoja pimpinellifolium (1), bordes enteros (3) u ondulados (7)

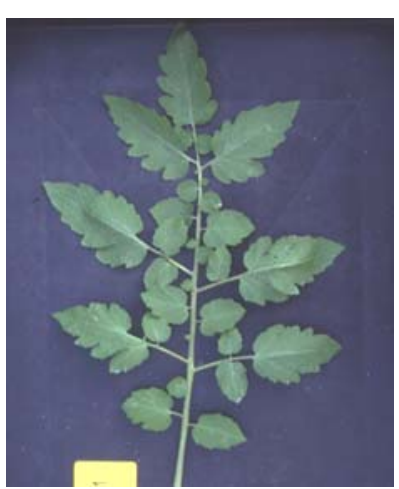

Hoja estándar (2), bordes dentados (5)

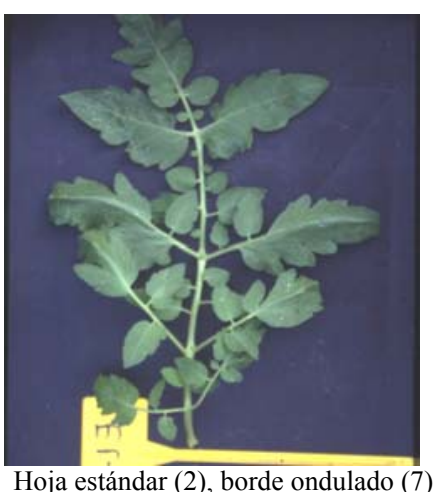

Resultados y Discusión

Posición del estilo y posición de los pétalos en la

Tipo de inflorescencia
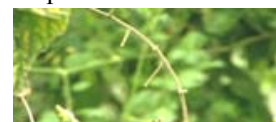

dested

(1)

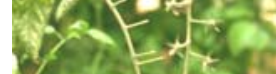

1 (.)

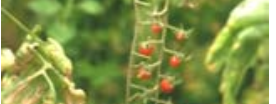

(2), $3 x$ if

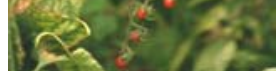

Unípara (3), desde 7 hasta 100 flores, normalmente 15-30 (3)

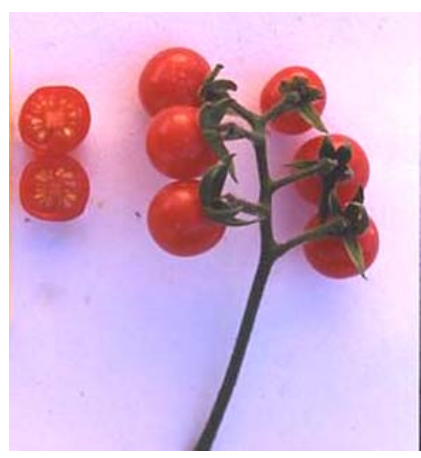

Unípara (3), entre 5-10 flores (5)

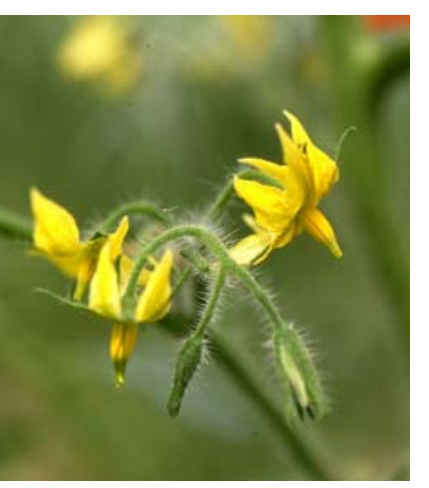

Uníparas y multíparas $(3,5,7)$,
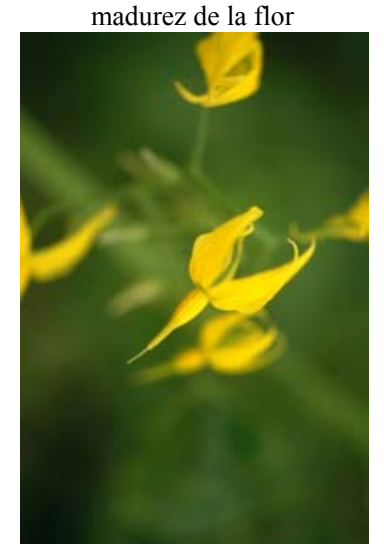

Estilo muy proyectado o

proyectado (3 y 5), pétalos muy curvados (3)

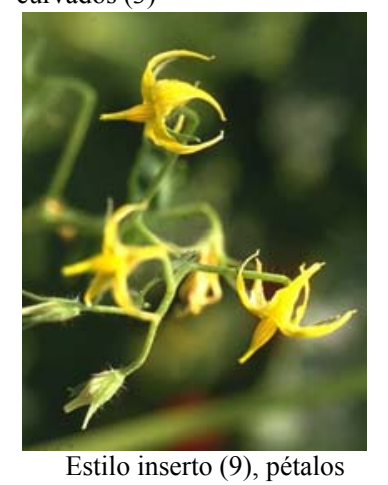

poco curvados (5)

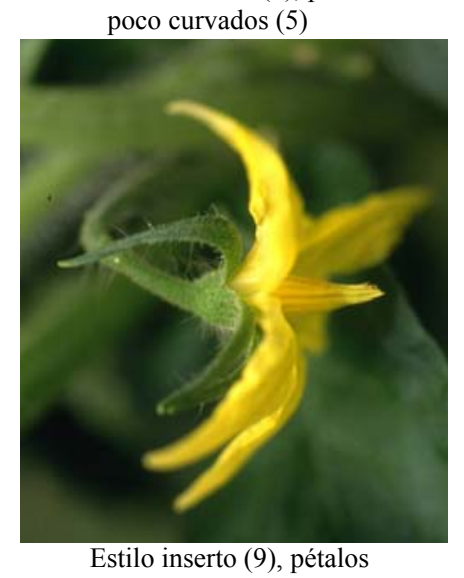

poco curvados (5)
Diámetro ecuatorial del fruto y número de lóculos
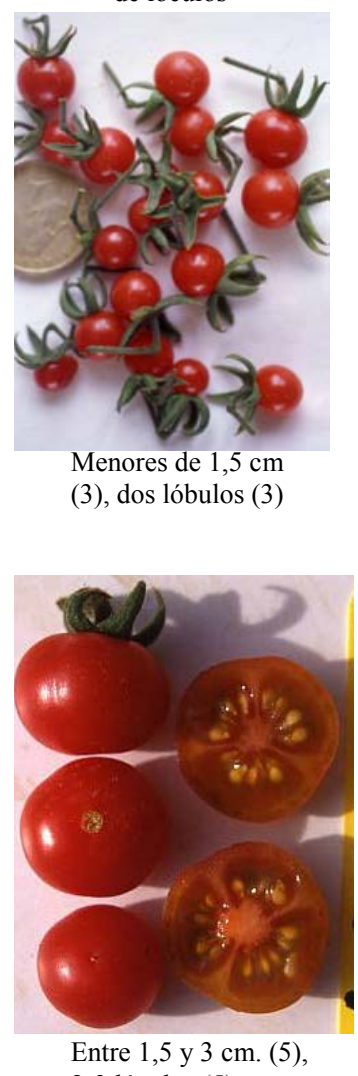
2-3 lóculos (5)

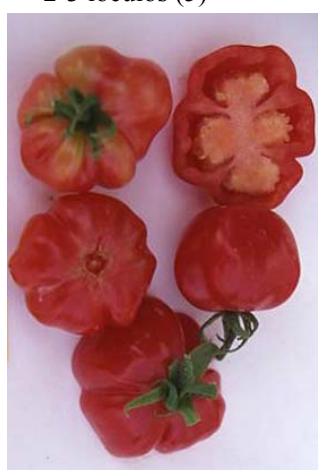

Más de $3 \mathrm{~cm}$. (7) Número de lóbulos variable (7). 
Figura 4.11. Ficha de algunos de los caracteres cuantitativos y cualitativos diferenciales entre especie.

Teniendo en cuenta lo anterior, se ha realizado una ficha que incluye los principales caracteres cuantitativos y cualitativos estables en distintos ambientes o tipos de cultivo.

Esta ficha puede ser de utilidad como guía para realizar una descripción rápida de una especie determinada en expediciones de colectas, donde las plantas se desarrollan en condiciones muchas veces restrictivas debido a estrés abiótico, como la sequía, que dificulta en gran medida el reconocimiento de la especie a la que pertenece.

\section{Análisis conjunto con caracteres cuantitativos y cualitativos}

Con el conjunto de datos de la caracterización morfológica (cuantitativos y cualitativos) se realizó un análisis cluster, cuya representación aparece en la Figura 4.12. Se observan dos grupos principales. El primero de ellos (Grupo I), subdividido en dos, estaría constituido por la mayor parte de entradas de L. esculentum, incluyendo las de México y España, y también algunas entradas consideradas como intermedias entre L. esculetum y la variedad cerasiforme. El grupo (II) se subdivide en dos subgrupos. El II-1 engloba la mayor parte de las entradas, incluyendo las de cerasiforme y $L$. pimpinellifolium, éstas últimas situadas en uno de los extremos. Incluye también la mayor parte de formas intermedias entre las especies en estudio. A pesar de que en este grupo podrían realizarse algunas subagrupaciones, como las entradas procedentes de Galápagos o las de L. esculentum var. cerasiforme, dependiendo de su origen (Ecuador y México), el hecho más destacable es precisamente la formación de este continuo sin separación clara entre la variedad cerasiforme y L. pimpinellifolium. Por último, el subgrupo II-2 está constituido únicamente por las entradas LA 1236, LA 1245 y LA 1261 que, por las características atípicas de sus frutos se mantienen separadas en estos análisis, al igual que en los ensayos realizados para la especie L. pimpinellifolium (ver Apartados 4.1.2.4 y 4.1.3). 


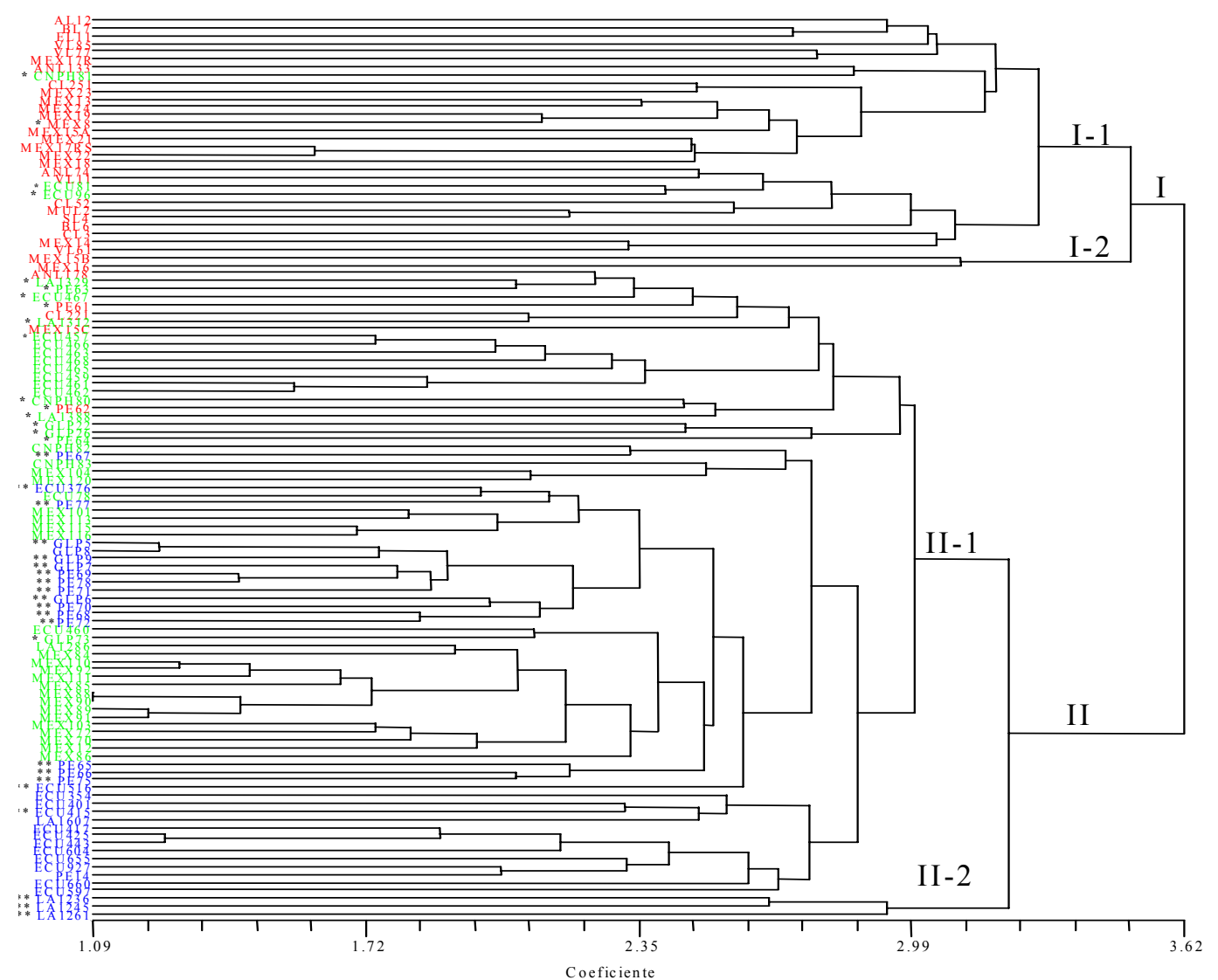




\section{Discusión sobre la caracterización morfológica del ensayo 2000-01.}

La caracterización morfológica del conjunto de entradas pertenecientes a las especies L. esculentum, L. esculentum var. cerasiforme y $L$. pimpinellifolium ha permitido constatar la existencia de una gradación continua entre las especies consideradas en este trabajo, coincidiendo con los estudios realizados por Rick (1958, 1976). Esto queda reflejado de forma clara en la representación de las entradas en el análisis de componentes principales (Figura 4.2), en la que aparece una nube única compuesta por todas las entradas. También se refleja en el dendrograma conjunto con datos cuantitativos y cualitativos (Figura 4.12).

Nesbitt y Tanskley (2002), basándose en un estudio sobre evolución de los alelos fw2.2 implicados en el control del tamaño del fruto del tomate, han estimado que el género Lycopersicon comenzó su divergencia hace más de siete millones de años y que L. esculentum y sus más cercanos parientes, L. pimpinellifolium y L. chesmanii, divergieron de un ancestro común hace un millón de años aproximadamente. La situación actual, en la que se observa un continuo y no una separación clara entre $L$. pimpinellifolium y L. esculentum podría ser consecuencia de que el proceso de especiación simpátrica o parapátrica seguiría produciéndose en la actualidad, no habiendo finalizado todavía una separación entre ambas espacies. Ambos tipos de especiación ocurren sin una separación geográfica completa de las poblaciones, como ocurre con las especies en estudio (Soler, 2002). En este caso, el cambio en el sistema reproductivo, con una autogamia mucho más marcada en el caso de L. esculentum podría haber contribuido al fenómeno de especiación incluso coexistendo en el mismo lugar.

Esta situación se vería además alimentada por la alogamia observada en $L$. esculentum en su lugar de origen. En efecto, a diferencia de lo que ocurre en áreas alejadas del centro de origen del género Lycopersicon, donde el tomate cultivado se comporta casi exclusivamente como un cultivo autógamo, en gran parte de su centro de origen primario y zonas próximas, existe una elevada tasa de polinización cruzada (Rick, 1958), en torno al $25.7 \%$ en Calana y $14.8 \%$ en Tacna (sur de Perú). Ello ha originado un flujo de genes entre el tomate y las especies del género Lycopersicon con las que no existen problemas de cruzabilidad y pueden darse cruzamientos de forma natural. Prueba de ello es la presencia de caracteres típicos de L. pimpinellifolium como la ausencia de tricomas largos, codificada por el gen $H$ o un tipo de malformación de las hojas típica de L. pimpinellifolium que se producen bajo ciertas condiciones térmicas 
(gen $\mathrm{cm}$ "curly mottled"), en muchas entradas de L. esculetum colectadas en lugares donde coexisten ambas especies. Dada la absoluta intercruzabilidad entre ambas especies y la existencia de hibridaciones naturales en numerosas áreas, Rick (1958) ha llegado a sugerir que ambas especies no deberían considerarse como tales y sería más adecuado considerar a L. pimpinellifolium como una variedad del tomate cultivado, al igual que L. esculetum var. cerasiforme.

Por su parte, $L$. esculentum var. cerasiforme representa una mezcla de alelos de $L$. esculentum y L. pimpinellifolium. Se han encontrado alelos de L. pimpinellifolium en entradas de cerasiforme incluso en áreas en las que no coexisten ambas especies.

Sin embargo, es necesario señalar que a pesar de estas evidencias, L. esculentum var. cesariforme y L. pimpinellifolium poseen gran cantidad de características propias no compartidas con el tomate cultivado. Una muestra de ello son los numerosos genes de interés para la mejora identificados en estas especies. Así, en la variedad cerasiforme se conocen entradas especialmente adaptadas a terrenos húmedos (Taylor, 1986), y otras resistentes a un elevado número de estrese bióticos (hongos, bacterias y diferentes plagas). L. pimpinellifolium ha sido una de las especies más utilizadas para la mejora del tomate, tanto en lo referente a caracteres de calidad interna de los frutos, como sobre todo a genes de resistencia a diferentes patógenos. Muchos de los genes de resistencia introducidos hoy en cultivares comerciales de tomate proceden de esta especie (genes de resistencia $C f-2, C f-5, C f-6$ y $C f-9$ a Cladosporium fulvum, Laterrot, 1989; gen de resistencia I-2 a Fusarium oxysporum, Bohn y Tucker, 1940; gen de resistencia Ph-2 a Phytophtora infestans Gallegly y Marcel, 1955; genes de resistencia Sm y Ve a Stemphyllium spp. y Verticillium dahliae respectivamente, Laterrot, 1989).

La caracterización morfológica ha permitido además, la identificación de caracteres propios de cada especie, tanto cualitativos como cuantitativos, que pueden ser de utilidad para la clasificación de entradas de estas especies en futuras recolecciones de germoplasma. Así mismo el extenso número de caracteres evaluados ha servido para eliminar de futuras caracterizaciones aquellos caracteres que presentan elevadas correlaciones con otros, permitiendo hacer una elección de caracteres no correlacionados entre sí. 


\section{1. 2. 2. L. esculentum var. cerasiforme}

\section{Agrupación de las entradas según el $A C P$}

En esta especie las tres primeras componentes principales explicaron un 25,77\%, un $14,73 \%$ y un $10,15 \%$, respectivamente, de la varianza total observada, suponiendo en conjunto un $50,65 \%$ del total.

Los caracteres más correlacionados con la primera componente principal son los de longitud del pedicelo 2, anchura, longitud y peso del fruto y la longitud de los pétalos, con la segunda, los caracteres vegetativos de anchura de la hoja, anchura del foliolo y longitud del foliolo y respecto a la tercera componente el carácter que explica la mayor parte de la variación es el número de hojas bajo la $1^{\mathrm{a}}$ inflorescencia (Figura 4.13).

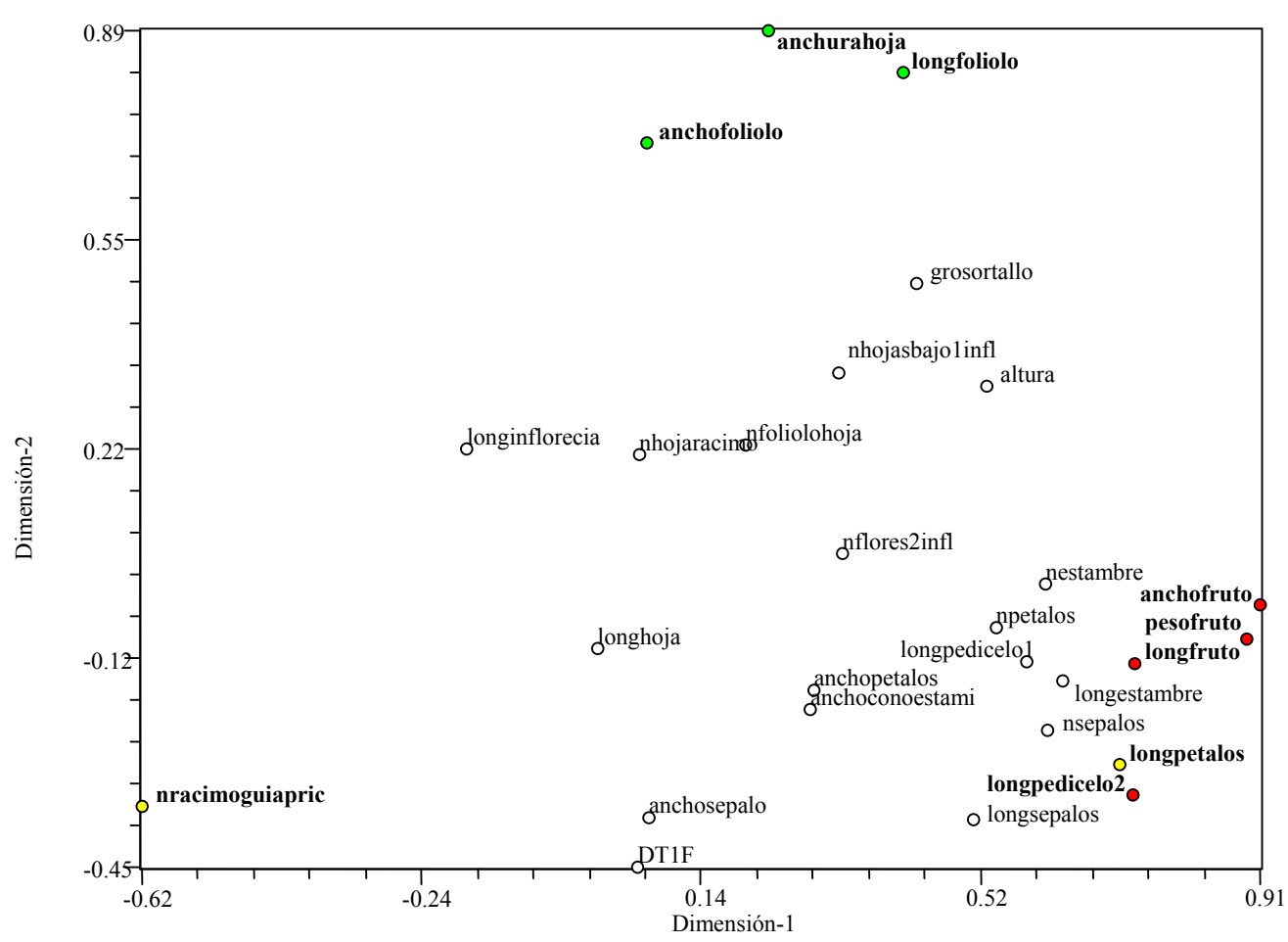

Figura 4.13. Representación de los coeficientes de los caracteres en los vectores propios que definen las dos primeras componentes principales. Entradas de L. esculentum var. cerasiforme ensayo 2000-01. En verde, se representan los caracteres vegetativos, en amarillo los de flor e inflorescencia y en rojo los de fruto.

Al proyectar las entradas sobre las dos primeras componentes se observa claramente una separación de las mismas en función de su origen (Figura 4.14). Así, las procedentes de México quedan separadas del resto y se agrupan próximas al eje izquierdo de la primera componente. Estas entradas son las de fruto más pequeño y 
redondeados, entre 1,19 y 3,3 g. Próximas a éstas se sitúan las de Ecuador, en general de mayor tamaño, oscilando su peso medio entre 1,73 y 8 g y compartiendo la característica de fruto arriñonada. A la derecha sobre el primer eje se encuentran otras entradas de distintos orígenes y que tiene en común el poseer frutos que no responden a los típicos de esta variedad (Figura 4.15).

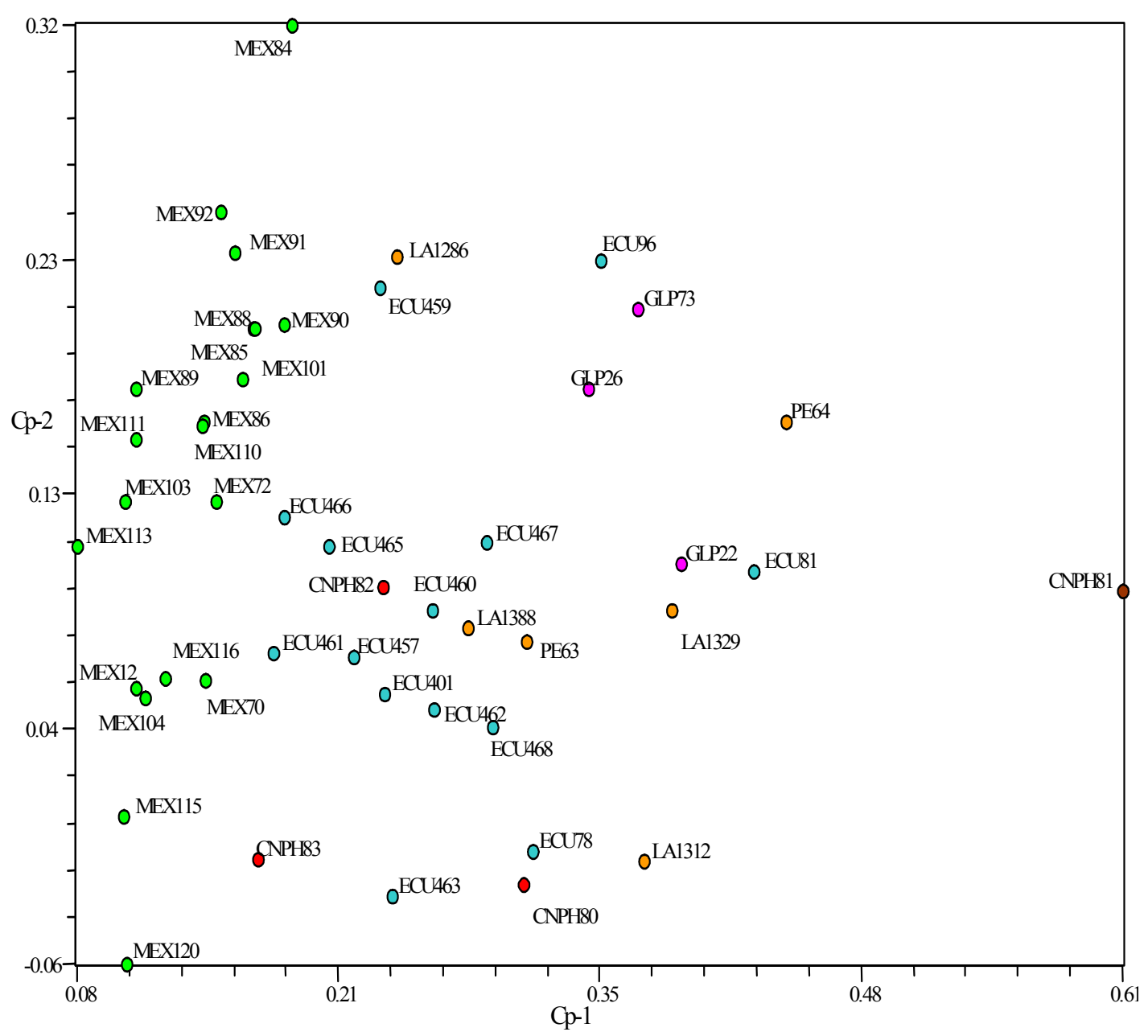

Figura 4.14. Representación de las entradas de L. esculentum var. cerasiforme, del ensayo 2000-01, respecto a las componentes principales 1 y 2. En verde se representan las entradas procedentes de México, en azul las de Ecuador, en naranja las de Perú, en rosa las de Galápagos y en rojo las de Brasil. 


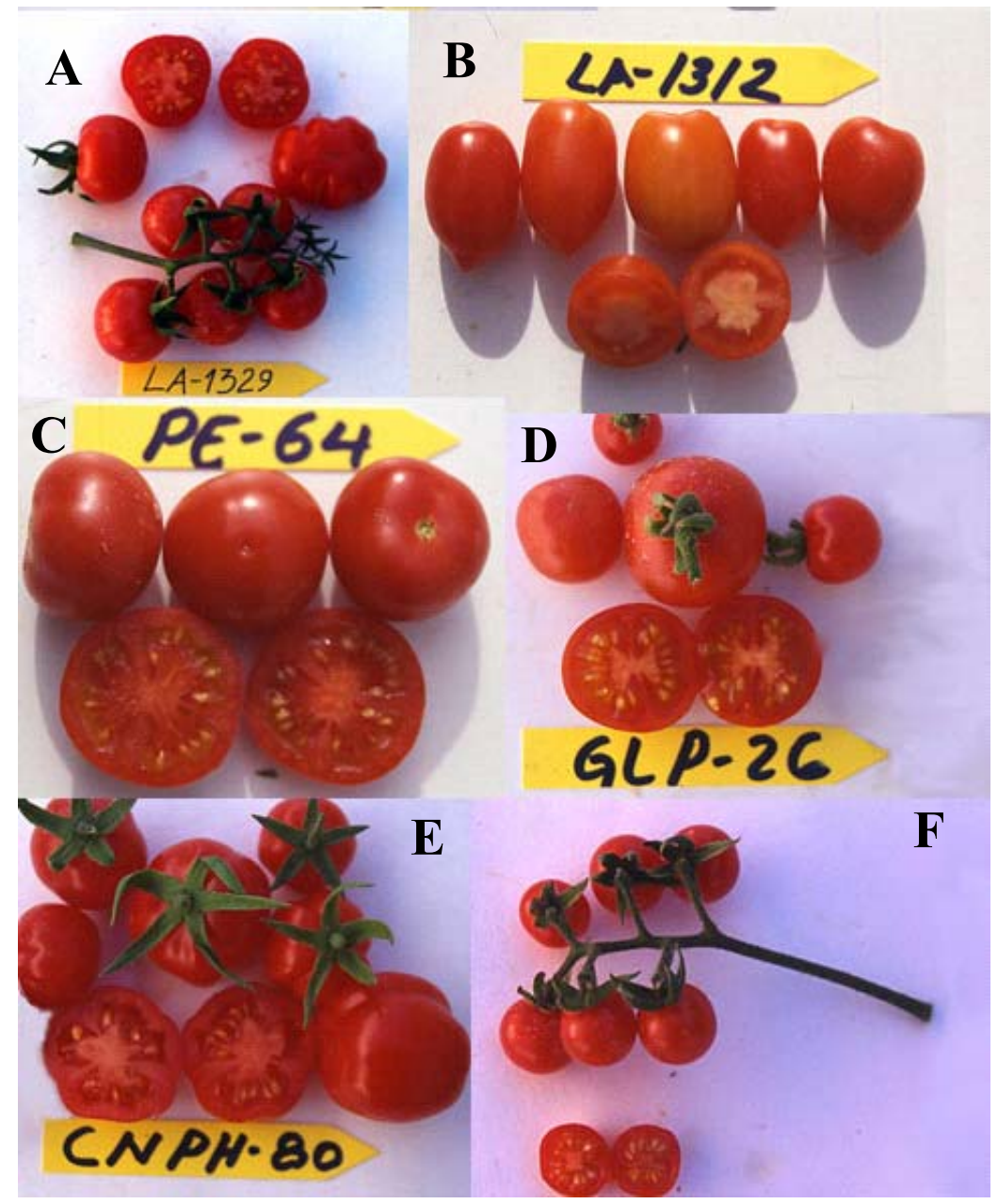

Figura 4.15. Frutos de L. esculentum var. cerasiforme. De izquierda a derecha y de arriba a bajo. A, B, C, D y E entrada con frutos atípicos y F frutos típicos (MEX72).

En cuanto a la segunda componente no aparece ninguna agrupación clara, debido a la elevada variabilidad para los caracteres vegetativos que presenta el conjunto de entradas estudiadas, y que son los más correlacionados con la segunda componente.

\section{Agrupación de las entradas según el análisis cluster: Análisis $Q$}

La agrupación de las entradas observada en el análisis de componentes principales es consistente con la que se obtiene en el análisis cluster (Figura 4.16). Se observan de nuevo los tres grupos vistos anteriormente: las entradas procedentes de México por una parte (subcluster I), la mayoría de las entradas de Ecuador junto con la LA 1388 y PE 63 (subcluster II) y otro grupo en el que se incluyen entradas de distintos orígenes: 3 de Galápagos (GLP), 2 entradas de Brasil (CNPH 80 y CNPH82), LA 1312, LA1329 y PE-64 procedentes de Perú y ECU 78, ECU 96 y ECU 81 de Ecuador (subcluster III) 
consideradas todas ellas como formas intermedias (Tabla 4.2). Como puede verse en la (Figura 4.15), todas ellas presentan frutos que distan mucho de ser los típicos de la variedad cerasiforme.

Sin pertenecer a ninguno de estos grupos tenemos las entradas CNPH81 y MEX 120, que también en la anterior proyección bidimensional aparecían totalmente separadas del resto de las entradas y también entre sí. Caracteres propios de estas entradas que posiblemente sean los responsables de esta separación son unas hojas muy pequeñas en el caso de MEX 120 y el fruto multilocular de CNPH81.

El análisis cluster realizado con los caracteres cualitativos produjo una agrupación similar, separando claramente las entradas según su origen.

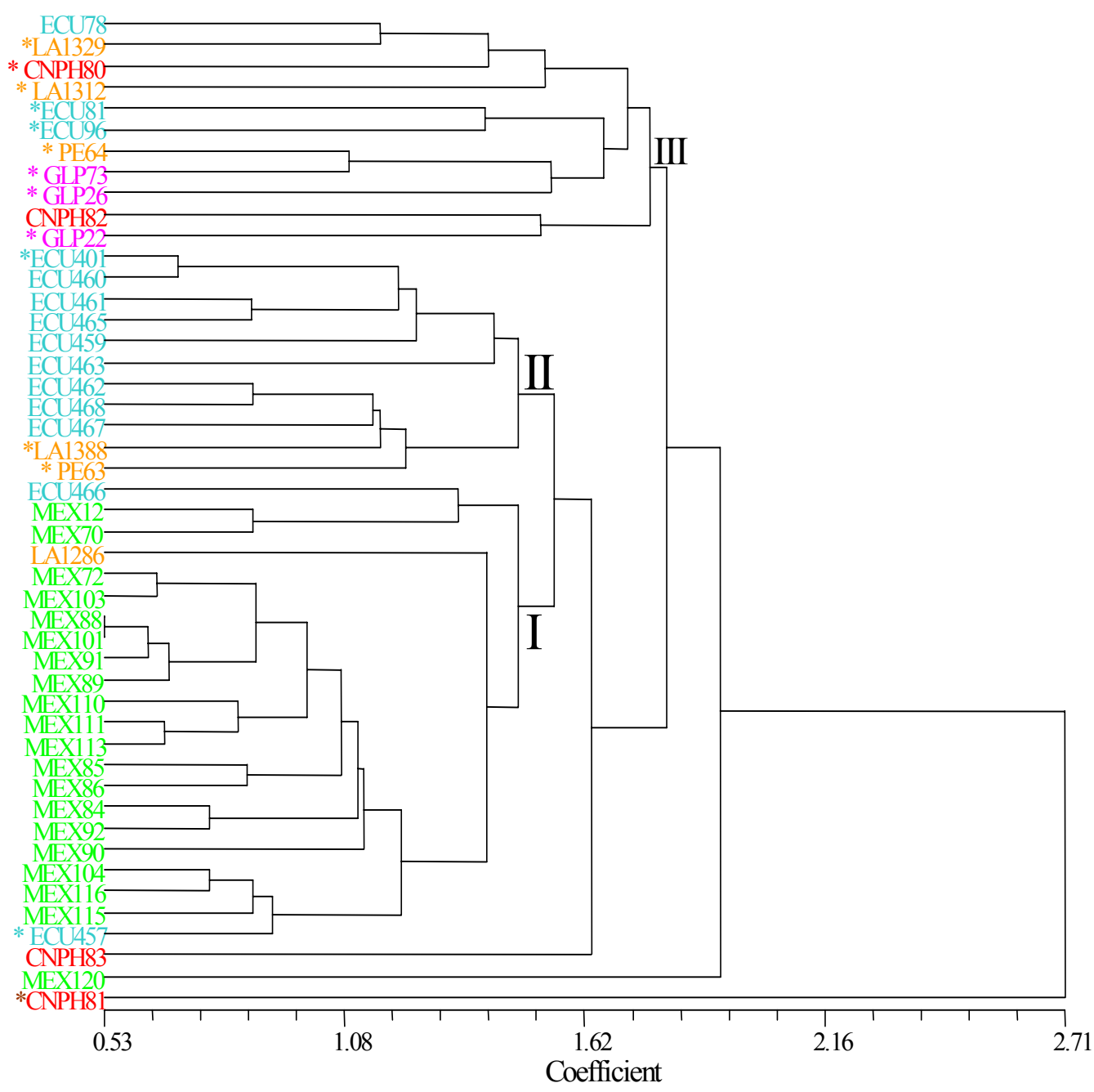

Figura 4.16. Dendrograma de las entradas de var. cerasiforme obtenido a partir de los datos cuantitativos, utilizando las distancias euclídeas y el método de análisis UPGMA. En color verde se representan las entradas procedentes de México, en rojo las de Brasil, en naranja las de Perú, en rosa las de Galápagos y en azul las de Ecuador. Con un asterisco se señalan las formas intermedias entre L. esculentum y L. esculentum var cerasiforme. 


\section{Discusión.}

En el conjunto de entradas incluidas en este estudio se evidencia una diferencia en características morfológicas entre entradas de distinta procedencia. Así, las entradas de México y Ecuador forman dos grupos claramente diferenciados en los análisis efectuados, tanto en el análisis cluster como en el de componentes principales. Estas diferencias entre procedencias, así como la similitud entre entradas de las mismas regiones fue detectada ya por Rick y Holle (1990) en un estudio en el que se incluían entradas de Colombia, Ecuador, Perú y Bolivia. En nuestro caso las entradas procedentes de México son las que más se asemejan a las características propias de la variedad cerasiforme, habiendo mayor uniformidad entre ellas, mientras que las de Ecuador muestran en muchas ocasiones formas arriñonadas o que exceden el tamaño de cerasiforme, siendo más variables entre sí. Estos resultados se ven apoyados por Rick y Fobes (1975) y Rick y Holle (1990) que encontraron una considerable variación alozímica entre genotipos de L. esculentum var. cerasiforme colectados en la costa de Perú y Ecuador, donde sólo el 30\% de los cultivares se asemejaban al tipo estándar, mientras que en otras zonas la variación alozímica era mucho menor.

El conocimiento de las diferencias de variabilidad propias de cada región puede servir para determinar la estrategia de recolección más adecuada. Así, cuando no se tiene conocimiento de la distribución de la variabilidad en una especie, Brown (1978) ha sugerido que una colección de germopalsma será más diversa cuantos más orígenes hayan representados. Sin embargo, en nuestro caso, el conocimiento de la mayor variabilidad en las entradas de cerasiforme recolectadas en Ecuador frente a las procedentes de México, aconsejan un mayor esfuerzo de recolección en Ecuador, mientras que en el caso de México con un menor número de entradas podría estar representada suficientemente la variabilidad existente en este país.

Estos resultados pueden generalizarse teniendo en cuenta las observaciones realizadas por otros autores. Así, se sabe que la forma silvestre del tomate cultivado es muy diversa morfológicamente. A esto ha contribuido la extrema adaptación de ciertos genotipos como malas hierbas, lo cual ha propiciado su dispersión por todas las regiones tropicales de América, incluso hasta el Sur de Texas y Florida y también por la mayoría de regiones tropicales del mundo. En este vasto rango de habitats el pariente silvestre del tomate tolera una amplia diversidad de condiciones ambientales, contribuyendo ello a aumentar su diversidad. Constituye además la excepción, por su adaptación a terrenos húmedos, cuando la situación general en el género Lycopersicon 
es la preferencia por climas secos y suelos bien drenados. En estas circunstancias, las recolecciones de germoplasma de esta especie deberían incluir todos los orígenes posibles, por otro lado, los datos disponibles de variabilidad morfológica, isozímica y molecular aconsejan realizar recolecciones más exhaustivas en lugares como Ecuador y Perú, donde la variabilidad es mucho mayor. Los lugares muy alejados de su centro de origen son de interés por las distintas características derivadas de su adaptación a los distintas condiciones medioambientales, pero, dada la escasa variabilidad encontrada en estos lugares, un pequeño número de recolecciones sería suficiente para recoger esta variabilidad específica.

Por otro lado, las entradas con características muy alejadas de las propias de cerasiforme, como las mostradas en la Figura 4.15, procedentes de Brasil, Perú, Ecuador e Islas Galápagos han sido descritas con anterioridad por Rick y Holle (1990), quienes han sugerido su procedencia a partir de hibridaciones entre plantas de la var. cerasiforme y cultivares de tomate introducidos en la misma región. Estos autores indican que tras el cruce inicial, sucesivos retrocruces hacia la variedad cerasiforme, nativa de esas zonas, originarían la introgresión de ciertos alelos responsables de caracteres morfológicos del fruto, altamente destacables a la vista, en el fondo genético de cerasiforme. Villand et al., (1998) apuntan igualmente, que la naturaleza simpátrica de ambas poblaciones y su facilidad para hibridar daría como resultado una gran similitud entre ellas y un proceso de mezcla entre esculentum y cerasiforme. Adicionalmente, y de la misma forma que ha sido comentado en el apartado 4.1.2.1 nuestra hipótesis es que se trata de un proceso de especiación que, en el momento actual seguiría su curso sin encontrarse completamente finalizado.

\section{1. 2. 3. Lycopersicon esculentum}

\section{Agrupación de las entradas según el ACP}

La primera componente explicó el 26\% de la variabilidad, la segunda el 14,7\% y la tercera el $12,3 \%$, totalizando el $53 \%$ de la variabilidad observada.

Los caracteres de tamaño de la hoja y del foliolo y la anchura del fruto son los que aparecen más positivamente correlacionados con la primera componente principal, con valores superiores a 0,7 en todos los casos. La segunda componente está correlacionada con los caracteres de flor (número de pétalos, $\mathrm{r}=0,78$; número de sépalos, $\mathrm{r}=0,72$; anchura de los pétalos $r=-0,68$ ) (Figura 4.17), mientras que con la tercera lo están el 
número de foliolos por hoja $(\mathrm{r}=0,42)$, número de racimos en la guía principal $(\mathrm{r}=0,42)$, el número de hojas bajo la primera inflorescencia $(\mathrm{r}=0,44)$, longitud de la hoja $(\mathrm{r}=0,62)$ y negativamente correlacionada con la longitud del fruto $(r=-0,74)$. (Figura 4.18).

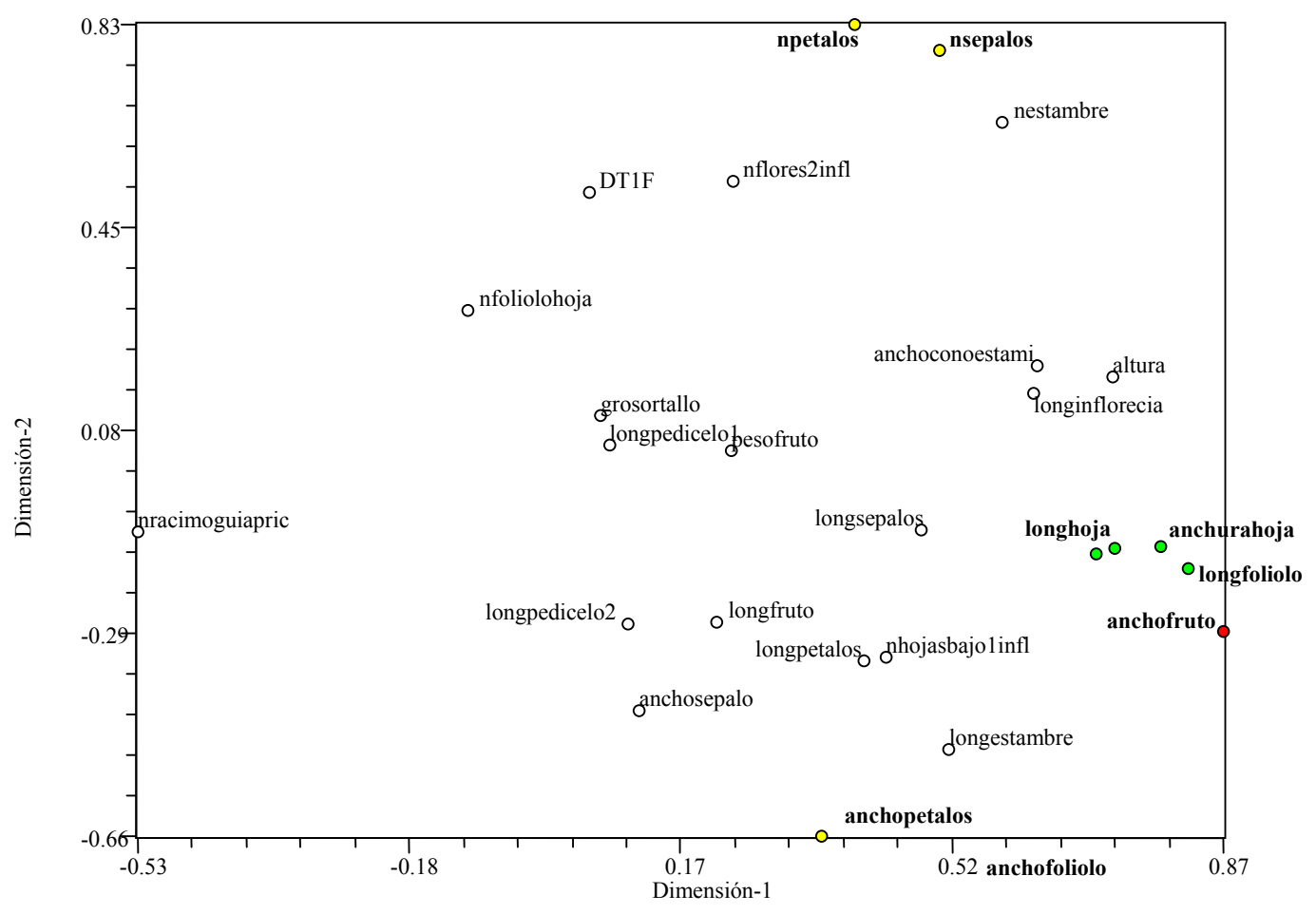

Figura 4.17. Representación de los coeficientes de los caracteres en los vectores propios que definen las dos primeras componentes principales Entradas de L. esculentum, ensayo 2000-01. En verde se representan los caracteres vegetativos, en amarillo los de flor e inflorescencia y en rojo los de fruto. 


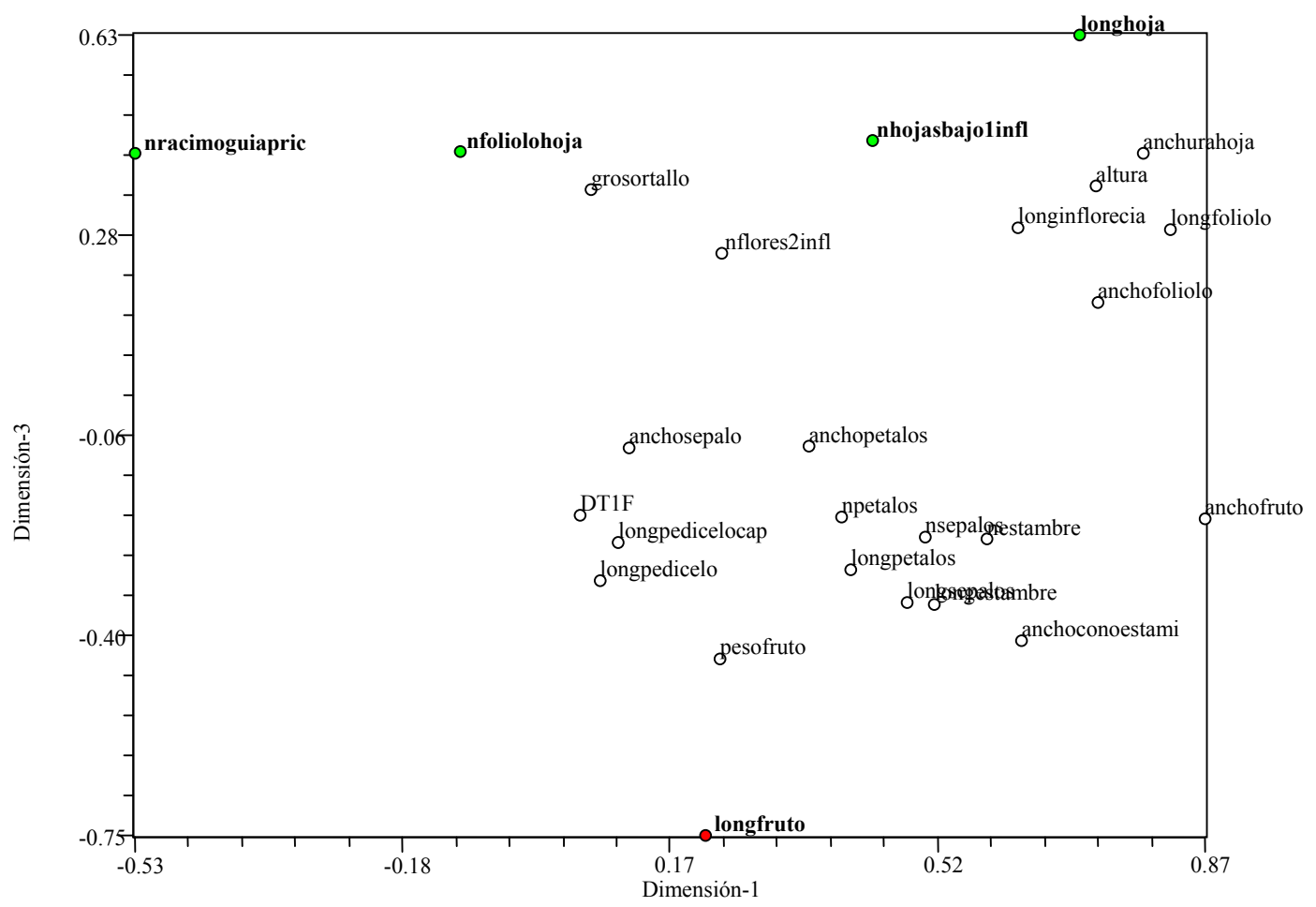

Figura 4.18. Representación de los coeficientes de los caracteres en los vectores propios que definen la primera y tercera componente principal. Entradas de L. esculentum, ensayo 2000-01. En verde se representan los caracteres vegetativos, en amarillo los de flor e inflorescencia y en rojo los de fruto.

La proyección de las entradas sobre las dos primeras componentes proporciona una separación de las mismas respecto a la segunda, mientras que respecto a la primera la separación es mucho menos patente (Figura 4.19). El peso de los frutos es un carácter muy correlacionado con el diámetro del fruto y éste último lo está con la primera componente principal. Las entradas procedentes de México son sensiblemente menores que las de España, siendo la media del peso de los frutos de 52,54 g y 108,37 respectivamente. En base a este carácter sería de esperar una separación clara entre ambos grupos de entradas. Sin embrago, la gran variabilidad de formas y tamaños de las hojas de L. esculentum (Figura 4.20) caracteres a su vez altamente correlacionados con la primera componente, podrían estar enmascarando el efecto de la diferencia en el tamaño de los frutos entre las entradas de México y España (Figuras 4.21 y 4.22). Esta podría ser la causa de que, aunque las entradas de México tienden a concentrarse en mayor medida que las de España, a la derecha de la figura, no se aprecie una separación completa. 


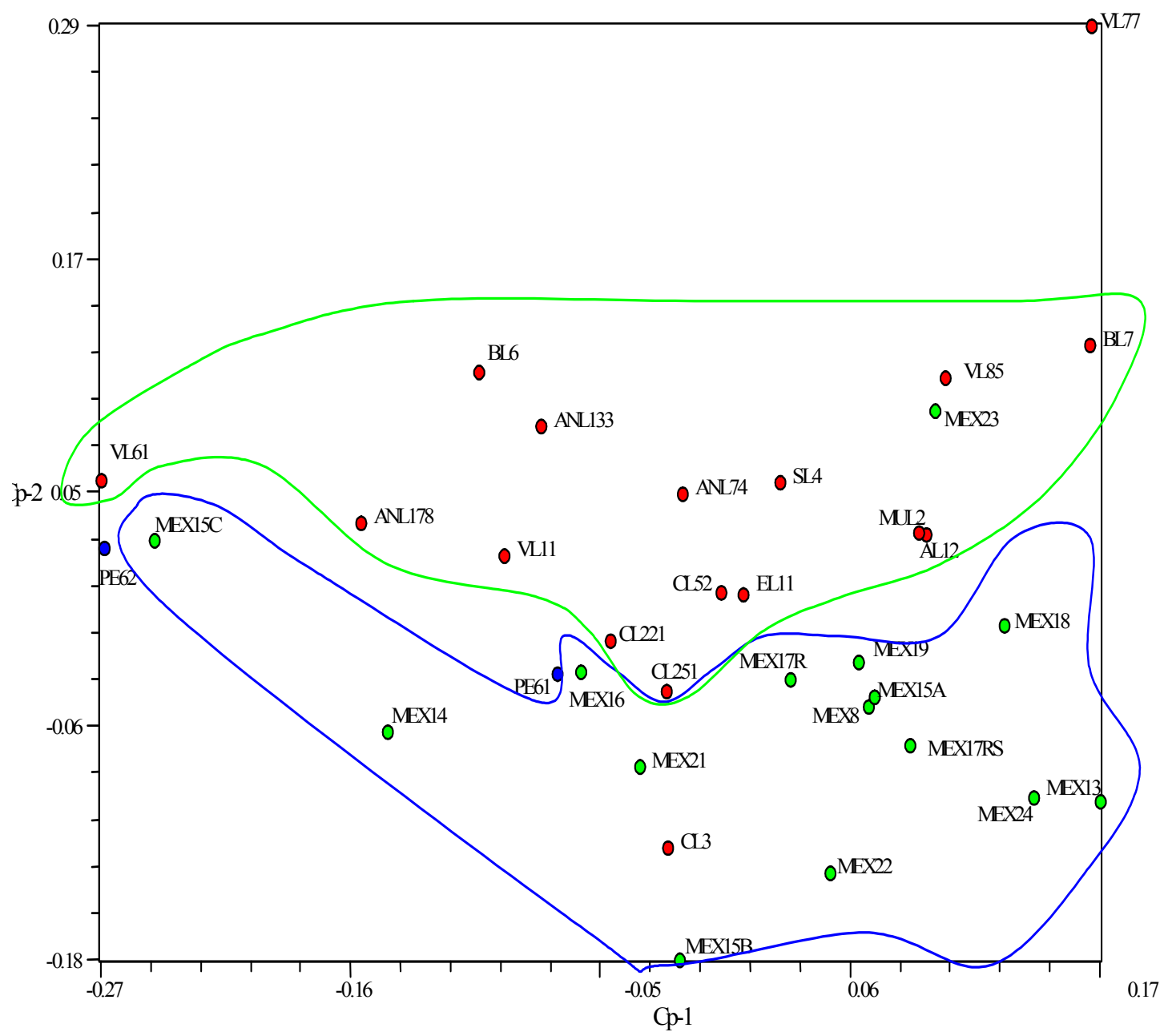

Figura 4.19. Representación de las entradas de L. esculentum, del ensayo 2000-01, respecto a las componentes principales 1 y 2 . En color verde se representan las entradas procedentes de México, en rojo las de España y en azul las de Perú. 


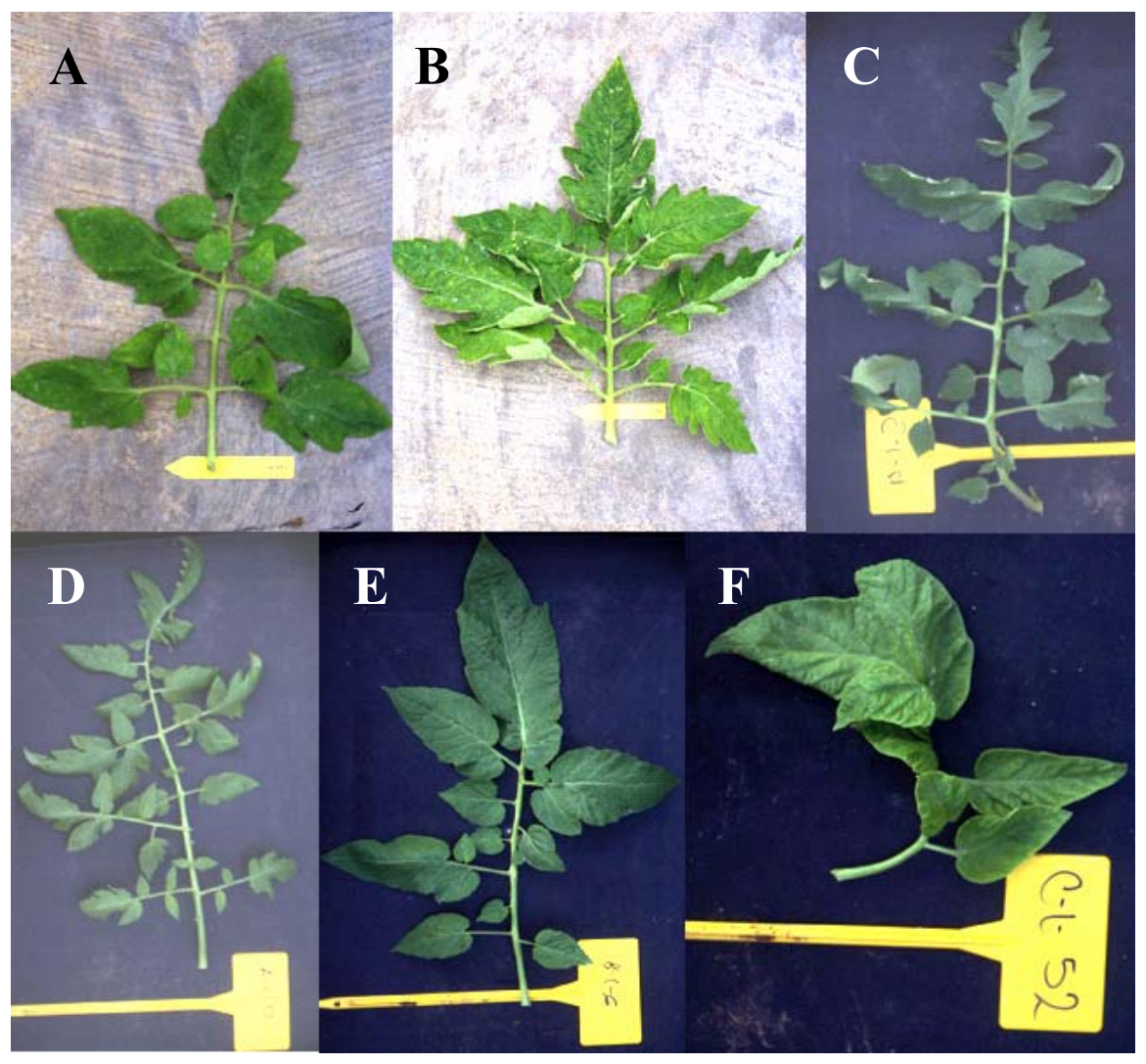

Figura 4.20. Hojas de L. esculentum. De izquierda a derecha y de arriba abajo A, B, C, D, E y F. Entradas procedentes de México (A y B) y de España (C, D, E y F). Campaña 2000-2001.

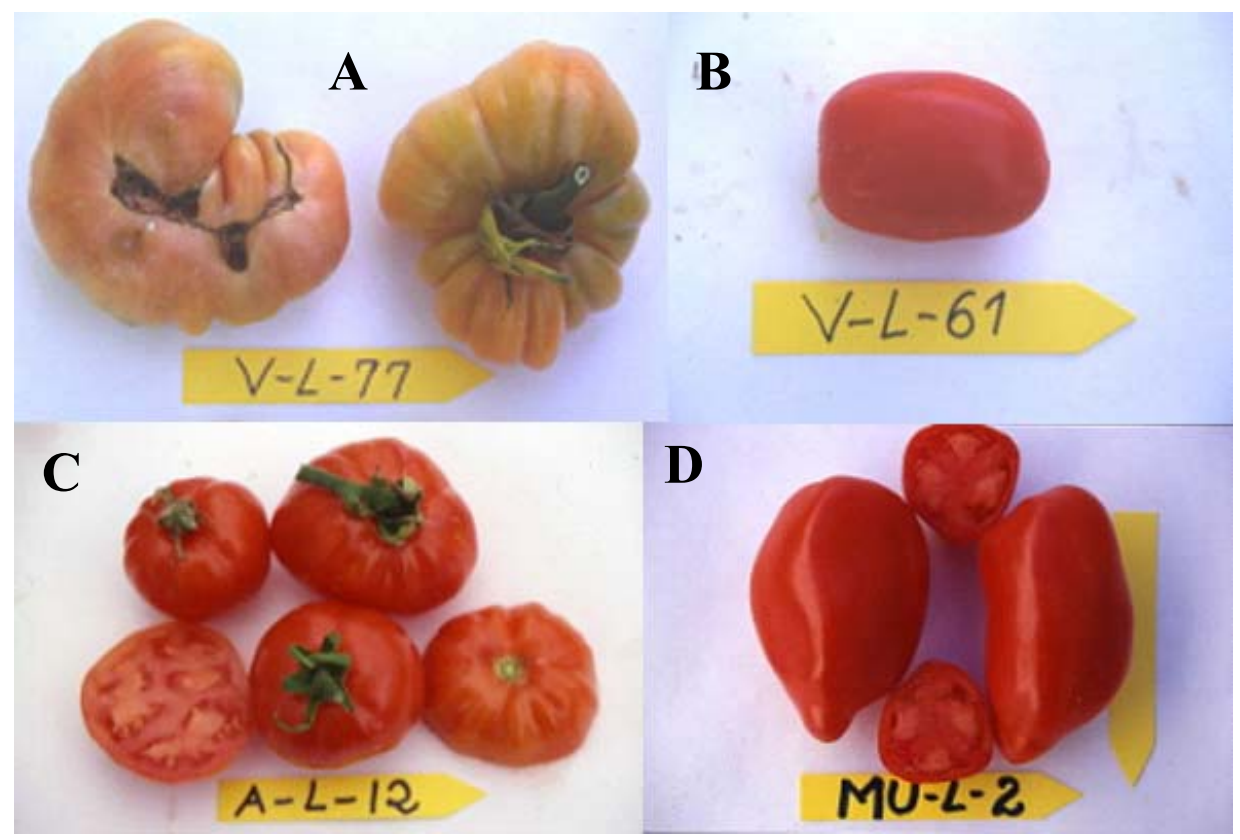

Figura 4.21.Frutos de L. esculentum de procedencia española. Campaña 2000-2001. 


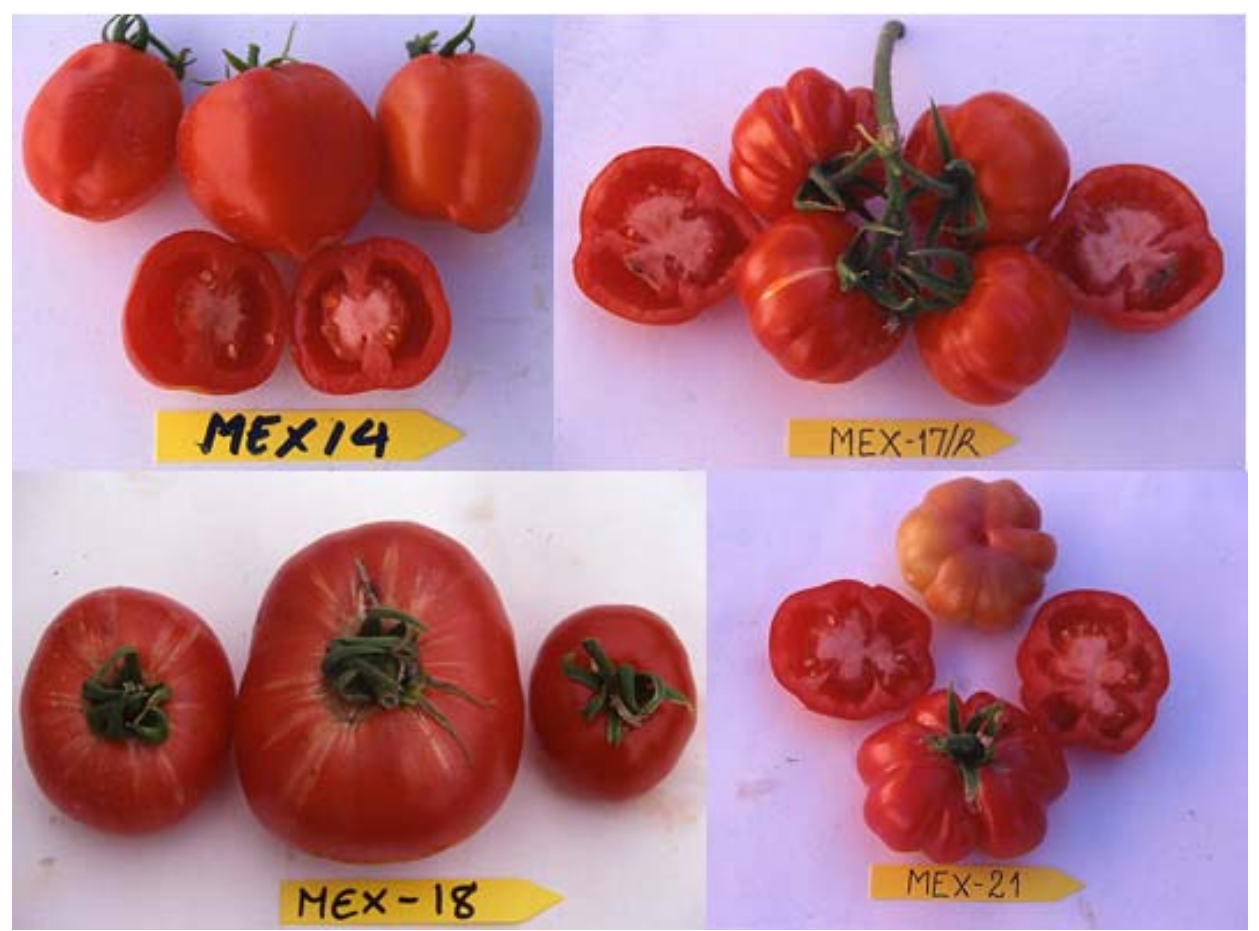

Figura 4.22. Frutos de L. esculentum de procedencia méxicana. MEX 14 es tipo "Tuchito", MEX 17R y MEX 21 de tipo "Zocato" y MEX 18 de tipo "Mazano". Campaña 2000-2001.

Lo que realmente separa las entradas de México y España son los caracteres relativos a la flor, correlacionados con la segunda componente. Así, las entradas mexicanas tienen un $71 \%$ de flores con más de 5 pétalos y sépalos, mientras que en las entradas españolas este valor aumenta hasta un $90 \%$.

Si proyectamos las entradas sobre la primea y tercera componentes (Figura 4.23), negativamente correlacionada con la longitud del fruto $(-0,74)$, se observa de nuevo una agrupación de las entradas según su procedencia. Así las mexicanas, de menor longitud, se sitúan en la parte superior de la figura, mientras que para valores similares de anchura, las entradas españolas, de frutos menos achatados se localizan en la parte inferior de la representación. 


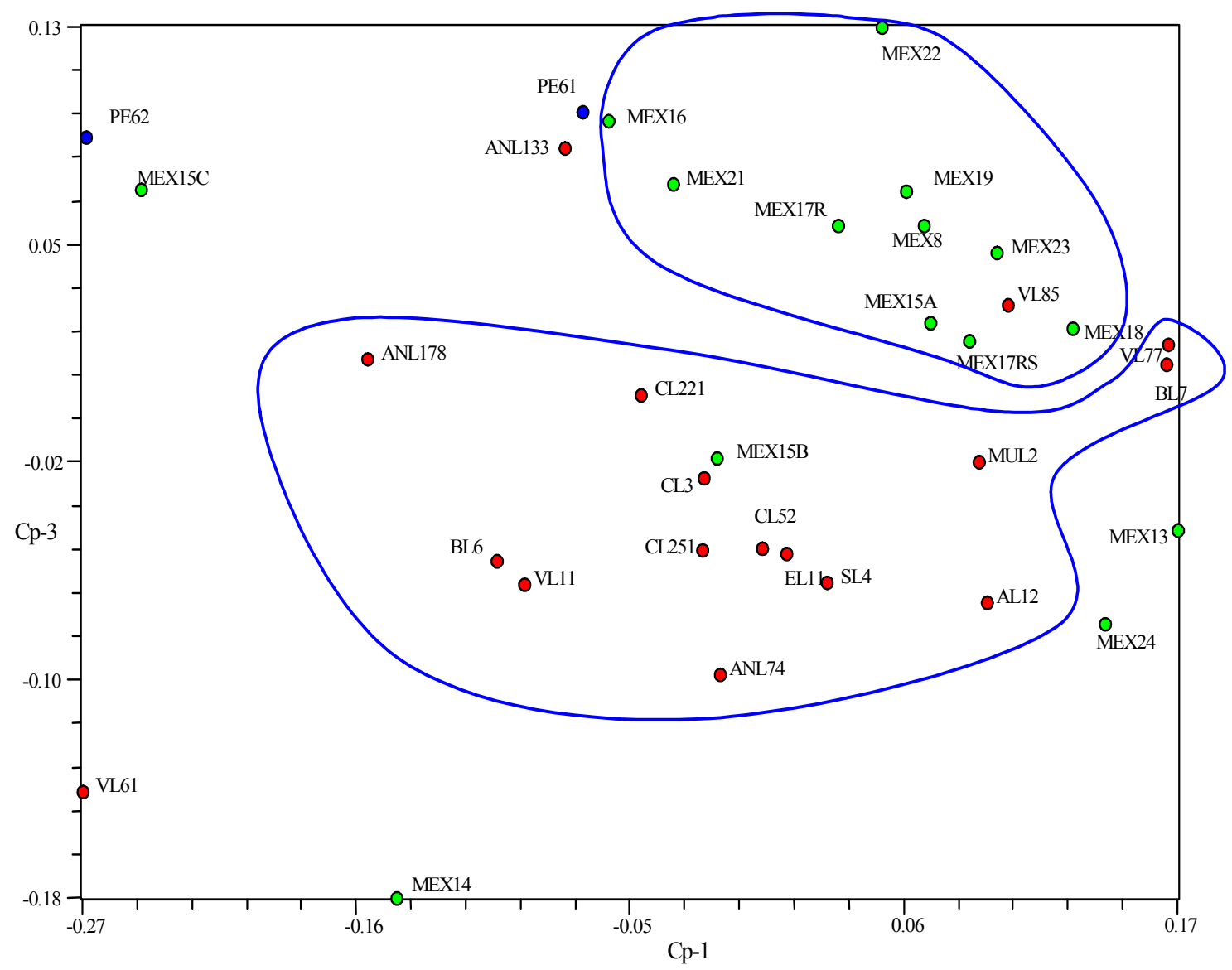

Figura 4.23. Representación de las entradas de L. esculentum, del ensayo 2000-01, respecto a las componentes principales 1 y 3 .En color verde se representan las entradas de México, en rojo las de España y en azul las de Perú.

En resumen, las diferencias principales entre las entradas de México y España son pues debidas a caracteres de flor y fruto.

\section{$\underline{\text { Análisis conjunto con caracteres cualitativos y cuantitativos }}$}

Con la totalidad de los caracteres se obtuvo una distribución de las entradas similar a la de la Figura 4.19, observándose una separación de las mismas según sus respectivos países y situándose las de España en la parte superior de la figura (Figura 4.24). 


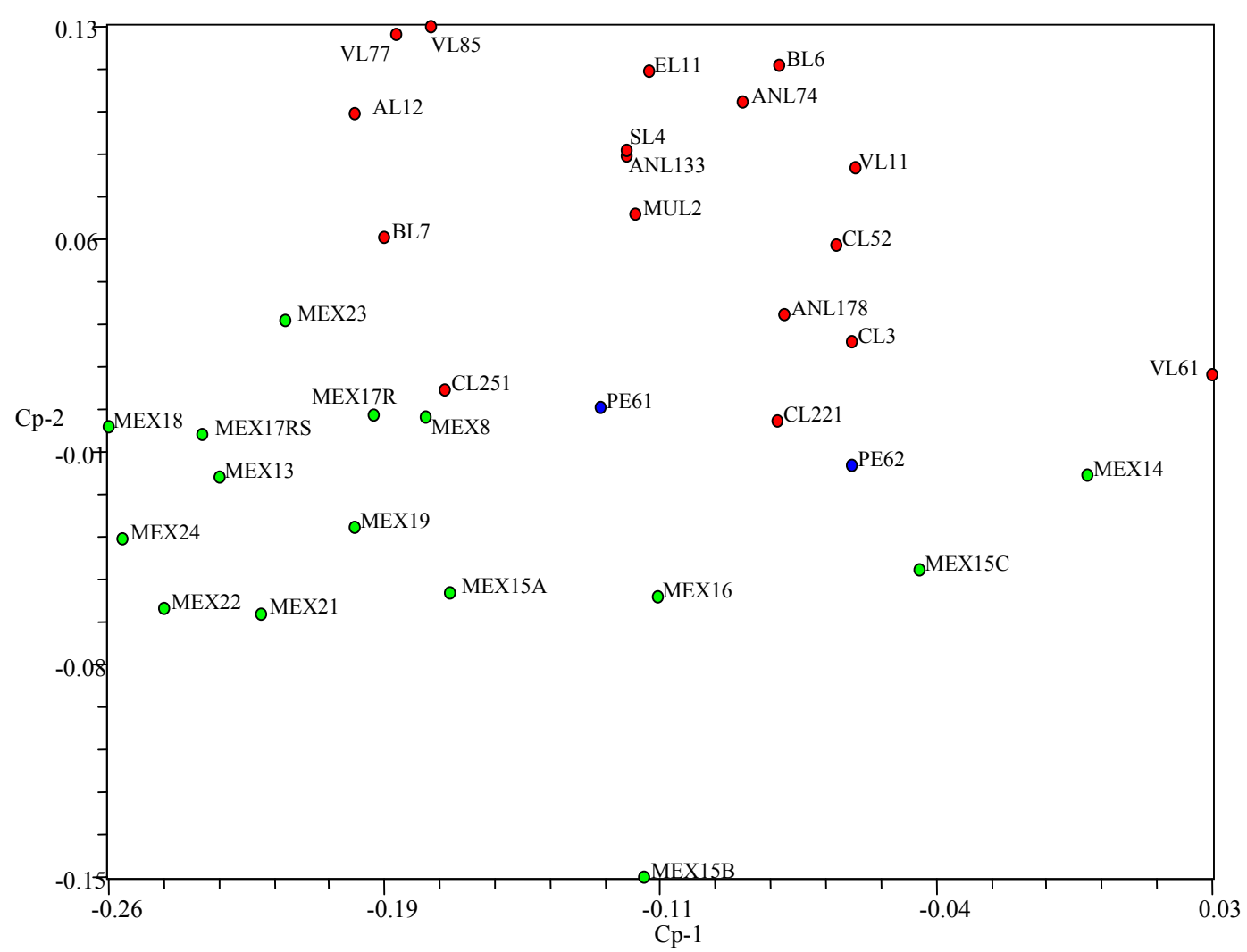

Figura 4.24. Representación de las entradas de L. esculentum frente a las componentes principales 1 y 2 , en el análisis de componentes principales realizado con todos los caracteres morfológicos (cuantitativos y cualitativos). Campaña 2000-2001. En verde se representan las entradas procedentes de México, en rojo las de España y en azul las de Perú.

\section{Discusión}

Tanto el análisis cluster como el ACP proporcionan una separación de las entradas según su origen. Una de las características asociadas a la domesticación de esta especie es la variabilidad de formas y tamaños, no sólo de los frutos, sino también de las partes vegetativas de la planta. En el primer caso suelen ir asociadas a las preferencias del consumidor y formas de uso, mientras que en el segundo son los responsables los requerimientos de la planta frente a distintas técnicas de cultivo y nuevos ambientes. Estas exigencias, muy diferentes en ambos países, ocasionarían la agrupación de forma separada de las entradas procedentes de cada país.

El conjunto de entradas de tomate procedentes de México incluidas en el estudio pertenecen a los tipos criollos, principalmente Zocato (MEX-13, MEX-17, MEX-21, MEX-22 y MEX-24), Tuchito (MEX-14) Manzano (MEX-18 Y MEX-19), Manzano Chico (MEX-15 y MEX-16) y Molpec (MEX-23). Se trata de cultivares frecuentemente muy acostillados y multiloculares, de distintos tamaños (Zocato, Molpec o Manzano) o 
de frutos que se asemejan al tipo conserva, cuadrados y más largos que anchos (MEX14), (Figura 4.22). Todos ellos proceden de la península de Yucatán y son los tipos demandados por los consumidores de esta región. Las características concretas y similares entre si de los cultivares locales de México estarían exacerbando las diferencias con el conjunto de entradas de procedencia española, a pesar de que éstas fueron seleccionadas por constituir un conjunto muy variable de formas y tamaños.

\section{1. 2. 4. Lycopersicon pimpinellifolium}

Se estudiaron un total de 89 entradas de Lycopersicon pimpinellifolium. En el primer año se ensayaron 15 entradas, representando fundamentalmente la zona sur de Ecuador (10 entradas) y la zona norte de Perú (5 entradas) más 11 colectadas en Cuzco que presentaban marcadas similitudes con esta especie. Con ello se pretendió tener una representación de la mayor parte de áreas de distribución de esta especie, para tener una visión global acerca de las diferencias existentes entre distintas procedencias.

El segundo año se ensayaron 72 entradas. Éstas incluyeron las 15 entradas ensayadas en el primer año. Además se añadieron 15 entradas recolectadas en Galápagos y se cubrió con mayor precisión la zona norte del Perú (38 entradas de los Departamentos de Lambayeque, La Libertad, Piura y Cajamarca), por ser ésta el área de distribución natural donde es más frecuente esta especie.

Los objetivos pretendidos en este estudio fueron profundizar en el conocimiento de la variabilidad existente con el fin de determinar las estrategias más adecuadas de conservación y utilización de los recursos genéticos. Dada la existencia de interacciones Entrada x Año detectadas para las entradas comunes caracterizadas en ambas campañas, no es posible el análisis conjunto de todas las entradas, por lo que consideraremos cada ensayo por separado.

\section{Agrupación de las entradas según el ACP}

El porcentaje de la variación explicado por las tres primeras componentes principales ascendió a un $62,85 \%$, correspondiendo un $29,11 \%$ a la primera componente, un $19,33 \%$ a la segunda y un $14,41 \%$ a la tercera.

Respecto a la primera componente principal destaca un grupo constituido por caracteres de fruto y otro por caracteres de flor, explicando entre ambos la mayor parte de su variación (Figura 4.25). Las correlaciones de estos caracteres con la primera componente son: longitud del fruto (correlación con el primer eje $r=0,93$ ), anchura del 
fruto $(\mathrm{r}=0,91)$, peso del fruto $(\mathrm{r}=0,93)$. Formando parte del segundo grupo tenemos: número de pétalos $(\mathrm{r}=0,87)$, número de estambres $(\mathrm{r}=0,86)$, número de sépalos $(\mathrm{r}=0,85)$ y longitud de los sépalos $(\mathrm{r}=0,80)$.

Respecto a la segunda componente principal, los caracteres más correlacionados son vegetativos y de inflorescencia: número de hojas bajo la primera inflorescencia (correlación con el segundo eje $\mathrm{r}=0,80$ ), número de flores de la $2^{\mathrm{a}}$ inflorescencia $(\mathrm{r}=0,72)$ y anchura del cono estaminal $(\mathrm{r}=-0,75)$ explicaron la mayor parte de la variación.

Respecto a la tercera los caracteres que explican la mayor parte de la variación son los de planta: anchura de la hoja (correlación con el tercer eje $\mathrm{r}=0,76$ ), longitud del foliolo $(r=0,75)$ y anchura del foliolo $(r=0,63)$ (figura 4.26).

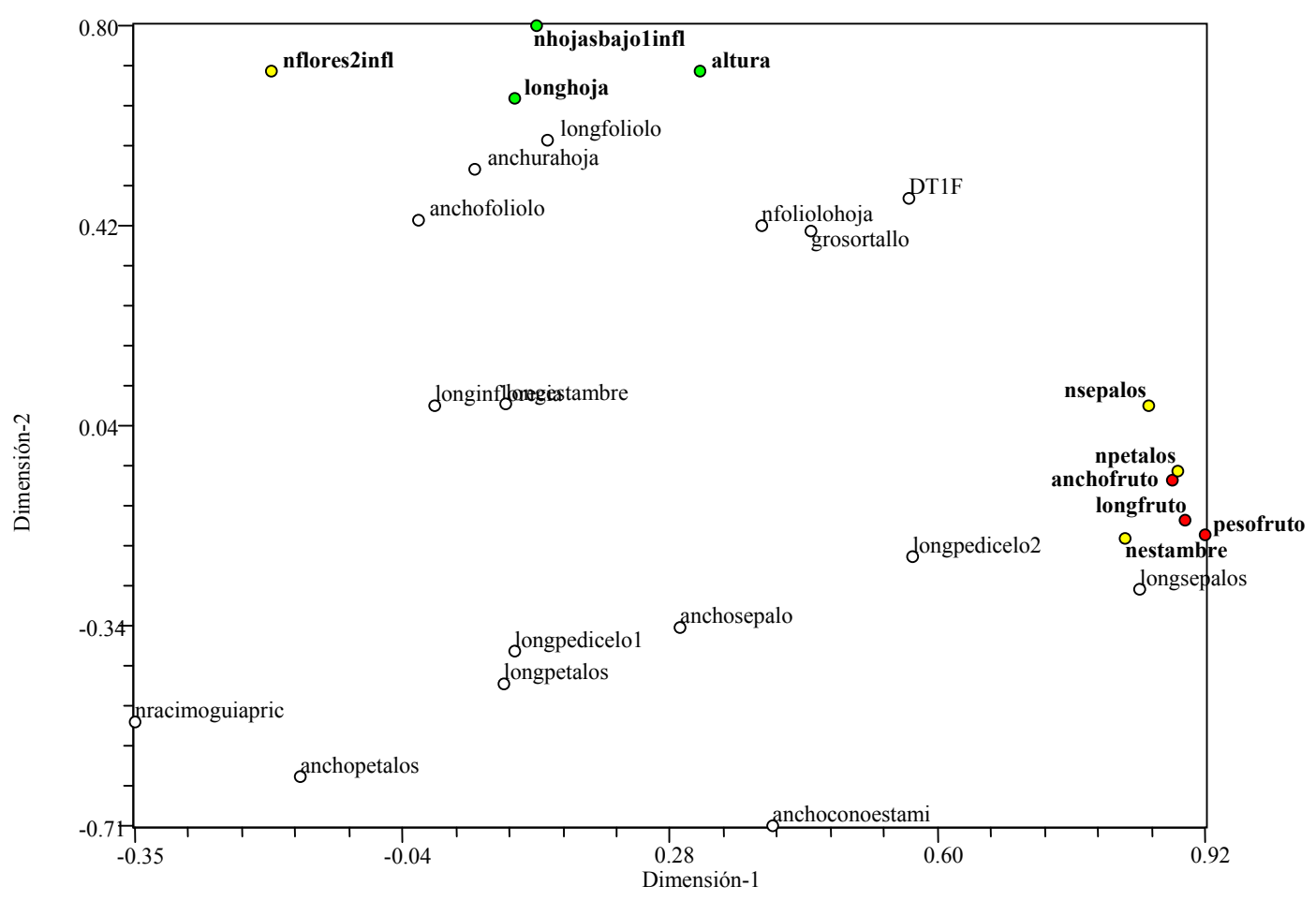

Figura 4.25. Representación de los coeficientes de los caracteres en los vectores propios que definen las dos primeras componentes principales. Entradas de L. pimpinellifolium, para el ensayo 2000-01. En verde se representan los caracteres vegetativos, en amarillo los de flor e inflorescencia y en rojo los de fruto. 


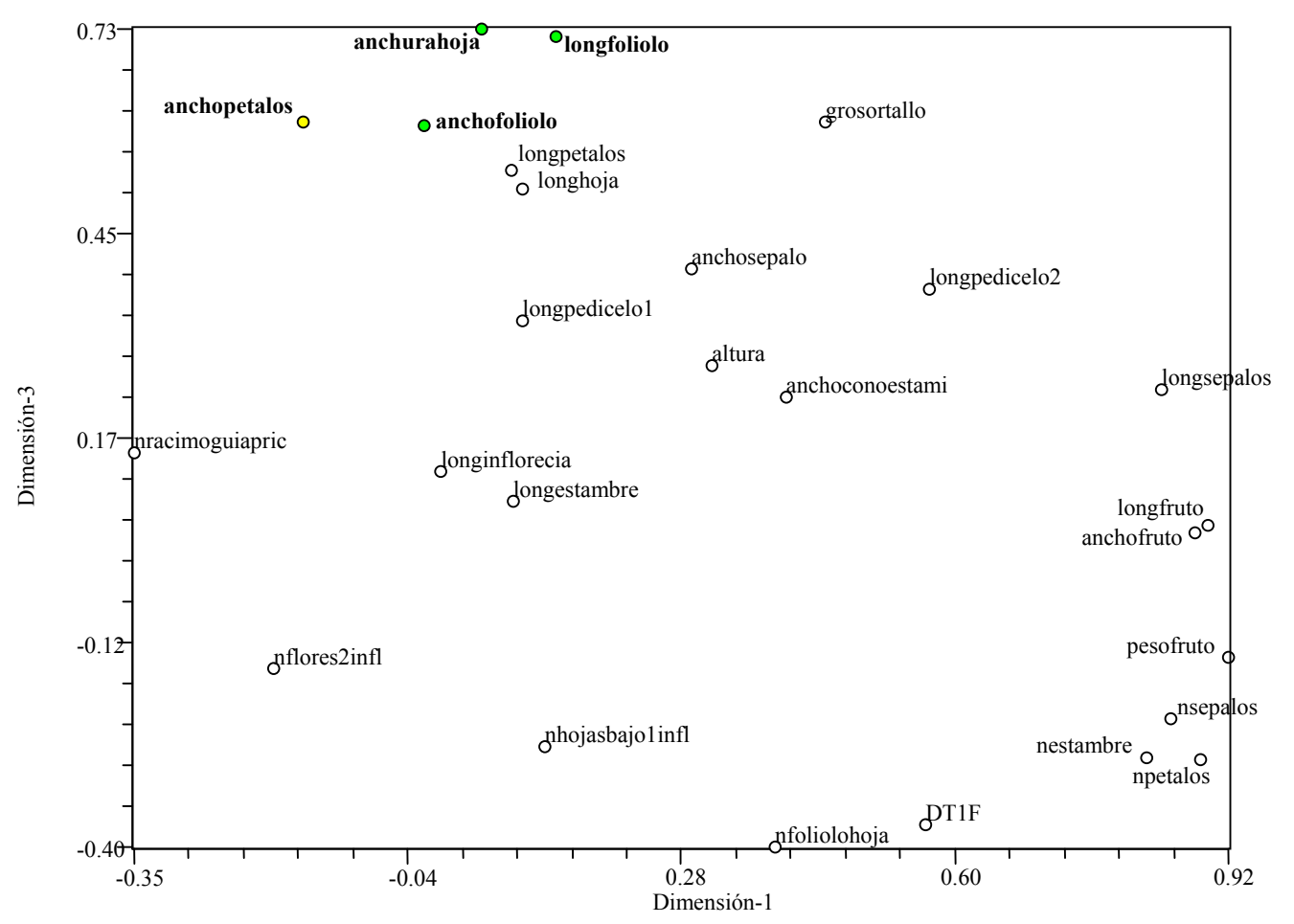

Figura 4.26. Representación de los coeficientes de los caracteres en los vectores propios que definen la primera y tercera componentes principales. Análisis efectuado con las entradas de L. pimpinellifolium ensayadas en 200-01. En verde se representan los caracteres vegetativos, en amarillo los de flor e inflorescencia y en rojo los de fruto.

Al representar las entradas de L. pimpinellifolium sobre las dos primeras componentes se puede observar que la mayoría quedan en el extremo izquierdo del eje de la primera componente, a excepción de las entradas LA 1261, LA 1245, LA 1236, ECU 376 y ECU 415, que presentan unos frutos de mayor tamaño, cercanos a los de $L$. esculentum var. cerasiforme (Figuras 4.27, entradas rodeadas en rojo y Figura 4.28) y número de lóculos distinto a 2 que es el habitual en L. pimpinellifolium. 


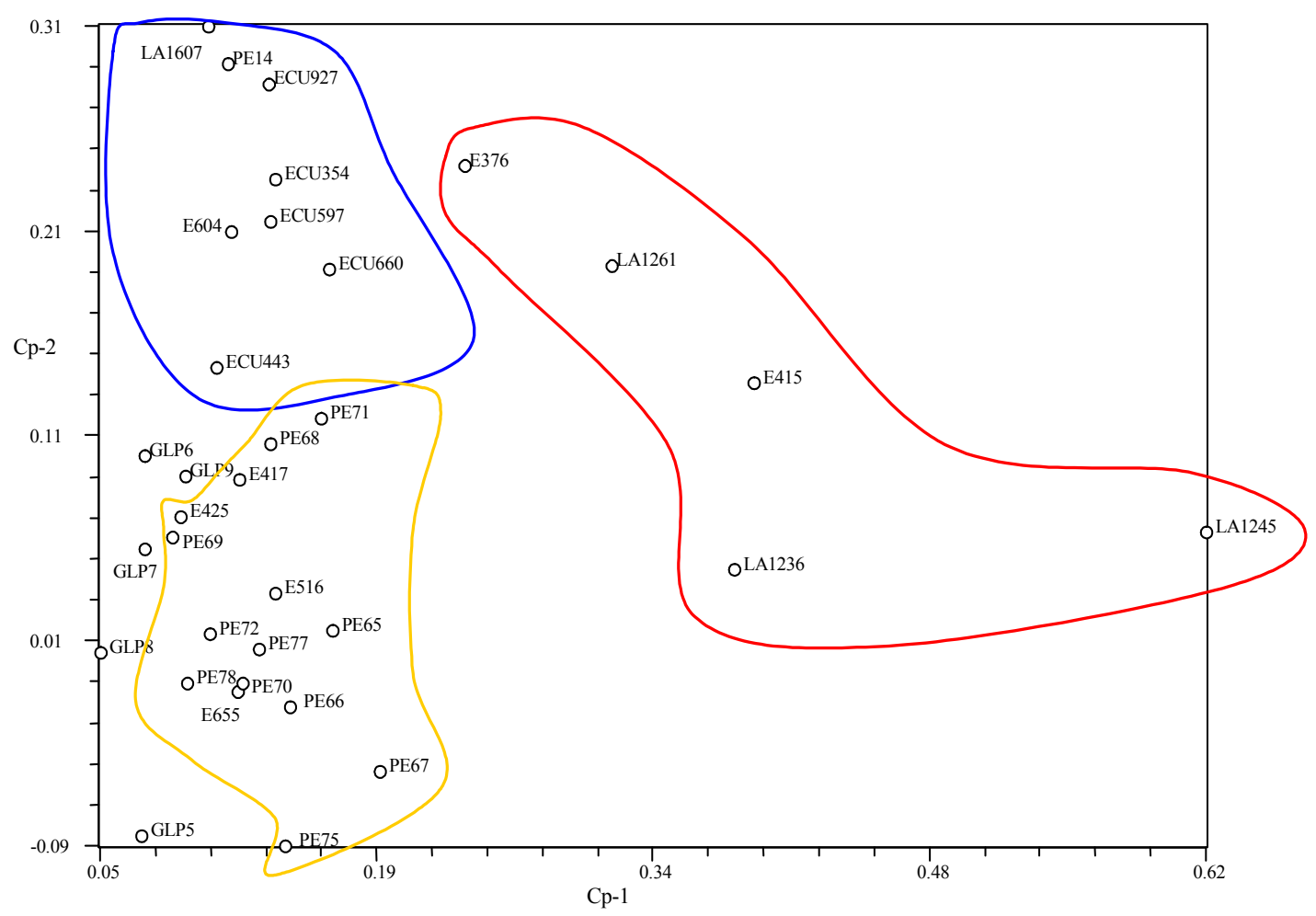

Figura 4.27. Representación de las entradas de L. pimpinellifolium, del ensayo 2000-01, respecto a las componentes principales 1 y 2 . 


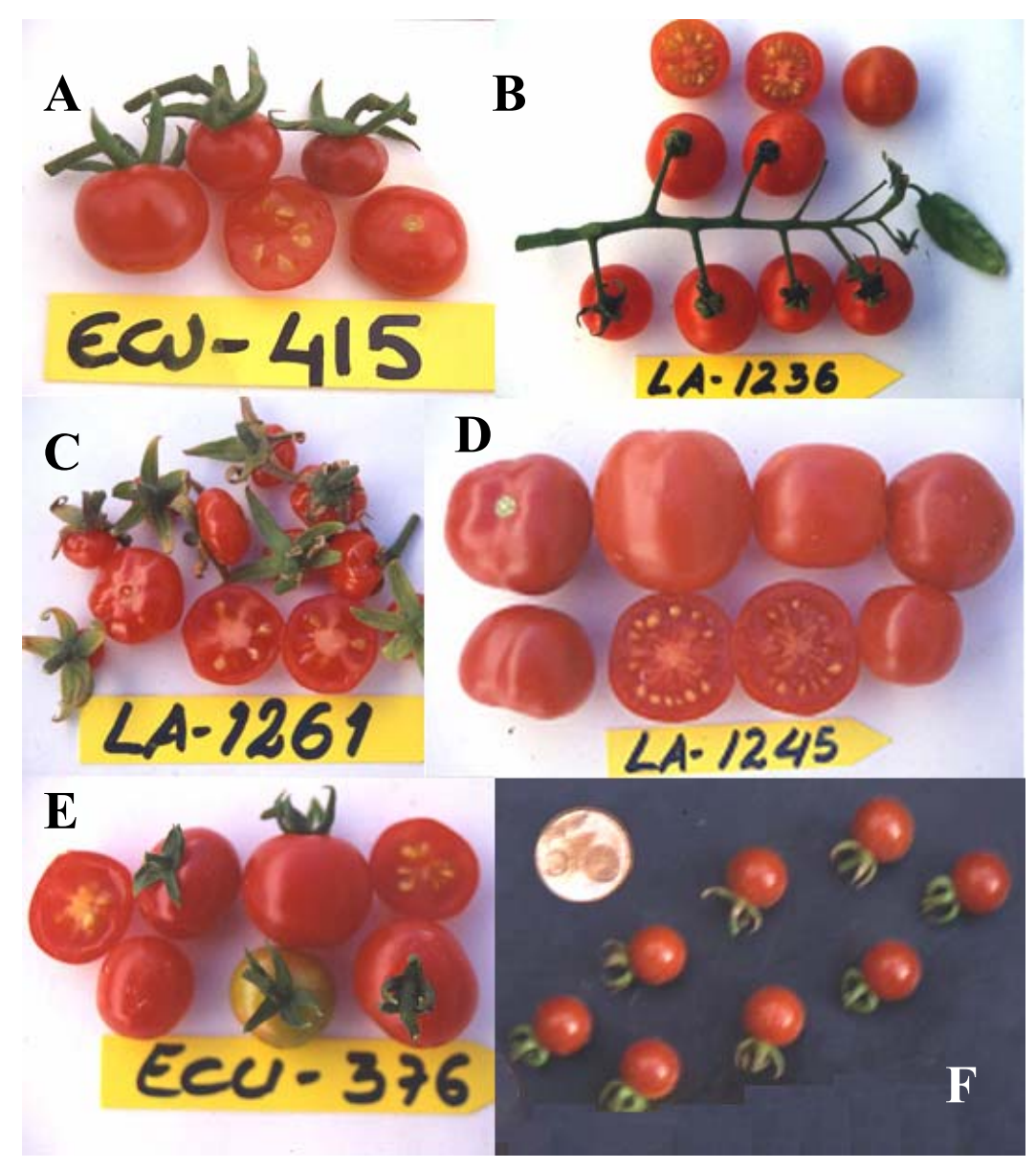

Figura 4.28. Frutos de L. pimpinellifolium. A, B, C, D y E: entradas descritas como formas intermedias, con frutos atípicos. F: frutos típicamente L. pimpinellifolium.

Respecto a la segunda componente se presentan dos agrupaciones. Por un lado las entradas procedentes de Cuzco (Perú, con código PE) (Figura 4.27 rodeadas en amarillo y Figura 4.29), en la parte inferior, que presentan pétalos más anchos, menor número de flores y mayor anchura del cono estaminal (media número de flores de las entradas PE: 7,73, media del resto: 17,04), además de hojas a menudo estándar y color del follaje más oscuro con borde de los foliolos aserrados. A pesar de que el tamaño de sus frutos es similar al de L. pimpinellifolium, su calibre es muy irregular (Figura 4.29), característica muy improbable en esta especie. Dentro de este grupo se encuentran además las entradas ECU-425, ECU-417, ECU-516, ECU-655, estas dos últimas también de origen peruano.

El tercer grupo queda constituido por la mayoría de entradas de Ecuador, con caracteres típicamente de L. pimpinellifolium (Figura 4.27, entradas rodeadas en azul). 


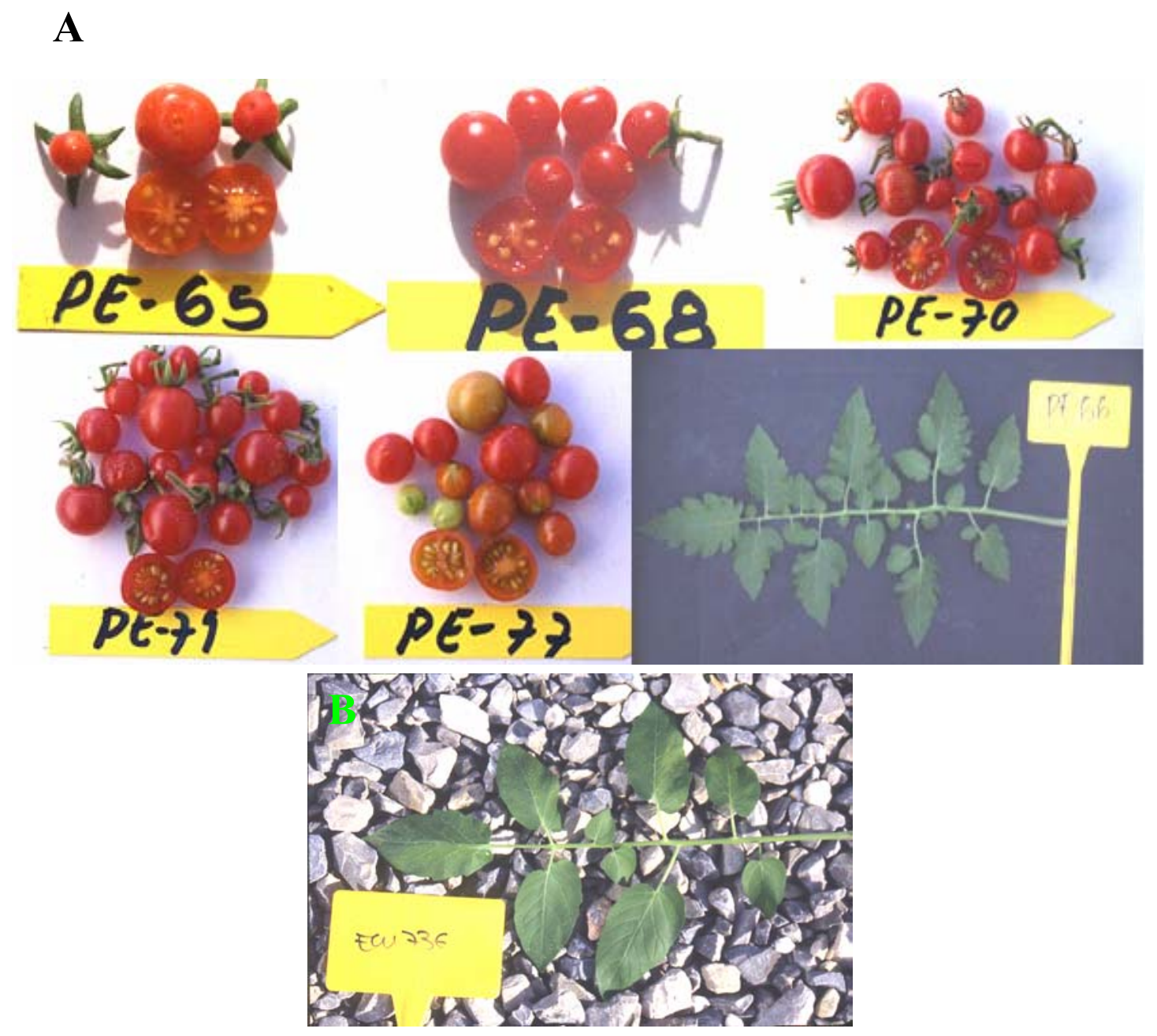

Figura 4.29.A: Frutos y hoja de algunas entradas colectadas en Cuzco (Perú). B: Hoja típica de L. pimpinellifolium de la entrada ECU736 colectada en La Libertad (Perú).

\section{Agrupación de las entradas según el análisis cluster: Análisis $Q$}

Las agrupaciones vistas anteriormente se mantienen con bastante consistencia en los análisis cluster efectuados tanto con los caracteres cuantitativos (Figura 4.30) como para los cualitativos (representaremos únicamente la primera, puesto que la segunda no aporta ninguna información adicional). Como puede observarse, aparecen de nuevo agrupadas las entradas LA 1261, LA 1245, LA 1236, ECU 376 y ECU 415, siguiendo las entradas de Perú y Galápagos y finalmente en el otro extremo las procedentes de Ecuador. 


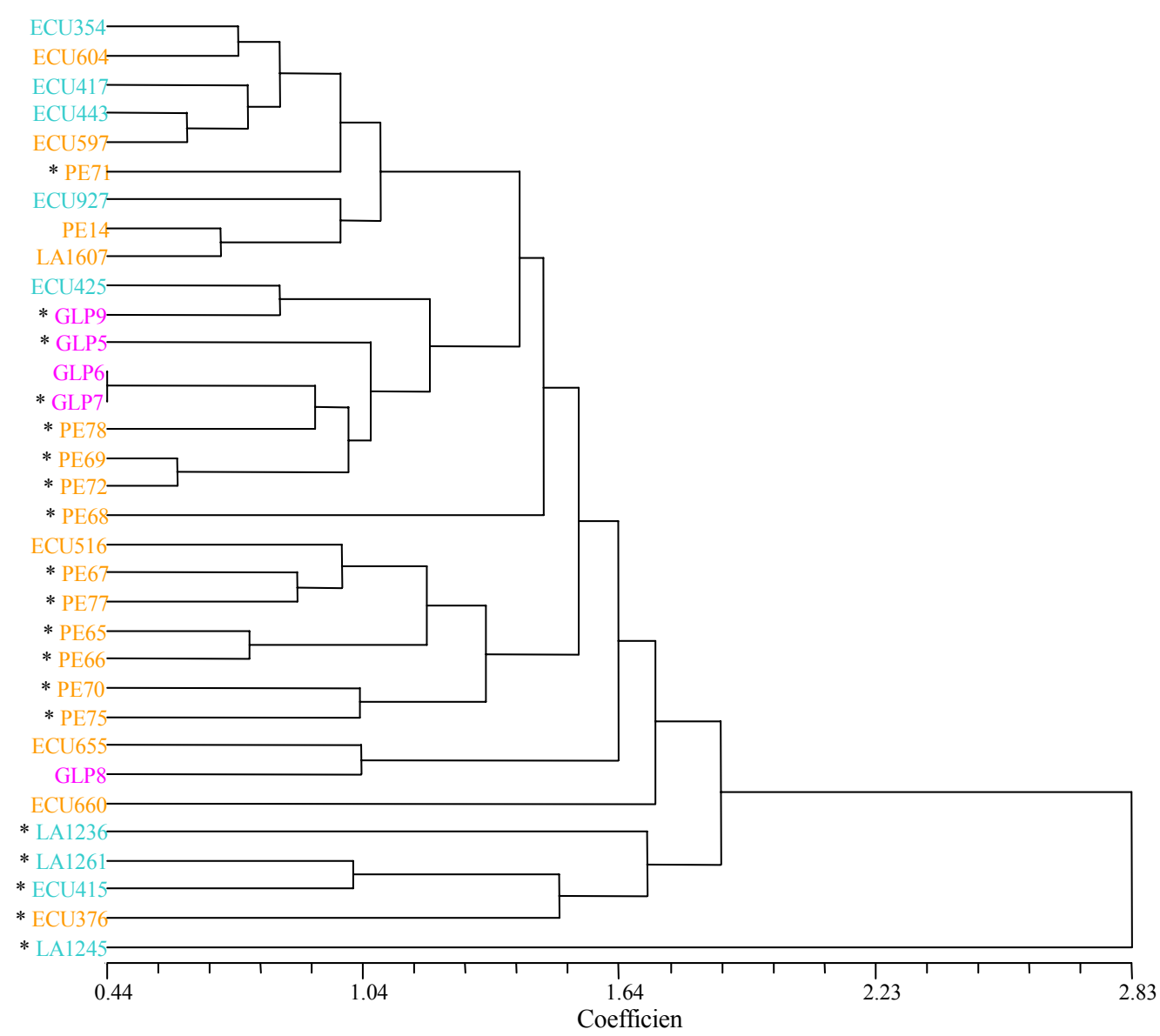

Figura 4.30. Dendrograma de las entradas de L. pimpinellifolium, del ensayo 2000-01, obtenido a partir de los datos cuantitativos, utilizando distancias euclídeas, con método de análisis UPGMA. En color naranja se representan las entradas procedentes de Perú, en rosa las de las Islas Galápagos y en azul las de Ecuador. Se señalan con asterisco las formas intermedias entre L. pimpinellifolium y L. esculentum var. cerasiforme.

\section{Discusión}

Las entradas procedentes de Cuzco no fueron adscritas en el momento de la recolección a ninguna especie en concreto por no tener unas características morfológicas que permitieran hacerlo con fiabilidad (Cuartero et al., 1985). Estas entradas proceden del Valle de Urubamba, lugar donde no ha sido descrita hasta el momento esta especie. De hecho, ninguna entrada de la colección del Tomato Genetic Resources Center, una de las principales colecciones de especies silvestres de tomate del mundo, es de esta procedencia. En la citada colección existen sin embargo, entradas de L. esculentum var. cerasiforme procedentes de diversas regiones ubicadas en el Valle de Urubamba (Figura 4.31), una de las cuales está incluida en este trabajo (LA 1312). Sin embargo, las características de nuestras entradas no se ajustan tampoco a las de la variedad cerasiforme. Una hipótesis para explicar la presencia de estas plantas en este 
lugar podría ser su introducción por el hombre y cruzamientos posteriores con plantas de cerasiforme existentes en esa área. Su posición intermedia entre las entradas de $L$. esculentum var. cerasiforme en el dendrograma realizado con todos los caracteres morfológicos analizados y la posición también cercana a las entradas de cerasiforme en el cluster molecular (Figura 4.38), apoyaría esta hipótesis. Este hecho puede tener implicaciones importantes en la pérdida de diversidad genética de las especies presentes en esta área con anterioridad a la llegada de las plantas supuestamente transportadas.

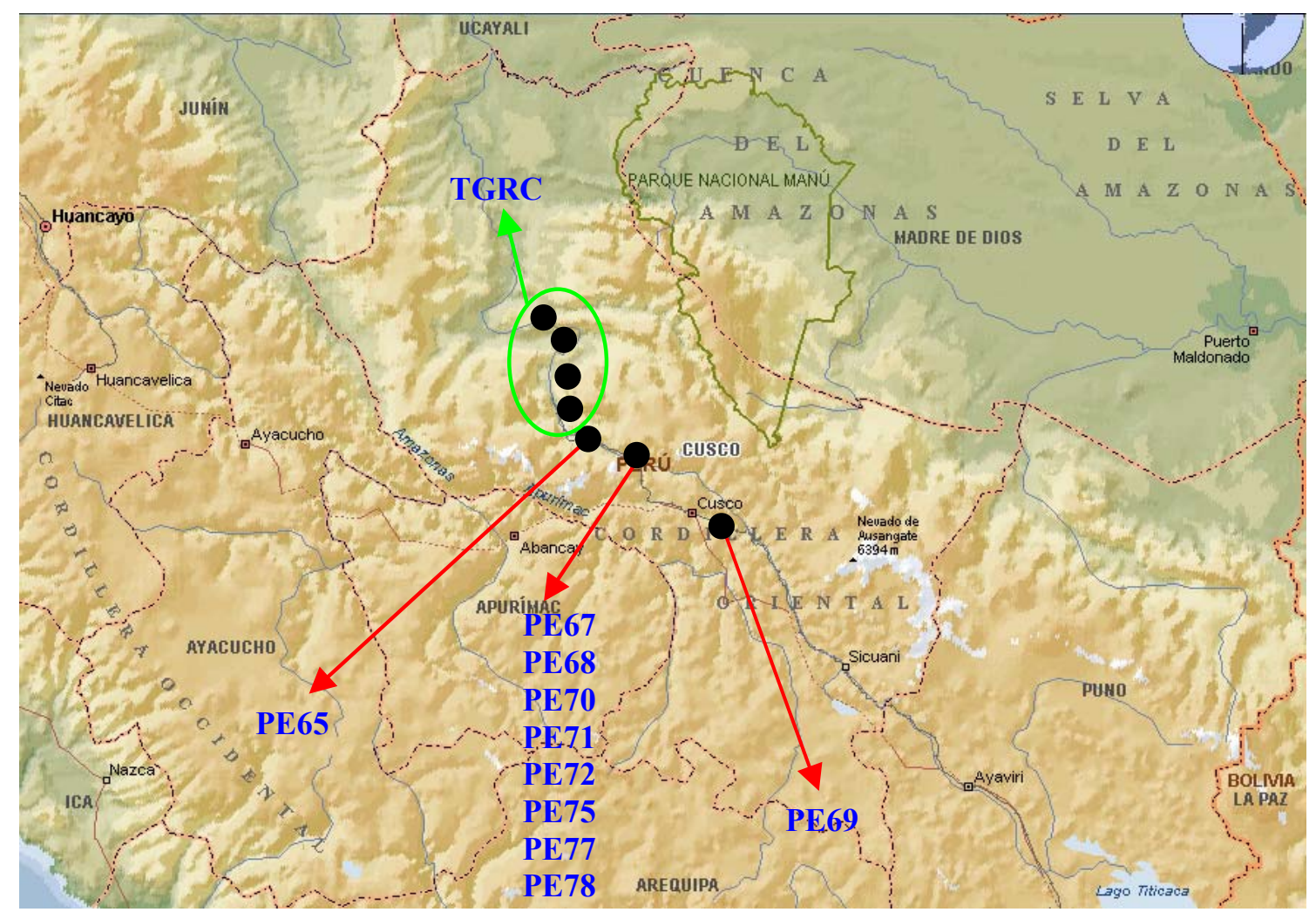

Figura 4.31. Localización geográfica de las entradas colectadas en el Valle de Urubamba, Departamento de Cuzco, incluidas en ensayo 2000-01 y las de L. esculentum var. cerasiforme del TGRC.

Del mismo modo, las entradas ECU376, LA1261, LA1245, LA1236 y ECU415, quedan absolutamente separadas del resto, y dado el anormal tamaño y forma de sus frutos, parece lógico pensar que se trata de formas derivadas por cruzamientos entre plantas de distintas especies.

Las entradas de Galápagos quedan también formando un grupo único. Este grupo será comentado en el ensayo efectuado en la campaña 2001-02, que incluye un número superior de entradas de esta procedencia. 


\section{1. 3. Análisis de las entradas ensayadas en la Campaña 2001-2002: Lycopersicon}

\section{pimpinellifolium}

En este ensayo se incluyeron 11 entradas de Ecuador, 15 de Galápagos, y 47 de Perú (13 de Piura, 11 de Lambayeque, 7 de Cajamarca y 12 de La Libertad, 3 de Ancash y 2 de Lima). Con ello queda suficientemente representada la zona norte de Perú y también las islas Galápagos.

\section{Agrupación de las entradas según ACP}

Las tres primeras componentes explicaron un $22,67 \%$, un $13,20 \%$ y un $8,8 \%$ de la variación observada respectivamente, acumulando entre ellas un 44,76\% de la variación total.

Los caracteres vegetativos, longitud y anchura de la hoja y longitud y anchura del foliolo, y de flor, longitud y anchura de los pétalos y longitud de los estambres, son los que explicaron la mayor parte de la variación respecto a la primera componente principal (Figura 4.32). Con la segunda componente el peso, anchura y longitud del fruto fueron los caracteres más correlacionados. En el caso de la tercera componente la altura de la planta hasta el tercer racimo y el número de hojas bajo la primera inflorescencia estuvieron positivamente correlacionados, mientras que la abundancia de foliolillos lo estuvo negativamente (Figura 4.33).

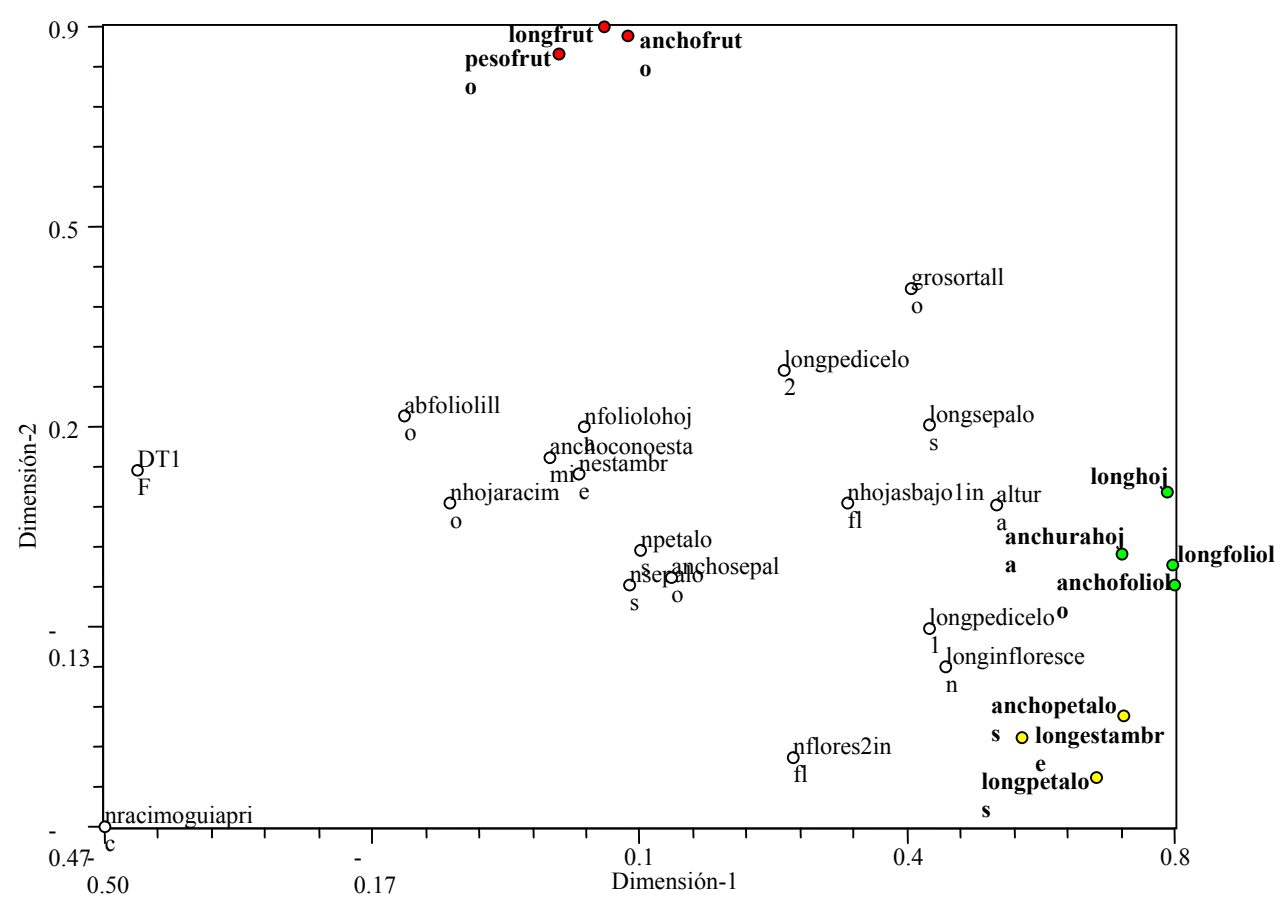

Figura 4.32. Representación de los coeficientes de los caracteres en los vectores propios que definen la primera y segunda componentes principales. Análisis efectuado con las entradas de L. pimpinellifolium ensayadas en 2001-02. En verde se representan los caracteres vegetativos, en amarillo los de flor e inflorescencia y en rojo los de fruto. 


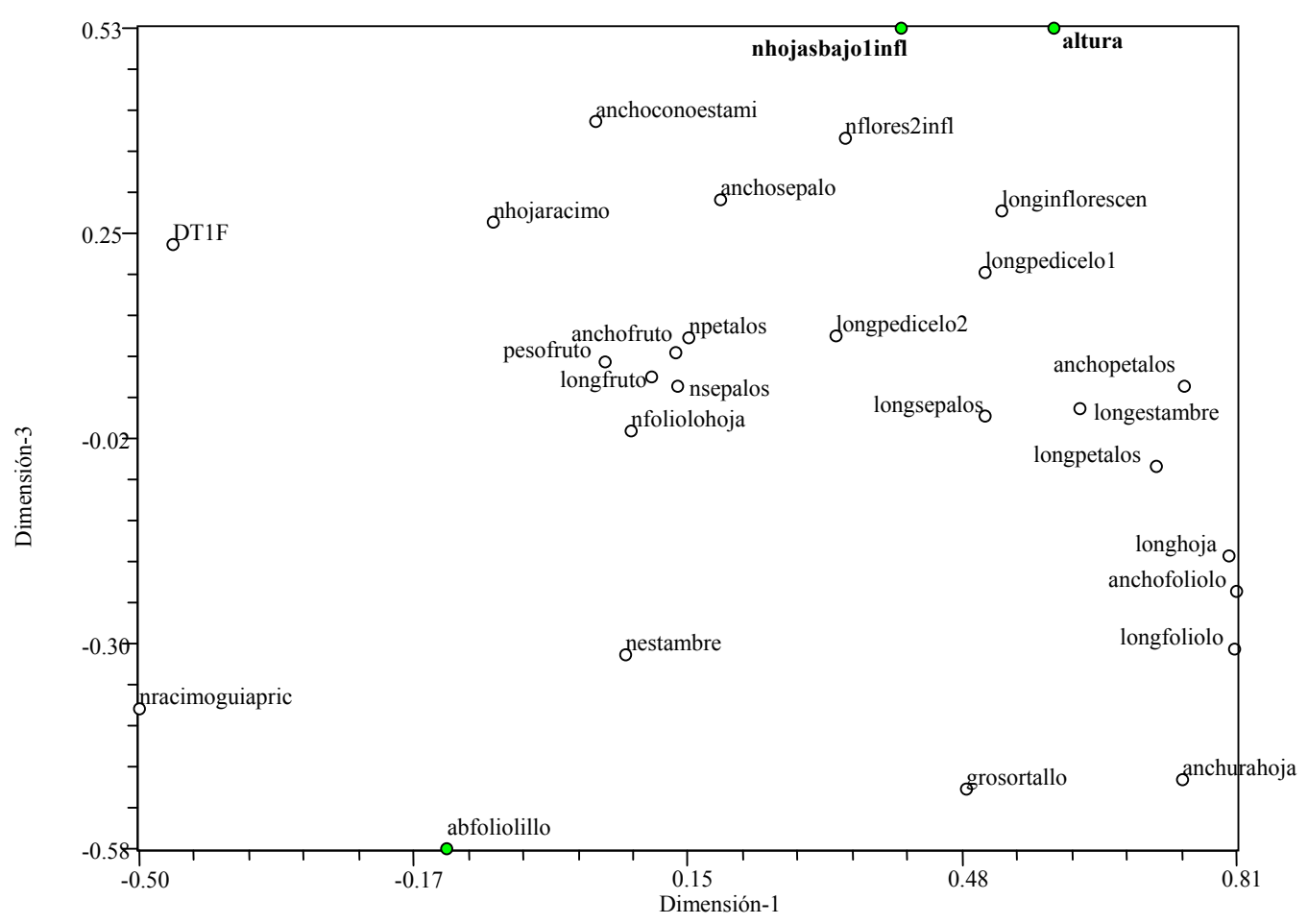

Figura 4.33. Representación de los coeficientes de los caracteres en los vectores propios que definen la primera y tercera componentes principales. Análisis efectuado con las entradas de L. pimpinellifolium ensayadas en 2001-02. En verde se representan los caracteres vegetativos.

Al proyectar las entradas respecto a las dos primeras componentes se observa que se distribuyen de forma continua a lo largo del eje de la primera componente, indicando la existencia de una elevada variabilidad en cuanto a caracteres vegetativos y de flor (Figura 4.34). 


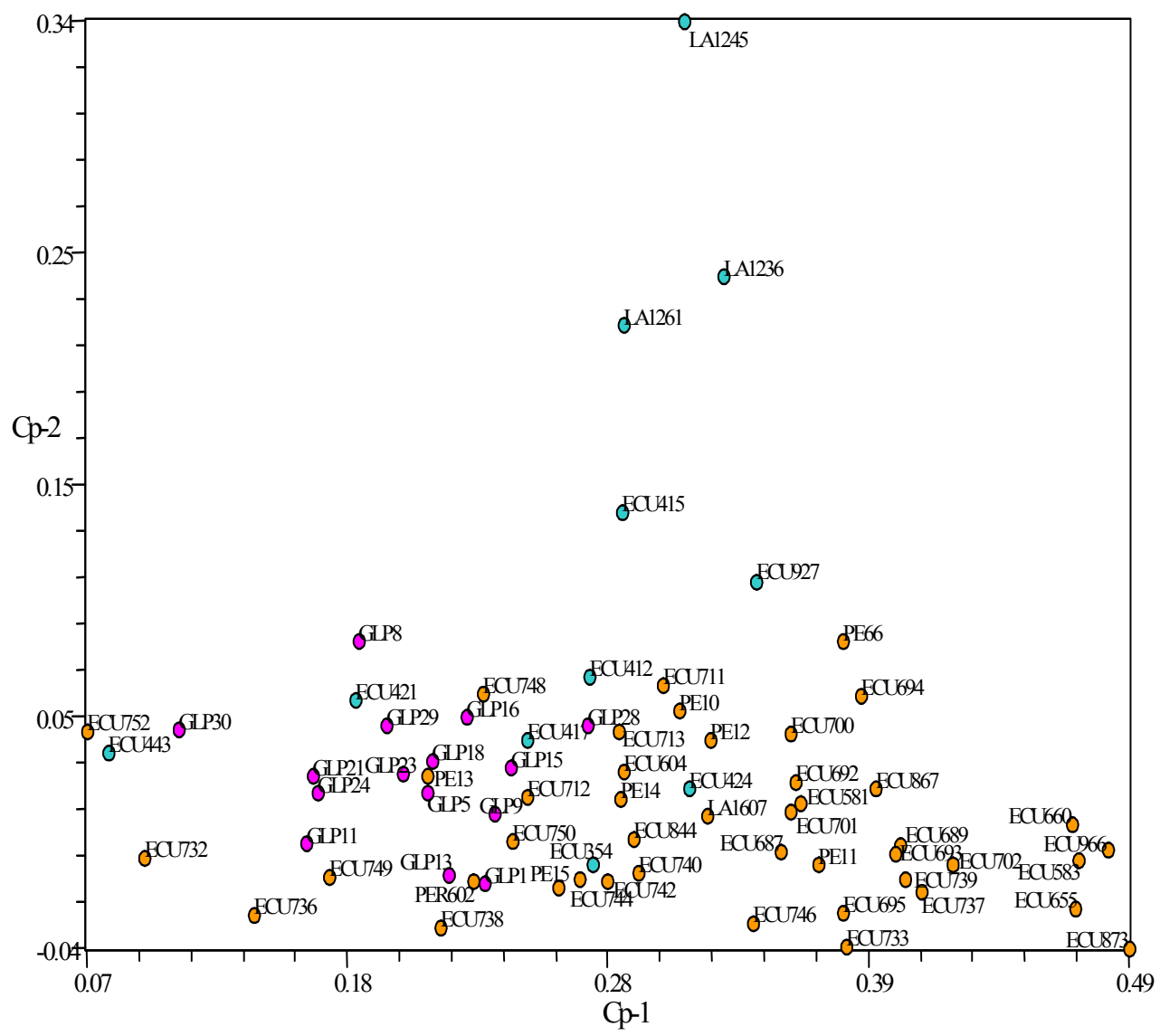

Figura 4.34. Representación de las entradas de L. pimpinellifolium del ensayo 2001-02 en el plano de las componentes principales 1 y 2 . En naranja se representan las entradas procedentes de Perú, en rosa las de las islas Galápagos y en azul las de Ecuador.

Sin embargo, en cuanto a la segunda componente se sitúan la mayoría de ellas cercanas al origen, a excepción de LA 1245, LA 1236, LA 1261 y ECU 415, que se distribuyen a lo largo del eje. Ello es debido a las características de fruto atípicas (mayor peso y tamaño) de estas entradas, vistas ya en el ensayo del pasado año. Es de destacar también la agrupación de las entradas por su origen, quedando a la derecha de la figura las procedentes de Perú, mientras que las de Ecuador (de Galápagos la mayor parte) se sitúan a la izquierda. De hecho, existen marcadas diferencias entre ambos grupos de entradas. Así, las procedentes de Perú, presentan órganos florales y hojas de mayor tamaño, que las de Galápagos (caracteres más correlacionados con la primera componente principal). En general, las entradas de Perú tienen plantas más altas, con mayor número de hojas bajo la primera inflorescencia, más precoces, de hojas más grandes y con escasa presencia de foliolillos y en muchas ocasiones de tipo estándar con bordes aserrados u ondulados, inflorescencias más largas y mayor número de flores por 
inflorescencia (Figura 4.36). Las flores son también más grandes (pétalos más largos y anchos).

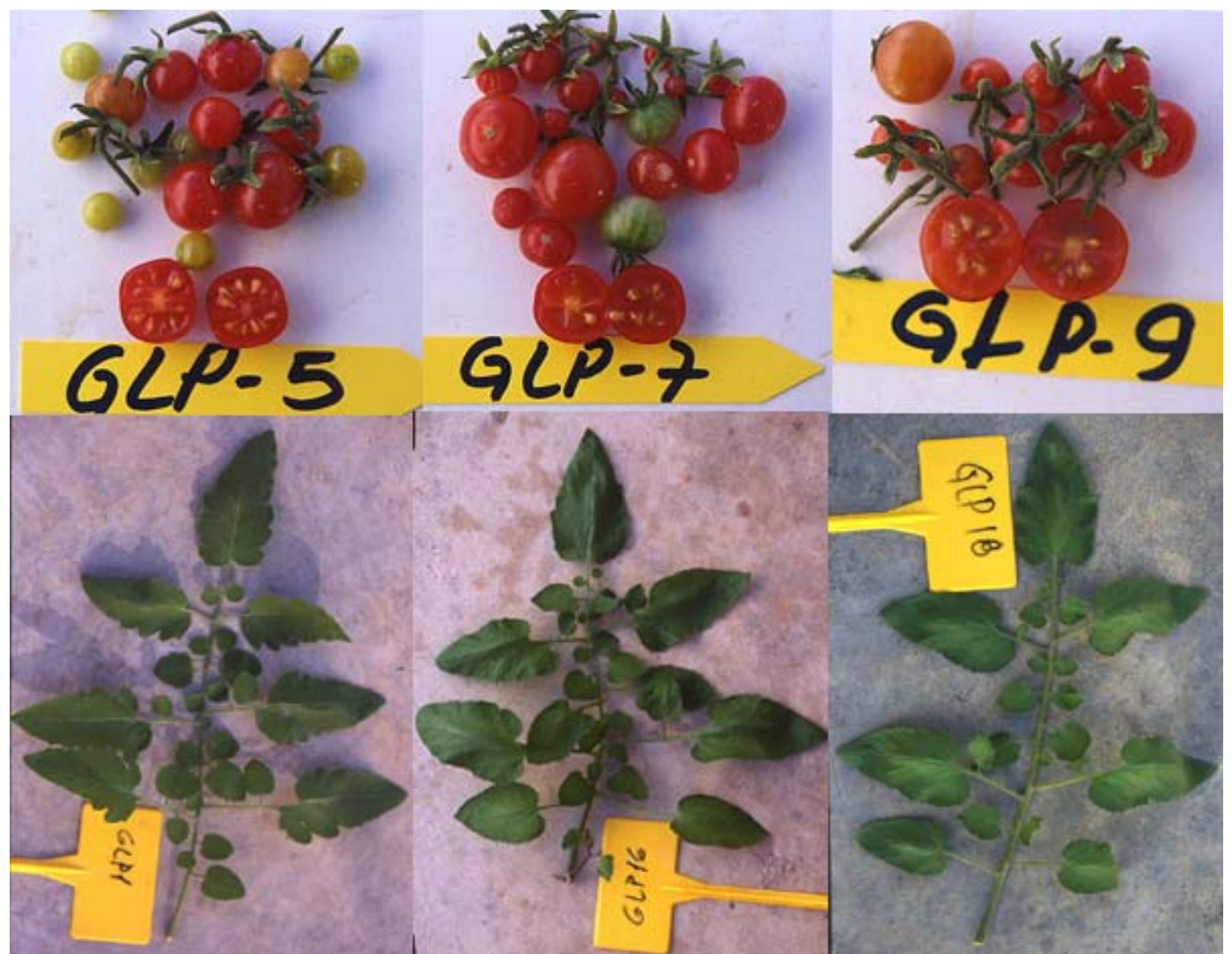

Figura 4.35. Frutos y hojas de diferentes entradas colectadas en las Islas Galápagos. 

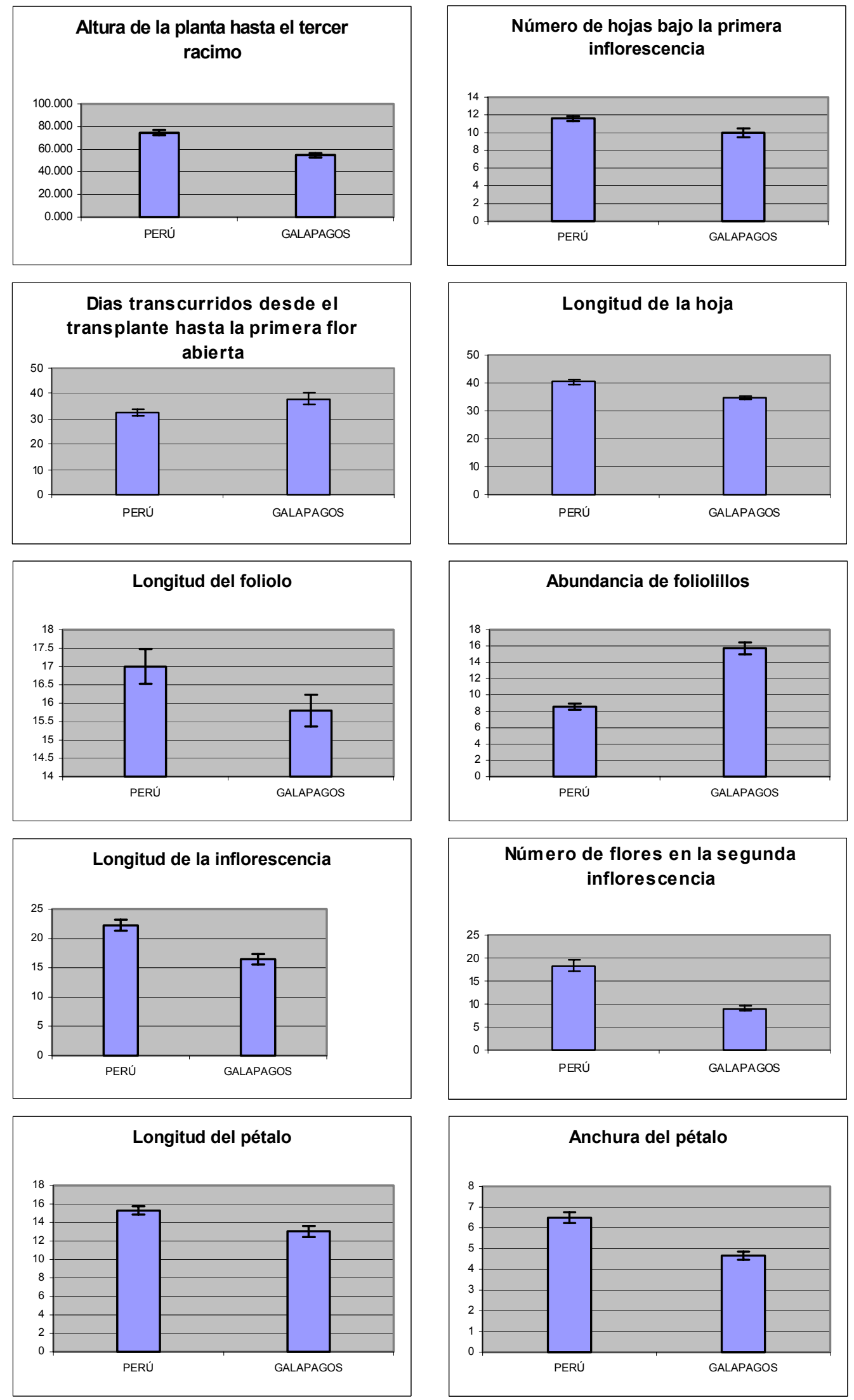

Figura 4.36. Histogramas realizados con los caracteres cualitativos de hoja y de flor de las entradas de L. pimpinellifolium procedentes de Perú y Galápagos del ensayo 200102. Las barras azules representan los valores medios para los caracteres diferenciales entre las dos procedencias. Las barritas representan los errores estándar. 
Por su parte, las entradas continentales de Ecuador tienden a distribuirse junto con las de Galápagos, a excepción de las comentadas anteriormente (LA 1245, LA 1236, LA 1261 y ECU 415) que se mantienen separadas del resto de entradas y distribuidas a lo largo del segundo eje, debido al tamaño de sus frutos.

\section{Estudio de la alogamia de las entradas según su procedencia.}

En estudios anteriores sobre variación genética de esta especie (Rick et al., 1977) se ha puesto de manifiesto una variación en cuanto al porcentaje de alogamia en función de la latitud. Estos autores encontraron una elevada correlación entre la exerción estigmática y tamaño de las flores y el grado de alogamia.

En las entradas estudiadas en este trabajo, se observa una gradación en cuanto a la exerción estigmática, encontrándose más frecuentemente entradas con estilo muy proyectado en las localidades más al Norte de Perú, Piura, y Lambayeque, mientras que a medida que bajamos hacia el sur (Departamentos de Cajamarca y La Libertad) es más frecuente la aparición de entradas con estilo al mismo nivel que el cono de anteras o incluso insertos (Figura 4.37). La mayor exerción estigmática va asociada por lo general a un mayor tamaño de los órganos florales (longitud y anchura de los pétalos y longitud de los estambres). Estos resultados concuerdan con los obtenidos por Rick et al., 1977, en los que las entradas de Piura y Lambayeque destacan también por su exerción estigmática y mayor tamaño de sus flores.
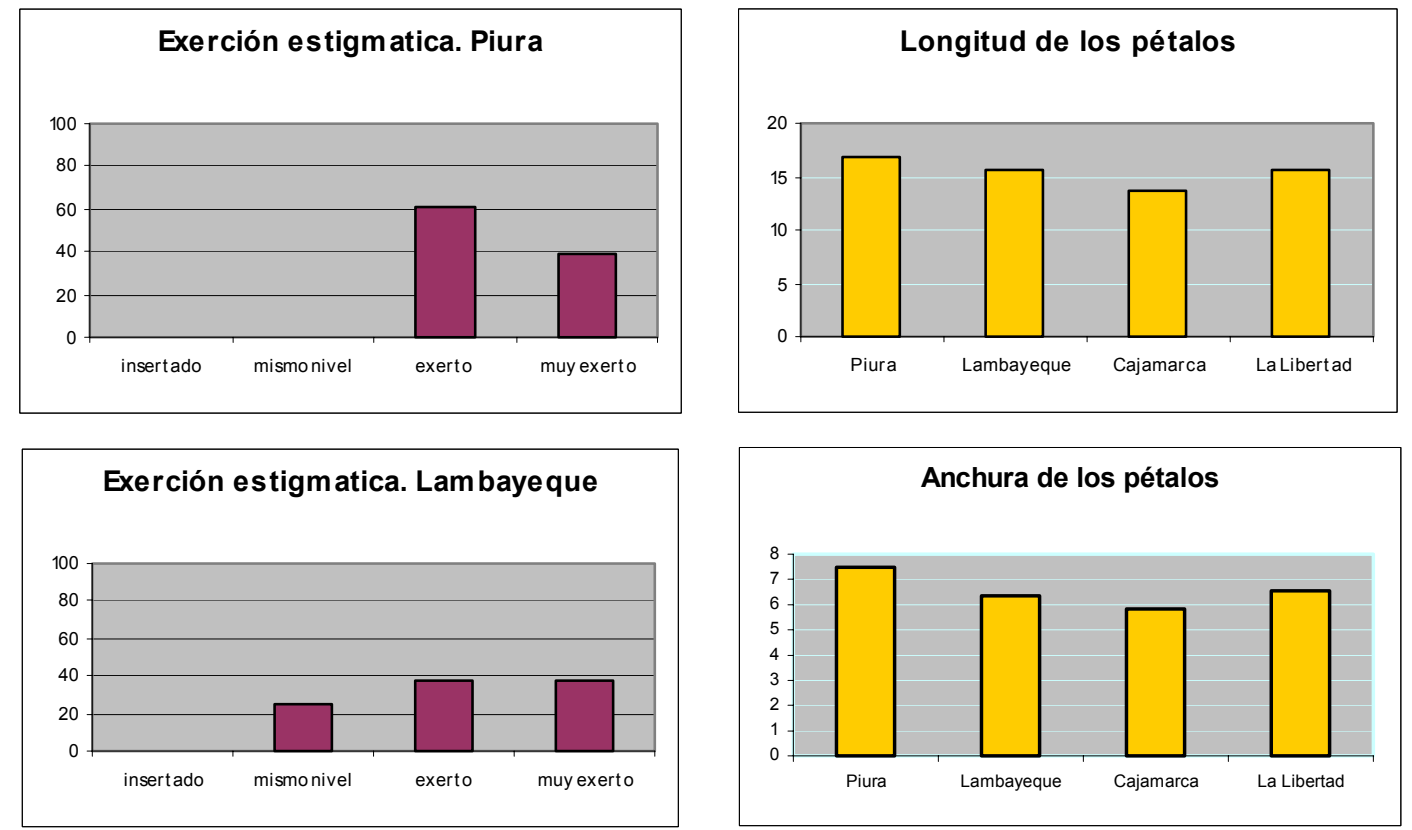

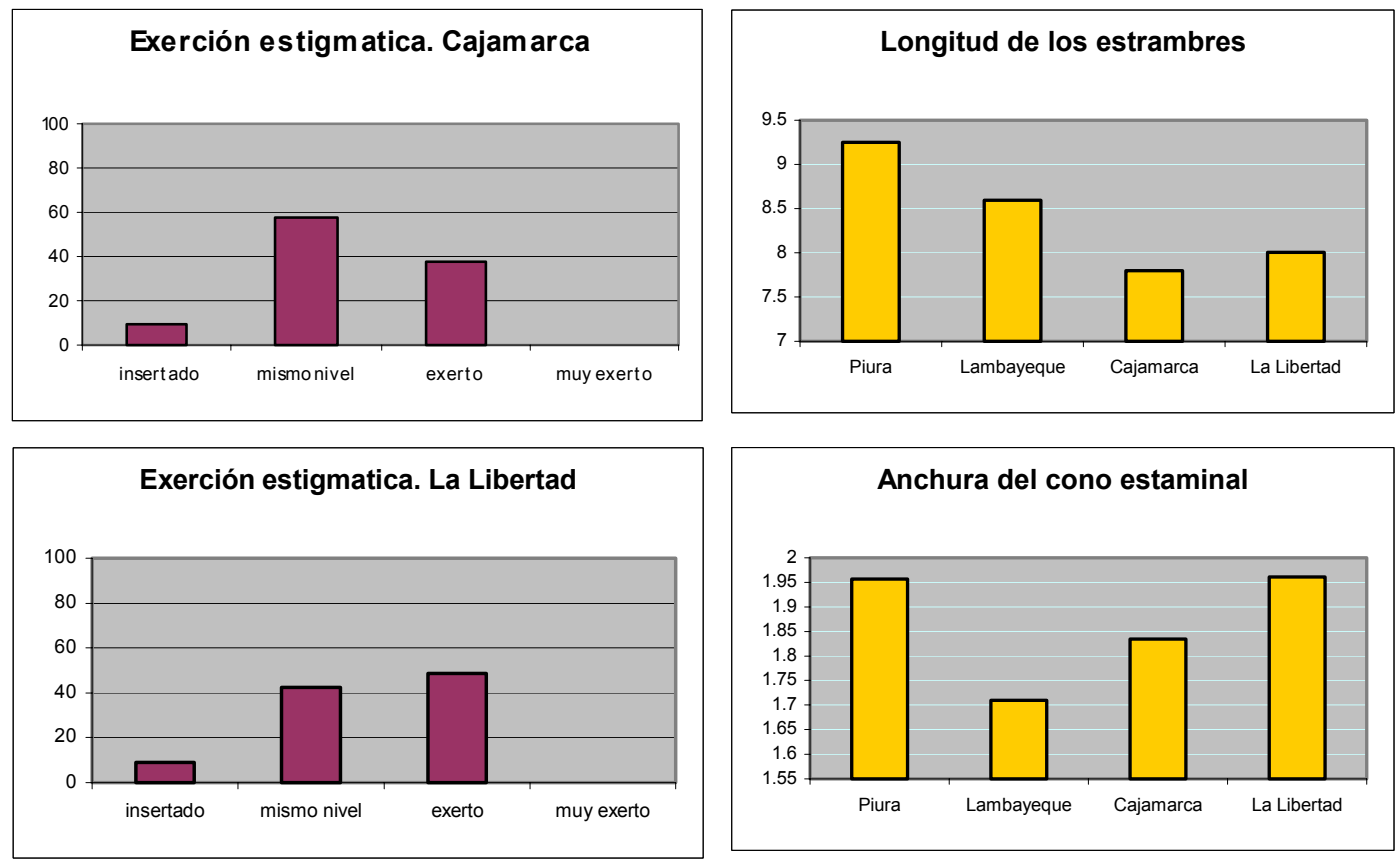

Figura 4.37. Histogramas de frecuencia de la exerción estigmática y tamaño de los órganos florales, de las entradas de L. pimpinellifolium del ensayo 2001-02, recolectadas en los Departamentos costeros más septentrionales de Perú: Piura, Lambayeque, Cajamarca y La Libertad.

En localidades situadas más al Sur (Ancash y Lima) la tendencia no se mantiene con exactitud (histogramas no mostrados). Sin embargo, el escaso número de entradas procedentes de estas localidades (3 de Ancash y 2 de Lima) hace que las conclusiones que puedan extraerse de ellas sean cuestionables. Destaca, por otra parte, la exerción estigmática encontrada en las entradas procedentes de Cuzco, la mayor de las entradas recolectadas en Perú. Por otro lado, en las entradas procedentes de Ecuador, el estilo se sitúa al mismo nivel o proyectado, destacando las entradas de Galápagos (Ecuador), en las que la situación es similar a la descrita en Cuzco.

\section{Discusión.}

El conjunto de entradas inicialmente incluidas en este trabajo como pertenecientes a la especie L. pimpinellifolium ha resultado ser un "pool" génico que incluye formas claramente diferentes a esta especie.

\section{Entradas procedentes de las Islas Galápagos}

En las expediciones efectuadas a las islas Galápagos se han identificado también entradas hasta ahora no descritas en estudios anteriores por otros autores. Además de $L$. cheesmannii, especie endémica de estas islas, Mackinney et al (1954) y Rick (1956) 
describieron otra forma que fue inicialmente considerada como un tipo anómalo de $L$. pimpinellifolium por su semejanza con esta especie. Más tarde, Rick (1963), en base a ciertos caracteres compartidos con L. cheesmannii, consideró a estas formas como un tipo específico de L. chessmannii, denominándolas L. cheesmanii tipo "pimpinellifolium". En colectas realizadas recientemente por el equipo del COMAV se recolectaron entre otras, las entradas incluidas en este trabajo (entradas con código GLP). Estas entradas presentan diferencias notables con las denominadas por Rick $L$. cheesmannii tipo "pimpinellifolium", por ser mucho más similares a L. pimpinellifolium y han sido denominadas "Gal red small" por Nuez et al., 2003 (en prensa). Sin embargo, la diferencia entre ellas y las pimpinellifolium procedentes de los Departamentos del norte de Perú, son notables en numerosas características vegetativas y de flor, dificultando la verdadera clasificación y sobre todo la determinación del origen de estas plantas.

El análisis molecular efectuado ha permitido la construcción de una hipótesis que se expondrá en el Apartado 4.2.1.

\section{Estudio de la alogamia de las entradas según su procedencia}

El estudio de las 43 entradas procedentes de los Departamentos de Piura, Lambayeque, Cajamarca y La Libertad ha permitido constatar la existencia de una gradación en la variabilidad para características florales, algunas de ellas relacionadas con la alogamia de la especie. Estas observaciones coinciden con las efectuadas por Rick (1976). A raíz de unos estudios previos sobre algunas entradas de esta especie, este autor puso de manifiesto la escasa uniformidad de la misma, determinando la existencia de marcadas clinas en el tamaño y estructuras florales y en el grado de exerción estigmática. Este hecho tiene importantes implicaciones para el muestreo de poblaciones y para su regeneración en colecciones de germoplasma. Así, en las poblaciones en las que el grado de exerción estigmática, y por consiguiente la alogamia, es mayor (Piura y Lambayeque, en nuestro experimento), deben recolectarse mayor cantidad de plantas, a fin de tener una representación más completa de los posibles alelos existentes en la población. Asimismo, para la reproducción de estas entradas será necesario disponer de un mayor número de plantas. También ha de tenerse en cuenta el aislamiento en los ensayos de reproducción, ya que según ha demostrado Widrlechner (1987), las entradas con un mayor nivel de polinización cruzada en unos lugares, suelen serlo también en otros lugares con especies de insectos diferentes, debido probablemente a la mayor 
atracción ejercida hacia diversos tipos de insectos por la vistosidad de las flores más grandes propias de las entradas más alógamas.

Rick et al. (1977) trata de explicar el porqué de la existencia de esta variabilidad en el sistema reproductivo de L. pimpinellifolium. Los aspectos ecológicos de los diferentes hábitats no parecen ser suficientes para justificar tales diferencias. Tampoco sería necesaria una mayor variabilidad para explicar la adaptación a determinados lugares, ya que L. esculentum var. cerasiforme, que comparte hábitats con L. pimpinellifolium, muestra un sistema reproductivo marcadamente autógamo en lugares donde $L$. pimpinellifolium tiene elevadas tasas de alogamia. La teoría más probable es que la parte norte de Perú es el centro de origen de L. pimpinellifolium, donde se mantienen los mayores niveles de alogamia. La migración fuera de esa región habría favorecido la autogamia. Esta teoría estaría de acuerdo con la hipótesis actual sobre la evolución de los sistemas reproductivos propuesta por Stebbins (1957), en la que se considera la alogamia como un carácter primitivo, a partir del cual se originarían las formas más autógamas. Éstas habrían sido seleccionadas para asegurar la fijación de los genotipos más adaptados a las nuevas condiciones. La autogamia supondría también una ventaja en circunstancias en las que los insectos polinizadores estuvieran ausentes. Una vez establecido un genotipo autógamo ventajoso, la existencia de flores más vistosas en otros más alógamos no tendría ninguna ventaja y con el tiempo irían desapareciendo. En este aspecto existe un paralelismo entre otras especies hermanas del género Lycopersion, L. parviflorum y L. chmielewskii, en las que la primera evolucionó hacia autogamia a partir de la segunda que conserva su alogamia en la actualidad. 


\section{2. ANÁLISIS DE LA VARIABILIDAD MOLECULAR MEDIANTE AFLP: ESTUDIO CONJUNTO DE LAS DOS CAMPAÑAS.}

\section{2. 1. Análisis de todas las entradas}

\section{Agrupación de las entradas en función de la distancia genética}

\section{Análisis Cluster}

El árbol construido con la totalidad de entradas de este trabajo, incluidas las formas intermedias, usando el coeficiente de Dice (1945) y el método UPGMA, presentó un coeficiente cofenético de $\mathrm{r}=0,94$, indicando un buen ajuste del árbol a la matriz de distancias (Figura 4.38). Los primeros nudos (I, II, III, IV y V) corresponden a entradas únicas, todas ellas de L. pimpinellifolium de Ecuador, a excepción de una que es de Perú y de otra que es de cerasiforme (Ecuador).

Después de estas separaciones se produce una bifurcación (grupos VI-1 y VI-2), agrupándose en el VI-2 la mayor parte de entradas de L. pimpinellifolium. Estas entradas, aunque no de una forma significativa, tienden a agruparse en dos bloques, uno constituido por las procedentes de Piura y Lambayeque, los Departamentos más al norte de Perú, y el otro por las de Cajamarca y La Libertad. Esta agrupación se mantiene consistente con la proporcionada por el análisis cluster efectuado con los datos moleculares del conjunto de entradas de L. pimpinellifolium (Apartado 4.2.4, Figura 4.44).

El grupo VI-1 se subdivide en dos, VII-1 y VII-2, éste ultimo formado sólo por dos entradas, mientras el otro incluye al resto de entradas del análisis: las de L. esculentum, las de L. esculentum var. cerasiforme y también algunas entradas de L. pimpinellifolium. Este gran grupo se subdivide en dos, VII-1-1 y VII-1-2. El primero incluye casi todas las entradas procedentes de Galápagos, mientras que el VII-1-2 aparece dividido en otros 6, en los que se mezclan entre sí las entradas de L. esculentum y las de L. esculentum var. cerasiforme, separadas éstas según su procedencia (Ecuador o Perú), además de las formas intermedias entre las especies en estudio, incluidas las de Cuzco. Hay que resaltar la inclusión en este grupo de las cinco entradas ECU 687, ECU 669, ECU 604, ECU597 y ECU 740 de L. pimpinellifolium procedentes de Perú, con características propias de esta especie. Igualmente es de destacar la ubicación de las entradas GLP8 y GLP29, muy separadas del resto de entradas de Galápagos. Esta excepción aparece también en el cluster efectuado con datos moleculares cuando se realiza solo para las entradas de L. pimpinellifolium del ensayo 2001-02 (dendrograma no mostrado). 


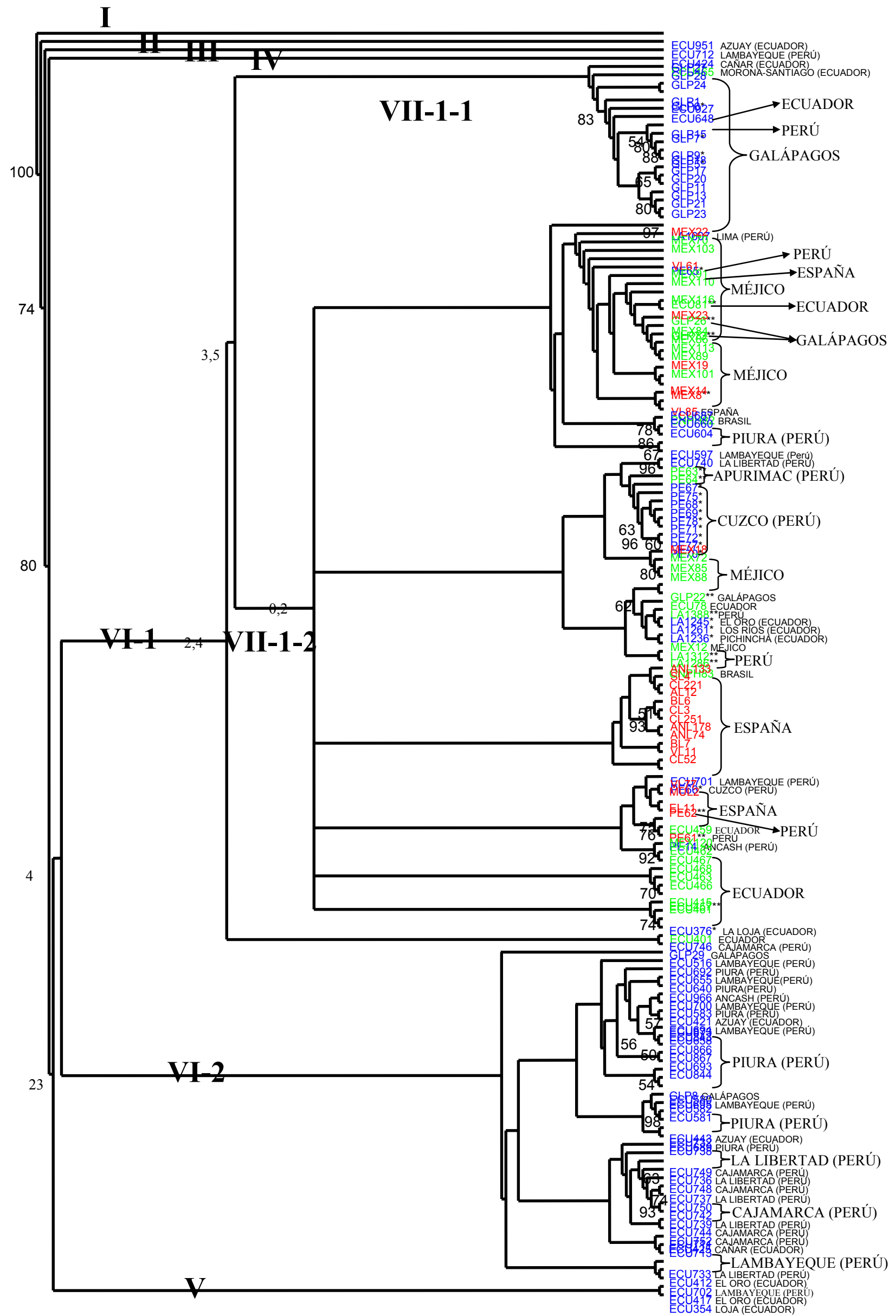




\section{Análisis de coordenadas principales}

La distribución de las entradas según el análisis de coordenadas principales dio lugar a una gradación continua, al igual que en la representación de las entradas en el análisis efectuado con datos cuantitativos (Apartado 4.1.2, Figura 4.2). Sin embargo, existe una diferencia importante entre ambas figuras. Mientras que en la Figura 4.2 se observa una mayor agrupación entre las entradas de L. pimpinellifolium y L. esculentum var. cerasiforme, quedando bastante separadas hacia la derecha las de L. esculentum, en la Figura 4.39 las entradas de L. pimpinellifolium se aproximan mucho entre sí, quedando las de L. esculentum y L. esculentum var. cerasiforme algo más cercanas y separadas de las de L. pimpinellifolium.

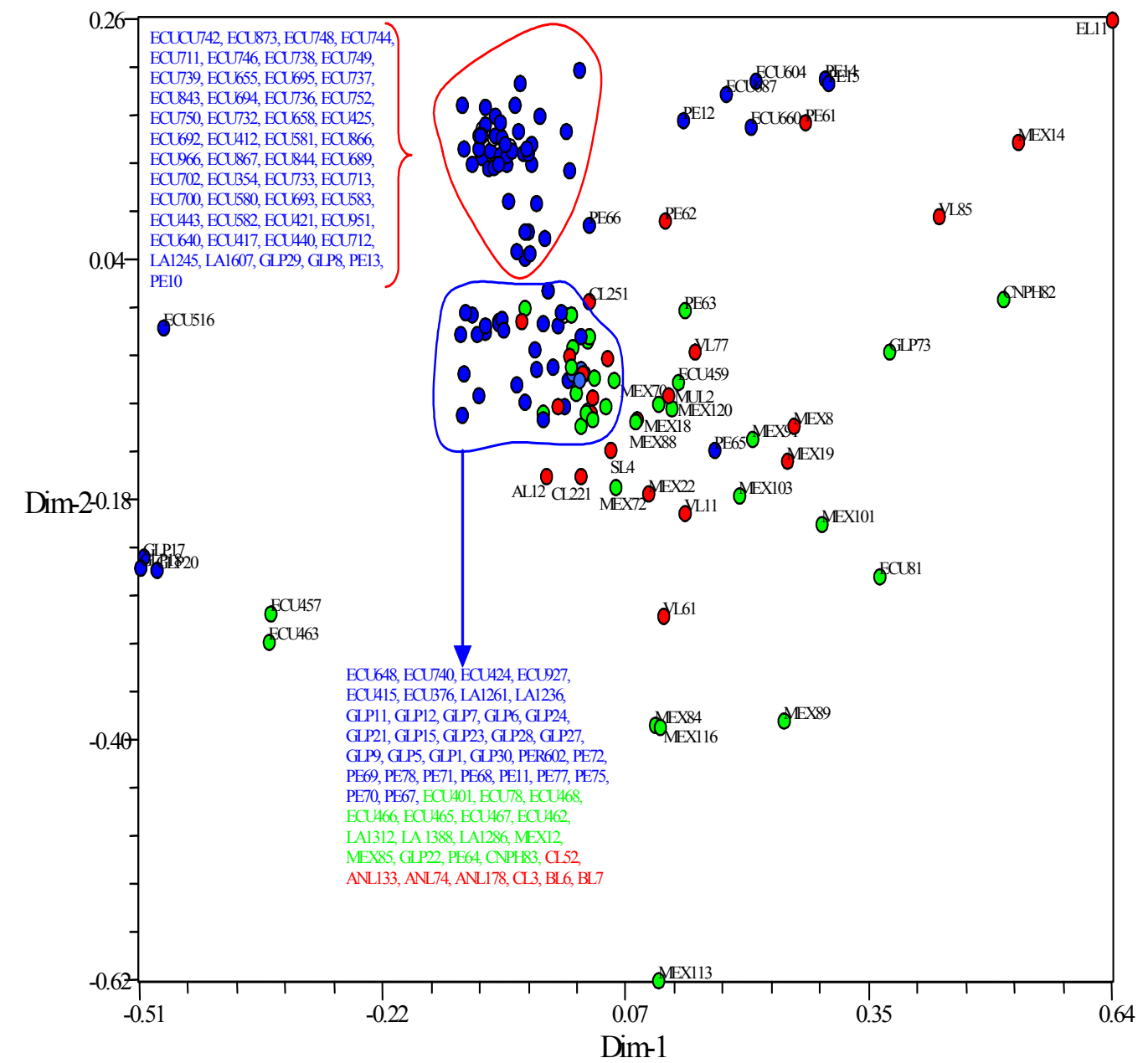

Figura 4.39. Representación de las entradas según el análisis de coordenadas principales realizado con datos obtenidos mediante AFLP. En azul se representan las entradas de $L$. pimpinellifolium, en verde las de $L$. esculentum var. cerasiforme y en rojo las de $L$. esculentum. 


\section{Discusión}

En conjunto, la agrupación de las entradas en el análisis cluster molecular concuerda con lo esperado, para las especies en estudio. Por un lado, la separación entre las entradas de L. pimpinellifolium de Ecuador y Perú apoya la amplia diferenciación genética entre estos orígenes ya observada por Rick y Fobes (1975), que encuentran una distribución de alelos alozímicos diferentes en Ecuador y Perú y también por Nuez et al., (2003, en prensa) en un estudio realizado con diversas especies del subgénero Eulycopersicon. La separación de las 5 entradas de L. pimpinellifolium anteriormente mencionadas y su inclusión entre las de L. esculentum y cerasiforme podría explicarse teniendo en cuenta los comprobados fenómenos de introgresión ocurridos entre $L$. pimpinellifolium y el tomate cultivado en ambos sentidos (Rick, 1958; Rick y Fobes, 1975). La posible presencia en el genoma de estas entradas de fragmentos procedentes de la especie cultivada o de su ancestro, podrían no influir directamente sobre los caracteres morfológicos discriminantes entre especies, pero ser suficientes para causar la inclusión de estas entradas en las de L. esculentum.

Las entradas de Galápagos y Cuzco, en principio consideradas como $L$. pimpinellifolium, se separan de las de esta especie, uniéndose también con el gran grupo formado por el resto de entradas. Conviene sin embargo, destacar que la existencia de las formas encontradas en Cuzco podría suponer un desplazamiento de esta especie a nuevos lugares no originarios de ella, como ha sido comentado anteriormente. Esta circunstancia vendría a cambiar el panorama descrito por Rick y Fobes en 1975, en el que, en base a la distribución de patrones isozímicos, afirman que "la distribución actual de esta especie es natural y no afectada por las actividades del hombre", repercutiendo además sobre la identidad genética de las especies nativas de la zona donde han sido introducidas.

En cuanto a las entradas colectadas en Galápagos, Nuez et al. (2003 en prensa) realizan un análisis molecular empleando AFLP, incluyendo diversas entradas del subgénero Eulycopersicon. En el cluster efectuado en el citado trabajo, estas entradas se separan en el dendrograma realizado con datos moleculares AFLP, de las pimpinellifolium continentales, agrupándose más con las de L. esculentum var. cerasiforme de Galápagos e incluso con L. esculentum. En nuestro caso también las entradas de Galápagos se agrupan más con las de L. esculentum var. cerasiforme (Figura 4.38). Una hipótesis planteada en la citada publicación para explicar la existencia de estas plantas es que hayan aparecido por naturalización de la var. cerasiforme. La 
presencia de L. esculentum var. cerasiforme en Galápagos ha sido documentada desde 1952 (Rick, 1956). La selección natural podría haber favorecido una reducción en el tamaño de los frutos, originando las formas “Gal red small”. De hecho, algunas entradas de cerasiforme colectadas en estas islas en 1991, tienen unos frutos de diámetro menor que el considerado como límite entre ambas especies (Rick et al., 1990). Aunque podría pensarse que hayan podido haber introgresiones entre L. escuelntum var. cerasiforme y las formas "Gal red small", el hecho de que éstas se agrupen en el dendrograma efectuado con datos moleculares (Figura 4.38) más cercanas a las de cerasiforme y esculentum sugiere que esta especie ha tenido un papel destacado en el origen de las formas "Gal red small”. De hecho la distancia genética entre L. pimpinellifolium y "Gal red small" es mucho mayor que la existente entre L. pimpinellifolium y L. cheesmanii, especies claramente diferentes. En cualquier caso, la cuestión del origen de las formas "Gal red small" no queda resuelta, siendo necesario realizar nuevos estudios para determinarlo con mayor precisión.

La distribución totalmente entremezclada de las entradas de L. esculentum y $L$. esculetum var. cerasiforme confirma la estrecha relación genética entre ellas, apoyando la hipótesis de que la var. cerasiforme es el ancestro a partir del cual se produjo la domesticación del tomate cultivado. Estos resultados concuerdan con los de Bretó et al. (1993), quienes estudiando los patrones isoenzimáticos de 11 isozimas, encontraron también una agrupación muy estrecha entre L. esculentum y cerasiforme, quedando un poco más alejada L. pimpinellifolium. Del mismo modo, Villand et al. (1998), hallan también una distribución mezclada de las entradas de L. esculentum y cerasiforme en los árboles filogenéticos efectuados con marcadores RAPD. La construcción de árboles filogenéticos con microsatélites, también llevó a un mayor acercamiento entre $L$. esculentum y cerasiforme frente a L. pimpinellifolium (Álvarez et al., 2001).

\section{Polimorfismo y diversidad genética}

Se realizó un análisis con 153 entradas ensayadas en las dos campañas, sin incluir las formas intermedias descritas anteriormente. Se identificaron un total de 461 fragmentos amplificados con una diversidad genética media de 0,32. El número de fragmentos polimórficos fue muy similar en las tres especies, 425 para $L$. pimpinellifolium, 428 para L. esculentum y 429 para L. esculentum var. cerasiforme, dando lugar a un nivel de polimorfismo del $92,19 \%, 92,84 \%$ y $93,06 \%$ respectivamente. 
La diversidad genética de Nei (1973) osciló entre 0,28 para L. pimpinellifolium, 0,30 para L. esculentum y 0,34 para L. esculentum var. cerasiforme (Tabla 4.5).

\begin{tabular}{|c|c|c|c|c|c|c|}
\hline Especies & $\begin{array}{l}\text { Número de } \\
\text { entradas }\end{array}$ & $\begin{array}{c}\mathrm{N}^{\mathrm{o}} \text { de loci } \\
\text { polimórficos } \\
(\%)\end{array}$ & $\mathrm{H}_{\mathrm{T}}$ & Dst & Hs & Gst \\
\hline $\begin{array}{c}L . \\
\text { pimpinellifolium }\end{array}$ & 74 & $425(92,19 \%)$ & $0,28(0,16)$ & - & - & - \\
\hline L. esculentum & 21 & $428(92,84 \%)$ & $0,30(0,17)$ & - & - & - \\
\hline $\begin{array}{l}\text { L. esculentum var. } \\
\text { cerasiforme }\end{array}$ & 29 & $429(93,06 \%)$ & $0,34(0,17)$ & - & - & - \\
\hline Total & 124 & $435(94,36)$ & $0,32(0,15)$ & 0,03 & $0,29(0,02)$ & $0,09(0,11)$ \\
\hline
\end{tabular}

Tabla 4.5. Estadísticos de diversidad genética (Nei, 1973) estimados a partir de los datos AFLP para L. pimpinellifolium, L. esculentum y L. esculentum var. cerasiforme.

$\mathrm{H}_{\mathrm{T}}$ : Diversidad genética total.

Dst: Diversidad genética entre grupos

Hs: Diversidad genética dentro de grupos

Gst: Magnitud relativa de diferenciación genética entre grupos Gst= Dst/ $\mathrm{H}_{\mathrm{T}}$

El número de fragmentos amplificados por cada combinación de cebador osciló entre 63 (para la combinación EcoAAC/MseCAC, con tamaños de bandas entre los 53,8pb$385,8 \mathrm{pb}$ ) y 90 (para la combinación EcoACT/MseCAA, con tamaños de bandas entre los $51,5 \mathrm{pb}-368,9 \mathrm{pb}$ ), con un valor medio de 76,83 fragmentos por combinación de cebador.

El nivel de polimorfismo detectado fue muy elevado, superior al $90 \%$ en todos los casos y muy similar en las tres especies estudiadas. Sorprende el hecho de que la diversidad genética sea superior en $L$. esculentum y en la variedad cerasiforme que en $L$. pimpinellifolium, ya que esta última especie, aunque autocompatible, tiene unos porcentajes de alogamia muy superiores a L. esculentum, dada la mayor exerción estigmática en la mayoría de las entradas. De hecho, este resultado no coincide con los encontrados por otros autores, que obtienen valores de diversidad genética superiores para L. pimpinellifolium (Nuez et al., 2003, en prensa). Una posible explicación podría residir en el particular conjunto de entradas de cada especie incluidos en este ensayo. Así, Villand et al. (2001) afirman que germoplasma de cerasiforme se ha encontrado más o menos variable que el tomate cultivado en función del conjunto de entradas estudiado, tanto para caracteres morfológicos (Rick, 1958), como para isozimas (Rick y 
Fobes, 1975) o marcadores moleculares (Miller y Tanksley, 1990; Williams y St. Clair, 1993).

Con objeto de tratar de esclarecer los resultados previos, se realizó la partición de la diversidad genética total $\left(\mathrm{H}_{\mathrm{T}}\right)$ en diversidad entre $\left(D_{S T}\right)$ y dentro $\left(H_{S}\right)$ de grupos, calculando posteriormente la diferenciación genética entre grupos $\left(G_{S T}\right)$ (Tabla 4.5). Esta partición se realizó con el conjunto completo de entradas.

Como se puede observar, se obtiene un valor de $\mathrm{H}_{\mathrm{S}}(0,29)$ muy superior a $\mathrm{D}_{\mathrm{ST}}(0,03)$, lo cual indica que existe una gran diversidad dentro de cada especie. Ello nos llevó a realizar el mismo análisis para cada especie por separado (Tabla 4.6). En el caso de $L$. pimpinellifolium se incluyeron en este análisis la zona norte de Perú (Departamentos de Piura, Lambayeque, Cajamarca y La Libertad), por ser ésta el área de procedencia de la mayor parte de las entradas.

Los valores del parámetro $\mathrm{G}_{\mathrm{ST}}$ ponen de manifiesto la diferenciación genética entre los grupos de entradas dentro de cada especie.

Así la mayor diferenciación genética entre grupos en el caso de L. esculetum y $L$. esculentum var. cerasiforme $(\mathrm{Gst}=0,06 \mathrm{y} \mathrm{Gst}=0,11)$ frente a la de L. pimpinellifolium $(G s t=0,02)$ podría influir de forma importante en la mayor diversidad genética total encontrada en $L$. esculentum y $L$. esculentum var. cerasiforme frente a $L$. pimpinellifolium, siendo ésta la causa de los resultados en principio no esperados.

En resumen, el bajo valor de diversidad genética obtenido para L. pimpinellifolium en el análisis conjunto de las tres especies podría ser debido a que los conjuntos de entradas de L. esculentum y L. esculentum var. cerasiforme incluidos en el ensayo, está en realidad formados por grupos de entradas muy distanciadas entre sí, mientras que esta circunstancia es mucho más atenuada en el caso de L. pimpinellifolium. 


\begin{tabular}{|c|c|c|c|c|c|c|c|}
\hline Especies & Procedencias & $\begin{array}{l}\text { Número } \\
\text { de } \\
\text { entradas }\end{array}$ & $\begin{array}{c}\mathrm{N}^{\mathrm{o}} \text { de loci } \\
\text { polimórficos } \\
(\%)\end{array}$ & $\mathrm{H}_{\mathrm{T}}$ & Dst & Hs & Gst \\
\hline \multirow[b]{2}{*}{ pimpinellifolium } & $\begin{array}{c}\text { Piura/ } \\
\text { Lambayeque }\end{array}$ & 26 & $313(68 \%)$ & $0,22(0,20)$ & \multirow{2}{*}{0,02} & \multirow{2}{*}{$0,19(0,03)$} & \multirow{2}{*}{0,09} \\
\hline & $\begin{array}{l}\text { Cajamarca/ } \\
\text { La Libertad }\end{array}$ & 14 & $224(48,5 \%)$ & $0,16(0,19)$ & & & \\
\hline \multirow{2}{*}{ L. esculentum } & México & 5 & $341(74 \%)$ & $0,28(0,19)$ & \multirow{2}{*}{0,06} & \multirow{2}{*}{$0,25(0,02)$} & \multirow{2}{*}{0,20} \\
\hline & España & 17 & $328(71 \%)$ & $0,21(0,19)$ & & & \\
\hline L. esculentum & Ecuador & 9 & $251(54,48)$ & $0,20(0,21)$ & \multirow{2}{*}{0,11} & \multirow{2}{*}{$0,17(0,01)$} & \multirow{2}{*}{0,35} \\
\hline var. cerasiforme & México & 11 & $397(86 \%)$ & $0,32(0,17)$ & & & \\
\hline Total & - & 124 & $435(94,36)$ & $0,32(0,15)$ & 0,03 & 0,29 & 0,09 \\
\hline
\end{tabular}

Tabla 4.6. Estadísticos de diversidad genética (Nei, 1973) estimados a partir de los datos AFLP para las especies en estudio por origen.

$\mathrm{H}_{\mathrm{T}}$ : Diversidad genética total de Nei (1973).

Dst: Diversidad genética entre grupos

Hs: Diversidad genética dentro de grupos

Gst: Magnitud relativa de diferenciación genética entre grupos Gst= Dst/ $\mathrm{H}_{\mathrm{T}}$

Analizando cada especie en particular, los resultados obtenidos para $L$. pimpinellifolium muestran mayor diversidad genética para las entradas de Piura y Lambayeque $\left(\mathrm{H}_{\mathrm{T}}=0,22\right)$ que para las de Cajamarca y La Libertad $\left(\mathrm{H}_{\mathrm{T}}=0,16\right)$. Como se vio en el apartado 4.1.3, fueron precisamente las entradas de Piura y Lambayeque las que presentaron mayor exerción estigmática (Figura 4.37), carácter correlacionado con una mayor alogamia. También en el caso de L. esculentum var. cerasiforme resalta la notable mayor diversidad genética en el caso de las entradas procedentes de México $\left(\mathrm{H}_{\mathrm{T}}\right.$ $=0,32)$ frente a las de Ecuador $\left(\mathrm{H}_{\mathrm{T}}=0,20\right)$. En este caso el resultado podría explicarse teniendo en cuenta la procedencia de las entradas dentro de cada país. Así, las 9 entradas de Ecuador proceden de tres localidades diferentes, mientras que las de México son de ocho localidades distintas (Tabla 4.7). Posiblemente, las ocho entradas procedentes de Morona-Santiago compartan gran parte de su genoma. Los valores de diversidad genética obtenidos para L. esculetum son anormalmente elevados. Pensamos que podrían estar influidos por el pequeño número de entradas incluidas en el estudio. 


\begin{tabular}{|c|c|c|c|}
\hline \multirow{2}{*}{ Entrada } & \multicolumn{3}{|c|}{ Procedencia } \\
\hline & Ubicación & Provincia & País \\
\hline \multicolumn{4}{|c|}{ Lycopersicon esculentum var. cerasiforme } \\
\hline ECU-78 & Timbara & Zamora-Chinchipe & Ecuador \\
\hline ECU-0459 & Indanza & Morona-Santiago & Ecuador \\
\hline ECU-0460 & Indanza & Morona-Santiago & Ecuador \\
\hline ECU-0461 & Indanza & Morona-Santiago & Ecuador \\
\hline ECU-0462 & Indanza & Morona-Santiago & Ecuador \\
\hline ECU-0463 & Indanza & Morona-Santiago & Ecuador \\
\hline ECU-0465 & Logroño & Morona-Santiago & Ecuador \\
\hline ECU-0466 & Logroño & Morona-Santiago & Ecuador \\
\hline ECU-0467 & Timbara & Zamora-Chinchipe & Ecuador \\
\hline ECU-0468 & Indanza & Morona-Santiago & Ecuador \\
\hline MEX-0012 & Entre Cansahcab y Dizdzautum & Yucatán & México \\
\hline MEX-0070 & Huenchinango & Puebla & México \\
\hline MEX-0072 & Huenchinango & Puebla & México \\
\hline MEX-0084 & Apachitempa (Platón Sánchez) & Veracruz & México \\
\hline MEX-0085 & Huejufla & Hidalgo & México \\
\hline MEX-0088 & Huejufla & Hidalgo & México \\
\hline MEX-0089 & Ciudad Vallés(Palo arco) & S. Luis de Potosí & México \\
\hline MEX-0091 & Chapulhuacan Grande & Hidalgo & México \\
\hline MEX-0101 & Río verdito & Querétaro & México \\
\hline MEX-0103 & Xilitla(El Balcón) & San Luís & México \\
\hline MEX-0110 & Culiacan.(El Vergel) & Sinaloa & México \\
\hline MEX-0113 & Ahomé (aeropuerto viejo de los Mochis) & Sinaloa & México \\
\hline MEX-0116 & Ahomé (La Biznaga) & Sinaloa & México \\
\hline MEX-0120 & Santispac & Nayarif & México \\
\hline
\end{tabular}

Tabla 4.7. Procedencia de las entradas de L. esculentum var. cerasiforme cultivadas en la campaña 2000-01.

\section{Bandas especificas de especie}

El elevado número de fragmentos identificados y el alto porcentaje de polimorfismo encontrado permitieron obtener una gran cantidad de información, aunque no se encontraron bandas específicas para cada una de las especies. Se identificaron 4 bandas con cierta consistencia entre las entradas de $L$. pimpinellifolium y ausentes en $L$. esculentum y L. esculentum var ceasiforme. Así, una de ellas apareció en 12 entradas, otra en 18, otra en 28 y otra en 32 de las 72 entradas de L. pimpinellifolium. Otras 2 bandas presentes en 20 y 30 entradas de L. pimpinellifolium respectivamente aparecieron en al menos una entrada de cerasiforme y esculentum. 


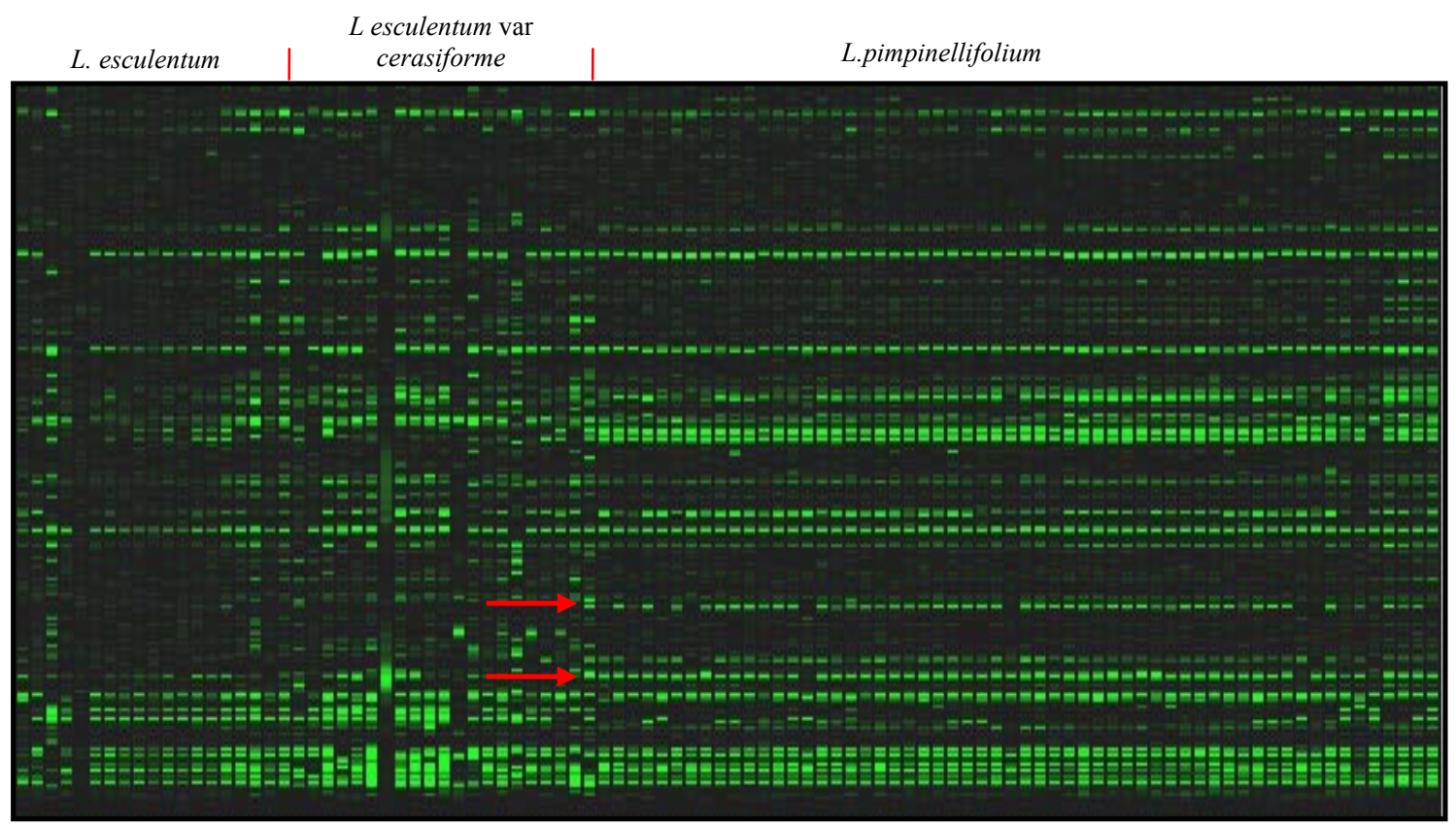

Figura 4.40. Representación de las bandas obtenidas a partir de AFLP, utilizando la combinación de cebadores EcoAGC/MseCAA, en la que se observan de izquierda a derecha 20 entradas de $L$. esculentum, 20 de $L$. esculentum var. cerasiforme y 58 de $L$. pimpinellifolium. Las flechas rojas indican bandas polimórficas entre L. esculentum y $L$. pimpinellifolium.

Considerando resultados procedentes de la amplificación con los cebadores EcoAGC/MseCAA (Figura 4.40), se llegaron a identificar 2 bandas que aprecieron en 47 y 55 entradas de L. pimpinellifolium estando ausentes en L. esculentum y L. esculentum var. cerasiforme.

\section{Discusión}

A pesar del elevado número de bandas identificadas mediante los marcadores AFLP, altamente polimórficos, no ha sido posible la identificación de bandas específicas de especie. En nuestra opinión este resultado viene a apoyar la conclusión a la que llega Rick (1958). En esta publicación, Rick realizó un extenso estudio sobre la cantidad de introgresión de L. pimpinellifolium en L. esculentum, en las áreas en las que coexisten ambas especies. Basándose en la continuidad de caracteres morfológicos en formas naturales en las áreas simpátricas, afirmó que estas evidencias aumentan al menos la duda sobre la actual separación de L. esculentum y L. pimpinellifolium en dos especies, sugiriendo que L . pimpinellifolium deberían ser consideradas como una variedad de $L$. esculentum. Rick y Fobes (1975) encuentraron a su vez una cantidad de alelos compartidos por L. esculentum y L. pimpinellifolium en las costas Ecuatorianas y 
Peruanas y no en otros lugares, lo que les llevó a sugerir que la domesticación del tomate tuvo lugar según la siguiente secuencia: L. pimpinellifolium $\rightarrow$ var. cerasiforme $\rightarrow L$. esculentum. La diferenciación actual entre el tomate cultivado y L. pimpinellifolium habría sido únicamente consecuencia de la migración a otros lugares y de los posteriores fenómenos de domesticación.

Compatible con la opinión emitida por Rick existiría la posibilidad anteriormente apuntada tras el estudio de la variabilidad morfológica (Apartado 4.1) de que pudiera tratarse de un proceso de especiación aun no finalizada en la actualidad.

\subsubsection{Análisis de la variabilidad molecular por especie}

\section{2. 2. 1. L. esculentum var. cerasiforme}

\section{Análisis cluster.}

Del total de las entradas analizadas en la caracterización morfológica se seleccionaron 37 entradas, con las cuales se realizó un análisis cluster.

En el dendrograma obtenido a partir de los datos moleculares se aprecia una separación bastante clara de las entradas según su procedencia (México o Ecuador), aunque con algunas excepciones que merecen ser comentadas. Así, de las 15 entradas de México incluidas en el análisis, 5 de ellas quedan englobadas con las de Ecuador, ya que los nodos que las separan tienen valores bootstrap inferiores al 50\%, mientras que las 10 restantes quedan totalmente separadas. Por otro lado, no se observa una separación clara, en cuanto a su procedencia, entre las 5 entradas próximas a las de Ecuador y las restantes. 


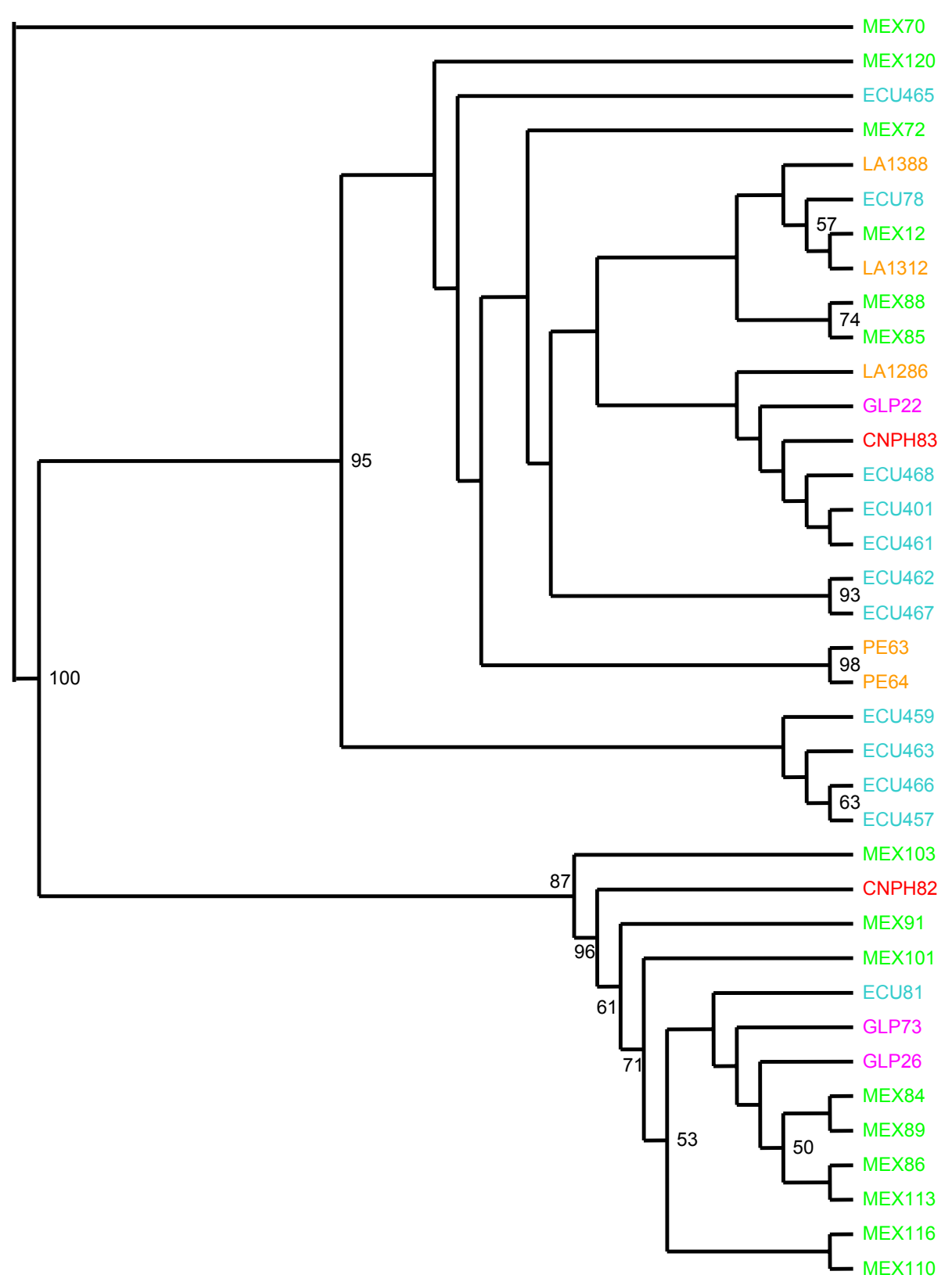

Figura 4.41. Representación del dendrograma calculado con 37 entradas de $L$. esculentum var. cerasiforme cultivadas en la campaña 2000-01, se indican en los nudos los valores de bootstrap superiores al 50\% utilizando el coeficiente de similitud de Dice (1945) y aplicando el análisis UPGMA. En color verde se representan las entradas procedentes de México, en rojo las de Brasil, en naranja las de Perú, en rosa las de Galápagos y en azul las de Ecuador.

\section{Discusión}

La distribución de las entradas a partir de los datos moleculares contrasta con la obtenida con los datos morfológicos, en la que se aprecia una separación mayor según el origen de las entradas. A pesar de que L. esculentum var. cerasiforme se encuentra normalmente en estado silvestre, en ocasiones es cultivada en los huertos por los nativos 
pudiendo en estos casos ser objeto de selección para ciertos caracteres morfológicos, en función de las preferencias de los consumidores. Esto estaría provocando una separación cuando se tienen en cuenta los caracteres morfológicos, mientras que molecularmente la situación sería diferente.

Es comúnmente aceptada la hipótesis según la cual, L. esculentum var. cerasiforme, originaria de la región Andina, fue exportada a México como mala hierba, donde se domesticó (Jenkins, 1948; Rick, 1958). Es muy probable que en el presente continúe este trasiego de materiales, lo que ocasionaría una diversidad en el fondo genético de esta especie en el país receptor, a la vez que una mayor semejanza en el fondo genético entre entradas introducidas más recientemente y aquellas de las que proceden en el país de origen. Así, la comparación de un conjunto de entradas de distintos países como la llevada a cabo en este trabajo, podría dar lugar a distintos resultados en función de las entradas concretas incluidas.

Por otro lado, la elevada autogamia propia de esta especie, estaría contribuyendo a aislar las poblaciones reproductivamente, contribuyendo a una separación mayor entre ellas. El sentido predominante de transporte de material desde Ecuador a México, al menos en épocas pasadas, habría ocasionado una reducción de variabilidad en las poblaciones de México, como ha quedado patente en los estudio realizados por Rick y Fobes (1975) y Rick y Holle (1990), quienes encontraron una considerable variación alozímica entre genotipos de L. esculentum var. cerasiforme colectados en la costa de Perú y Ecuador, sensiblemente mayor que en otros lugares.

\section{2. 2. 2. Lycopersicon esculentum}

\section{Análisis cluster.}

Se realizó un análisis cluster con los datos moleculares obtenidos mediante AFLP. Se utilizó el método UPGMA, aplicando la técnica de remuestreo bootstrap a un conjunto de 25 entradas de L. esculentum, 6 de las cuales procedían de México y 19 de España (Figura 4.42). 


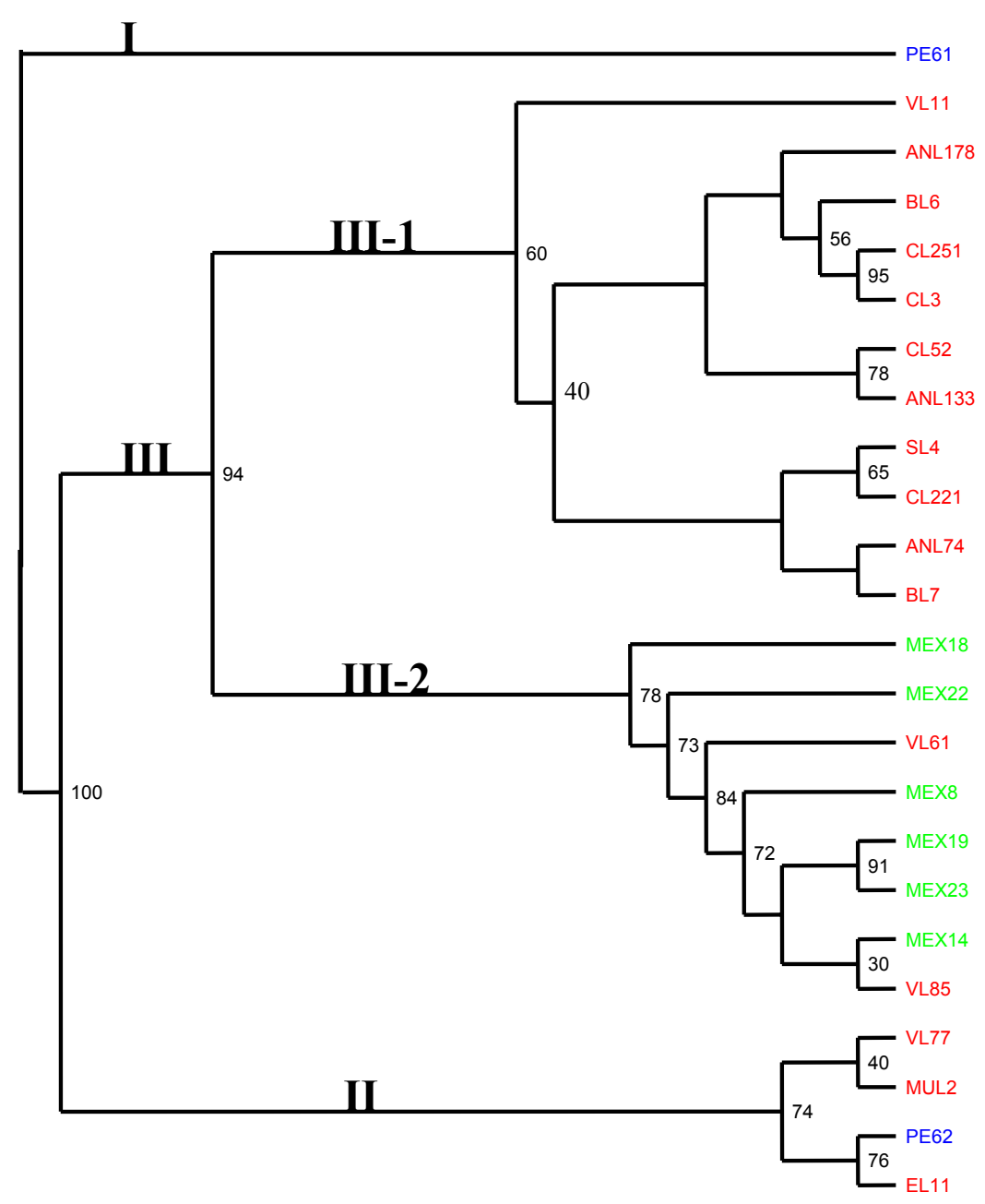

Figura 4.42. Representación del dendrograma calculado con 25 entradas de $L$. esculentum, utilizando el coeficiente de similitud de Dice (1945) y el método de análisis UPGMA . En color verde se representan las entradas procedentes de México, en azul las de Perú y en rojo las de España. En los nodos se indican los valores de bootstrap.

La entrada PE61 procedente de Perú queda completamente separada de las demás, con una frecuencia del $100 \%$, constituyendo el subgrupo I. La siguiente bifurcación separa a cuatro entradas, entre las que se incluye la otra de procedencia peruana. Finalmente, el resto de entradas queda englobado en dos grupos, uno de ellos constituido por entradas exclusivamente españolas y las otras mexicanas, a excepción de V-L-61 y V-L-85 de procedencia española.

\section{Discusión}

La separación observada en función de su origen en el análisis con datos moleculares es consistente con lo observado en el análisis morfológico, en el que apareció una 
similitud entre entradas de la misma procedencia basada en características florales y de fruto. A nivel molecular, la diferencia entre ambas procedencias viene apoyada por el parámetro $\mathrm{G}_{\mathrm{ST}}$, con un valor de 0,20. A partir de su introducción en España, las distintas presiones de selección ejercidas habrían contribuido a la diferenciación en relación a las entradas de México. Además la diversidad genética total, $H t$, mayor para el conjunto de entradas de México (0.28) que para las de España (0.21), apoyarían la existencia del cuello de botella debido al transporte de un número limitado de entradas desde México a España, a partir de donde se inició su difusión por Europa. Este hecho ha quedado también demostrado por la escasa presencia de polimorfismo en los cultivares europeos respecto a los regionales de Sudamérica, Centroamérica y México (Millar y Tanksley, 1990; Williams y St. Clair, 1993; Smulders et al., 1997; Bredemeijer et al., 1998).

\section{2. 2. 3 Lycopersicon pimpinellifolium}

\section{Análisis de las entradas ensayadas en las dos campañas}

\section{Análisis de coordenadas principales y cluster}

La distribución de las entradas en el análisis de coordenadas principales (Figura 4.43), al igual que en el dendrograma realizado con todas las entradas catalogadas como pimpinellifolium al inicio de este trabajo (Figura 4.44), se asemeja a lo establecido según la caracterización morfológica, observándose una agrupación de todas las entradas con características diferentes a $L$. pimpinellifolium, mientras que el resto incluye la mayor parte de las del norte del Perú y las de Ecuador, más acordes con las características de esta especie. 


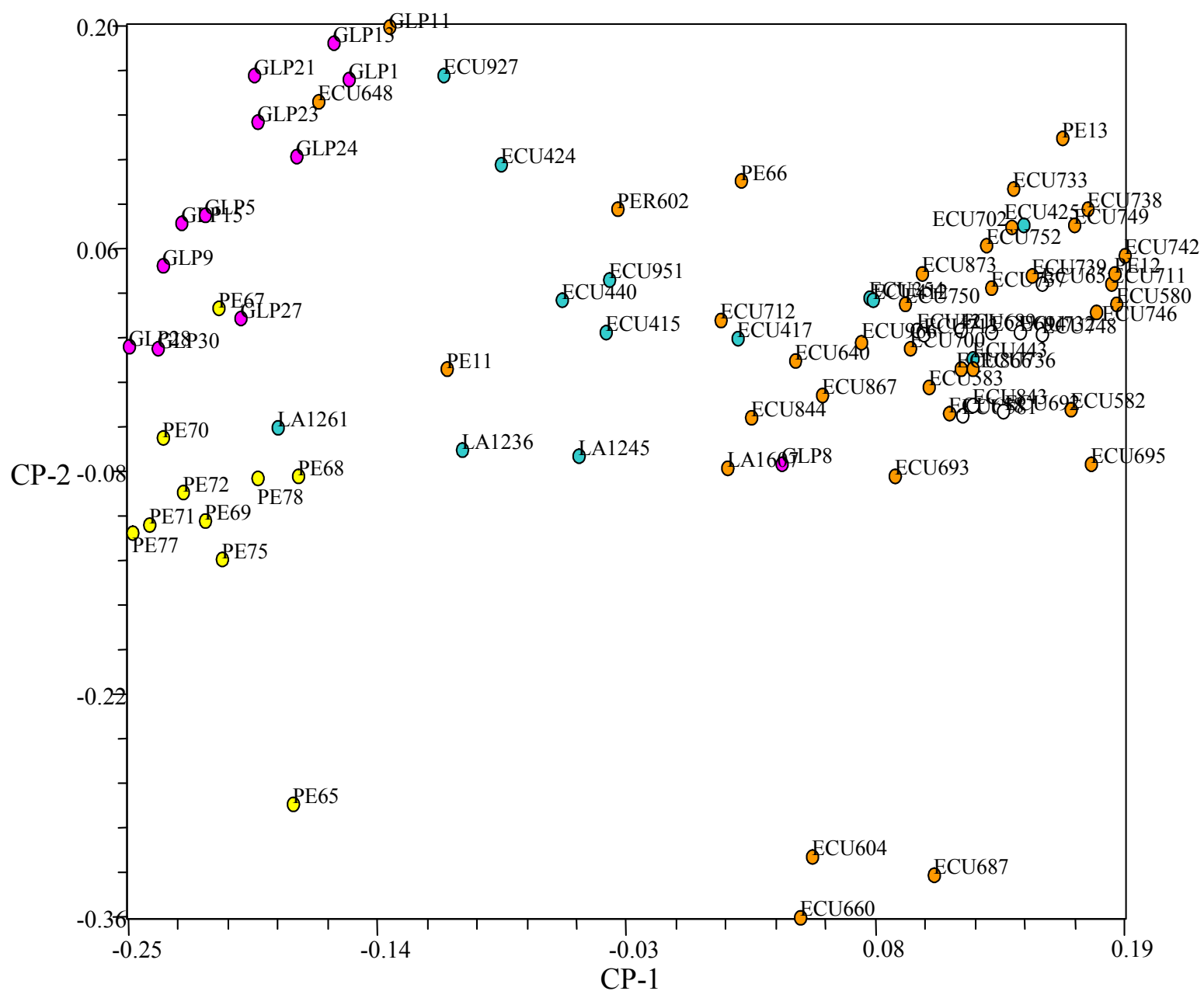

Figura 4.43. Representación de las entradas de L. pimpinellifolium ensayadas en las dos campañas en función de la primera y segunda coordenadas principales. En color rosa están representadas las entradas procedentes de Galápagos, en azul las de Ecuador, en naranja las de Perú y en amarillo las de Cuzco (Perú). 


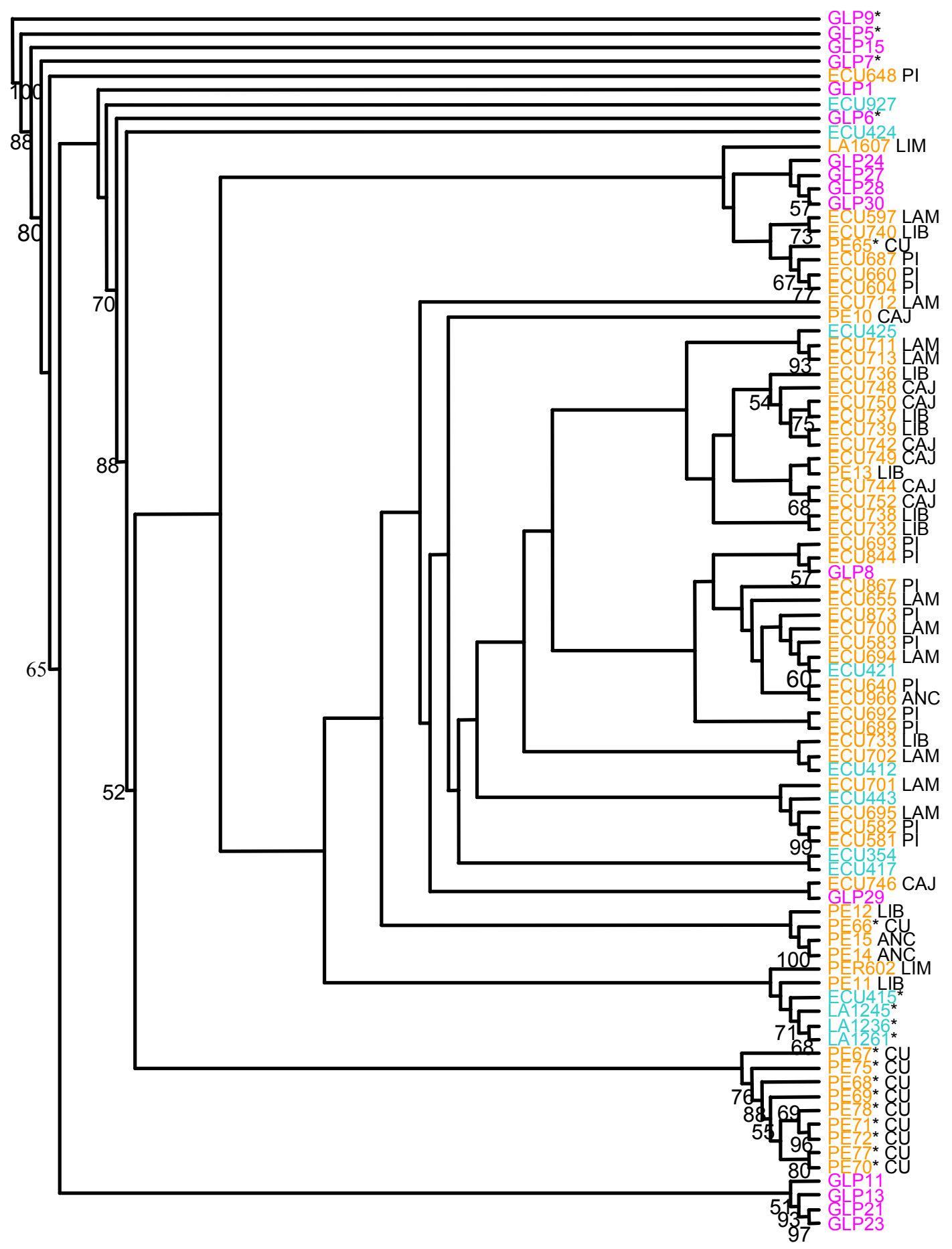

Figura 4.44. Representación del dendrograma para el conjunto de entradas de $L$. pimpinellifolium ensayadas en las dos campañas. Análisis molecular con marcadores AFLP, utilizando el coeficiente de similitud de Dice (1945) y aplicando el análisis UPGMA. En color rosa se representan las entradas procedentes de Galápagos, en azul las de Ecuador y en naranja las de Perú. Las entradas marcadas con un asterisco son las formas intermedias entre L. pimpinellifolium y L. esculentum var. cerasiforme. Los valores bootstrap (\%)(1000 repeticiones) que indican los nodos. Aparecen representados los valores superiores al 50\%. En las entradas de Perú se han señalado las procedencias con los siguientes códigos: PI Piura; LIM Lima; LIB La Libertad; LAM Lambayeque; CU Cuzco; ANC Ancash; CAJ Cajamarca. 


\section{Bandas especificas por origen}

La comparación de fragmentos amplificados mediante la técnica AFLP presentes en las entradas de cada una de estas procedencias corrobora las afirmaciones anteriores. Así, en la Figura 4.45 se pueden visualizar ciertas bandas (A, B y C) que aparecen con elevada consistencia en las entradas de Cuzco y Galápagos, mientras que no aparecen en ningún caso en las entradas de Perú y sólo en algún caso aislado en las de Ecuador.

La inexistencia de bandas comunes entre Perú, Ecuador y Galápagos apoya lo visto en el cluster molecular general. Lo mismo con las de Cuzco.
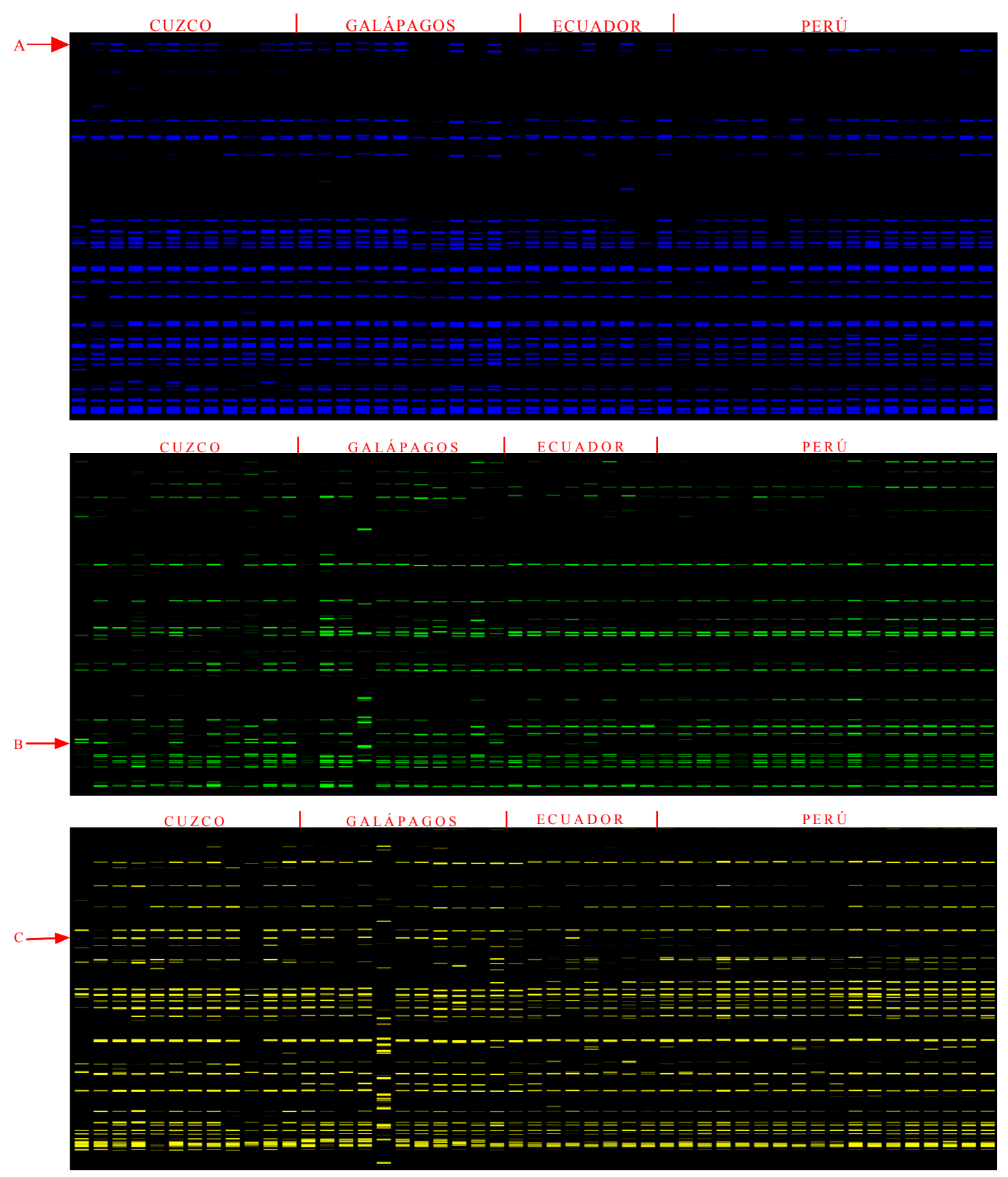
Figura 4.45. Bandas obtenidas mediante el programa Genographer a partir de los fragmentos amplificados, utilizando las combinaciones de cebadores de la serie A (Tabla 3.4). Se representan 12 entradas de Cuzco, 12 entradas de Galápagos para el color azul y 11 para los colores verde y amarillo, 8 entradas de Ecuador y 18 entradas de Perú.

\section{Análisis de la variabilidad molecular de las poblaciones de L. pimpinellifolium del} norte de Perú

A fin de conocer hasta qué punto las poblaciones de L. pimpinellifolium del norte de Perú suponen un continuo o se trata más bien de poblaciones aisladas, se ha realizado un análisis tomando sólo el conjunto de entradas recolectadas en los cuatro Departamentos costeros más septentrionales del país: Piura, Lambayeque, Cajamarca y La Libertad (Figura 4.46).

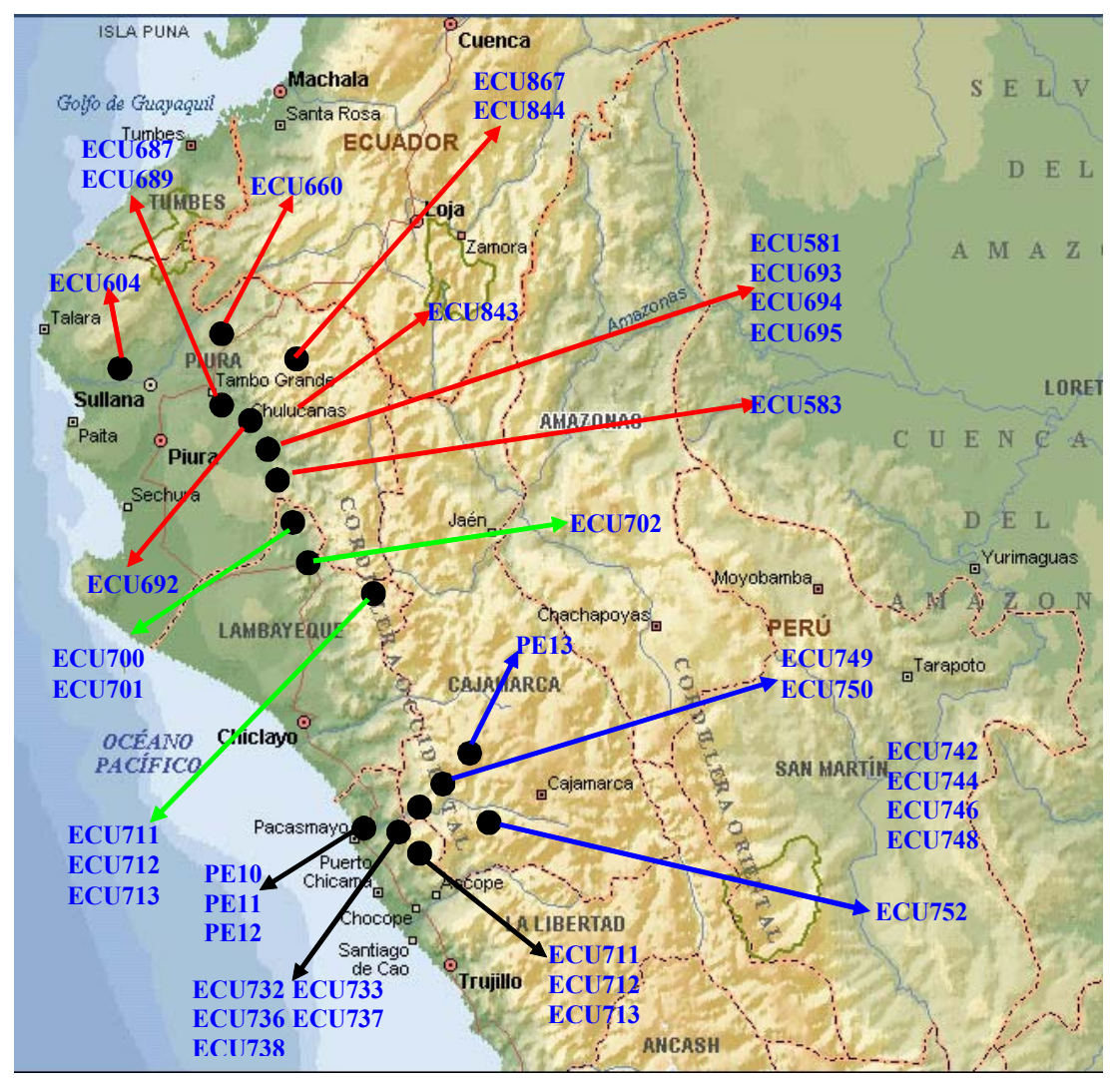

Figura 4.46. Localización de las entradas recolectadas en los Departamentos más septentrionales de Perú, las fechas de color rojo representan las entradas procedentes de Piura, en verde las de Lambayeque, en azul las de Cajamarca y en negra las de La Libertad.

En el dendrograma efectuado se ve que tienden a agruparse las entradas procedentes de Piura y Lambayeque por una parte, mientras que las de las de Cajamarca y La Libertad tienden a agruparse separadas de aquellas (Figura 4.47). Este hecho puede 
explicarse en base a la localización geográfica de las entradas recolectadas que, como puede observarse en la (Figura 4.46) constituyen dos conjuntos separados entre sí 178 $\mathrm{Km}$, mientras que en cada uno de ellos la proximidad entre las entradas recolectadas es elevada.

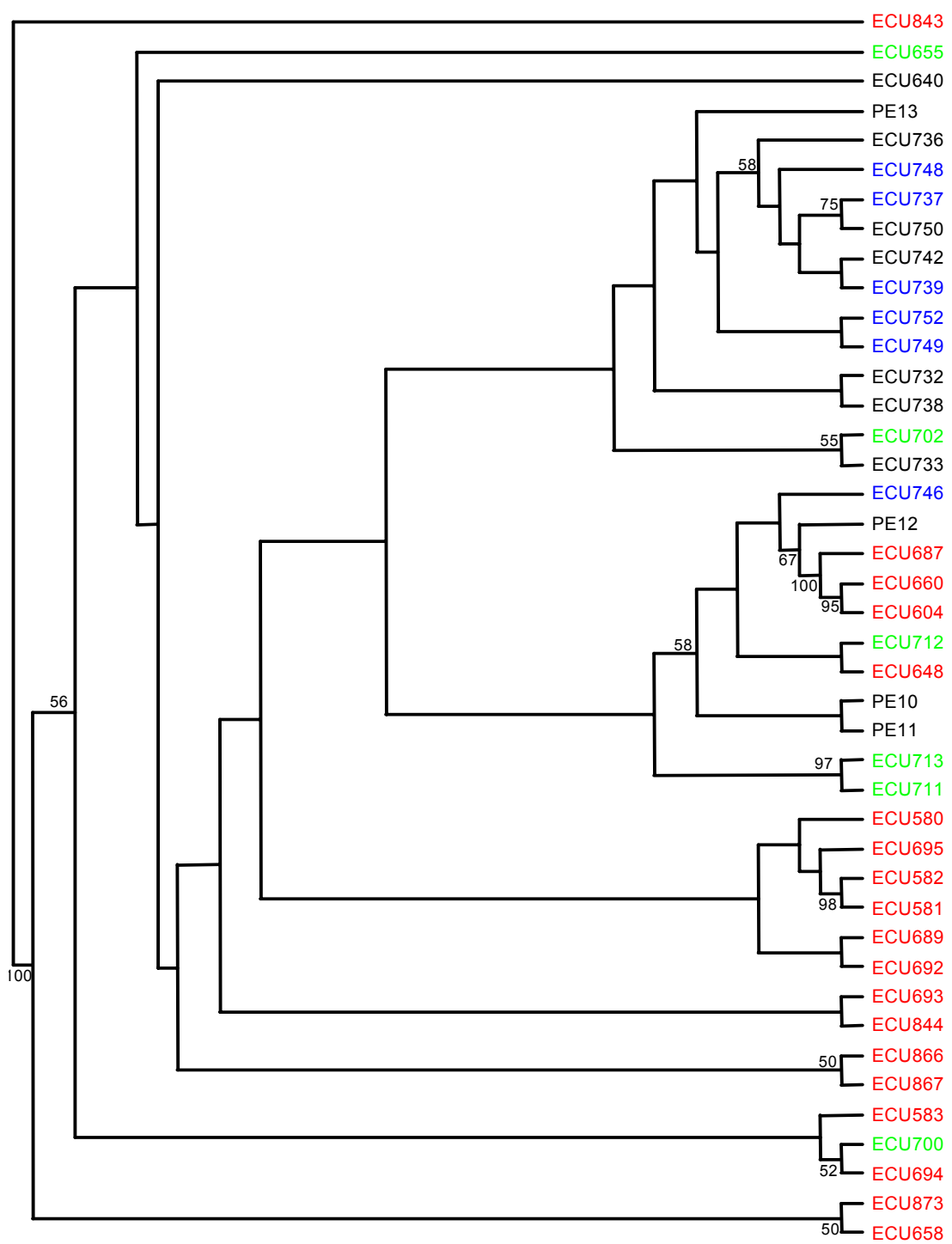

Figura 4.47. Dendrograma realizado con el conjunto de entradas del norte del Perú a partir de la matriz de datos moleculares, ensayo 2001-02 utilizando el coeficiente de similitud de Dice (1945) y aplicando el método de análisis UPGMA. En color rojo se representan las entradas de Piura, en Verde las de Lambayeque, en negro las de La Libertad y en color azul las de Cajamarca. Los valores bootstrap (\%)(1000 repeticiones) que indican los nodos. Aparecen representados los valores superiores al 50\%. 


\section{$\underline{\text { Discusión }}$}

La representación de las entradas obtenida en el análisis de componentes principales y cluster confirma la diferencia genotípica y no sólo morfológica entre las entradas procedentes de Cuzco y Galápagos con respecto a las de Ecuador y Perú. Lo mismo ocurre con los patrones de bandas obtenidos mediante AFLP. Estos resultados no contradicen la hipótesis establecida anteriormente acerca del origen de las entradas de Cuzco, en nuestra opinión transportadas a este lugar probablemente por el hombre. Igualmente estos resultados apoyarían también la explicación dada para explicar las formas "Gal red small” encontradas en las islas Galápagos, que según se comentó en el Apartado 4.1.3 derivarían con más probabilidad a partir de L. esculentum var. cerasiforme presente en estas mismas islas, que de plantas de L. pimpinellifolium continentales.

Las diferencias observadas, en cuanto a los caracteres florales y reproductivos, en el conjunto de entradas de L. pimpinellifolium colectadas en los Departamentos más septentrionales de Perú, parece mantenerse cuando analizamos la variabilidad molecular mediante marcadores AFLP. En el cluster efectuado se observa una tendencia a agruparse las entradas de Piura y Lambayeque, mientras que las de Cajamarca y la Libertad se agrupan también entre sí y más distanciadas de aquellas. Algunos valores bootstrap muy elevados que unen dos o muy pocas entradas indican que se trata probablemente de distintas colectas realizadas sobre la misma población., lo cual tiene importantes implicaciones para la eliminación de duplicados y la elección de entradas para la formación de una colección nuclear. La distinta variabilidad encontrada para estos dos conjuntos de entradas, estimada mediante el parámetro $H_{T}\left(H_{T}=0.22\right.$ para Piura-Lambayeque y $H_{T}=0.16$ para Cajamarca y La Libertad) tiene también implicaciones en la elección de entradas para la formación nuclear, debiendo estar más representada la zona de Piura-Lambayeque, dada la mayor diversidad genética existente en ésta área, que se corresponde además con el centro de origen de esta especie.

\section{3. COMPARACIÓN DEL ANÁLISIS MORFOLÓGICO Y MOLECULAR}

Los grupos establecidos en los análisis cluster efectuados con el conjunto de caracteres morfológicos (Figura 4.12) y los moleculares (Figura 4.38) difieren notablemente en un aspecto. Mientras que el cluster efectuado con los caracteres 
morfológicos agrupa claramente a las entradas de L. pimpinellifolium con las de la var. cerasiforme, sin duda debido a su similitud en las características morfológicas de fruto, en el obtenido con los datos moleculares se observa una agrupación de L. esculentum con la var. cerasiforme, separándose ambas de las entradas de L. pimpinellifolium.

Lo mismo puede observarse en la representación de las entradas según el análisis de componentes principales y el de coordenadas principales. Esto apoya la estrecha relación existente entre el tomate cultivado $\mathrm{y}$ su ancestro L. esculentum var. cerasiforme. En este caso la comparación de los análisis morfológicos y moleculares han permitido realizar una correcta interpretación acerca de la proximidad entre las especies en estudio, aportando el análisis molecular nuevas evidencias de la domesticación del tomate a partir de su ancestro, la variedad cerasiforme.

En el caso de L. esculentum, tanto en los análisis realizados con caracteres morfológicos como moleculares, se aprecia una separación en función del origen. Las diferencias entre las entradas procedentes de México y España no se limitan sólo a las características de los frutos y de la planta, como consecuencia de los distintos gustos y técnicas de cultivo de ambos países, sino que la separación ocurrida desde su introducción en España, hace aproximadamente 500 años, había originado un distanciamiento del fondo genético que se refleja en la separación en el cluster molecular según el país de origen.

Para L. escuelntum var. cerasiforme la distribución de las entradas a partir de los datos moleculares contrasta con los obtenidos con los datos morfológicos, en la que se aprecia una separación según el origen de las entradas. A pesar de que L. esculentum var. cerasiforme se encuentra normalmente en estado silvestre, en ocasiones es cultivada en los huertos por los nativos pudiendo en estos casos ser objeto de selección para ciertos caracteres morfológicos, en función de las preferencias de los consumidores. Esto provocaría una separación en cuanto a caracteres morfológicos, mientras que molecularmente existiría un fondo genético muy diverso pero no muy diferente entre distintos lugares.

Las entradas de L. pimpinellifolium incluidas en este ensayo han resultado ser un conjunto formado por grupos bastante diferentes morfológicamente y también desde el punto de vista molecular. En este caso, las diferencias morfológicas observadas obedecen a diferencias importantes en el fondo genético, que explicarían las agrupaciones similares de las entradas cuando se comparan los dendrogramas obtenidos empleando datos morfológicos o moleculares. En ambos tipos de dendrogramas se 
separan las entradas de Cuzco y Galápagos. También las procedentes de los Departamentos del norte de Perú tienden a separarse en dos grupos, según su sistema reproductivo predominante, estrechamente relacionado con la exerción estigmática, mayor en Piura y Lambayeque y menor en Cajamarca y La Libertad. Los cambios asociados a los sistemas reproductivos se traducirían en cambios detectables a nivel molecular con los marcadores empleados, dando lugar a las agrupaciones similares observadas.

\section{4. INICIO DE LA FORMACIÓN NUCLEAR DE LA COLECCIÓN DE ENTRADAS DE L. PIMPINELLIFOLIUM DEL BANCO DE GERMOPLASMA DEL COMAV}

El estudio de las entradas incluidas en el presente trabajo ha permitido establecer algunos criterios para la elección de las entradas que entrarán a formar parte de la colección nuclear de L. pimpinellifolium del COMAV. El escaso número de entradas de L. esculentum y de cerasiforme incluidas en este trabajo no permiten el establecimiento de tales criterios para estas especies.

En primer lugar, el conjunto de entradas de L. pimpinellifolium incluidas en este estudio ha resultado ser altamente variables. Se han podido establecer tres grupos de entradas, las procedentes de las Islas Galápagos, las colectadas en Cuzco y las del Norte de Perú y Ecuador, con características morfológicas y fondo genético marcadamente diferente. Los tres grupos por tanto, deberían estar representados en la colección nuclear. En cuanto a las entradas del norte de Perú, deberían incluirse representantes de todos los Departamentos, por poseer características diferentes. El estudio de diversidad genética realizado con las entradas procedentes de los Departamentos más septentrionales, permite decidir sobre el número de entradas a incluir en la colección nuclear. Así, los Departamentos de Piura y Lambayeque, con valores de diversidad genética más elevados, deberían estar representados por un mayor número de entradas, mientras que en el caso de las de Cajamarca y La Libertad, sería suficiente un menor número para asegurar que la mayor parte de la diversidad existente en ellos queda representada en la colección.

Las conclusiones extraídas de este estudio están siendo en la actualidad ampliadas con la información procedente de otro ensayo efectuado con un conjunto 
diferente de entradas de L. pimpinellifolium. La elaboración conjunta de todos los datos permitirá realizar la elección definitiva de las entradas que constituirán la colección nuclear de esta especie. 
5. CONCLUSIONES 


\section{Estudio conjunto de L. pimpinelifolium, L. esculentum var. cerasiforme $y \mathbf{L}$. esculentum}

- El análisis de componentes principales efectuado con el conjunto de las entradas estudiadas ha permitido la adscripción de gran parte de ellas a las especies de Lycopersicon esculentum, L. pimpinellifolium y L. esculentum var cerasiforme. Sin embargo, las entradas de estas especies no forman grupos discretos, sino que se observa una gradación continua entre ellas, probablemente como consecuencia de un proceso de especiación simpátrica no finalizado en el momento actual. La no identificación de marcadores moleculares específicos de especie apoyan esta hipótesis. La existencia de cruzamientos interespecíficos contribuiría al mantenimiento de esta situación, constituyendo $L$. esculentum, $L$. esculentum var. cerasiforme y $L$. pimpinellifolium formas extremas de este continuo.

- Se identificaron una serie de caracteres cualitativos propios de las formas más típicas de las especies en estudio. Así, el color antociánico del tallo, el tipo de hoja "pimpinellifolium", (generalmente de menor tamaño, pinnada y con bordes enteros) y el estilo muy proyectado fueron característicos de $L$. pimpinellifolium. L. esculentum se caracterizó fundamentalmente por caracteres relativos al fruto, como la variación en la forma y el color del fruto maduro, formas irregulares de la sección transversal, de la cicatriz estilar y del ápice del fruto, todo ello asociado al proceso de domesticación sufrido por esta especie. La ausencia de los caracteres típicos de las dos especies descritas caracterizó a la var. cerasiforme.

- El número de flores por inflorescencia, el número de pétalos y la longitud, anchura y peso del fruto, no mostraron interacciones Entrada x Año. Estos caracteres, junto con los cualitativos comentados anteriormente, se consideran como los más discriminantes entre L. pimpinellifolium, L. esculentum var. cerasiforme y L. esculentum.

- La identificación de los caracteres discriminantes entre especies que no se encuentran incluidos en los descriptores actuales para el género Lycopersicon 
publicados por el IPGRI, cuestionan la validez de tales descriptores para la caracterización de especies silvestres y apuntan claramente hacia la necesidad de la elaboración de unos descriptores específicos para este tipo de especies.

- El análisis cluster efectuado con el conjunto de caracteres morfológicos agrupa a las entradas de L. pimpinellifolium con las de var. cerasiforme, mientras que el realizado con datos moleculares agrupa $L$. esculentum con var. cerasiforme, quedando L. pimpinellifolium separada de ambas. Esto apoya la hipótesis de que la var. cerasiforme es el ancestro a partir del cual se produjo la domesticación del tomate.

- El hecho de que las entradas de las Islas Galápagos se agrupen en el cluster molecular más cerca de las de esculentum y cerasiforme sugiere que esta especie ha tenido un papel destacado en el origen de las formas "Gal red small" recolectadas en Galápagos, aparentemente similares a $L$. pimpinellifolium. Este hecho se ve apoyado por la mayor distancia genética entre L. pimpinellifolium y "Gal red small" que la existente entre $L$. pimpinellifolium y L. chesmanii especies claramente diferentes.

\section{Lycopersicon pimpinellifolium}

-El conjunto de entradas estudiadas de L. pimpinellifolium ha presentado elevada variabilidad para características vegetativas, de flor y de fruto, contribuyendo junto con estudios realizados por otros autores, a demostrar que L. pimpinellifolium, es una especie muy variable, en contra de lo establecido anteriormente. Otros estudios realizados con estas entradas han demostrado también su variabilidad para características de calidad y de resistencia a enfermedades, convirtiéndola en una colección sumamente útil para la mejora.

-En las entradas estudiadas en este trabajo se observa una gradación en cuanto a la exerción estigmática, asociada a órganos florales de mayor tamaño y mayor grado de alogamia, encontrándose mayor frecuencia de estilo muy proyectado en los 
Departamentos más septentrionales de Piura y Lambayeque, mientras que en Cajamarca y La Libertad, abundan las entradas con estilos no proyectados o incluso insertos.

Las poblaciones procedentes de Piura y Lambayeque tienen una diversidad genética total mayor, probablemente como consecuencia del mayor grado de alogamia. Este hecho tiene importantes implicaciones en las labores de muestreo y regeneración en los Bancos de Germoplasma.

\section{L. esculentum var. cerasiforme}

-El conjunto de entradas caracterizadas han mostrado una elevada variabilidad para caracteres morfológicos, tanto vegetativos como de fruto. Esta variabilidad ha resultado estar asociada al origen, siendo mucho más uniformes y con características propias de cerasiforme las procedentes de México, mientras que las de Ecuador y otras procedencias son mucho más variables, no correspondiendo en ocasiones a la forma típica de esta variedad.

- La elevada variabilidad encontrada en L. esculentum var. cerasiforme no se limita sólo a los caracteres morfológicos, habiéndose descrito en esta especie adaptaciones a múltiples condiciones climáticas y edáficas, así como resistencia a diferentes patógenos fúngicos. Por ello, la colección estudiada representa una colección de genes de indudable valor para el mejorador.

\section{L. esculentum}

- Las entradas de L. esculetum estudiadas se agrupan según su origen, México o España, tanto según sus características morfológicas como molecularmente. En el primer caso se debe probablemente a las diferentes presiones de selección ejercidas en ambos países. En el segundo sería consecuencia del distanciamiento geográfico de ambos grupos de entradas hace más de 500 años. Las entradas procedentes de México pertenecen a tipos criollos, muy apreciadas por sus características de calidad, resistencia al agrietado y capacidad para cuajar a bajas temperaturas. Estas entradas serán de gran utilidad para su empleo en programas de mejora. 
- La mayor diversidad genética total encontrada para las entradas de México, apoyaría la existencia de un cuello de botella debido al limitado número de individuos transportados desde México a España, donde se inició la difusión por Europa.

Inicio de la formación de la colección de entradas nuclear de L. pimpinellifolium del COMAV

- Se han establecido tres grupos de entradas de L. pimpinellifolium, las procedentes de las Islas Galápagos, las colectadas en Cuzco y las del norte de Perú y Ecuador, con marcadas diferencias tanto morfológicas como moleculares. Todos ellos deberán estar representadas en la colección nuclear de esta especie del Banco de Germoplasma del COMAV.

- Mediante la realización de análisis cluster se ha determinado la existencia de duplicados en la colección, mediante su agrupamiento en los árboles con valores de bootstrap muy elevados. Esta información permitirá la eliminación de tales entradas para la formación de la colección nuclear.

- La mayor diversidad genética en las entradas procedentes de los Departamentos de Piura y Lambayeque frente a las de Cajamarca y La Libertad aconsejan una mayor representación de las primeras en la colección nuclear, a fin de asegurar que la mayor parte de esta diversidad genética quede recogida en la colección. 
6. BIBLIOGRAFÍA 
Aldanondo, A. M. 1995. Cultivo y producción de tomate en la Unión Europea. En: "Nuez, F. (Ed.). El cultivo del tomate. Ediciones Mundi Prensa, Madrid, Barcelona, México", pp. 695-740.

Alvarez, A. E.; van de Wiel, C. C. M.; Smolders, M. J. M.; Vosman, B. 2001. Use of microsatellites to evaluate genetic diversity and species relatioships in the genus Lycopersicon. Theor. Appl.Genet 103: 1283-1292.

Anuario de Producción F.A.O. (2001) http://apps.fao.org/.

Arens, P.; Odinot, P.; van Heusden, A. W.; Lindhout, P. and Vosman, B. 1995. GATA- and GACA-repeats are not envenly distributed throughout the tomato genome. Genome 38: 84-90.

Areshchenkova, T.; Ganal, M. W. 1999. Long tomato microsatellite are predominantly associated with centromeric regions. Genome 42: 536-544.

Ayuso, M. C.; Nuez, F.; Cuartero, J.; Báguena, M. 1987. Aprovechamiento de la variabilidad genética existente en especies silvestres relacionadas con Lycopersicon esculentum. SECH. Actas de las $6^{\mathrm{a}}$ Jornadas de Selección y Mejora de Plantas Hortícolas. Murcia 2-4 de Junio 1987: 13-30.

Bernatzky, R.; Tanksley, S. D. 1986. Genetics of actinrelated sequences in tomato.Theor. Appl. Genet 72:314-321.

Bohn, G.W.; Tucker, C.M. (1940) Inmunity to Fusarium wilt in the tomato. Science 89:603-604.

Bonnema, G.; van den Berg, P.; Lindhout, P. 2002. AFLPs mark different genomic regions compared with RFLPs: A case study in tomato. Genome 45: 217-221.

Bredemeijer, G. M. M.; Arens, P.; Wouters, D.; Visser, D.; Vosman, B. 1998. The use of semi-automated fluorescent microsatellite analysis for tomato cultivar identification. Theoretical and Applied Genetics 97: 584-590. 
Bredemeijer, G. M. M.; Cooke, R. J.; Ganal, M. W.; Peeters, R.; Isaac, P.; Noordijk, Y.; Rendell, S.; Jackson, J.; Röder, M. S.; Wendehake, K.; Dijeks, M.; Amelaine, M.; Wickaert, V.; Bertrand, L.; Vosman, B. 2002. Construction and testing of a microsatellite dadabase containing more than 500 tomato varieties. Theor Appl Genet. 105: 1019-1026.

Bretó, M. P.; Asins, M. J.; Carbonell, E. A. 1992. Genetic variability in Lycopersicon species and their genetic relationships. Theor Appl Genet 86:113-120

Brown, A. H. D. 1978. Isozimes, plant population genetic structure and genetic conservation. Theor. Appl. Genet. 52:145-157.

Cole-Rodgers, P.; Smith, D. W.; Bosland, P. W. 1997. A novel statistical approach to analyze genetic resource evaluations using Capsicum as an example. Crop Science. 37: 1000-1002.

Cronquist, A. 1981. An integrated system of classification of flowering plants, New York.

Cuartero, J.; Gómez-Guillamón, M. L.; Díaz, A. 1985. Catalog of collections of Lycopersicon from Peruvian central areas. TGR Report 35: 32-35.

Cuartero, J.; Nuez, F.; Díaz, A. 1984. Catalog of collections of Lycopersicon and L. pennellii from northwest of Perú. TGC Report 34: 42-46.

D’Arcy, W. G. 1979. The classification of the Solanaceae. En: "Hawkes, J.G.; Lester, R.N. y Skelding A.D. (Eds). The biology and Taxonomy of the Solanaceae. Academic Press, London.”, pp. 3-47.

D'Arcy, W. G. 1991. The Solanaceae since 1976, with a review of its biogeography. En: "Hawkes, J.G.; Lester, R.N.; Nee, M.; Estrada, N. (Eds). Solanaceae III: Taxonomy, Chemistry, Evolution. Royal Botanic Gardens, Kew”, pp. 75-137. 
Daunay, M. C.; Lester, R. N.; Laterrot, H. 1991. The use of wild especies for the genetic improvement of brinjal egg-plant (Solanum melongena) and tomato (Lycopersicon esculentum). En: "Hawkes, J.G.; Lester, R.N.; Nee, M.; Estrada, N. (Eds). Solanaceae III: Taxonomy, Chemistry, Evolution. Royal Botanic Gardens, Kew”, pp. 389-412.

Dice, L. R. 1945. Measure of the amount of ecologic association beetwen species. Ecology, 26:297-302.

Díez, M. J. 1995. Tipos varietales. En: "Nuez, F. (Ed.). El cultivo del tomate. Ediciones Mundi Prensa, Madrid, Barcelona, México”, pp. 93-130.

Eshed, Y., Zamir, D. 1995. An introgression in line population of Lycopersicon pennellii in the cultivates tomato enables the identification and fine mapping of yeldassociated QTL. Genetics, 141: 1147-1162.

Esquinas-Alcázar, J.; Nuez, F. 1995. Situación taxonómica, domesticación y difusión del tomate. En: "Nuez, F. (Ed.). El cultivo del tomate. Ediciones Mundi Prensa, Madrid, Barcelona, México", pp. 14-42.

Felsenstein, J. 1985. Confidence limits on phylogenies: an approach using the bootstrap. Evolution 39: 783-791.

Fraley, C. and Raftery, A. E. 2002. Mclust: software for model-based clustering, discriminant analysis, and density estimation, Technical report No 415, department of Statistics, University of Washington, September 2002.

Gallegly, M.E.; Marcel, M.E. (1955) Inheritanceof tomato race O of Phytophthora infestans. Phytopathology 45: 103-109.

Grandillo, S.; Tanksley, S.D. (1996) Genetic analysis of RFLPs, GATA microsatellites and RAPDs in a cross between L. esculentum and L. pimpinellifolium. Theor. Appl. Genet. 92: 957-965. 
Hamilton, E. E. 1976. What the New World economy gave the old. In: First images of America: The impact of the New World on The Old. Chiappelli (ed), vol 2. University of California Press, Los Angeles, pp. 853-884.

Henn, G.; Neitz, A. W. H.; Louw, A. I. 1992. Identification of tomato cultivars (Lycopersicon esculentum) by polyacrilamide isoelectric focusing. Euphytica 62:77-82.

Highton, R. 1993. The relationship between the number of loci and the statistical support for topology of UPGMA trees obtained from genetic distance data. Molecular Phylogenetics and Evolution 2:337-343.

IPGRI.1996. Descriptor for tomato (Lycopersicon spp). International Plant Genetic Resources Institute, Rome.

Jenkins, J. A. 1948. The origin of the cultivated tomato. Economic Botany 2: 379-392.

Kaemmer, D.; Weising, K.; Bayermann, B.; Börner, T.; Epplen, J. T.; Kahl, G. 1995. Oligonucleiotid fingerprinting of tomato DNA. Plant- Breeding.114: 1, 12-17; 31 ref.

Kalloo, G. 1991. Breeding for enviromental stress resistance in tomato. En:"Kalloo, G. (Ed.). Genetic improvement of tomato. Springer-Verlag, Berlín and Heidelberg”, pp. 153-165.

Kardolus, J. P.; van Eck, H. J.; van den Berg, R. G. 1998. The potencial of AFLP's in biosystematics: a first application in Solanum taxonomy (Solanaceae). Plant Systematics and Evolution 210:87-103.

Laterrot, H. (1989) La tomate. Intérêt et utilisation des espéces sauvages pour la création variétale. P.H.M. Revue Horticole 295.

Lin, J.J. y Kuo, J. 1995. En: FOCUS 17: 66. 
Luckwill L. C. 1943. The genus Lycopersicon, an historical, biological and taxonomic survey of the wild and cultivated tomatoes. Aberdeen University Studies, Escocia 120: 43.

Mackinney, G.; Rick, C. M.; Jenkins, J. A. 1954. Carotenoid differences in Lycopersicon: hybrids of an unusual race of L. pimpinellifolium. Proceedings of the National Academy of Sciences of the United States of America. 40: 695-699.

McClean, P. E.; Hansen, M. 1986. Mithocondrial DNA sequence divergence among Lycopersicon and related Solanum especies. Genetics 112: 649-667.

Miller, J. C.; Tanksley, S. D. 1990. RFLP analysis of phylogenetic relationships and genetic variation in the genus Lycopersicon. Theoretical and Applied Genetics 80: 437448.

Montes, S.; Aguirre, J. R. 1992. Tomate de cáscara (Physalis philadelphica). En “Hernández, J.E.; León, J. (Eds.). Cultivos marginados. Otra perspectiva de 1492. FAO, Roma": 115-120.

Muller, C. H. 1940. A revision of the genus Lycopersicon. United States Departament of Agriculture. Miscellaneus Publication No 382.

Nei, M. 1973. Analysis of gene diversity in subdivided populations. Proc. Nat. Acad. Sci. USA 70: 3321-3323.

Nesbitt, T. C. and Tanksley, S. D. 2002. Comparative sequencing in the genus Lycopersicon: Implications for the evolution of fruit size in the domestication of cultivated tomatoes. Genetics 162: 365-379.

Nuez, F. ; Prohens, J. ; Blanca. J. (2003 remitido a publicar). Relationships, Origen and Diversity of Galápagos Tomatoes: Implications for the Conservation of Natural Populations. American Journal of Botany. 
Olmstead, R.; Palmer, J. D. 1991. Chloroplast DNA and systematics of the Solanaceae. En: "Hawkes, J.G.; Lester, R.N.; Nee, M.; Estrada, N. (Eds). Solanaceae III: Taxonomy, Chemistry, Evolution. Royal Botanic Gardens, Kew”, pp. 161-168.

Palmer, J. D.; Zamir, D. 1982. Chloroplast DNA evolution and phylogenetic relationships in Lycopersicon. Proceedings of the National Academy of Science, USA, 79: 5005-5010.

Picó, B.; Sifres, A.; Elia, M.; Diez, M.J.; Nuez, F. 2000. Searching for new resistance source to tomato leaf curl virus within a highly variable wild Lycopersicon genetic pool. Acta Physiol. Plantarum 22: 344-350.

Rick, C.M. 1950. Pollination relations of Lycopersicon esculentum in native and foreing regions. Evolution 4: 110-122.

Rick , C. M. 1956. Genetic and systematic studies on accessions of Lycopersicon from the Galápagos Islands. American Journal of Botany 43:687-696.

Rick, C. M. 1958. The role of natural hybridisation in the derivation of cultivated tomatoes of western South America. Econ. Bot. 12: 346-367.

Rick, C. M. 1963. Biosystematic studies on Galapagos Tomatoes. Occasional Papers of the California Academy of Sciences 44: 59-77.

Rick, C.M. 1973. Potential genetic resources in tomato species: clues from observations in native habitats. Srb, A. M. Genes, enzymes, and populations. Plenum, N. Y. 225-269.

Rick, C. M. 1976. Tomato. En: Simmonds, N.W. (Ed.).'Evolution of crops plants. Longman, London \& New York": 262-273.

Rick, C. M. 1978. The Tomato. Scientific American 239 (2): 76-87. 
Rick, C. M. 1979. Biosystematics estudies in Lycopersicon and closely related species of Solanum. En: "Hawkes, J.G.; Lester, R.N.; Skelding, A.D. (Eds). The biology and taxonomy of the Solanaceae. Academic Press, New York \& London”, pp. 667-678.

Rick, C. M.; Lamm R. 1955. Biosystematic studies on the estatus of Lycopersicon chilense. American Journal of Botany 42: 663-675.

Rick, C.M.; Butler. 1956. Cytogenetics of the tomato. Advances in Genetics 8: 267382

Rick, C. M.; Zobel, R. W.; Fobes, J. F. 1974. Four peroxidase loci in redfruited tomato especies: genetics and geographic distribution. Proceedings of the National Academy of Science, USA 71: 835-839.

Rick, C. M. Fobes, J. F. 1975. Allozyme variation in the cultivated tomato and closely related species. Bull. Torrey Bot. Club 102: 376-386.

Rick, C. M.; Kesicki, E.; Fobes, J. F.; Holle, M. 1976. Genetic and biosystematic studies on two new sibling species of Lycopersicon from interandean Peru. Theoretical and Applied Genetics 47: 55-68.

Rick, C. M., Fobes, J. F. and Holle, M. 1977. Genetic variation in Lycopersicon pimpinellifolium: evidence of evolucionary change in mating systems. Plant Systematics and Evolution. 127: 139-170.

Rick, C. M.; Yoder, J. I. 1978. Classical and molecular genetics of the tomato: highlighths and prospects. Annual Review Genetics 22: 281-300.

Rick, C. M.; Holle, M. 1990. Andean Lycopersicon esculentum var. Cerasifrome: Genetic variation and its evolutionary significance. Econ. Biot. 44 (Supp): 69-78.

Rick, C. M.; Laterrote, H.; Philouze, J. 1990. A revised key for the Lycopersicon species. Tomato Genetics Cooperative Report 40: 31.

Romesburg, H.Ch. 1984. Cluster analysis for researchres. Wadsworth Inc., EEUU. 
Rus-Kortekaas, W.; Smulders, M. J. M.; Arens, P.; Vosman, B. 1993. Direct comparasion of levels of genetic variation in tomato detected by a GACA-containing microsatellite probe and by random amplified polymorphic DNA. Genome 37: 375-381. Sánchez, M.C.; Cámara, M.; Roselló, S.; Galiana-Balaguer, L.; Torija, M.E. ; Nuez, F. (2000). Breeding for flavour of fresh market tomato: sources for increasing acid content. Acta Physiologiae Plantarum 22(3): 250-253.

Schaible, L. W. 1962. Fruit setting responses of tomatoes to high temperatures. Proc. Plant Science Symp. (Camden, NY): 80-88.

Smulders, M. J. M.; Bredemeijer, G.; Rus-Kortekaas, W.; Arens, P.; Vosman, B. 1997. Use of short microsatellites from database sequences to generate polymorphisms among Lycopersicon esculentum cultivars and accessions of other Lycopersicon species. Theoretical and Applied Genetics 97: 264-272.

Sneath, P. H. A.; Sokal, R. R. 1973. Numerical taxonomy. W.H. Freeman and Co. San Francisco.

Soler, M. 2002. Evolución: La base de la biología. Manuel Soler editor. Proyecto Sur. Granada. 559 p.

Stebbins, G. C. 1957. Self-fertilization and population variability in the higher plants. Amer. Natur. 91: 337-354.

Stevens, M. A.; Rick, C. M. 1986. Genetics and breeding. En: “Atherton, J.G.; Rudich, J. (Eds.). The tomato crop. A scientific basis for improvement. Chapman and Hall, London \& New York”, pp. 35-109.

Tal, M. 1971. Salt tolerance in the wild relatives of the cultivated tomato: responses in Lycopersicon esculentum, L. peruvianum and L. esculentum minor to sodium chloride solution. Austral. J. Agr. Res. 22: 631-638. 
Taylor, I. B. 1986. Biosystematics of the tomato. En: "Atherton, J.G.; Rudich, J. (Eds). The Tomato Crop. A scientific basis for improvement. Chapman and Hall, London \& New York", pp. 1-34.

Tindall, H.D. 1977. Vegetable crops In: Leaky, C.L.A.;Wills, J.B. (Eds.). "Food crops of the lowland tropics. Oxford University Press, Oxford”: 101-125.

Villand, J. M. 1995. Comparison of molecular marker and morphological data to determine genetic distance among tomato cultivars. M.S. Thesis. Univ. Of Wiconsin., Madison.

Villand, J.; Skroch, P. W.; Lai, T.; Hanson, P.; Kuo, C. G.; Nienhuis, J. 1998. Genetic variation among tomato accessions from primary and secondary centres of diversity. Crop Science 38: 1339-1347.

Villarreal, R. L. 1980. Tomatoes in the tropics. West view Press. Boulder, Colorado.

Vos, P.; Bleeker M.; Rijans M.; Van de Lee T.; Hornes, M.; Frijters, A.; Pot J.; Peleman, J.; Kuiper, M.; Zabeau, M. 1995. AFLP: a new techniques for DNA fingerprinting. Nucleic Acids Res 23:4404-4414.

Vosman, B.; Arens, P.; Rus-Kortekaas, W.; Smulders, M. J. M. 1992. Identification of highly polymorphic DNA regions in tomato. Theoretical and Applied Genetics 85: 239-244.

Warnock, S. J. 1991. Natural habitats of Lycopersicon especies. Hort-Science 26 (5): 446-471.

Widrlechener, M. P. 1987. Variation in the breeding system of Lycopersicon pimpinellifolium. Implications for germplasm maintenance. Plant Genetic Resources Newsletter 70: 38-43.

Williams, C. E.; St. Clair, D. A. 1993. Phenetic relationships and levels of variability detected by restriction fragment length polymorphism and random amplified 
polymorphic DNA analysis of cultivated and wild accessions of L. esculentum. Genome 36: 619-630.

Williams, J. G. K.; Kubelik, A. R.; Livak, K. J.; Rafalsky, J. A.; Tingey, S.V. 1990. DNA polimorphisms amplified by arbitrary primers are useful as genetic markers. Nucleic Acids Research 18 (22): 6531-6535. 
7. ANEXOS 
Anexo 1. Niveles de los caracteres cualitativos determinados en la caracterización morfológica.

\section{Caracteres de planta}

- Tipo de crecimiento

- Enano

- Determinado

- Semideterminado

- Indeterminado

- Densidad de la pubescencia del tallo

- Escasa

- Intermedia

- Densa

- Longitud de la pubescencia del tallo

- Escasa

- Intermedia

- Densa

- Densidad del follaje

- Escasa

- Intermedia

- Densa

- Posición de la hoja

- Semierecta

- Horizontal

- Inclinada

- Coloración antociánica del tallo

- Oscuro

- Normal

- Tipo de hoja ( Figura 7.1)

- Tipo enano (1)

- Tipo papa (2)

- Tipo estándar (3) 
- Tipo "peruvianum"(4)

- Tipo "pinpinellifolium"(5)

- Tipo “hirsutum"(6)

- Otros.

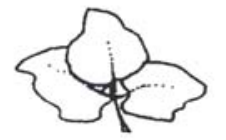

1
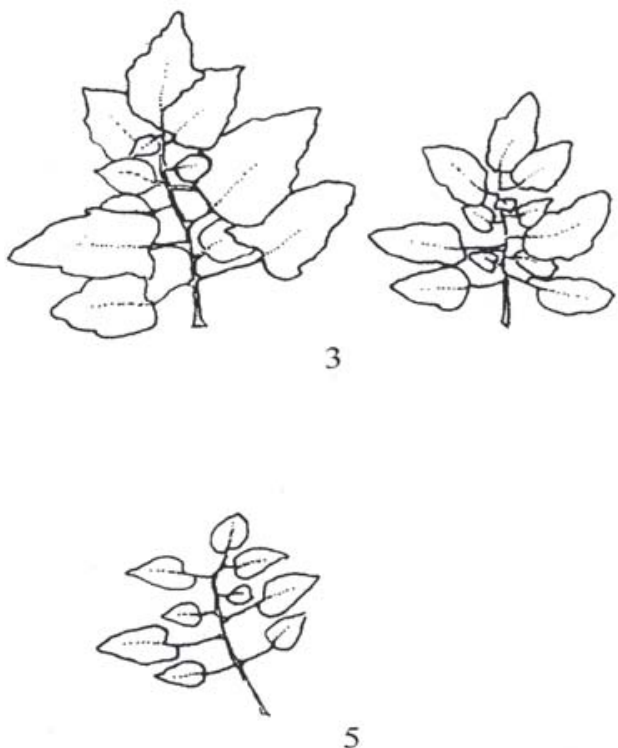

5
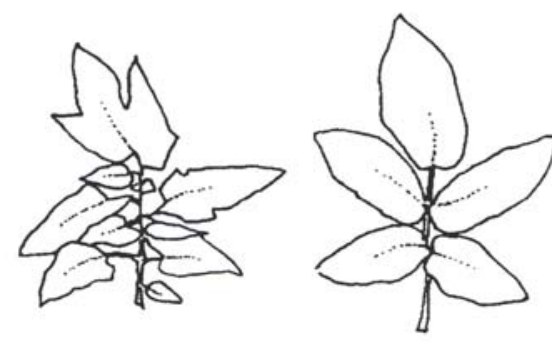

2
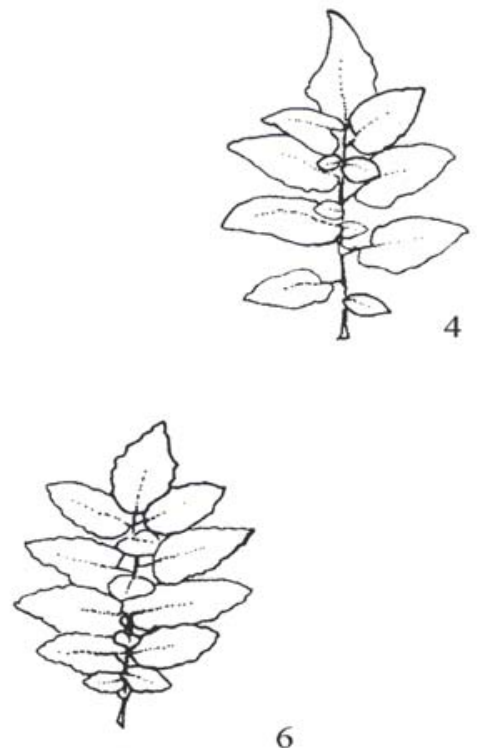

Figura 7.1. Diferentes tipos de hojas.

- Pubescencia de los foliolos

- Escasa

- Intermedia

- Densa

- Color de los foliolos

- Verde claro

- Verde medio

- Verde oscuro 
- Borde de los foliolos

- Entero

- Aserrado

- Ondulado

- Presencia de estipulas

- Ausente

- Presente

- Coloración antociánica de las venas

- Oscuras

- Normales

- Vigor de la planta

- Alto

- Medio

- Bajo

\section{Caracteres de flor e inflorescencia}

- Posición del estilo

- Inserto

- A nivel de los estambres

- Ligeramente exerto

- Muy exerto

- Brácteas en la inserción de la inflorescencia con el tallo

- Ausente

- Presente

- Tipo de inflorescencia

- Unípara

- Multipara

- Inflorescencia terminada en hoja

- Ausente

- Presente 


\section{Caracteres de fruto}

- Color del fruto no maduro

- Verde blanquecino

- Verde claro

- Verde

- Verde oscuro

- Verde muy oscuro

- Forma del hombro del fruto

- Aplanada

- Ligeramente aplanada

- Ligeramente hundida

- Hundida

- Forma del fruto (Figura 7. 2)

- Achatado (1)

- Ligeramente achatado (2)

- Redondo (3)

- Redondo-alargado (4)

- Cordiforme (5)

- cilindrico(6)

- Piriforme(7)

- $\quad$ Elipsoide (8) 

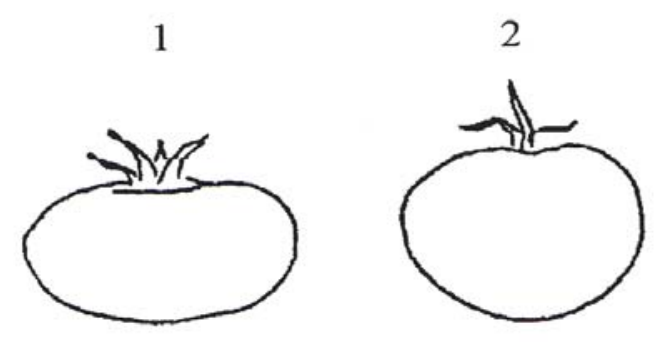

3

4
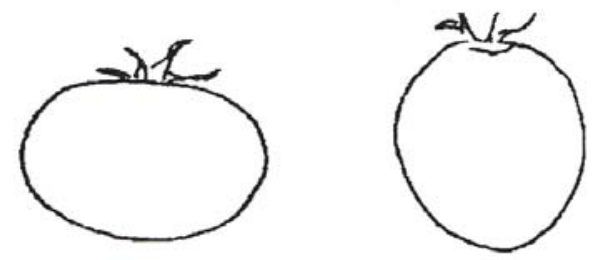

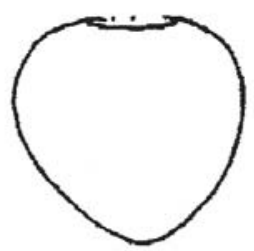

5

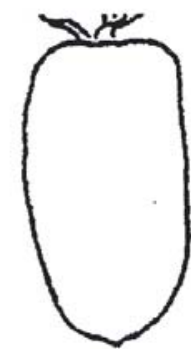

6

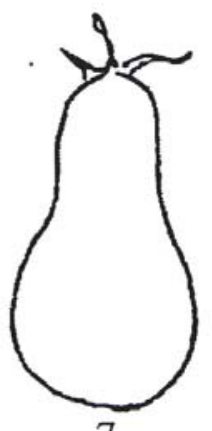

7

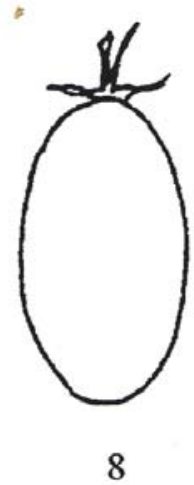

Figura 7. 2 Diferentes formas del fruto.

- color del fruto maduro

- Amarillo

- Naranja

- Rosado

- Rojo

- Verde

- ancho de la cicatriz peduncular

- Angosta

- Intermedia

- Ancha

- Color de la carne del pericarpio

- Verde

- Amarilla

- Naranja

- Rosa

- Roja 
- Otros

- Capa de abscisión

- Ausente

- Presente

- Forma terminal de la floración del fruto

- Indentada

- Aplanada

- Puntiaguda

- Irregular

- Color de la piel del fruto

- Incolora

- Amarilla

- Acostillado del fruto

- Ausente

- Presente

- Intensidad de los hombros del fruto

- Ausentes

- Ligeros

- Medios

- Fuertes

- Frutos biloculares

- Ausente

- Presente 
Anexo 2. Preparación de los diferentes reactivos usados en el análisis molecular.

\section{TAMPÓN DE EXTRACCIÓN.}

\section{$2 \% \mathrm{CTAB}$}

$20 \mathrm{mM}$ EDTA, acompleja los iones magnesio que son catalizadores de las nucleasas

$100 \mathrm{mM}$ Tris, crea un medio salino que rompe paredes

$1,42 \mathrm{M} \mathrm{NaCl}$, crea un medio salino que rompe paredes

Ajustar a $\mathrm{PH} 8$

Autoclavar

TE

$10 \mathrm{mM}$ Tris

$1 \mathrm{mM}$ EDTA

Ajustar a PH 8

\section{TAMPÓN DE CORRIDA}

$100 \mathrm{ml}$ de TBE $5 \mathrm{x}$

$1 \mathrm{~L}$ de agua destilada

TBE 5x

Tris base $0,45 \mathrm{M}$

Ácido Bórico 0,45M

EDTA $10 \mathrm{mM}$

Ajustar a PH 8

GEL DE AGAROSA $0.8 \%$

0,8 gr de agarosa

$100 \mathrm{ml}$ de TBE $5 \mathrm{x}$

Fundir en microondas

Se Añadió $6 \mu 1$ de Bromuro de etídio al 1\% 